\title{
THE FUNCTIONAL MORPHOLOGY OF AVICULARIA IN CHEILOSTOME BRYOZOANS
}

\author{
By \\ Michelle Clare Carter
}

\begin{abstract}
A thesis
submitted to the Victoria University of Wellington in fulfillment of the requirements for the degree of Doctor of Philosophy in Marine Biology
\end{abstract}

Victoria University of Wellington

2008 


\section{ABSTRACT}

Avicularia are modified zooids characteristic of cheilostome bryozoans. Through evolutionary time the functional capacity of the polypide has evolved and is now a vestigial feature within the avicularium. The functional role of avicularia in the colony is unclear. Unable to feed, avicularia are dependent on nutrients from the parental or neighbouring zooids and therefore constitute a significant metabolic cost in production and maintenance, a cost which must be met by some reciprocal function. Details on the functional morphology of avicularia are severely lacking with avicularia constituting a large gap in the knowledge of cheilostome biology. By examining their biology, this study will enhance our understanding of the evolution and functional capacity of avicularia. Fundamentally this study will provide insight into the degree of morphological and morphometric divergence among avicularia. The objective of this study was to: (1) conduct a morphological survey of the putative sensory structures associated with the palate (or orificial structures) of avicularia (SEM); (2) conduct an ultrastructural-level study (TEM) of the vestigial polypide from two species of bugulids from disparate habitats; and (3) incorporate a holistic study on the behaviour and functional evolution of character traits in Bugula flabellata. The avicularia from 38 species of cheilostome bryozoans were examined covering 11 superfamilies, 18 families and 29 genera. The results indicate that avicularia are morphologically diverse and display extensive variation in avicularian orifice morphology. Structures associated with the orifice varied from tufts of cilia, simple pores, tubular protuberances, and pores with an organic exude. The adventitious avicularia dominated $(83 \%)$ and displayed the greatest morphometric diversity compared with interzooidal, vicarious and vibracular types. Within superfamilies, only the catenicellids displayed a significant level of morphometric and anatomical congruence. The density of avicularia within a colony was greatest by combining adventitious and vibracular types (e.g. Caberea). This finding may represent an evolutionary shift towards maximisation of function within a smaller spatial scale. The ultrastructure of the vestigial polypide of the subtidal $B$. flabellata and deep-sea Nordgaardia cornucopioides revealed disparities suggestive of differing functional roles either as a result of habitat differences or differing stages of evolutionary development. The avicularium of $B$. flabellata has undergone significant modification in character traits from the plesiomorphic autozooid. The current anatomy and behaviour of this avicularium provides strong evidence for a mechanoreceptive function whereby detection of tactile stimuli from passing invaders is important in the functional role of the bird's-head avicularium of $B$. flabellata. This study is the first to examine the functional morphology of avicularia in such detail. The techniques used in this study have never been applied to avicularia before allowing numerous features such as the muscles, orificial structures and vestigial polypide anatomy to be discerned. The results indicate that avicularia are morphologically diverse and anatomically equipped to perform a variety of functions. The morphological diversity of avicularia may be of immense ecological importance and represent differing responses to various selective pressures in the environment. 


\section{ACKNOWLEDGEMENTS}

There are many people who helped contribute to the success of this research for which I am extremely grateful. I would not have been able to carry out this research without funding and support from the Commonwealth Scholarship and complete my thesis without the PhD Completion Scholarship (VUW). I am grateful to my supervisors Dennis Gordon (NIWA) and Jonathan Gardner (VUW) for their support, guidance and for an amazingly fast-turnaround in editing chapters that enabled me to meet my proposed deadline. I wish to thank Jonathan for being proactive in all issues and I am truly grateful for all your support and encouragement. So, thanks for rising to the challenge and I hope you are now suitably educated about bryozoans. I would not have survived the trauma of TEM without David Flynn of the electron microscopy facility (SCPS) by offering advice, sympathy, humour, coffee and for fighting my cause. Thanks also for all the assistance with SEM and putting up with my unfortunate ability to render all technical equipment nonfunctional simply by looking at it. I am grateful to Richard Tilley and the School of Chemistry and Physical Sciences for allowing me access to various pieces of equipment (CPD, fume hood, microtome). For assistance and guidance with electron microscopy I also thank Ken Ryan (VUW). I am truly grateful to St. John Wakefield (Otago University School of Medicine, Wellington) for free use of the TEM as well as offering guidance and advice. The assistance of Kay Card (IRL) with SEM is much appreciated. For confocal microscopy I am grateful for the time and assistance offered by Hilary Holloway (Auckland University) and Bronwyn Kivell (VUW) and appreciate the tips given by Scott Santagata (Smithsonian Environmental Research Center). I am grateful to Simon Davy (VUW) for all his support, discussions and feedback and Jo Davy (VUW) for words of encouragement. Thanks to Scott Lidgard (Field Museum, Chicago) for inspiration, insightful discussions and for recognising my potential. Most of the bryozoans used in this study would not have been made available to me, or in some cases not discovered, without the help of numerous NIWA divers. I am very grateful to Owen Anderson, Malcolm Francis, Steve Mercer, Pete Notman, Dean Stotter, Robb Stewart and Adam Smith. I am also grateful to the non-NIWA divers for collecting bryozoans: Anna Smith (VUW), Jade Berman (VUW) and Kirsty Knowles (Forest \& Bird). I also thank Malcolm Clark for allowing me the opportunity to collect deep-sea bryozoans on a RV Tangaroa trip to the Chatham Rise and for giving me a fantastic opportunity to expand on my knowledge of deep-sea invertebrates overall. I am grateful to Chazz Marriott (NIWA) for all the bryozoan images (Nordgaardia cornucopioides is included in this thesis). Thanks to Arne Pallentin (NIWA) for the maps of New Zealand and Wellington. I am incredibly grateful to have had the opportunity to be a part of an organisation such as NIWA where there are certain individuals that are only too happy to help out where they can and make my life a little easier. I am therefore grateful to Kath O'Shaughnessy (Library) for sorting out my Endnote glitches, Pauline Allen for Word issues, Nito and Afa for IT issues and a big thanks to Nito for giving me extra hard drive space for thesis writing. Thanks also to Rachel Lundberg (Library) for finding work for Cailean after school, Rob Stewart for aquacultural help at Greta Point and on the Tangaroa trip and all the guys at Mahanga Bay for all their help with aquaculture and the collecting of Bugula. John Illingworth was particularly helpful with the initial set-up of culturing tanks for which I am incredibly grateful as I have no plumbing skills at all as I found out much to John's amusement. Many thanks to Phil James and Graeme Moss for taking me out to the rafts on the boat. I am grateful to Sarah Allan for putting aside microalgae for me. I 
am also grateful for the words of encouragement whilst writing from NIWA staff and to Meri in the café for providing my essential sanity preservers- fresh muffins and scones. I would especially like to thank the Biodiversity \& Biosecurity group at NIWA for their guidance, support and offers of help. I am grateful to Kate Neill for taking time out to read material. Thanks to my office-mate, fellow PhD-sufferer and friend Sebastien Delaux for being French and having a sense of humour. There are many people in Wellington who have been a great source of friendship and support during my Doctoral research and who have really made the whole process mildly enjoyable, for which I am truly grateful.

I wish to thank my examiners Andrew Ostrovsky, Abby Smith and Ken Ryan for all the useful comments and feedback that enabled me to improve the thesis.

The deep-sea samples used in this thesis were collected as part of a research programme studying the ecology of seamounts: "Effects of fishing on underwater topographic features", undertaken by NIWA and funded by the New Zealand Ministry of Fisheries (ENV2005-16) with additional funding from the New Zealand Foundation for Research, Science, and Technology (contract nos. C01X0508). 


\title{
This $\mathrm{PhD}$ thesis is dedicated to
}

\author{
Cailean Andrew Carter
}

A true source of inspiration

“When are you going to finish your $\mathrm{PhD}$ and get a proper job?" Cailean Carter, 2007 


\section{CONTENTS}

CHAPTER 1 General Introduction 1

1.1 Introduction 1

1.2 Evolution of avicularia 5

$\begin{array}{lll}1.3 & \text { Biology of avicularia and evidence for homology } & 10\end{array}$

$\begin{array}{lll}1.4 & \text { Vibracula } & 12\end{array}$

$\begin{array}{lll}1.5 & \text { Historical perspectives } & 12\end{array}$

1.6 Possible functions of avicularia: a review of the evidence 14

$\begin{array}{lll}1.7 & \text { Spatial arrangement of avicularia within colonies } & 23\end{array}$

$\begin{array}{ll}1.8 & \text { Colony energetics and ergonomics } \\ 1.9 & 24\end{array}$

1.9 Conclusions 26

$\begin{array}{ll}1.10 \text { Research objectives } & 27\end{array}$

1.11 References 28

CHAPTER 2 A Morphometric Analysis and Anatomical Survey of Avicularia 33

2.1 Introduction $\quad 33$

2.1.1 Evolution of avicularia 33

$\begin{array}{ll}\text { 2.1.2 Morphology of avicularia } & 35\end{array}$

2.1.3 Correlating form and function in avicularia 36

2.1.4 Scanning electron microscopy (SEM) 37

2.1.5 Research objectives 38

2.2 Materials and Methods $\quad 38$

2.2.1 Collection and distribution 38

2.2.2 Scanning electron microscopy (SEM) 40

2.2.3 Morphometrics 41

2.2.4 Density of avicularia 41

2.2.5 Statistical analyses $\quad 42$

2.3 Results 44

2.3.1 Anatomical observations (SEM) 44

2.3.2 Morphometric analyses 78

$\begin{array}{lll}2.4 & \text { Discussion } & 92\end{array}$

$\begin{array}{lll}2.5 & \text { Conclusions } & 97\end{array}$

$\begin{array}{lll}2.6 & \text { References } & 98\end{array}$

CHAPTER 3 A Comparative Ultrastructural Study of the Avicularia From Two

$\begin{array}{lr}\text { Species of Bugulidae from Disparate Environments } & 102\end{array}$

$\begin{array}{lll}3.1 & \text { Introduction } & 102\end{array}$

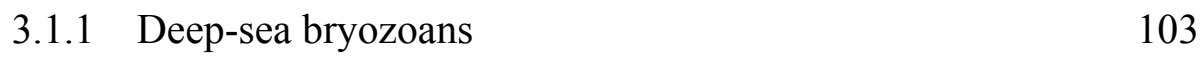

$\begin{array}{ll}3.1 .2 & \text { Adventive bryozoans } \\ 3.1 .3 & 104\end{array}$

3.1.3 Ecological role of avicularia 106

3.1.4 Transmission electron microscopy (TEM) 107

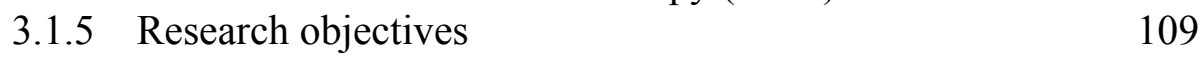

$\begin{array}{ll}3.2 \text { Materials and Methods } & 110\end{array}$

3.2.1 Distribution and sample collection 110

3.2.2 Scanning electron microscopy (SEM) 112

3.2.3 Photomicroscopy 112

3.2.4 Transmission electron microscopy (TEM) 112 
3.3 Results 114

3.3.1 Bugula flabellata 114

3.3.2 Nordgaardia cornucopioides 124

3.4 Discussion $\quad 132$

$\begin{array}{lll}3.5 & \text { Conclusions } & 140\end{array}$

$\begin{array}{lll}3.6 & \text { References } & 140\end{array}$

CHAPTER 4 Immunocytochemistry of the Nervous System and the Musculature of the Bird's-Head Avicularium of Bugula flabellata 146

4.1 Introduction 146

4.1.1 Laser scanning confocal microscopy 148

4.1.2 The muscular anatomy of cheilostome bryozoans $\quad 149$

4.1.3 The bryozoan nervous system 151

4.1.4 The serotonergic nervous system 152

4.1.5 Research objectives $\quad 154$

4.2 Materials and Methods $\quad 155$

4.2.1 Collection of Bugula flabellata 155

4.2.2 Scanning electron microscopy (SEM) 156

4.2.3 Histochemistry of the muscular anatomy 156

4.2.4 Serotonergic neuroanatomy of the bird's-head avicularium 156

4.3 Results 157

4.3.1 Behavioural observations 157

4.3.2 SEM and optical microscopy 162

4.3.3 Muscular anatomy of Bugula flabellata 164

4.3.4 Serotonergic neuroanatomy of the bird's-head avicularium 167

$\begin{array}{lll}4.4 & \text { Discussion } & 173\end{array}$

$\begin{array}{lll}4.5 \text { Conclusions } & 180\end{array}$

4.6 References $\quad 180$

$\begin{array}{lr}\text { CHAPTER } 5 \text { General Discussion } & 186\end{array}$

5.1 Functional morphology of avicularia 186

5.1.1 Defence 187

5.1.2 Cleaning 193

5.1.3 Bait traps 193

$\begin{array}{ll}\text { 5.1.4 Larval inoculation } & 194\end{array}$

5.1.5 Distribution of food/nutrient storage 195

5.1.6 Current manipulation $\quad 195$

5.1.7 Support and locomotion 196

5.2 Evolutionary and ecological implications of the study 197

$\begin{array}{lll}5.3 & \text { Future research } & 198\end{array}$

5.3.1 Biochemical analyses of avicularian glands 201

$\begin{array}{ll}5.4 \text { Conclusions } & 202\end{array}$

5.5 References 203

APPENDICES

Appendix 1: Glossary 206

Appendix 2: Protocols and solutions for electron microscopy 209

Solutions for laser scanning confocal microscopy 215

Modification to the immunohistochemistry protocol 217 
Appendix 3: Table 2.8 Taxonomic spread of anascan bryozoans in New Zealand

Table 2.9 Taxonomic spread of ascophoran bryozoans in New Zealand

Appendix 4: URL addresses to view all images 


\section{LIST OF FIGURES}

\section{CHAPTER 1}

Figure 1.1 Diagram of an autozooid and avicularium 3

Figure 1.2 Avicularian morphologies 5

Figure 1.3 Evolution of avicularia in Wilbertopora

$\begin{array}{lr}\text { Figure 1.4 Antropora leucocypha } & 10\end{array}$

Figure 1.5 Avicularian glands $\quad 22$

\section{CHAPTER 2}

Figure 2.1 Map of New Zealand with collection sites $\quad 39$

Figure 2.2 Map of Chatham Rise $\quad 40$

Figure 2.3 Avicularium with morphological variables annotated 43

Figure 2.4 SEM: Chaperiopsis cf. rubida and Odontionella cylops 51

Figure 2.5 SEM: Bicellariella ciliata and Bugula flabellata 52

Figure 2.6 SEM: Nordgaardia cornucopioides, Beania magellanica and Tricellaria catalinensis 53

Figure 2.7 SEM: Caberea zelandica and C. rostrata 55

Figure 2.8 SEM: Caberea sp. and Scrupocellaria ornithorhyncus 56

Figure 2.9 SEM: Opaeophora lepida, Cellaria pilosa and C. tenuirostris 57

Figure 2.10 SEM: Euthyroides jellyae and Parkermavella n. sp. 58

Figure 2.11 SEM: Catenicella pseudoelegans and Cribricellina cribraria 60

Figure 2.12 SEM: Claviporella aurita $\quad 61$

Figure 2.13 SEM: Costaticella bicuspis and C. solida 62

Figure 2.14 SEM: Arachnopusia unicornis $\quad 63$

Figure 2.15 SEM: Escharoides angela and E. excavata 64

Figure 2.16 SEM: Exochella armata, E. jullieni and Mucropetraliella n. sp. 66

Figure 2.17 SEM: Chiastosella exuberans, $C$. watersi and Hippomenella vellicata 67

Figure 2.18 SEM: Microporella agonistes $\quad 68$

Figure 2.19 SEM: Celleporina grandis, C. wellingtonensis and Osthimosia sirena $\quad 69$

Figure 2.20 SEM: Stephanollona scintillans and Reteporella gracilis 71

Figure 2.21 SEM: Reteporella aurantiace $\quad 72$

Figure 2.22 SEM: Rhynchozoon zealandicum 73

$\begin{array}{ll}\text { Figure 2.23 Graph showing colony density of avicularia } & 79\end{array}$

Figure 2.24 MDS ordination plot: Avicularian type $\quad 82$

$\begin{array}{ll}\text { Figure 2.25 MDS ordination plot: Superfamilies } & 87\end{array}$

$\begin{array}{ll}\text { Figure 2.26 MDS ordination plot: Superfamilies } & 90\end{array}$

\section{CHAPTER 3}

$\begin{array}{ll}\text { Figure 3.1 Diagram of an autozooid and tentacle } & 109\end{array}$

Figure 3.2 Queens Wharf, Wellington and Bugula flabellata in-situ 111

$\begin{array}{ll}\text { Figure 3.3 Zombie seamount and Nordgaardia cornucopioides } & 112\end{array}$

Figure 3.4 TEM: Vestigial polypide of Bugula flabellata 115

$\begin{array}{ll}\text { Figure 3.5 TEM: Vestigial polypide of Bugula flabellata } & 116\end{array}$

$\begin{array}{ll}\text { Figure 3.6 Diagram of the cells from the vestigial polypide of Bugula flabellata } & 117\end{array}$

$\begin{array}{ll}\text { Figure 3.7 TEM: Vestigial polypide of Bugula flabellata } & 117\end{array}$

$\begin{array}{lr}\text { Figure 3.8 TEM: Cerebral ganglion of Bugula flabellata } & 118\end{array}$

$\begin{array}{ll}\text { Figure 3.9 TEM: Cerebral ganglion of Bugula flabellata } & 119\end{array}$

Figure 3.10 TEM: Funicular system of the avicularium of Bugula flabellata 121

Figure 3.11 TEM: Rostrum in Bugula flabellata 122

$\begin{array}{ll}\text { Figure 3.12 TEM: Mucous glands in Bugula flabellata } & 123\end{array}$

Figure 3.13 SEM \& TEM: Peduncle cushion in Bugula flabellata 123 
$\begin{array}{lr}\text { Figure 3.14 Diagram of the avicularium of Bugula flabellata } & 124\end{array}$

$\begin{array}{lr}\text { Figure 3.15 Photomicrographs of Nordgaardia cornucopioides } & 125\end{array}$

Figure 3.16 SEM \& photomicrographs of Nordgaardia cornucopioides 126

$\begin{array}{ll}\text { Figure 3.17 TEM: Vestigial polypide of Nordgaardia cornucopioides } & 127\end{array}$

$\begin{array}{ll}\text { Figure 3.18 TEM: Vestigial polypide of Nordgaardia cornucopioides } & 128\end{array}$

$\begin{array}{ll}\text { Figure 3.19 TEM: Vestigial polypide of Nordgaardia cornucopioides } & 129\end{array}$

Figure 3.20 TEM: Cerebral ganglion of Nordgaardia cornucopioides 130

$\begin{array}{ll}\text { Figure 3.21 Diagram of the avicularium of Nordgaardia cornucopioides } & 131\end{array}$

\section{CHAPTER 4}

$\begin{array}{lr}\text { Figure 4.1 Decorator crab with Bugula flabellata } & 158\end{array}$

$\begin{array}{lr}\text { Figure 4.2 SEM: Bugula flabellata from Mahanga Bay } & 159\end{array}$

$\begin{array}{lr}\text { Figure 4.3 SEM: Bugula flabellata from Queens wharf } & 160\end{array}$

$\begin{array}{ll}\text { Figure 4.4 SEM: Bugula flabellata } & 161\end{array}$

Figure 4.5 DIC: Avicularium with lacuna 163

$\begin{array}{ll}\text { Figure 4.6 DIC: Avicularium showing tendons of the mandible } & 164\end{array}$

$\begin{array}{ll}\text { Figure 4.7 LSCM: Phalloidin stained colony of Bugula flabellata } & 168\end{array}$

$\begin{array}{ll}\text { Figure 4.8 LSCM: Phalloidin stained avicularia of Bugula flabellata } & 169\end{array}$

$\begin{array}{ll}\text { Figure 4.9 Diagram of the muscular system in the avicularium of Bugula flabellata } & 171\end{array}$

Figure 4.10 LSCM: Serotonergic nervous system of Bugula flabellata 172

\section{CHAPTER 5}

$\begin{array}{ll}\text { Figure 5.1 Graph of response variables to inducer concentrations } & 192\end{array}$

$\begin{array}{ll}\text { Figure 5.2 Graph of thresholds for avicularian production } & 192\end{array}$

$\begin{array}{ll}\text { Figure 5.3 Laboratory experimental design } & 200\end{array}$

$\begin{array}{ll}\text { Figure 5.4 Field experimental design } & 201\end{array}$

\section{LIST OF TABLES}

CHAPTER 2

Table 2.1 Species, locality and avicularian morphology 74

$\begin{array}{ll}\text { Table 2.2 Species collected from the Chatham Rise } & 78\end{array}$

Table 2.3 ANOSIM: Avicularian type $\quad 83$

$\begin{array}{lr}\text { Table 2.4 Discriminant function analysis } & 83\end{array}$

$\begin{array}{lr}\text { Table 2.5 Classification analysis } & 84\end{array}$

Table 2.6 Mahalonobis Distance analysis $\quad 84$

$\begin{array}{ll}\text { Table 2.7 ANOSIM: Superfamilies } & 91\end{array}$

\section{CHAPTER 3}

Table 3.1 Comparative habitat characteristics of Bugula flabellata and Nordgaardia cornucopioides

Table 3.2 Comparative ultrastructural characteristics of Bugula flabellata and

Nordgaardia cornucopioides

CHAPTER 4

Table 4.1 Comparison between autozooids and avicularium of Bugula flabellata

CHAPTER 5

Table 5.1 Scenarios and consequences of avicularian production 


\section{CHAPTER 1}

\section{General Introduction}

\subsection{Introduction}

Bryozoans are a phylum of predominantly sessile, suspension-feeding, colonial invertebrates which can be found in freshwater, brackish, and marine environments. Each colony arises from a founding zooid or ancestrula formed by metamorphosis of a sexually produced larva; colony growth then follows by zooidal (asexual) budding (Ryland 1970; Silén 1982). Bryozoans have the potential to display extensive morphological specialisation (i.e. polymorphism) of different units (or zooids) indicative of the highest form of integration in colonial organisms (Harvell 1994). One particular order of bryozoans, the Cheilostomata, exhibits the greatest complexity of polymorphism. Colonies comprise a few to millions of zooids that either function autonomously (autozooids) or are dependent (heterozooids) on resources from neighbouring autozooids (Ryland 1970; Silén 1977; McKinney \& Jackson 1989).

The basic autozooid structure in cheilostome bryozoans consists of calcified side and basal walls, forming a box filled with coelomic fluid, cells and internal organs, and covered by a frontal wall which may vary in degree of calcification (Winston 1984). The main forms of polymorphism exhibited in cheilostome bryozoans are: sexually dimorphic male and female zooids; kenozooids, which are heterozooids that lack a polypide and musculature, hence are devoid of any feeding ability (e.g. articulated spines, rootlets, support structures); and avicularia, whose functions are uncertain (Schopf 1973; Silén 1977).

On a gross level, avicularia are simply operculated chambers connected to autozooids by communication organs (Banta 1973). Organic continuity is maintained between autozooids and avicularia by a strand of tissue called the funicular system (Ryland 1970). The distribution of avicularia within the order has proven to be an 
enigma - they may be completely absent in some genera or even present in one species of a genus but absent in congeners (Winston 1984).

There are three main types of avicularia, the size and shape of which are highly variable and one colony can possess more than one form: 1) vicarious avicularia, which are situated between zooids in a colony and occupy the position of a normal zooid, are characterised by an enlarged operculum and either have a polypide (gut and lophophore combined), lack one, or have a vestige of one; 2) interzooidal avicularia, which are smaller than vicarious avicularia, are squeezed in between zooids; 3) adventitious avicularia, which are frequently quite small, develop on the lateral, frontal, or basal walls of an autozooid (Ryland 1970; Schopf 1973; Winston 1984; McKinney \& Jackson 1989).

Avicularia exhibit an extensive range of morphologies, with the simplest resembling an autozooid but having a larger operculum (mandible). The mandible normally lies open and the modified orifice is derived from a membrane (the palate) in which there is an inferred sense organ derived from, or associated with, the polypide vestige. A complete or partial bar (or mandibular pivots) delimits the palate and acts to reinforce it. Occlusor (or adductor) muscles enable the mandible to open and close (Ryland 1970; Winston 1984). Figure 1.1 illustrates the morphological deviation of an avicularium from an autozooid in Flustra foliacea. 

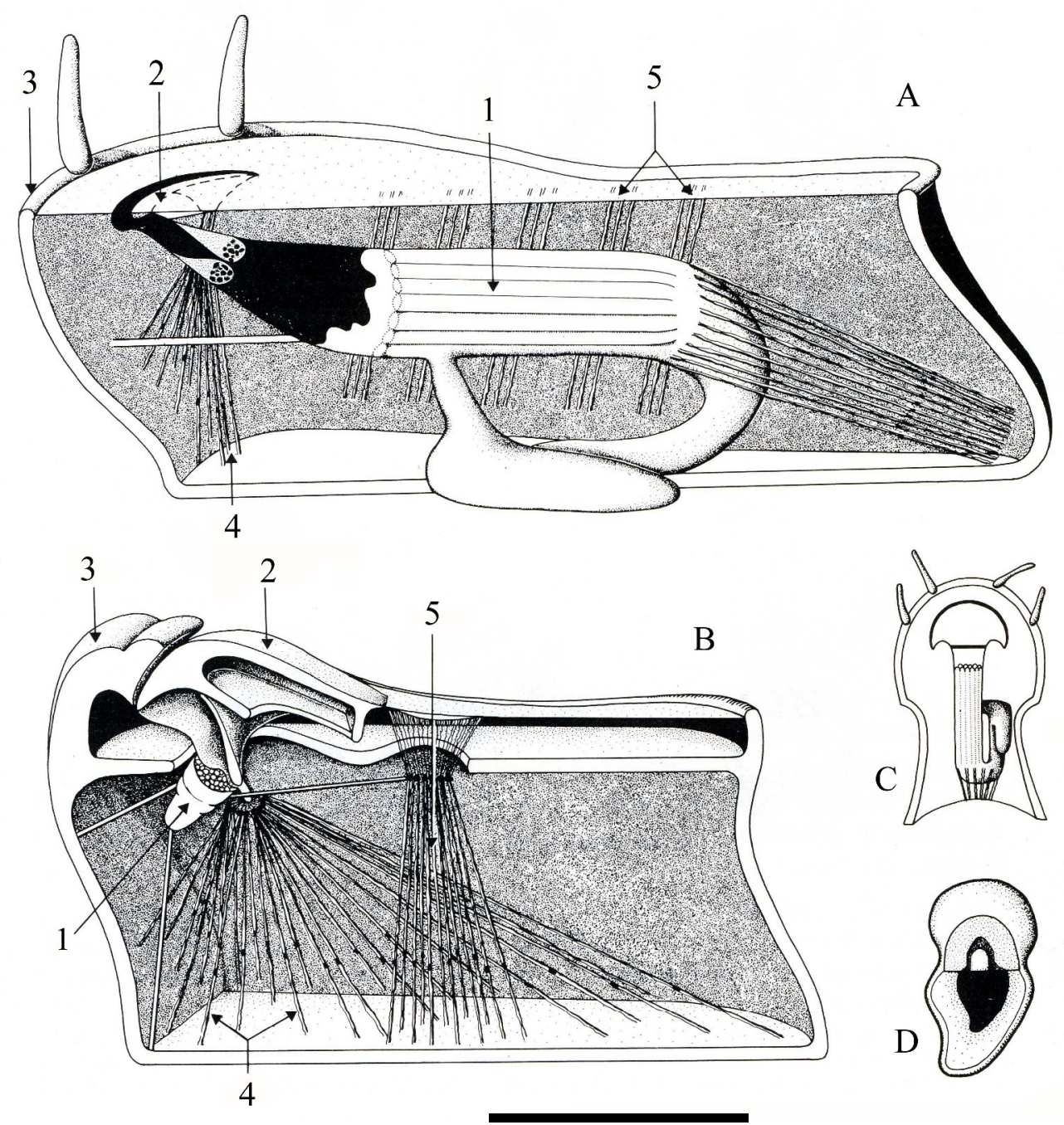

Figure 1.1. Diagrammatical representation of Flustra foliacea. (A) Autozooid; (B) Avicularium; (C) Frontal view of an autozooid; (D) Frontal view of an avicularium. The main anatomical deviations of avicularium from autozooid. (1) Polypide reduced to sensory organ; (2) operculum enlarged into mandible; (3) distal area strengthened into rostrum; (4) the occlusor muscles of the orifice are enlarged into the adductors of the mandible; (5) the parietal muscles condensed into the abductors. After Silén (1977). Scale bar $100 \mu \mathrm{m}$ (suggested, not present in original). 
Few studies have been carried out to elucidate the precise function of avicularia. Those that have been conducted provide equivocal results, and therefore specific avicularium function still remains an enigma. The most extensive investigation has been carried out by Winston (1984) who proposed a range of functions including defence, food gathering, creation of water currents, respiration, cleaning, and nutrient storage, although her focus was primarily on the defensive capacity of avicularia.

The bird's-head, found in a number of genera in the superfamily Buguloidea, was the first type of avicularium to be observed and documented and is considered to be the most complex and differentiated form (Harmer 1930). This type of avicularium is adventitious, lightly calcified, and attached by a short peduncle to the parent zooid (McKinney \& Jackson 1989). It has been observed to capture various organisms of between $0.5-4.0 \mathrm{~mm}$ in length (Winston 1984). This behaviour instigated the belief that avicularia have a defensive function, yet the bird's-head morphology is present only in relatively few families (Winston 1986). Throughout the order various other morphologies and sizes exist, which may be allometrically constrained to perform a similar function (Figure 1.2). Undoubtedly this raises the question of the functional specificity of the various avicularium forms. It is this extensive variation in avicularian morphology that has elicited much interest since the mid- $18^{\text {th }}$ Century with very little advancement.

Another polymorph, considered to be a form of avicularium, is the vibraculum (Figure 1.2e). The vibracular seta, an elongate bristle-like mandible articulating at one end of the vibraculum, is sensitive to mechanical stimulation. A major stimulus, such as a small animal passing across a series of zooids bearing vibracula, triggers a wave of movement or 'sweeping' motion in all setae (Winston 1991). Such movements have been associated with the cleaning of colony surfaces of sediment, extending free-living colonies above a sediment surface for feeding, and colony locomotion (Winston 1986). 
a
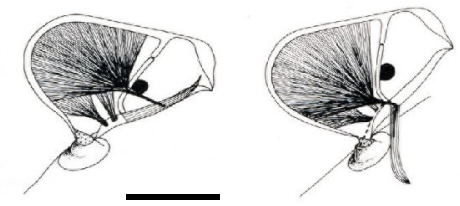

b

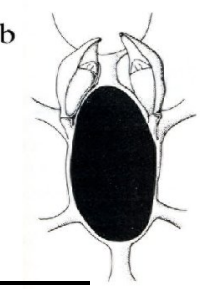

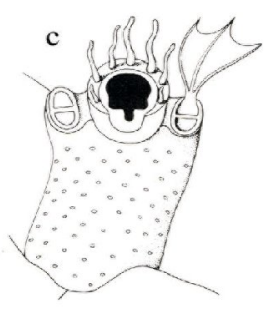

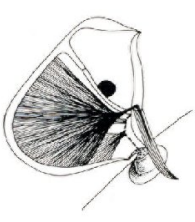

$\mathrm{d}$

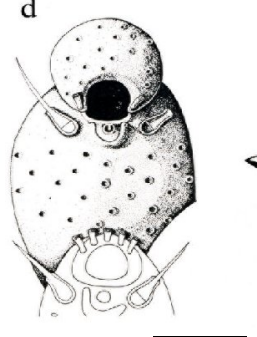

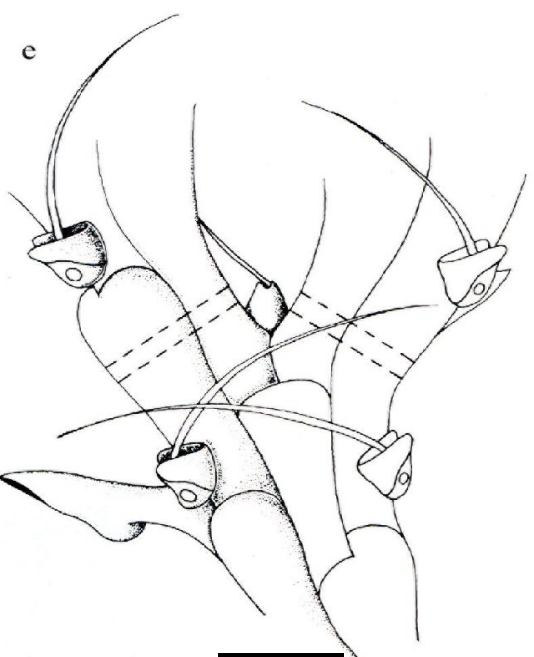

Figure 1.2. Avicularian morphologies: (a) Bird's-head avicularium of Bugula showing path of movement. Scale bar $100 \mu \mathrm{m}$; (b) Beania magellanica with a pair of sessile bird's-head-type avicularia. Scale bar $150 \mu \mathrm{m}$; (c) Pesanserine pesanseris and avicularia with mandibles resembling webbed feet. Scale bar $20 \mu \mathrm{m}$; (d) Microporella appendiculata with setiform avicularia. Scale bar $50 \mu \mathrm{m}$; (e) Scrupocellaria varians with dorsal vibracula. Scale bar $200 \mu \mathrm{m}$ After Silén (1977) with taxonomic modifications by D.P. Gordon.

\subsection{Evolution of avicularia}

Cheilostome bryozoans have a long and extensive fossil record dating back to the Late Jurassic ( 144 Ma) (Taylor 1994). Early cheilostomes are characterised by a serial arrangement of monomorphic zooids (McKinney \& Jackson 1989) with a progressive increase in colony integration through evolutionary time towards the appearance of polymorphic zooids in parallel with physiological complexity (Boardman \& Cheetham 1973; Cheetham 1973). The oldest recorded cheilostomes, the Late Jurassic Pyriporopsis pohowskyi and P. portlandensis, are characteristically uniserial to pluriserial in appearance (Taylor 1994). Multiserial sheet-like colonies were first evident in Wawalia, and the appearance of ovicells and avicularia is apparent in the younger Early Cretaceous (Albian-Cenomanian) Wilbertopora (Cheetham \& Cook 1983; Cheetham et al. 2006).

Anatomical and fossil evidence has led to the belief that avicularia evolved from autozooids (Banta 1973; Schopf 1973). The anatomy of avicularia bears many similarities to autozooids; instead of an operculum, avicularia possess a mandible operated by augmented adductor muscles and the polypide is vestigial and represented 
by a mass of cells. Further support is evident in the observed similarities in budding patterns between avicularia and autozooids (Banta 1973).

A recent revision of the Wilbertopora mutabilis complex by Cheetham et al. (2006) revealed consistent morphological differentiation of avicularian-like polymorphs among congeneric species. The stratigraphic occurrence of Wilbertopora has provided key information in establishing the evolution of avicularia. Based on avicularian morphometrics, Wilbertopora congeners were divided into two clades with W. mutabilis representing the ancestral form followed by subsequent morphological divergence through geological time. The occurrence of similar series of morphologically differentiated heterozooids in more recent stratigraphic collections implies that avicularia have evolved, independently, several times through the order and are not residual traits of early Wilbertopora.

Early Wilbertopora avicularia were vicarious and possessed a functional polypide as evidenced by their intermittent occurrence as maternal zooids with ovicells. In the later, more differentiated avicularia, it appears unlikely a functional gut was present owing to an apparent reduction in the width of the orifice wall (mandible) relative to the frontal wall (Figure 1.3). Both interzooidal and adventitious avicularia were present by the Late Cretaceous with spathulate and triangular forms appearing early in cheilostome evolution (Cheetham \& Cook 1983; Winston 1984; Cheetham et al. 2006). The divergence in morphology in contemporary colonies is presumed to reflect the evolution of avicularia through different lineages (Winston 1984). What forces have driven such morphological divergence? Possible factors influencing morphological differentiation may be localised and environmentally driven as a result of changes in predator and epizoite intensity, hydrodynamics, sedimentation fluxes, or nutrient fluxes. 

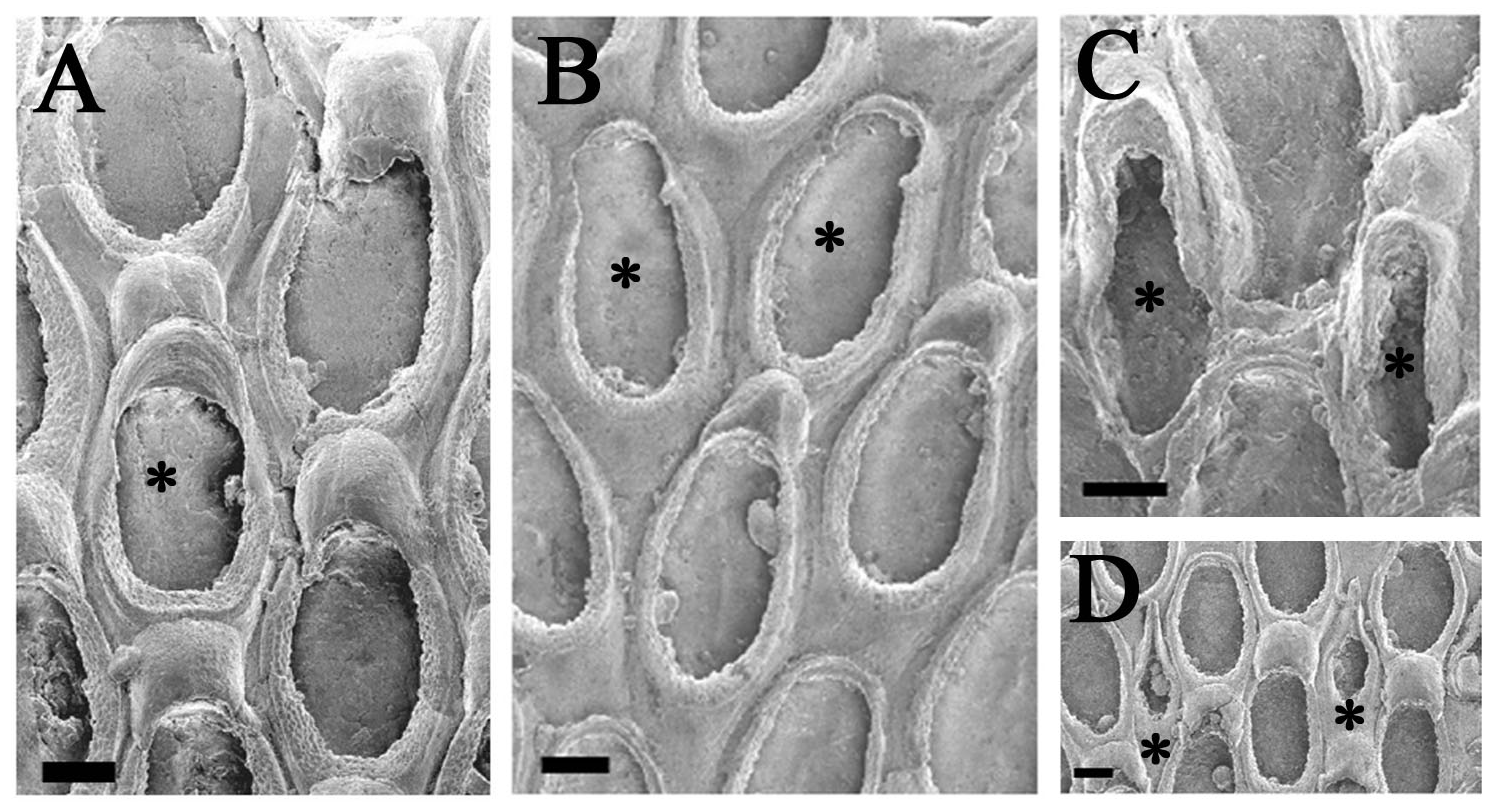

Figure 1.3, Evolution of avicularia in Wilbertopora species complex. (A) Wilbertopora listokinae (Lower Cenomanian). Asterisk denotes avicularium with svicell and two ovicellbearing maternal autozooids to the right. Incipient condyles are evident in the avicularium. Scale bar $100 \mu \mathrm{m}$; (B) Wilbertopora mutabilis (Upper Albian). Asterisk denotes avicularia. Scale bar $100 \mu \mathrm{m}$; (C) Wilbertopora improcera (Upper Albian). Asterisk denotes avicularia. Scale bar $100 \mu \mathrm{m}$; (D) Wibertopora acuminata (Lower Cenomanian). Asterisk denotes avicularia. Scale bar $100 \mu \mathrm{m}$. After Cheetham et al. (2006).

Studies have shown that, in some Tertiary lineages, there was an increase in polymorphism over time and in other lineage, a decrease. Some other lineages were characterised by an increase in polymorphism followed by a decrease. The observed trend may reflect differences in adaptation to different environments. The material examined occurred sympatrically and was therefore exposed to similar environmental influences. However, the observed patterns may indicate that each lineage was responding to different facets of the same general environment (Cheetham 1973).

Despite the lack of any fossil evidence, it has been proposed that adventitious avicularia evolved from vicarious avicularia, a process that would presumably involve the transfer of the primogenial buds to an adventitious position from a vertical position. Through this process, the autozooid acquires an appendage, with the adventitious avicularium constituting an energetic cost to the autozooid and/or colony (Banta 1973). What, therefore, are the benefits of such an association? If we are to assume that vicarious avicularia served a specific function, then those functions are assumed to have 
become modified in derivative forms of avicularia, with wider consequences operating at the level of the colony.

The evolution of polymorphism, as evident in the cheilostomes, really equates to an overall increase in coloniality from the ancestral monomorphic colony through to an extreme level of coloniality and colony function as a result of the gradual modification of individual units (e.g. avicularia). Based on the criteria proposed by Banta (1973), an increase in coloniality is defined as: (1) physiological dependence of one zooid on another; (2) structural dependence (organic continuity) between zooids, and (3) division of labour (specialisation) among zooids in a colony. Certainly criteria (1) and (2) are applicable to avicularia; with a complete absence of any functional gut and any active feeding mechanism, avicularia are highly dependant on nutrients from either the parental and/or neighbouring zooids. As for (3), at this stage it can only be assumed that the occurrence of structurally diverse avicularia implies specialisation, despite their exact role being unknown.

In adventitious avicularia the structural and physiological make-up of the parental zooid is sacrificed in order to accommodate an additional (specialised?) chamber. The evolutionary consequences of such a transformation i.e. the transition of the primogenial buds from a vertical position to an adventitious position (Banta 1973) along with a distinct morphological differentiation between autozooid and adventitious avicularia possibly suggests that specialisation within the colony has increased as a consequence, and hence an increase in the division of labour. However no obvious evidence exists to demonstrate division of labour (e.g. the function of avicularia remains unknown).

Contemporary avicularia and vibracula are generally characterised by the absence of a functional polypide. Some exceptions include the B-zooids of Steginoporella and avicularia of Crassimarginatella (Harmer 1926; Ryland 1970; Boardman \& Cheetham 1973). The decrease in dependence of the avicularian polymorphs in these two genera is correlated with slight morphological differentiation from autozooids, a pattern observed in fossil cheilostomes, suggesting that early avicularia were the least dependent (Boardman \& Cheetham 1973).

Harmer $(1900,1926)$ proposed that the existence of polymorphic zooids, which are referred to as A-zooids and B-zooids, in many species of Steginoporella bears similarities to primitive cheilostomes at early stages of avicularian evolution. The B- 
zooids of Steginoporella, when compared with the A- zooids, have augmented opercular and opercular muscles, and are budded as a normal zooid (or A-zooid). Never do conventional avicularia occur in species which have B-zooids (Harmer 1902; Banta 1973).

The B-zooids of most Steginoporella spp. have lophophores, whilst in $S$. mandibulata interzooidal avicularia are present, but lophophores and B-zooids are absent (Cook 1977). It is possible that B-zooids evolved by gradual modification of an autozooid in a monomorphic colony (Harmer 1900), a theory contested by Silén (1938) who suggested that homology would be impossible owing to differences in budding pattern between interzooidal avicularia and B-zooids. Interzooidal avicularia, as in $S$. mandibulata, develop distal to the bifurcation of a longitudinal row whilst in $S$. magnilabris the B-zooids develop proximal to the bifurcation of a zooid row and bud two zooids rather than one. Banta (1972) refuted Silén's theory and suggested that the same zooid type can be translocated from one budding site to another and that B-zooids are incipient avicularia.

Marcus (1939) examined the internal anatomy of Antropora leucocypha (as Crassimarginatella) using histological techniques. In any one colony two kinds of vicarious avicularium may be present, one with and one without a polypide. As in Steginoporella buskii, the polypide of C. leucocypha is reduced whilst in the avicularia the polypide vestige resembles a ganglion (Figure 1.4). With respect to the avicularium form with a polypide, Marcus (1939) concurred with Harmer (1900) and considered this form as an incipient avicularium.

As this section has highlighted, avicularia have undergone extensive morphological divergence since the first avicularia appeared in the late Early Cretaceous. Such diversity suggests that avicularia have evolved to perform several functions. 


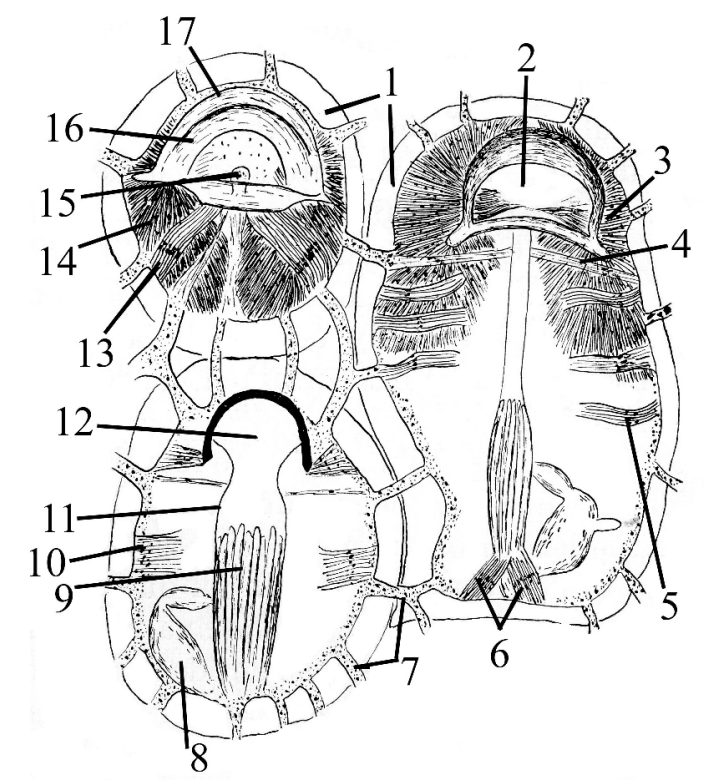

Figure 1.4. Antropora leucocypha (as Crassimarginatella leucocypha). (Top) Vicarious avicularium without polypide; (Right) Vicarious avicularium with polypide; (Left) Autozooid. Scale bar $200 \mu \mathrm{m}$. After Hymen (1959) and based on the original from Marcus (1939). 1, Avicularium; 2, operculum; 3, adductor muscle; 4, dilators of the tentacle sheath; 5, parietal muscle; 6 , retractors of the lophophore; 7 , interzooidal communications; 8 , digestive tract; 9 , tentacles; 10, parietal muscles; 11, tentacle sheath; 12, operculum; 13, abductor muscle; 14, adductor (occlusor) muscle; 15, vestigial polypide; 16, operculum; 17, rostrum.

\subsection{Biology of avicularia and evidence for homology}

Detailed examination of avicularia reveals they are modified zooids (heterozooids) possessing a general structure similar to a cheilostome autozooid usually with a calcified cystid (body wall), differing fundamentally in the highly augmented opercular (mandibular) and muscle systems (Harmer 1909; Hyman 1959; Cook 1977; Winston 1986).

The mandibles of avicularia vary in shape from broad to spathulate to narrow and pointed (Kaufmann 1971; McKinney \& Jackson 1989). Even in one species a myriad of forms may be displayed, for example, in the fenestrate Triphyllozoon monoiliferum avicularia may be small and located at the pinnacle of ascending processes; small, oval and distributed over autozooids; tall aviculiferous processes; and gigantic subspathulate avicularia that far exceed the length of an autozooid and may be found at the top of the fenestrae (Hincks 1878).

However, despite such variation in avicularian morphology, there are common core characteristics: sensory body, mandible, muscles, and rostrum (Silén 1977). 
Typically the palate is elongated and narrowed distally. The palate is exposed by the contraction of abductor muscles situated along the proximal portion of the mandible (Figure 1.1). The mandible is capable of snapping shut extremely rapidly by adductor muscles that are attached to one or two ligaments that are inserted approximately midway along the mandible (McKinney \& Jackson 1989). The mandible is generally composed of two layers of cuticle with a space that communicates with the coelom. During closure, the mandible abuts the rostrum, an area highly thickened and strengthened generally as a result of extensive calcification (Hyman 1959).

In the pedunculate-type avicularium typical of the genus Bugula, the rostrum resembles the upper beak of a bird. Behind the mandible lies an area resembling a frontal membrane, occasionally underlain by a cryptocyst. A calcareous cross-bar may be present that delimits the frontal area and effectively hinges the mandible. The abductor muscles act by pulling in the frontal membrane causing the mandible to open. The abductors are composed of smooth muscle tissue whilst the adductor fibres are striated (Hyman 1959).

The categorisation of the three main types of avicularia is based on budding pattern and position in the colony. Vicarious avicularia replace an ordinary autozooid in the budding pattern and can be the same size, smaller or larger than zooids in the same colony. Vicarious avicularia are capable of budding another zooid. Interzooidal avicularia are smaller than autozooids of the same colony and tend to be squeezed in between zooids and develop from the pore chamber of the neighbouring zooid (e.g. Microporella coronata (Hastings 1963)). Interzooidal avicularia are incapable of budding another zooid. Adventitious avicularia are reduced in size and are located on the frontal surface of the zooid. They commonly occur around the orifice of the parental zooid, appearing as appendages. Adventitious avicularia may be sessile, adherent to the autozooid by their dorsal wall or embedded in the frontal wall of the parental zooid, or they may be pedunculate. Pedunculate avicularia are mounted on a stalk and resemble a bird's-head (e.g. Bugula) and it is the 'head' that is capable of movement by swinging forwards and backwards on the stalk (Figure 1.2a). Adventitious avicularia are incapable of budding another zooid (Harmer 1930; Hyman 1959; Silén 1977; Winston 1984; McKinney \& Jackson 1989). 
Another type of heteromorph often considered as a type of avicularium by some workers is the vibraculum. Although bearing morphological similarities, vibracula possess distinctive characters that differentiate them from avicularia.

\subsection{Vibracula}

Vibracula are heterozooids in which the operculum has been modified into a prolonged seta (Figure 1.2e) (Harmer 1930; Hyman 1959; Silén 1977; McKinney \& Jackson 1989). Waters (1913) was the first to recognise the distinction between avicularia and vibracula. Avicularia with setiform mandibles (Figure 1.2d) have a symmetrical base with a straight proximal edge that works against a bar or teeth (incomplete bar). The mandible of an avicularium moves in one plane only, opening and closing in a vertical direction. In the vibraculum, the seta has no straight-based edge, does not work against a bar, and has an asymmetric base, allowing a sweeping motion in all planes. The presence of lateral gyrator muscles also allows the rotary motion (Hastings 1963; Winston 1991).

The core characteristics common to all avicularia also apply to vibracula. Within the cystid is the polypide vestige possibly with sensory bristles and adductor and abductor muscles to move the seta (Hyman 1959). In certain genera e.g. Scrupocellaria and Caberea, vibracula occur on every branch. Observations on Floridian and Californian species of Scrupocellaria revealed that vibracula appear to move in unison with no apparent stimulant (Winston 1984). The function of vibracula has remained a mystery although it has been suggested they are used in cleaning the colony surface of debris and for locomotion (Winston 1984).

\subsection{Historical perspectives}

The presence of avicularia in bryozoans was first noted by Ellis (1755) in the "Bird's-head coralline" (later named Bugula avicularia); he described the avicularia as “..... a bird's-head with a crooked beak opening wide". Similarly, during the voyage of the Beagle, Darwin (1845 p201) made detailed observations on specimens collected from Tierra del Fuego and the Falkland Islands:

The organ, in the greater number of cases, very closely resembles the head of a vulture; but the lower mandible can be opened much wider than in a real bird's 
beak. The head itself possesses considerable powers of movement, by means of a short neck. In one zoophyte the head itself was fixed, but the lower jaw free: in another it was replaced by a triangular hood, with a beautifully-fitted trap-door, which evidently answered to the lower mandible. In the greater number of species, each cell was provided with one head, but in others each cell had two ... Their movements varied according to the species; but in some I never saw the least motion; while others, with the lower mandible generally wide open, oscillated backwards and forwards at the rate of about five seconds each turn; others moved rapidly and by starts. When touched with a needle, the beak generally seized the point so firmly, that the whole branch might be shaken. Darwin 1845, p201.

It was Darwin who actually coined the term 'avicularium' (avis, Latin, bird) following his observations of the bird's-head avicularium. During his observations, Darwin touched the exposed palate of the avicularium with a fine needle and upon contact the mandible closed and found that he was able to lift the whole colony out of the water by a single avicularium. On this basis Darwin deduced they had some degree of sensory capabilities and suggested a defensive role, a theory subsequently endorsed by Busk (1854). Busk discussed the morphological diversity of avicularia and suggested that their overall design is well suited for grasping. The defence theory was again endorsed by Harmer (1909) during his 1908 presidential address to the British Association for the Advancement of Science. Harmer considered avicularia to have a defensive function in a similar way to the pedicellariae of echinoderms. Johnston (1847) speculated that the 'pincers' of the bird's-head may seize passing organisms and pass the captured prey onto the neighbouring tentacles of a feeding zooid. The hair-like bristles (vibracula), Johnston conjectured, were structures designed to deter predators.

It became widely accepted that avicularia possess some type of sensory function. The polypide vestige, or setiferous organ, of some taxa bears a tuft of stiff cilia-like bristles and suggests some form of sensory function (Forbes 1938; Marcus 1939; Winston 1986); but whether to mechanical (Forbes 1938) or chemical (Winston 1991) stimuli is not certain. Darwin discussed avicularia again in the sixth edition of the 'The Origin of Species...' (1872). He commented on the extensive morphological differentiation between avicularia and vibracula in their extreme forms (i.e. bird's-head and setae) whilst accepting that intergradations between the two forms do exist even within one colony whilst no intergradations exist between autozooids and avicularia 
(though later disputed by Harmer (1900) with respect to the incipient avicularia or Bzooids of Steginoporella). As Darwin himself noted, it is fascinating to find that such extreme forms actually developed from a common origin. Darwin proposed that the primary function of avicularia and vibracula is for protection, but in different ways and under different circumstances. In support of the defence hypothesis, Darwin speculated that avicularia had the added ability to capture and kill small animals, which may subsequently be swept by the feeding current and into the path of the tentacles of the autozooids.

Contemporary studies and behavioural observations have added an array of theories. Despite this, determining the adaptive function of avicularia has remained elusive. The following section reviews historical and contemporary theories on the function of avicularia.

\subsection{Possible functions of avicularia: a review of the evidence}

Winston (1991) carried out an extensive survey involving observations on the behaviour of avicularia to various stimuli in 60 species of cheilostome bryozoans. The results of the study revealed that despite extensive variation in morphology, avicularia tended to respond similarly to a physical stimulus. The overall conclusion from the study suggests that avicularia are predominantly mechanoreceptors, responding to physical stimuli (poking of the mandible with a fine needle or stiff hair), either by closing of mandibles or synchronized sweeping over the colony.

Historically there have been numerous theories presented as to the possible function of avicularia and these are reviewed here.

\section{Defence and protection}

The most widely accepted theory for the function of avicularia is defence (Busk 1854; Canu \& Bassler 1929; Hyman 1959). This notion is derived from observations on the behaviour of the bird's-head avicularia typical of the genus Bugula.

In addition to Darwin, many other workers have observed the strong mandibles of the bird's-head avicularia to clamp down on either an artificial object (e.g. bristle of a brush) or even stray invertebrates (Johnston 1847; Kaufmann 1968, 1971; Silén 1977; Winston 1986). Hincks (1888), on the other hand, noted the variability in morphology 
of avicularian mandibles and suggested that avicularia must therefore have different functions. Even in one colony a variety of avicularian morphologies may exist and many may be allometrically constrained in performing a similar function as seen in the bird's-head, although, as Silén (1977) suggested, the observed variation in avicularian morphology does not detract from a fundamental defensive role, only the differences lie in the size or type of prey captured.

The main predators of bryozoans at the level of the zooid are: amphipods, copepods, nudibranchs and pycnogonids. Fishes, decapods and echinoids are more generalist predators and consume bryozoans incidentally during the consumption of their target prey (Lidgard 2008). Certainly avicularia would be mechanically restricted to capture large generalist predators but anecdotal evidence exists demonstrating the ability of avicularia to capture smaller organisms (Kaufmann 1971; Winston 1984).

One argument for the defence theory is that avicularia are commonly located in the immediate area of the orifice of the zooid and therefore act as guards to protect the tentacle sheath (Harmer 1909). However, this would only apply to adventitious avicularia as the interzooidal and vicarious types are dispersed through the colony and between zooids, presumably unable to perform such a function.

Observations on colonies in the presence of known predators of bryozoans, the pycnogonids, have failed to provide any conclusive results other than indicate that avicularia are ineffective in protecting the colony against their predation. Wyer \& King (1973) noted that the pycnogonid Achelia echinata uses its proboscis to penetrate the orifice and clip at the tentacles with the jaws at the end of the proboscis. On a colony of Bugula sp., A. echinata feeds on detritus surrounding inactive avicularia. When encountering an avicularium the pycnogonid moved tentatively, the palps were raised and the proboscis retracted, whilst remaining still for a while. Ensuring the avicularium was inactive the pycnogonid commenced feeding by rapidly inserting its proboscis into the soft tissue of the avicularium. Around active avicularia the pycnogonid's movements were even more cautious and their palps were withdrawn more frequently. Wyer \& King (1973) made the critical observation that the gape of the avicularia was not wide enough to trap any part of the pycnogonid except for the terminal claws. Achelia echinata also feeds upon zooids of Flustra foliacea but even in this instance the avicularia were too small and low in abundance $(0.5 \%$ of population) to afford any 
protection (Wyer \& King 1973). The avicularia appeared therefore to be ineffective in defending the colony against predation from pycnogonids, or specifically A. echinata.

Kaufmann's $(1968,1971)$ studies provided theoretical parameters regarding the defensive capabilities of the Bugula-type bird's-head avicularia. By calculating the length of the moment arm as a function of the angular opening of the mandible it was established that the capture potential increases for organisms $<0.1 \mathrm{~mm}$ when the mandible is opened at $90^{\circ}$. When the mandible is opened to $50^{\circ}$, the moment arm is half the maximum and an organism $0.05 \mathrm{~mm}$ in diameter would be able to fit in the space between the rostrum and the mandible. Given these parameters, the main zooid-level predators of bryozoans far exceed those dimensions and avicularia may therefore have limited capacity in the capture of predators. Kaufmann (1968) went on to suggest that the Bugula-type bird's-head avicularia may be effective in reducing the occupation of gammarid amphipod tubes on the colony. The numerous appendages of Corophium insidiosum and Jassa falcata often became trapped in the mandibles of the avicularia, which hold on to them for anything from minutes to hours. These amphipods are not predators of bryozoans but tend to build their tubes over colonies and obstruct the orifice of feeding zooids.

The capture of a known bryozoan predator has been demonstrated by the large spathulate interzooidal avicularia of Celleporaria albirostris. The mandibles were observed to close rapidly in a spring-like action on a syllid polychaete and remain closed for 24 hours (Winston 1986). It may be possible that these spathulate forms help reduce the occurrence of predatory organisms on the colony.

Harmer (1909) also advocated the role of protection for avicularia and vibracula, conjecturing that they would be actively involved in deterring the settlement of epibionts as well as preventing other organisms from removing food particles otherwise intended for autozooids. Marcus (1926) refuted both of these hypotheses on the basis that avicularia are too widely dispersed within a colony to be effective in preventing larval settlement. Secondly, the capture of phytoplankton, the main source of food for bryozoans, would not be possible for any avicularian type.

Observations on active and non-active portions of a colony may provide clues. For example, in the genus Reteporella the branching of the colony is such that a calcareous mesh is formed with large gaps called fenestrae between the branches. Avicularia of various shapes and sizes are located around these fenestrae and where 
these avicularia are active the colony is completely free from encrusting organisms. Even the larvae of conspecifics do not appear to settle in these areas (Harmer 1909; Canu \& Bassler 1929). Presumably if the avicularia are not active then the parental/neighbouring zooid(s) are not active either and it may be more likely that it is the localised current created by the individual autozooids that is capable of removing invading epibionts (Cook 1977).

Vibracula have been observed swinging over the colony and have been inferred to perform a cleaning function on the basis that colonies with setiform avicularia such as lunulitiform bryozoans are commonly found on sandy habitats and are capable of removing any sediment particles from the colony (Cook 1963). Whether vibracula can actively remove or deter settling larvae has not been established.

\section{Bait traps}

Another proposed theory is that avicularia may function as bait traps because trespassing organisms may become trapped by a closing mandible for hours or even days (Goldstein 1880; Harmer 1909; Winston 1986, 1991). The organisms captured by the avicularia are generally too large to be ingested by autozooid polypides, but ciliates are attracted to decaying organisms and it is these ciliates that bryozoans are known to feed on (Winston 1991). Hence the avicularia may act as bait traps.

\section{Larval inoculation}

Winston (1984) suggested that the circumoral and suboral avicularia of some species may inoculate developing eggs in transit between the body cavity and the ovicell. This hypothesis was based on the findings of Woollacott (1981) who discovered that the larvae of some species of Bugula carry their own bacteria putatively to prepare a potential settlement site by releasing the bacteria prior to settlement. Out of the five species (B. stolonifera, B. pacifica, B. neritina, B. simplex, B. turrita), only the larvae of B. neritina, B. simplex, and B. pacifica were found to carry their own bacteria. More recent work has revealed that the bacteria present in the larvae of $B$. neritina produce a bioactive compound, bryostatin, which has been experimentally shown to deter predation (Lindquist 1996; Lindquist \& Hay 1996). The bacterial symbiont has also been located in the funicular system of adult autozooids. The larvae are inoculated with bryostatin before being released from the maternal zooid and this protective coating of 
bryostatins remains on the exterior of B. neritina after settlement and throughout metamorphosis until the chitinous cuticle develops on the ancestrula (see Paul et al. 2007 for review). B. neritina is the only species of the genus not to have avicularia and in this instance the bacteria of the larvae could not be supplied by avicularia and hence the larval inoculation theory is rather tenuous.

\section{Distribution of food/nutrient storage}

Hastings (1945) described the large avicularia of Crassimarginatella exilimargo as possessing a miniature polypide, complete gut, tentacle sheath, diaphragm, fully developed musculature, and 2-4 thick tentacles. Hastings (1945) suggested that these avicularia must possess a fully functional polypide as evidenced by the presence of brown granules, presumably food particles, in the lumen of the caecum. It may be possible in the case of $C$. exilimargo that the avicularia could potentially play an active role in colony feeding.

Where active feeding is not possible, avicularia could possibly act as a storage reserve for nutrients and distribute resources during unfavourable conditions which are likely to induce autozooid degeneration (Winston 1984).

\section{Current manipulation/ sanitation}

A possible explanation as to why avicularia mandibles are open when relaxed and located sporadically around the colony is that they may act as current baffles, directing trespassers and colony waste away from the colony (Winston 1984). Winston (1984) noted the position of stereo pairs of avicularia in the colony of Parasmittina serrula that resembled the arms in a pinball machine, and on this basis suggested that perhaps this orientation is designed to act as baffles, directing currents and waste away from the colony. This theory has not been tested empirically though colony-induced currents from feeding autozooids has been examined. Feeding autozooids are capable of producing a colony-wide water current (Cook 1977); the exhalent current driven by everted lophophores carries faecal pellets and debris away from the colony (Cook 1977; Lidgard 1981). It appears that the feeding behaviour of the autozooids may provide an effective colony current and whether open avicularian mandibles have an impact on the hydrodynamics of the colony and whether they can potentially influence current manipulation and sanitation of the colony is unknown. 


\section{Cleaning}

A role of colony cleaning has been attributed to vibracula and avicularia with setiform mandibles. Benthic lunulitiform bryozoans are restricted to areas on sandy sediments where current action is strong. Lunulitiform bryozoans are relatively freeliving and avoid being buried in the sand by movement of their vibracula. The vibracula of Discoporella umbellata have been observed cleaning sand particles off the colony by their sweeping movements (Cook 1963). However, Marcus and Marcus (1962) suggested that the biological significance of the vibracula is not in cleaning of the colony but fundamentally function in the protection of the frontal membranes and polypides when the colonies fall upside down.

The mandible of a vibraculum may be distally smooth or toothed along one or both sides and along with its potential sweeping motion, suggests a cleaning function, mechanically removing debris or preventing larvae from settling (Hyman 1959). Stimulation of the sensory body within the vibraculum appeared to elicit a series of movements of the seta, which sweeps to and fro over the surface of the zooids (Silén 1977). Similarly, stimulation of neighbouring autozooids elicited a response from the vibracula. When relaxed, vibracular setae project almost perpendicular to their base and are capable of rapid adduction when the frontal membrane of neighbouring autozooids is stimulated. An increase in stimulation appeared to elicit an increased response whereby an increased number of vibracula become active (Marcus \& Marcus 1962).

Cook and Chimonides (1978) observed colony behaviour in Selenaria maculata and noted distinct behavioural patterns with colony-wide cooperation; the setiform avicularia of $S$. maculata appeared to function in unison and in association with feeding autozooids. Following feeding, autozooids withdrew their tentacles simultaneously; the frontal setae then opened and closed simultaneously, moving across the colony surface in an apparent cleaning motion. After a period of time, the swinging motion ceased and feeding recommenced and the cycle began again.

\section{Support and locomotion}

In free-living lunulitiform bryozoans (Cupuladriidae, Lunulitidae, Otionellidae, Selenariidae), the colonies are discoidal or cup-shaped and support themselves on the surface of sandy sediments by long, setiform mandibles of the marginal avicularia. The avicularia are budded in regular patterns among the autozooids with an apparent 
functional differentiation in avicularia of differing astogenetic stages. Whilst the peripheral avicularia have a supportive function, earlier astogenetic generations are redundant in this function and instead clean the colony of any sediment (Chimonides \& Cook 1981).

Some lunulitiform species have phototactic capabilities, whereby colonies have been observed moving towards a light source using peripheral avicularia e.g. Selenaria maculata (Cook \& Chimonides 1978; Chimonides \& Cook 1981). Where the phototactic sensors are located was not stated so the possibility these receptors are located in the vibracula cannot be excluded.

\section{Chemical defence and chemotaxis}

The possibility that some avicularia may be a source of chemical defence cannot be excluded and future research could potentially be focused on avicularia. There is currently intense interest and research in marine natural products with many invertebrates yielding bioactive compounds useful in biomedical research. Secondary metabolites also play vital roles in the chemical defence of many marine organisms with the potential to influence the community structure of entire ecosystems (see Paul et al. 2007 for review). The possibility of avicularian derived chemical defence has been postulated (Winston, 1984) based on the internal examination of avicularian morphology which has revealed the existence of glands in some species (Marcus 1939; Hyman 1959; Silén 1977; Ström 1977). The avicularian glands are located dorsally to the vestigial polypide and are homologous with the vestibular glands found in autozooids (Hyman 1959).

Figure 1.5 shows various forms of avicularian glands or corresponding thickenings of the vestibular epithelium. The avicularia of some species do not possess glands (e.g. Vittaticella elegans and Orthoscuticella lorica). Whilst the corresponding oral, or vestibular, glands of the autozooids of Synnotum aegyptiacum are not present, the avicularia of this species possess very large glands. The function of these avicularian glands remains an enigma; Marcus (1939) suggested they may contain toxic compounds, though for what purpose and what evidence this assumption was based on was not stated.

Earlier work by Lutaud (1964, 1965, 1969) examined autozooidal vestibular glands and avicularian glands using histological techniques. The avicularian glands 
were found to consist of thin pouches derived from the outpocketing of the tentacle sheath of the polypide or polypide rudiment. The glands themselves are filled with a mucopolysaccharide-type substance, possibly a by-product of the gland. If chemical production is correlated with the presence of avicularian glands then what is their primary function? No evidence of any chemicals being exuded from avicularia has been reported. Rod-like bacteria have been discovered in some avicularian glands. The bacteria are non-pathogenic and species-specific (Lutaud, 1964).

In other marine organisms, chemical defence has been located in areas of biological value such as growing edges and reproductive regions as a predatory deterrent (Becerro et al. 1998). Most avicularia are in close proximity to the orifice of the autozooid or ovicells, areas of biological importance in a bryozoan; the role of any bacteria and their specific location within an adult colony is relatively understudied and little understood. Whether bacteria occur consistently in avicularia is not known and at this stage no conclusions can be made regarding avicularian localised bacterial defence.

The potential for avicularia to have any chemotactic detection has been tested by a few authors. Forbes (1938) exposed Bugula sp. to extracts from various species of molluscs and found that the overall activity of the bird's-head increased; the interval time between closure of the mandibles decreased and swaying increased. Winston (1991) exposed four species of cheilostomes to chemicals previously known to provoke responses in other invertebrates such as metabolites (known feeding stimulant) and neuroactive agents (involved in chemical signaling). The four species chosen exhibit extremes in avicularian morphology: Microporella vibraculifera, Bugula californica, Parasmittina collifera, and Celleporaria brunnea. Amino acids are known feeding simulators and provoked a response in all species. Microporella vibraculifera (with a setiform mandible) showed the clearest response to amino acids in addition to acetylcholine and ATP. The exact response performed by the avicularia of each species to a chemical stimulus and how this behaviour differed from 'normal' behaviour was not described. 

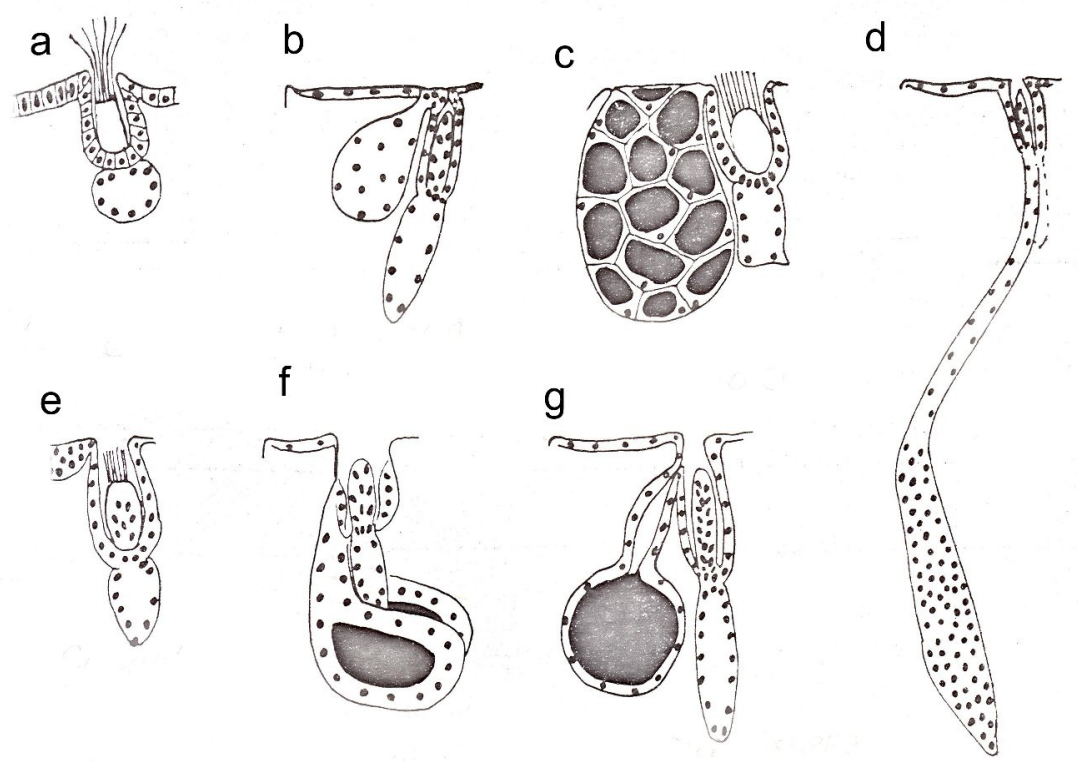

Figure 1.5. Avicularian glands of (a) Bugula ditrupae; (b) Rhynchozoon pharynoglossum; (c) Synnotum aegyptaiacum; (d) Microporella ciliata; (e) Celleporina diota; (f) Schizoporella carvalhoi; (g) Stephanollona contracta. Taken from Marcus (1939).

\section{Internal avicularia}

Levinsen (1909) was the first to document the occurrence of an apparent chamber within the body cavity of some autozooids in Menipea roborata. He described the chambers as possessing distinct mandibles with an overall resemblance to avicularia. Harmer (1923) agreed with this, following his detailed examination of a preserved colony of Menipea marionenesis. On the inner side of the autozooid frontal wall was an avicularium, roughly cylindrical in shape with a beaked rostrum attached to an acute, triangular mandible which in a live and active colony would presumably open and close in contact with the polypide of the autozooid.

Neither Levinsen (1909) or Harmer (1923) offered an explanation of the purpose of the internal avicularia but Harmer did comment on their inconvenient location. Indeed, if such structures do exist (and can only be confirmed upon examination of live and active specimens) what is their function? Their capacity to perform the functions previously described would be highly compromised owing to the cryptic location of these internal avicularia. These putative internal avicularia would be highly impractical and inefficient at offering any defence against predation; any approaching predator 
striking an autozooid would have encountered the polypide before the avicularian mandibles. Likewise, the avicularian mandibles would be highly inefficient at deterring any settling epibionts. Alternatively, these avicularia may offer defence via chemical means. If chemicals are being exuded by the internal avicularia, the soft-tissues of the autozooid may become coated in these chemicals during tentacle evertion and retraction ensuring protection against predation.

Alternatively the internal avicularia may perform a different role. The location of the internal avicularia may assist in larval inoculation whereby developing eggs in transit between the body cavity and the ovicell are inoculated with bacteria from neighbouring avicularia. This hypothesis was presented by Winston (1984) for Bugula upon discovery that the larvae of Bugula carry their own bacteria (Woollacott 1981). Though, as previously discussed, avicularia are not the source for bacteria in Bugula, the possibility that avicularia from other taxa may harbour bacteria cannot be excluded and until evidence is provided to suggest otherwise, the internal avicularia of Menipea could potentially offer bioactive mediated defence.

\subsection{Spatial arrangement of avicularia within colonies}

The distribution of avicularia across cheilostome taxa is puzzling with avicularia occurring sporadically within a colony in some taxa and in others occurring consistently whereby each autozooid will bud off a definite number of avicularia. The often unpredictable distribution is possibly why no studies involving avicularia have explicitly analysed their arrangement within a colony in the context of establishing colony ergonomics. At the same time, without any parallel experimental and physiological studies, this would be a highly superficial method and prone to anecdotal interpretation.

An examination of cheilostome systematics reinforces the high degree of variability in morphology and spatial arrangement of avicularia. This differentiation is evident not just at the level of confamilial taxa but even between colonies of the same species. For example, in Schizoretepora tessellata, a small avicularium is consistently present frontally on each zooid whilst in confamilial Triphyllozoon moniliferum the avicularian mandibles are presented in a diverse array of morphologies (Hincks 1878).

Vicarious and interzooidal avicularia may appear regularly in a certain position in the budding pattern of the colony. In Wilbertopora and Thalamoporella, avicularia 
are commonly located distolateral to a bifurcating lineal series, whereas in Steginoporella the avicularium-like B-zooids commonly occur at a bifurcation in the budding series; and in Metrarabdotos there appears to be a degree of regularity in the distribution of avicularia. Whilst brooding zooids are distributed irregularly through the colony, they are consistently accompanied by zooids possessing special forms of adventitious avicularia (Boardman \& Cheetham 1973).

Often in species with vibracula or setiform mandibles there is an apparent regularity to their distribution within the colony. This suggests some degree of functional importance, and observations of active colonies appear to support this. The free-living lunulitiform bryozoans form discoidal and cup-shaped colonies and inhabit sandy sediments. The setiform avicularia of the lunulitiform species are located in regular patterns within the colony and, depending on location, perform a specific function: the setae of marginal avicularia raise the colony above the sediment whilst setae of earlier astogenetic generations clean the colony of sediment. In some species of lunulitiform bryozoans the colony consists of distinct zones of peri-ancestrula zooids, female zooids, non-feeding autozooids, non-feeding males, mature zooids (mainly males), and avicularia (Chimonides \& Cook 1981). In species of Cupuladria and Discoporella the vibraculum is located distal to each zooid and in any radial row the direction of asymmetry of the vibracula is alternate. In contrast, the vibracula in Selenaria species are vicarious and sparsely distributed within the colony, possibly indicating a different function than the more regularly arranged vibracula of Discoporella (Cook 1963).

The overall arrangement and position of avicularia within a colony may be highly significant yet this significance can only be established once the precise function of the specific avicularium in question has been determined. This requires speciesspecific analysis as undoubtedly what may be of importance to one species may be insignificant to another and the avicularia of the two species may have disparate functions.

\subsection{Colony energetics and ergonomics}

Cheilostome bryozoans display extensive morphological variation, with individual modules performing different functions (polymorphism). The degree of integration between individual modules within a colony is dependent on how the 
polymorph is budded and its specific function (Schopf 1973). Avicularia are highly polymorphic suggesting variable functions between each avicularium form, especially within a single colony.

Colony integration is defined as a measure of the degree of interdependence and cooperation among modules within a colony. Key features of integration include an increase in colonial over modular functions and/or the formation of non-feeding heterozooids (e.g. avicularia) (Schopf 1973; McKinney \& Jackson 1989).

An increase in colonial integration may have numerous advantages: the production of stronger and more coordinated feeding currents; increased directional growth; and improved distribution of polymorphic zooids enabling a more successful and superior architectural design. All of these factors may increase overall fitness (McKinney \& Jackson 1989). If the production of avicularia increases colonial integration with the overall objective to increase fitness, what advantages do avicularia confer in total colony ergonomics?

The principal function of all cheilostome polymorphs has been established, except for avicularia. In any one colony a polymorph may be present that is specialised to perform any one of the following functions: feeding; sperm release; brooding of embryos; defence against predators (e.g. spines); and reinforcement/strengthening of the colony. All of these polymorphs have been extensively studied whilst the avicularia remain an enigma.

Like other heterozooids that are incapable of feeding (e.g. kenozooids), avicularia are dependent on nutrients from neighbouring zooids and therefore constitute an energetic cost to the colony, a cost that surely should be balanced by a reciprocal activity, a function that only avicularia can perform. There has to be some justification for their costly production and subsequent maintenance. This theory was discussed by Schopf (1973) with respect to polymorphism in general. Schopf (1973) suggested that where several polymorphs exist in one colony, the justification for the expression of a polymorph over another is that polymorph A must perform a task better than polymorph $\mathrm{B}$ under certain selection pressures and vice versa under a different set of selection pressures. Such hypotheses can only be addressed once the precise function of avicularia has been established along with the selection pressures responsible for their induction and how avicularia are likely to contribute to colony ergonomics. 
Making trade-offs in tandem with allocation shifts has already been demonstrated in Membranipora membranacea. The chemical cues from a predatory mollusc induce spine formation in M. membranacea, resulting in an overall reduction in reproductive output and growth as a result of re-allocation of resources into producing the defensive spines Harvell (1986, 1991, 1992). Similarly, crowding by conspecifics results in accelerated reproduction in order to compensate for the lack of space for colony growth (Harvell \& Helling 1993).

With respect to avicularia, where avicularia occur sporadically within any one colony it may be possible to ask questions about potential trade-offs. Can avicularia be produced in response to predation pressure? Will the overall fitness of the colony be reduced if important biological activities are compromised (reproduction and growth) as a result of the investment in avicularia production? Perhaps avicularia production is limited to certain stages of ontogeny, such as the reproductive phase, in order to protect such a biologically valuable resource (developing embryo). However, when we consider taxa that consistently have an avicularium on each zooid, such as most members of the genus Bugula, then these hypotheses become rather tenuous. On this basis, the overall factor influencing avicularium evolution may be environmentally driven, either by biotic or abiotic factors. Those taxa without avicularia may respond to such factors differently at the level of the zooid. These ideas are speculative but are highlighted in order to build up a picture as to how further development may be directed.

\subsection{Conclusions}

The divergence in avicularian morphologies since the Cretaceous suggests that avicularia have evolved to perform several functions, presumably in response to differing selection pressures, otherwise the ancestral form would have remained in evolutionary stasis through time. Therefore avicularia can be considered an important component in total colony functionality. Biological data on avicularia has been severely lacking since their discovery and documentation with little advancement since. Historically, gross structural biology has been ascertained by histological techniques, but no information exists concerning avicularian fine structure. On a gross-level, a myriad of avicularian morphologies exist, and as corollary, would be expected to exhibit a myriad of anatomical complexities. 
Ascertaining the level of morphological diversity can provide a critical insight into the functioning of an ecologically important invertebrate. Bryozoans are an important component of the aquatic ecosystem: Ecologically, bryozoans increase and enhance local biodiversity by creating suitable substrata and shelter for a variety of organisms (Morgado \& Tanaka 2001; Pederson \& Peterson 2002). Bryozoans display, paradoxically, disparate embryological and morphological complexities (Valentine 1997; Nielsen 2002). Combined with ambiguous and inconsistent molecular analyses, many evolutionary and phylogenetic questions remain unanswered (Halanych 2004; Helmkampf et al. 2008). Economically, bryozoans are rapidly becoming a prolific source of novel bioactive compounds (Paul et al. 2007), contributing significantly to the development of pharmaceuticals including anti-cancer drugs (Haygood et al. 1999; Davidson et al. 2001; Sharp et al. 2007). Bryozoans, therefore, play a number of major roles in the world oceans and critical our understanding of their biology is complete. Our knowledge of avicularian biology is incomplete particularly as potentially, they could be influential in how some of those ecological and economical aspects are directed.

With the advancement of microscopic techniques (such as confocal) techniques can be developed that allow the probing of cellular and even molecular-level structures. Such techniques are particularly useful when dealing with small structures such as avicularia (50-1000 $\mu \mathrm{m}$ in length), which at this size do not lend themselves readily to experimentation. By utilising a suite of microscopic techniques it may then be possible to conduct gross and ultrastructural studies in order to describe the biological make-up of a range of avicularian types and subsequently fill a substantial gap in bryozoan biology.

\subsection{Research objectives}

The objective of this study is to examine the functional morphology of avicularia from a range of taxa and environments. This study will offer insight into the internal mechanisms of avicularia by examining the ultrastructural anatomy of two species of bugulids with similar forms of avicularia. A survey of avicularian morphology will provide an evaluation of the degree of morphological diversity displayed by avicularia including examination of palatal structures. By comparing morphology between species 
it may then be possible to formulate hypotheses related to the evolution and functional capacity of avicularia. Therefore the components of this study are as follows:

- An extensive comparative survey of avicularian types (i.e. adventitious, interzooidal, vicarious, and vibracula) using scanning electron microscopy (SEM). The objective here is to construct a morphological and morphometric database of avicularia (Chapter 2).

- A comparative ultrastructural study of avicularian anatomy in two species of bugulids each possessing a bird's-head form of avicularia and inhabiting very different depths. This component of the study offers immense insight into the evolution of the anatomy and functional diversification in avicularia. This research component will be achieved using transmission electron microscopy (TEM) (Chapter 3).

- A detailed anatomical study of the bird's-head avicularium of Bugula flabellata. Phalloidin histochemistry will be employed to describe the musculature of autozooids and avicularia in order to establish the evolutionary divergence of morphology, whilst the serotonergic nervous system of the avicularium will be examined using immunocytochemical techniques. A detailed construction of the neuro-muscular system will provide a clearer understanding of the underlying mechanics driving the observed behaviour of this avicularium. Laser scanning confocal microscopy will be utilised in order to achieve this objective (Chapter 4).

\subsection{References}

Banta, W.C., 1972. The body wall of cheilostome Bryozoa, V, Frontal budding in Schizoporella unicornis floridana. Marine Biology 14: 63-71.

Banta, W.C., 1973. Evolution of avicularia in cheilostome Bryozoa. In: Boardman, R.S., Cheetham, A. \& Oliver, W. (Eds), Animal colonies. Dowden, Hutchinson and Ross, Inc, Pennsylvania, pp. 295-303.

Becerro, M.A., Paul, V.J. \& Starmer, J., 1998. Intracolonial variation in chemical defenses of the sponge Cacospongia sp. and its consequences on generalist fish predators and the specialist nudibranch predator Glossodoris pallida. Marine Ecology Progress Series 168: 187-196. 
Boardman, R.S. \& Cheetham, A.H., 1973. Degrees of colony dominance in stenolaemate and gymnolaemate Bryozoa. In: Boardman, R.S., Cheetham, A.H. \& Oliver, W.A. (Eds), Animal colonies. Development and function through time. Dowden, Hutchinson \& Ross, Inc, Stroudsburg, pp. 121-220.

Busk, G., 1854. Remarks on the structure and function of the avicularian organs of bryozoans; and on their value as diagnostic and vibracular characters in the classification of those creatures. Transactions of the Microscopical Society 2: 26-33.

Canu, F. \& Bassler, R.S., 1929. Bryozoa of the Philippine region. Smithsonian Institute. U.S. National Museum Bulletin 100: 1-685.

Cheetham, A., 1973. Study of cheilostome polymorphism using principal component analysis. In: Larwood, G.P. (Ed.), Living and Fossil Bryozoa. Academic Press, London, pp. 385-409.

Cheetham, A.H. \& Cook, P.L., 1983. General features of the class Gymnolaemata. In: Robison, R.A. (Ed.), Treatise on Invertebrate Paleontology, Part G, Bryozoa. Geological Society of America and University of Kansas Press, Lawrence, pp. 138-207.

Cheetham, A.H., Sanner, J., Taylor, P.D. \& Ostrovsky, A.N., 2006. Morphological differentiation of avicularia and the proliferation of species in mid-Cretaceous Wilbertopora Cheetham, 1954 (Bryozoa: Cheilostomata). Journal of Paleontology 80: 49-71.

Chimonides, P.J. \& Cook, P.L., 1981. Observations on living colonies of Selenaria (Bryozoa, Cheilostomata). II. Cahiers de Biologie Marine 22: 207-219.

Cook, P.L., 1963. Observations on live lunulitiform zoaria of polyzoa. Cahiers de Biologie Marine 4: 407-413.

Cook, P.L., 1977. Colony-wide water currents in living Bryozoa. Cahiers de Biologie Marine 18: 31-47.

Cook, P.L. \& Chimonides, P.J., 1978. Observations on living colonies of Selenaria (Bryozoa, Cheilostomata). I. Cahiers de Biologie Marine 19: 147-158.

Darwin, C., 1845. Journal of researches into the natural history and geology of the countries visited during the voyage of H.M.S. 'Beagle' around the world, under the command of Capt. Fitzroy, R.N. Second edn., corrected with additions. Ward, Locke, and Co., London, 492 pp.

Darwin, C., 1872. On the origin of species by means of natural selection, or the preservation of favoured races in the struggle for life. Sixth edition with additions and corrections. John Murray, London, $458 \mathrm{pp}$.

Davidson, S.K., Allen, S.W., Lim, G.E., Anderson, C.M. \& Haygood, M.G., 2001. Evidence for the biosynthesis of bryostatins by the bacterial symbiont "Candidatus Endobugula sertula" of the bryozoan Bugula neritina. Applied and Environmental Microbiology 67: 4531-4537.

Ellis, J., 1755. An essay towards a natural history of the corallines and other marine productions of the like kind, commonly found on the coasts of Great Britain and Ireland. Privately Published, London, 103 pp.

Forbes, A., 1938. Conditions affecting the response of the avicularia of Bugula. Biological Bulletin 65: 469-479.

Goldstein, J.R.Y., 1880. Notes on living Polyzoa. Journal of the Microscopical Society of Victoria 1: 42-50.

Halanych, K.M., 2004. The new view of animal phylogeny. Annual Review of Ecology and Systematics 35: 229-256. 
Harmer, S.F., 1900. A revision of the genus Steginoporella. Quarterly Journal of the Microscopical Society 43: 225-297.

Harmer, S.F., 1902. On the morphology of the Cheilostomata. The Quarterly Journal of Microscopical Science 46: 263-350.

Harmer, S.F., 1909. Presidential address, Report, 78th meeting of the British

Association for the Advancement for Science, 1908, pp. 715-731.

Harmer, S.F., 1923. On cellularine and other Polyzoa. Linnean Journal of Zoology 35: 22-361.

Harmer, S.F., 1926. The Polyzoa of the Siboga expedition. Part II, Cheilostomata Anasca. Siboga-Expeditie 28b: viii, 181-501, pls 113-134.

Harmer, S.F., 1930. Polyzoa. Proceedings of the Linnean Society of London 141: 68118.

Harvell, C.D., 1986. The ecology and evolution of inducible defenses in a marine bryozoan: Cues, costs, and consequences. The American Naturalist 128: 810823.

Harvell, C.D., 1991. Coloniality and inducible polymorphism. The American Naturalist 138: $1-14$.

Harvell, C.D., 1992. Inducible defenses and allocation shifts in a marine bryozoan. Ecology 73: 1567-1576.

Harvell, C.D., 1994. The evolution of polymorphism in colonial invertebrates and social insects. The Quarterly Review of Biology 69: 155- 185.

Harvell, C.D. \& Helling, R., 1993. Experimental induction of localized reproduction in a marine bryozoan. Biological Bulletin 184: 286-295.

Hastings, A.B., 1945. Notes on Polyzoa (Bryozoa).-II. Membranipora crassimarginata auctt., with remarks on some genera. Annals and Magazine of Natural History, series 11 12: 69-103.

Hastings, A.B., 1963. Notes on Polyzoa (Bryozoa) VI. Some setiform heterozooecia. Annals and Magazine of Natural History, series 13 6: 177-184.

Haygood, M.G., Schmidt, E.W., Davidson, S.K. \& Faulkner, D.J., 1999. Microbial symbionts of marine invertebrates: opportunities for microbial biotechnology. Journal of Microbial Biotechnology 1: 33-43.

Helmkampf, M., Bruchhaus, I. \& Hausdorf, B., 2008. Multigene analysis of lophophorate and chaetognath phylogenetic relationships. Molecular Phylogenetics and Evolution 46: 206-214.

Hincks, T., 1878. Notes on the genus Retepora with descriptions of new species. Annals and Magazine of Natural History, series 5, 1:352-365.

Hincks, T., 1888. The Polyzoa of the St. Lawrence: a study of Arctic forms. Annals and Magazine of Natural History, series 6, 1: 214-231.

Hyman, L.H., 1959. The invertebrates: Smaller coelomate groups Chaetognatha, Hemichordata, Pogonophora, Phoronida, Ectoprocta, Brachiopoda, Sipunculida. The coelomate bilateria. McGraw-Hill Book Company, Inc, New York, 783 pp.

Johnston, G., 1847. A history of the British zoophytes. Van Voorst, London.

Kaufmann, K.W., 1968. The biological role of Bugula-type avicularia (Bryozoa). In: Annoscia, E. (Ed.), Proceedings of the first international conference on Bryozoa. Atti della Società Italiana di Scienze Naturali e del Museo Civico di Storia Naturale di Milano 108, pp. 54-60.

Kaufmann, K.W., 1971. The form and functions of the avicularia of Bugula (Phylum Ectoprocta). Postilla 151: 1-26. 
Levinsen, G.M.R., 1909. Morphological and systematic studies on the cheilostomatous Bryozoa. Nationale Forfatteres Forlag, Copenhagen, 427 pp.

Lidgard, S., 1981. Water flow, feeding, and colony form in an encrusting cheilostome. In: Larwood, G.P. \& Nielsen, C. (Eds), Recent and fossil Bryozoa. Olsen \& Olsen, Fredensborg, pp. 135-142.

Lidgard, S., 2008. Predation on marine bryozoan colonies: taxa, traits and trophic groups. Marine Ecology Progress Series 359: 117-131.

Lindquist, N., 1996. Palatability of invertebrate larvae to corals and sea anemones. Marine Biology 126: 745-755.

Lindquist, N. \& Hay, M.E., 1996. Palatability and chemical defense of marine invertebrate larvae. Ecological Monographs 66: 431-450.

Lutaud, G., 1964. Sur la structure et le rôle des glandes vestibulaires et sur la nature de certains organes de la cavité cystidienne chez les Bryozaires chilostomes. Cahiers de Biologie Marine 5: 201-231.

Lutaud, G., 1965. Sur la présence de microorganismes spécifiques dans les glandes vestibulaires de Palmicellaria skenei (Ellis et Solander), Bryozoaire chilostome. Cahiers Biologie Marine 6: 181-190.

Lutaud, G., 1969. La nature des corps funiculaires des cellularines Bryozoaires chilostomes. Archives de Zoologie Expérimentale et Générale 110: 2-30.

Marcus, E., 1926. Bryozoa. In: Grimpe, G. \& Wagler, E. (Eds), Die Tierwelt der Nordund Ostee. Verlagsgesellschaft, Leipzig, pp. 1-100.

Marcus, E., 1939. Bryozoarios marinhos Brasileiros. III. BoletiMs da Faculdade de Filosofia, Ciências e Letras, Universidade de São Paulo, Zoologia 3: 111-353.

Marcus, E. \& Marcus, E., 1962. On some lunulitiform Bryozoa. BoletiMs da Faculdade de Filosofia, Ciências e Letras, Universidade de São Paulo, Zoologia 24: 281324.

McKinney, F.K. \& Jackson, J.B.C., 1989. Bryozoan Evolution. Unwin Hyman, Boston, $287 \mathrm{pp}$.

Morgado, E.H. \& Tanaka, M.O., 2001. The macrofauna associated with the bryozoan Schizoporella errata (Walters) in southeastern Brazil. Scientia Marina 65: 173181.

Nielsen, C., 2002. The phylogenetic position of Entoprocta, Ectoprocta, Phoronida, and Brachiopoda. Integrative and Comparative Biology 42: 685-691.

Paul, V.J., Arthur, K.E., Ritson-Williams, R., Ross, C. \& Sharp, K., 2007. Chemical defenses: from compounds to communities. Biological Bulletin 213: 226-251.

Pederson, E.J. \& Peterson, M.S., 2002. Bryozoans as ephemeral estuarine habitat and a larval transport mechanism for mobile benthos and young fishes in the northcentral Gulf of Mexico. Marine Biology 140: 935-947.

Ryland, J.S., 1970. Bryozoans. Hutchinson University Library, London, 175 pp.

Schopf, T.J.M., 1973. Ergonomics of polymorphism: Its relation to the colony as the unit of natural selection in species of the phylum Ectoprocta. In: Boardman, R.S., Cheetham, A.H. \& Oliver, W.A. (Eds), Animal colonies. Dowden, Hutchinson \& Ross Inc., Stroudsburg, pp. 247-294.

Sharp, J.H., Winson, M.K. \& Porter, J.S., 2007. Bryozoan metabolites: an ecological perspective. Natural Product Reports 24: 659-673.

Silén, L., 1938. Zur Kenntnis des Polymorphismus der Bryozoen. Die Avicularien der Cheilostomata Anasca. Zoologiska Bidrag frân Uppsala 17: 149-366.

Silén, L., 1977. Polymorphism. In: Woollacott, R.M. \& Zimmer, R.L. (Eds), Biology of bryozoans. Academic Press, New York, pp. 184-231. 
Silén, L., 1982. Multizooidal budding in Parasmittina trispinosa (Johnston) (Bryozoa, Cheilostomata). Acta Zoologica 63: 25-32.

Ström, R., 1977. Brooding patterns of bryozoans. In: Woollacott, R.M. \& Zimmer, R.L. (Eds), Biology of Bryozoans. Academic Press, New York, pp. 23-55.

Taylor, P.D., 1994. An early cheilostome bryozoan from the Upper Jurassic of Yemen. Neues Jahrbuch für Geologie und Paläontologie Abhandlungen 191: 331-344.

Valentine, J.W., 1997. Cleavage patterns and the topolgy of the metazoan tree of life. Proceedings of the National Academy of Science 94: 8001-8005.

Waters, W.M., 1913. The marine fauna of British East Africa and Zanzibar, from collections made by Cyril Crossland, MA., B.S.c., F.Z.S., in the years 19011902. Bryozoa- Cheilostomata. Proceedings of the Zoological Society of London 1913: 458-537.

Winston, J.E., 1984. Why bryozoans have avicularia - A review of the evidence. American Museum Novitates 2789: 1-26.

Winston, J.E., 1986. Victims of avicularia. Marine Ecology 7: 193-199.

Winston, J.E., 1991. Avicularian behaviour - A progress report. In: Bigey, F.P. (Ed.), Bryozoa Living and Fossil. Bulletin de la Société des Sciences Naturelles de l'Ouest de France, Mémoire, H.S, Nantes, pp. 531-540.

Woollacott, R.M., 1981. Association of bacteria with bryozoan larvae. Marine Biology 65: 155-158.

Wyer, D.W. \& King, P.E., 1973. Relationship between some British littoral and sublittoral bryozoans and pycnogonids. In: Larwood, G.P. (Ed.), Living and Fossil Bryozoa. Academic Press, London, pp. 199-207. 


\section{CHAPTER 2}

\section{A Morphometric Analysis and Anatomical Survey of Avicularia}

\subsection{Introduction}

The diversity of size and morphology of avicularia has made establishing a consensus on their function difficult (Winston 1984). Equally, there may be subtle modifications in their anatomy such as the presence of cilia or glands and overall vestigial polypide morphology (see Marcus 1939). The significance of these morphological modifications in a behavioural and ecological sense is unclear. Behavioural observations of avicularia in the wild are non-existent owing to their small size (often $<100 \mu \mathrm{m}$ in length) (Winston 1991) and very few have been conducted in the laboratory.

The diversity of avicularian forms implies they have evolved to perform several functions, or variations of a specific function (Hyman 1959; Banta 1973; Silén 1977; Winston 1984). The objective of this study is to address this issue by examining the morphology of a variety of avicularia and to qualitatively and quantitatively assess the degree of morphological divergence. Ascertaining the degree of morphological divergence can provide useful information on the functional evolution of avicularia. The evolution of avicularia is an enigma and recent studies have started to reveal information about the transition of avicularian skeletal development through geological time, though no information is available on possible environmental triggers.

\subsubsection{Evolution of avicularia}

Very little information is available on the evolution of cheilostome bryozoans in the fossil record (Dzik 1975): The oldest cheilostome bryozoans are from the Late 
Jurassic ( 144-208 Ma) (Taylor 1994) and consist of uniserial monomorphic zooids (Dzik 1975). The earliest known avicularia to occur in bryozoans appeared in the genus Wilbertopora from the Early Cretaceous ( $\sim 97 \mathrm{Ma}$ ) (Cheetham et al. 2006) at a time when colony morphology was diversifying (McKinney \& Jackson 1989). The ancestral avicularia did not differ in size or manner of budding to ordinary zooids (and were therefore vicarious) (Boardman \& Cheetham 1973), indicating that specialisation of the operculum preceded the decrease in avicularian dimensions (Dzik 1975). In the later Upper Albian and Cenomanian, the avicularia of the genus Mystriopora are smaller and more specialised (Boardman \& Cheetham 1973; Dzik 1975). The early avicularia of Wilbertopora were characterised by an enlarged operculum and the presence of incipient condyles. These ancestral vicarious avicularia were thought to possess a functional polypide on the basis of their association with ovicells. In contemporary ovicellate cheilostome bryozoans, a lophophore is typically required to transfer the fertilised egg from zooid to ovicell (Silén 1945). The Early Cretaceous is therefore associated with the inception of increased specialisation and colony integration in cheilostome bryozoans.

A comprehensive study of the evolution of avicularia through the order is certainly warranted. Details have recently emerged from a species complex of Wilbertopora (Cheetham et al. 2006) as described earlier, and from Metrarabdotos, an Atlantic Ocean dwelling genus of the Cenozoic era to present. The population of Metrarabdotos studied included 12 distinct species whose evolution was characterised by long intervals of stasis, punctuated with rapidly splitting lineages. Convergent evolution was evident in species with avicularia displaying similar morphometrics that were in separate lineages (see McKinney \& Jackson 1989). The distribution of Wilbertopora in the fossil record has revealed morphologically ancestral zooids in more recent stratigraphic occurrences, suggesting avicularia have evolved more than once (Cheetham et al. 2006). Further support for the independent evolution of avicularia may lie in the present day B-zooids characteristic of the genus Steginoporella. The B-zooids differ morphologically from the A-zooids (autozooids) in the same colony by the possession of a larger operculum and an augmented adductor system. On this basis it is believed the B-zooids are incipient avicularia (Harmer 1900; Banta 1973). The pattern of avicularian evolution appears complex and further research, in parallel with a study of co-occurring environmental regimes, is certainly warranted. Avicularian anatomical 
evolution provides a greater challenge to investigate as inferences must be made based on the anatomy of contemporary avicularia using histological techniques.

\subsubsection{Morphology of avicularia}

Avicularian anatomy is based on homology with autozooid anatomy (Figure 1.1). The palate and orifice are homologous to the tentacle sheath of an autozooid (Marcus 1939; Hyman 1959). The tentacle sheath is morphologically an introvert and is a cuticle-free layer that encases the pharynx and terminal part of the rectum thereby joining the lophophore to the lower portion of the autozooid (Ryland 1970). In avicularia this sheath is now the palate, part of which introverts into the avicularium cystid and encases the vestigial polypide (Marcus 1939). Based on histological studies of avicularia from a few species, a mass of internal cells or rudimentary polypide exists (Marcus 1939) and in some instances extends through the orifice in the palate and it is this portion that has been termed the setiferous (setigerous) organ (Banta 1973; Silén 1977). This extensile mass is considered to be the sensory portion of the avicularium based on behavioural observations, mainly on the bird's-head form of Bugula. Even under light microscopy, tufts of cilia can be seen extending from the palate and, when stimulated, have instigated the rapid closure of the mandible onto the stimulant (Darwin 1845; Johnston 1847; Forbes 1938; Kaufmann 1968; Silén 1977; Winston 1991). Other than the avicularia of Bugula, no documentation exists detailing the palate anatomy of other types of avicularia, or specifically the avicularian orifice, the presumed sensory area of the avicularium. For instance, how ubiquitous in the Buguloidea is the presence of external sensory cilia and whether they exist in other superfamilies is unknown.

A pertinent point to consider also is, if a range of orificial structures exist and therefore a range of sensory functions, then what is the driving force for their occurrence? The sensory perception and subsequent behavioural response of avicularia to specific environmental cues could certainly have wider ecological consequences. The dynamics that result in a behavioural response of avicularia to associated epifauna can ultimately alter organismal interactions. On this basis, if we are to assume that avicularia have evolved in order to respond to specific, or a variety of, environmental cues, then a greater understanding of the functional morphology of avicularia is required. 


\subsubsection{Correlating form and function in avicularia}

It has become a well established phenomenon in biology that phenotypic differences among individuals of a species are related to differences in their ecology. Implicit in this is the capacity for morphology to determine ecological patterns (Wainwright 1994), facilitating ecological inferences based on morphological patterns (Ricklefs \& Miles 1994). Functional morphology can be a useful tool in ecological research, especially when understanding the functional basis for an observed performance or behaviour (Wainwright 1994). Studies on the pedicellariae of echinoderms are an example of correlating morphology with function. Pedicellariae are pincer-like organs with movable jaws, or valves, found on the external surface of some asteroids and all echinoids (Campbell 1983). Analogies have often been made between avicularia and pedicellariae (Darwin 1872; Hyman 1959). Much of the early work on pedicellariae, with respect to establishing their function, was based on observation and inference (Campbell 1983; Guenther et al. 2007), much like studies on avicularia. The difficulty in examining their function is that pedicellariae are diverse in form, and behave capriciously (Campbell 1983). There are four main classes of pedicellariae (Campbell \& Jensen 1993), with the shape of each class being closely related to function (Coppard \& Campbell 2006). Examples include tridentate pedicellariae with a series of serrated jaws; they function in the removal of foreign particles from off the test. Globiferous pedicellariae contain a toxic chemical but respond only in the presence of an ecologically relevant chemical stimulant such as a predator (Campbell 1983). The Ophicephalous pedicellariae are multi-functional and are used for cleaning and defence. These pedicellariae carry large glands that secrete chemicals over the test in order to repel fouling organisms (Lewis \& Saluja 1967; Coppard \& Campbell 2006).

In avicularia many inferences have been made about their function based on morphology and behavioural observations, particularly on those with extremes of morphology such as the bird's-head avicularia (Busk 1854; Kaufmann 1968, 1971; Winston 1984) and vibracula (Busk 1854; Cook 1963). The vibracula of lunulitiform bryozoans are interzooidal in location and have been observed cleaning colony surfaces of sand particles with their long hair-like mandibles whilst he peripheral vibracula lift the colony above the sand by the tips of their mandibles (Cook 1963). This multifunctional capacity of vibracula in lunulitiform bryozoans may constitute a mode of increasing performance and functional diversity (see Wainwright 2007). Observations 
on the behaviour of lunulitiform bryozoans are the only consistent and unambiguous evidence for a functional role for avicularia whereas the function of the vibracula characteristic of species of Caberea and Scrupocellaria is far more ambiguous. The water current manipulation pattern of the lophophores of the autozooids of Caberea and Scrupocellaria is far more effective at removing foreign particles (Winston 1984). This disparity in correlating morphology with function warrants a certain degree of caution when correlating form and function in any biological structure (Wainwright 2007).

Few examples have been documented that describe the functional capacity of avicularia but include syllid polychaetes being caught by the adventitious avicularium of Reptadeonella costulata and interzooidal avicularium of Celleporaria albirostris (Winston 1986). Also gammarid amphipods and planarian worms by the bird's-head form of Bugula (Forbes 1938; Kaufmann 1971). The avicularia are responding to tactile stimuli and must therefore possess some form of sensory structures on or within the exposed palate in order to initiate mandible closure. If the detection of tactile stimuli is important then presumably sensory structures such as the cilia of the bird's-head avicularia of Bugula may be a common occurrence. Obviously the nature of the surface anatomy will depend on the biological role of that specific avicularium; hence a comparative survey is required.

\subsubsection{Scanning electron microscopy (SEM)}

Scanning electron microscopy is a particularly useful tool for studying morphology. SEM has great power of resolution and a high depth of focus, giving images a pseudo-three-dimensionality (Minnich et al. 1999). The arrival of the SEM proved to be useful in bryozoology, particularly in taxonomy. Cheilostome bryozoans secrete a calcium carbonate skeleton that can often consist of intricate spines and pores with each species exhibiting subtle differences in morphology (Taylor \& Jones 1996). It is such characteristics that dominate taxonomic studies of extant and fossil bryozoans with the SEM providing an essential tool in discerning those subtle characteristics (Sandberg 1971; Taylor 1990). The SEM has also proven to be a useful tool for discerning surface anatomy and ciliary sensory structures in a range of invertebrates such as phoronid larvae (Santagata 2002, 2004), adult and larval bryozoans (Nielsen \& Riisgård 1998; Nielsen 2002; Shunatova \& Nielsen 2002), brachiopods (James 1997) 
and polychaetes (Lindsay et al. 2004; Purschke \& Hausen 2007). The high resolving power of the SEM (Minnich et al. 1999; Valdecasas \& Camacho 2005) means it is an important tool for discerning surface structures and therefore critical in the examination of anatomical and sensory structures in avicularia.

\subsubsection{Research objectives}

No extensive examination of comparative avicularian anatomy has been carried out before, especially of the palate, the putative sensory area. Such an examination will offer insight into the functional morphology of avicularia and the elucidation of any phylogenetic relationships among species and/or among superfamilies. The overall objective of this study is to expand our knowledge of avicularian anatomy and functional morphology in the context of bryozoan ecology and evolution. Therefore the objectives of this study are as follows: (1) Conduct an anatomical survey of avicularia using scanning electron microscopy; (2) Construct a standardised nomenclature for avicularian anatomy; (3) Compile a morphometric database of avicularia, and; (4) Use multivariate statistics to describe and quantify species and avicularian-type relationships

\subsection{Materials and Methods}

\subsubsection{Collection and distribution}

Bryozoans were collected from a variety of depths and locations around New Zealand (Figure 2.1) between April 2005 and January 2008. Intertidal and shallow subtidal $(0-0.4 \mathrm{~m})$ taxa were collected by hand. Intertidal bryozoans were generally found encrusting shells and stones whereas subtidal bryozoans were found on wharf pilings, shells, stones, and algal holdfasts. Subtidal ( $>4 \mathrm{~m}$ ) bryozoans were collected by NIWA SCUBA divers. The colonies were generally found encrusting shells, stones, and seaweed or simply picked off rock faces. Deep-sea $(\sim 800-1600 \mathrm{~m})$ bryozoans were collected from the Graveyard Seamount Complex on the Chatham Rise (Figure 2.2) by epibenthic sled during a scientific research voyage onboard the NIWA research vessel Tangaroa during May/June 2006. The contents of the epibenthic sled were sorted immediately following release onto the deck. Once located, bryozoans were placed into filtered seawater and fixed as soon as possible following collection (20 $\min$ to $3 \mathrm{~h}$ ). 


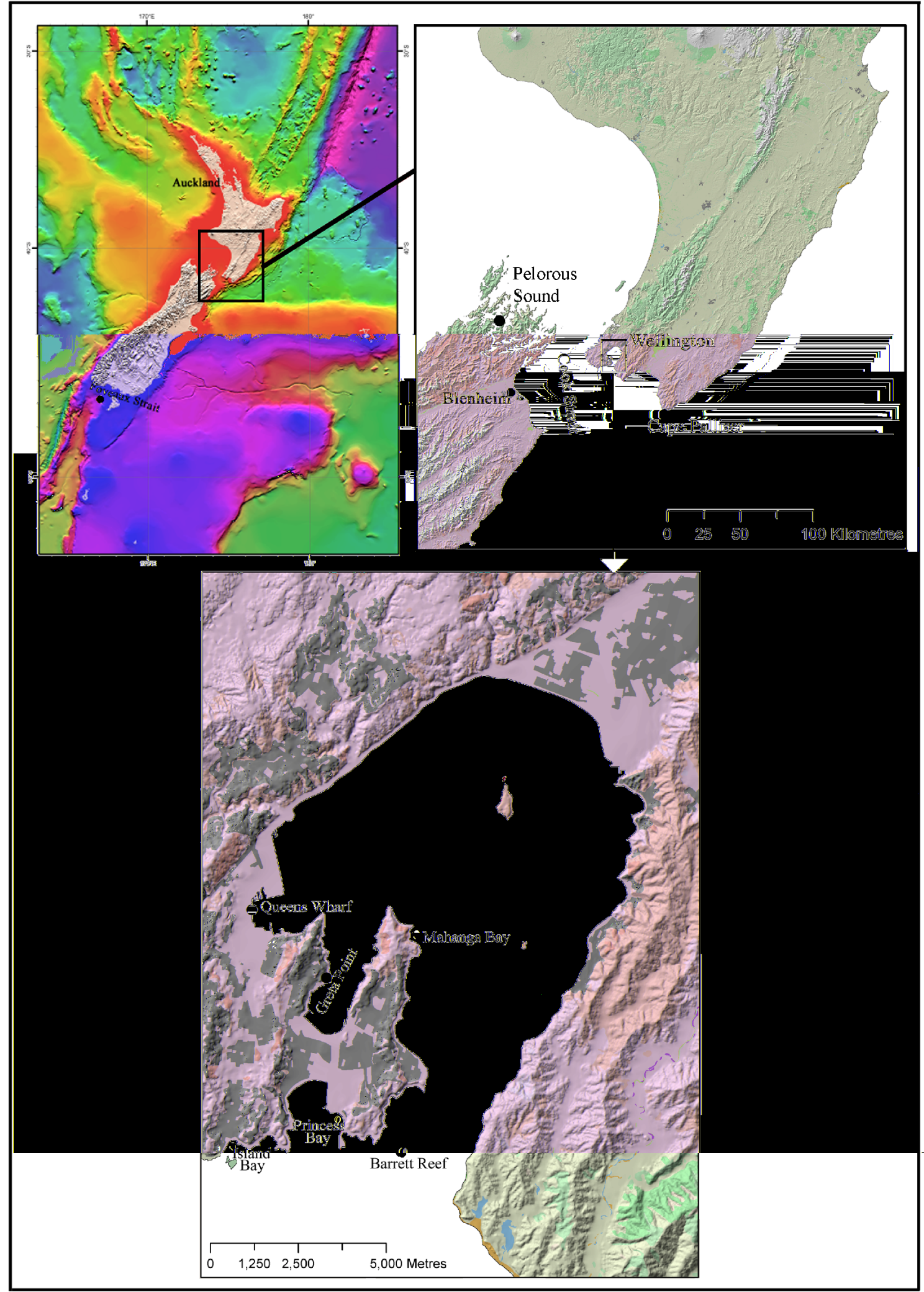

Figure 2.1. Distribution and collection sites around New Zealand $(\bullet)$ for the intertidal and shallow subtidal ( $0-4 \mathrm{~m}$ ), and subtidal ( $>4 \mathrm{~m}$ ) bryozoans. Maps provided by A. Pallentine (NIWA). 

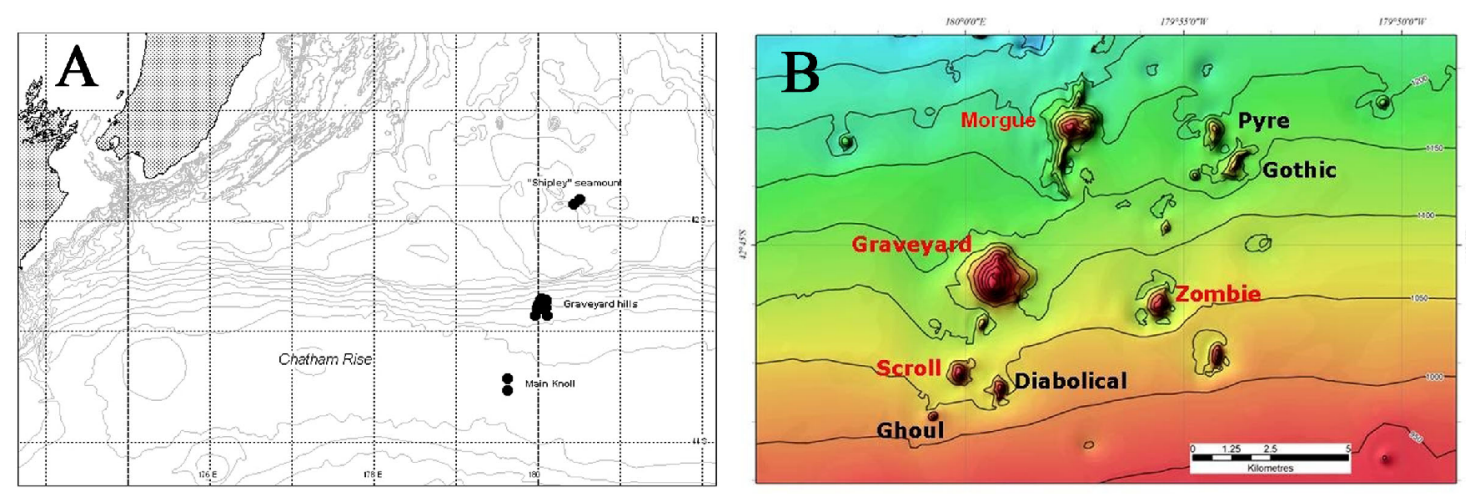

Figure 2.2. Distribution and collection sites for the deep-sea bryozoans: (A) Location of the Chatham Rise Graveyard seamount complex; (B) Graveyard seamount complex. Images provided by NIWA.

\subsubsection{Scanning electron microscopy (SEM)}

The samples used in this study have been archived at the NIWA Invertebrate Collection, Greta Point, Hataitai, Wellington and can be accessed through the collection manager.

The methods and solutions required for the following protocols are documented in Appendix 2.

\section{Intertidal and subtidal bryozoans}

The following protocol was derived from Nielsen (2002). Colonies were initially relaxed in $7 \% \mathrm{MgCl}_{2}$ for 20 min prior to fixation in $1 \% \mathrm{OsO}_{4}$ in $0.1 \mathrm{M}$ sodium cacodylate buffer $(7.4 \mathrm{pH})$ and $10.26 \%$ sucrose $(\mathrm{CAB})(750 \mathrm{mOsMol})$ for $2 \mathrm{~h}$. Colonies were then washed three times in $\mathrm{CAB}$ for $10 \mathrm{~min}$ each wash, dehydrated in a graded ethanol/acetone series ending in $100 \%$ acetone, critical point dried, mounted on SEM stubs and coated in either carbon or gold in a sputter coater prior to being viewed in either a Jeol 6500, Jeol 5300 LV, or Leo 440 SEM.

\section{Deep-sea bryozoans}

No protocol exists for the preservation of live deep-sea bryozoans intended for SEM. The following protocol is basically a modified version of the protocol of Nielsen (2002) with the modifications proposed by Prof. S.J Wakefield (Pathology Dept, Wellington School of Medicine). The protocol involved two stages; an initial onboard fixation stage following collection of colonies, an interim storage period, and finally the post-fixation stage at an onshore laboratory. 
Following collection onboard the research vessel, colonies were initially relaxed in $7 \% \mathrm{MgCl}_{2}$ (20-60 min) prior to fixation in $2.5 \%$ glutaraldehyde in $\mathrm{CAB}$ for $2-3 \mathrm{~h}$ and then placed in airtight plastic containers containing filtered seawater for storage purposes. Seawater is a natural buffer and therefore a suitable medium for the extended storage period (5-25 d). The samples were kept cool during storage. Once back onshore, colonies were post-fixed in $1 \%$ osmium in $\mathrm{CAB}$ then taken through the dehydration process as described for the intertidal and subtidal bryozoans.

\section{Imaging}

In order to negate any effect of image distortion (due to the imperfect orientation of the avicularium) and obtain a close as possible morphometric perspective, between one and five images per avicularium and between one and 25 images of that avicularian type per species were taken. The number of measurements obtained between species was highly variable due to the reliance on avicularia with their mandibles open. Intercolony inconsistencies in the occurrence of avicularia in some species, and number of colonies actually collected also added to the variability.

\subsubsection{Morphometrics}

Data for morphological measurements were obtained from digital SEM images of avicularia using the Jeol SemaFore Image Analysis software. Variables used for analysis are described in Figure 2.3. For each image of an avicularium, the following measurements were obtained: Length of avicularium (Lav), width of avicularium (Wav), length of palate (Lpal), width of palate (Wpal), length of orifice (Lo), width orifice (Wo). For the purpose of this study, avicularia were grouped into four main types: adventitious, interzooidal, vibracula and vicarious. Strictly speaking the vibracula forms collected in this study are adventitious in location but are characteristically different in morphology owing to their elongated, bristle-like mandibles. They have been segregated from the adventitious group for comparative purposes.

\subsubsection{Density of avicularia}

Digital SEM images of colonies, or zooids, were used to calculate the density (number of avicularia per $\mu^{2}$ ) of avicularia using the Jeol SemaFore Image Analysis software. 


\subsubsection{Statistical analyses}

In order to condense the data set for multivariate analyses, repeated measurements for an individual avicularium were averaged in order to obtain a value that was most similar to all the measurements for that specific avicularium. The resulting data set consisted of one set of six measurements per avicularium (Lav, Wav, Lp, Wp, Lo, and Wo). In a previous study, linear regression revealed a statistically significant linear relationship between length of orifice (Lo) and length of avicularium (Lav) $\left(\mathrm{R}^{2}=0.0636 ; P<0.01\right)$ which contributed significantly to morphometric variability (Carter et al. 2008). On that basis the data for this study was standardised and the following variables analysed: Wav/Lav, $\mathrm{Lp} / \mathrm{Lav}, \mathrm{Wp} / \mathrm{Lav}, \mathrm{Lo} / \mathrm{Lav}$, and $\mathrm{Wo} / \mathrm{Lav}$. In subsequent references these variables will be prefixed with ' $s$ ' to indicate their standardised status. The standardisation of data was carried out in Microsoft Excel.

Multivariate statistical techniques were used for the five variables to describe similarities in the morphometrics of avicularia among avicularian types and species. The Bray-Curtis similarity index was calculated between avicularia from a range of species and avicularian types and organised in a similarity matrix. This then formed the basis for non-parametric multidimensional scaling (MDS) and an analysis of similarities (ANOSIM) to test statistically the null hypothesis that there is no morphometric difference between avicularia. The MDS and ANOSIM were carried out using the PRIMER 6 (Clarke \& Gorley 2006) statistical package.

A discriminant function analysis (DFA) was employed and the data $\log 10$ transformed prior to analysis in order to meet the assumptions of normality for the DFA. The transformation of data was carried out in Microsoft Excel. The objective of this analysis was to calculate the Mahalanobis distance and its statistical significance between a given species' avicularium and each type of avicularia. The Mahalanobis Distance is a measure of the distance between the variables of a given avicularium to the mean, or group centroid value of all variables for each avicularium type. If the distance between the morphometrics of a given avicularium and the group centroid of an avicularium type (e.g. adventitious) is small, then the morphometrics are similar. If the distance is large, then the morphometrics are dissimilar.

DFA was also employed as an assignment test to determine what percentage of individuals (with an observed avicularium type) could be correctly assigned to that type based on their given morphometrics. Preliminary comparative analyses were carried out 
to compare the outcome of the DFA using either standardised only or standardised $\log _{10}$ transformed data. By employing the standardised $\log _{10}$ data, the ability to classify the vicarious types is lost but the adventitious types were classified with a greater accuracy. In order to maintain consistency and therefore ensure a comparable data set with the standardised variables analysed in the MDS, standardised $\log _{10}$ transformed data was used in the DFA. The standardised $\log _{10}$ transformed data were then analysed using Statistica v.7 (StatSoft Inc. 2005).

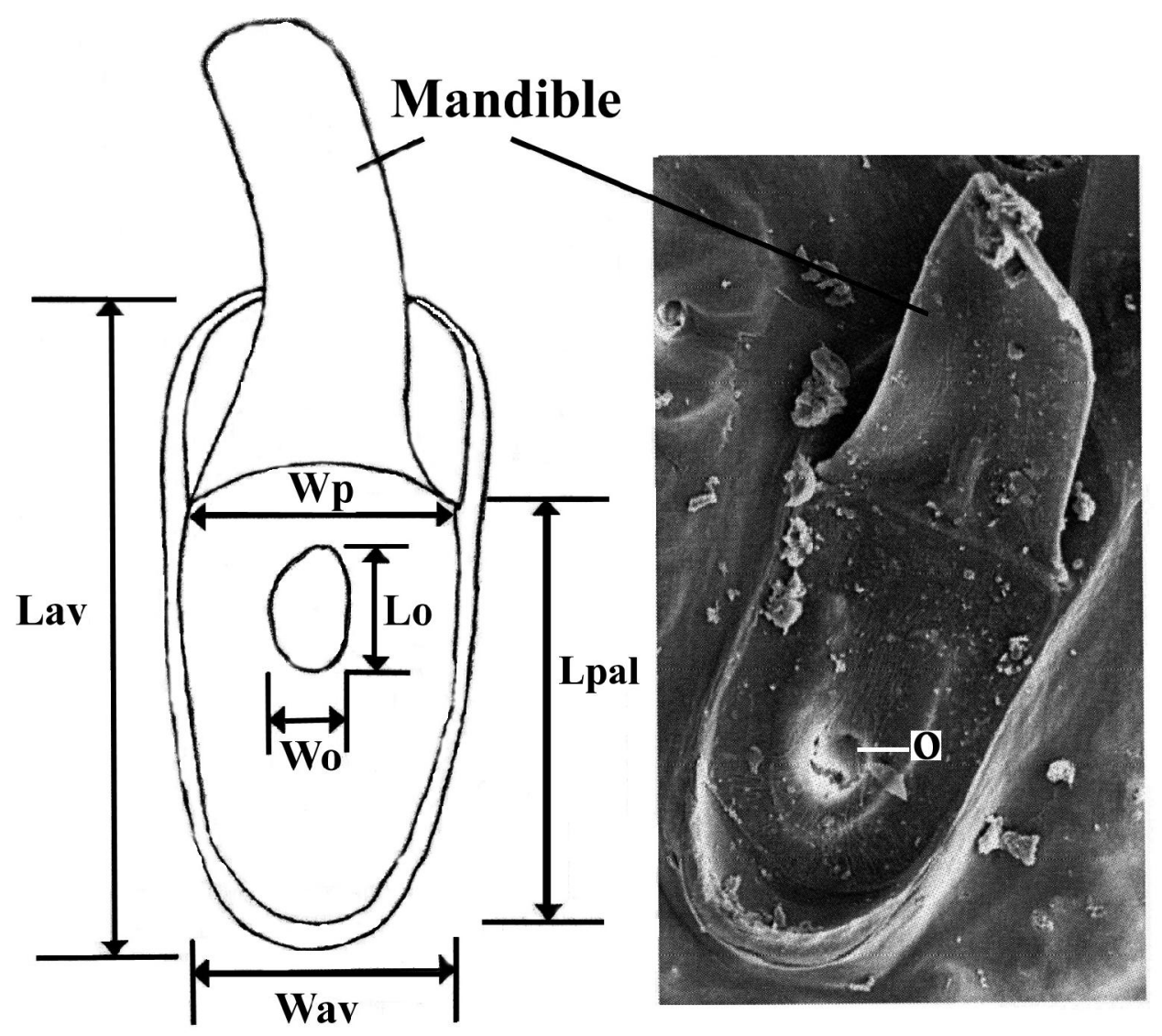

Figure 2.3. A diagrammatic representation of an avicularium in frontal view (left) with the morphological variables annotated: Length of avicularium (Lav), width of avicularium (Wav), length of palate (Lpal), width of palate (Wpal), length of orifice (Lo), width of orifice (Wo). Right is a scanning electron micrograph of an avicularium from Parkermavella n.sp.(orientated slightly to the left with respect to the diagram) in order to place the diagrammatic measurements into context. $\mathrm{O}$, orifice in the palate of the avicularium. 


\subsection{RESULTS}

\subsubsection{Anatomical observations (SEM)}

The cheilostomes examined in this study were a good representation of the order (see Tables $2.8 \& 2.9$ in Appendix) and consisted of 11 superfamilies, 18 families, and 38 species (Table 2.1). Six of those species were deep-sea and collected from four of the 10 seamounts from the Chatham Rise: Diabolical, Graveyard, Main Knoll and Zombie (Table 2.2). With respect to the avicularia actually examined, the adventitious types were from 34 species, the interzooidal from four species, the vicarious from four species, and the vibracular types from two species. For descriptive and comparative purposes, species have been grouped into superfamilies.

\section{Anascan bryozoans}

There are morphological differences between the avicularia in the two members of the superfamily Calloporoidea. Chaperiopsis cf. rubida Hincks, 1881 has interzooidal and adventitious types of avicularia (Figure 2.4A). The orificial anatomy of the acute adventitious types consists of a small pore in the plane of the palate with organic material emerging from the orifice (Figure 2.4B). The orifice of the columnar interzooidal avicularia is located in the centre of the palate and consists of a circular mass with a central pore (Figure 2.4C). In the small acute adventitious avicularia of Odontionella cyclops Busk, 1854 (Figures 2.4D, E), the palate is distended and occupies most of the exposed palate and terminates in a small pore (the orifice proper). The degree of distension between avicularia is highly variable whereby the palate can often be flattened in some avicularia and bulbous in others (as in Figure 2.4E).

Within the Buguloidea there is significant anatomical diversity even between species with similar avicularian forms. Species examined in this study possess either adventitious or vibracular types of avicularia or both within any given colony. Members of the Beaniidae (Beania magellanica Busk, 1852) and Bugulidae (Bicellariella ciliata Linnaeus, 1758, Bugula flabellata Thompson in Gray, 1848 and Nordgaardia cornucopioides d'Hondt, 1983) all possess an adventitiously located bird's-head form of avicularium (Figures 2.5A, D, 2.6A, C respectively). Despite the possession of a common avicularian form, there are clearly species-specific differences in the morphology of the avicularian orifice. The avicularian orifice of B. ciliata comprises of 
a pore in the plane of the palate with organic material emerging from the pore (Figure $2.5 \mathrm{~B}, \mathrm{C})$. In contrast, the orifice in the avicularium of $B$. flabellata, whilst in the plane of the palate, has a tuft of cilia emerging from the pore (Figures 2.5E, F). The deep-sea species of $N$. cornucopioides has a tubular bird's-head form of avicularium (Figure 2.6A). The orifice of the avicularium consists of a pore that is sub-palatally located, embedded to a degree within the avicularium cystid (Figure 2.6B). The autozooids of $B$. magellanica possess paired distolateral avicularia (Figure 2.6C). The orifice of the avicularium consists of a very small pore in the centre of a rectangular protrusion of the palate (Figure 2.6D). In contrast, the overall morphology of the avicularia in members of the family Candidae is very similar. Tricellaria catalinensis Robertson, 1905 has laterally located acute adventitious avicularia (Figure 2.6E). The orifice consists of a pore in the plane of the palate (Figures $2.6 \mathrm{~F}, \mathrm{G}$ ) and a tuft of cilia is often observed within the orificial pore (Figure 2.6F). Caberea zelandica Gray, 1843 (Figure 2.7A), C. rostrata Busk, 1884 (Figure 2.7D), and Caberea sp. (Figure 2.8A), all have small acute frontal adventitious avicularia as well as lateral vibracula. C. rostrata also has an occasional large acute frontal avicularium but all mandibles were closed in the samples studied. In the three species examined, there is anatomical consistency among all the adventitious types and among the vibracula. The acute adventitious avicularia in all species of Caberea possess an orifice in the plane of the palate (Figures 2.7B, E, 2.8D), whilst the orifice of the vibracula has a tubular extension of the palate with a bulbous structure submerged at the base of the tube (Figures $2.7 \mathrm{C}, 2.8 \mathrm{~B}$, no data available for $C$. rostrata). In contrast, confamilial Scrupocellaria ornithorhyncus Thomson, 1858 has large acute lateral adventitious avicularia as well as lateral vibracula (Figure 2.8E). No anatomical data are available for the vibracula as all the mandibles were closed (Figure $2.8 \mathrm{E}$ ), however the adventitious types all possess a pore in the plane of the palate, and are therefore morphologically similar to those in Caberea species and to T. catalinensis (Figure 2.8F).

Within the Microporoidea, Opaeophora lepida Hincks, 1881 has scimitarshaped interzooidal avicularia (Figure 2.9A), the orifice of which consisted of slightly raised extensions in the centre of the palate (Figure 2.9B).

Within the Cellarioidea the two members examined each have vicarious avicularia differing greatly in shape (Figures 2.9C, E). The avicularia of Cellaria pilosa Kirchenpauer, 1869 and C. tenuirostris Busk, 1852 each possess an avicularian orifice 
located at the mandibular cross-bar. The vicarious avicularia of C. pilosa possess a large rounded mandible and an orifice in the plane of the palate with organic material emerging from the orifice (Figure 2.9D). The mandible of the C. tenuirostris avicularium is narrower and the orifice consisted of a circular extension of the palate (Figure 2.9E).

\section{Ascophoran bryozoans}

Within the Cribrilinoidea, the vicarious avicularia of Euthyroides jellyae Levinsen, 1909 are spatulate and the edges of the mandible curl inward and fail to completely seal the avicularium base (Figure 2.10A). The orifice of the avicularium consists of a minute pore in the plane of the palate and can be difficult to locate in the majority of avicularia. In one instance a ring of organic material was found around the vicinity of the orifice (Figure 2.10B).

Parkermavella n. sp. was the sole representative for the Smittinoidea; the adventitious avicularia of Parkermavella n. sp. has a T-shaped depression in the palate (Figure 2.10D) terminating in a centralised circular pore (Figure 2.10E).

The avicularia of the Catenicelloidea are distolateral and adventitious (e.g. Figure 2.11A) and occasionally large (the full length of an autozooid). In Catenicella pseudoelegans Gordon 2008, each avicularium possesses a large pore (proportional to the size of the avicularium) in the plane of the palate and often cilia can be observed within the pore (Figure 2.11B). In Cribricellina cribraria Busk, 1852 (Figures 2.11C-E) the orifice of the avicularium is morphologically similar to the orifice of the autozooid with convoluted edges resembling a rosette. Similarly, the orifice of the adventitious avicularia and autozooid of Claviporella aurita Busk, 1852 are morphologically like those in the other catenicellids, enlarged and rosette-like in appearance (Figures 2.12A, $\mathrm{B}, \mathrm{C})$. In contrast, the orifice of the large lateral avicularia is morphologically dissimilar and resembled a lacuna (Figures 2.12D, E). The overall morphology and orificial morphology of the adventitious avicularia of Costaticella bicuspis Gray, 1843 and $C$. solida Levinsen, 1909 are similar to Catenicella pseudoelegans, C. cribrilina and $C$. aurita (Figures 2.13A, B, C, D).

In Arachnopusia unicornis Hutton, 1873 (Arachnopusioidea) adventitious and interzooidal types can each be abundant within any given colony (Figure 2.14A), even in cryptic locations such as the frontal foramen of an autozooid (Figure 2.14B). The 
adventitious avicularia are acute and the orifice comprises an extension of the palate and cilia can often be found protruding, very slightly, from it (Figures 2.14C, D). The interzooidal avicularia are oval in shape (Figure 2.14E) with an orifice that consists of a bulbous, circular protrusion of the palate with a central pore (Figure 2.14F).

Morphological variability is evident in the adventitious avicularia of the genera of Lepralielloidea that were examined. Escharoides angela Hutton, 1873 and Escharoides excavata MacGillivray, 1860 each possess large spatulate laterally located adventitious avicularia (Figures 2.15A, B). In addition, Escharoides excavata possess small oval adventitious avicularia located on the frontal surface of the autozooid (Figures 2.15C). In E. angela, the palate of the avicularium covered approximately a quarter of the total length with an extensively calcified rostrum. The orifice consists of an extension of the palate with an organic matrix emerging from the orifice in many avicularia (Figure 2.15A). All the mandibles were closed on the spatulate avicularia of Escharoides excavata therefore no data are available. The only data on the oval avicularia came from a single avicularium the orifice of which obscured by an extensive covering of organic material and epibionts (Figure 2.15C).

The avicularia of confamilial Exochella armata Hincks, 1882 and E. jullieni Gordon, 1989 are adventitious and acute. In E. armata, the avicularia are laterally located (Figure 2.16A) with an orifice that consists of a pore in the plane of the palate (Figure 2. 16B). In E. jullieni the avicularia are located laterally and approximately halfway down the autozooid so that the mandible and rostrum margins extend to the operculum of the adjacent autozooid (Figure 2.16C). The avicularia has an extensive rostrum and the orifice a constricted pore (Figure 2.16D).

There is a high degree of morphological variability within the Schizoporelloidea, not just in overall gross morphology but in palatal and avicularian orificial morphology also. Mucropetraliella n. sp. (Petraliellidae) has small oval adventitious avicularia consistently located laterally to the operculum of the autozooid (Figure 2.16E). The mandible of the avicularia is serrated in a similar way to the distal rim of the autozooidal operculum and the orifice of the avicularium consists of a pore in the plane of the palate (Figure 2.16F). In Chiastosella exuberans Busk, 1852 (Escharinidae), each autozooid frequently has two avicularia located either side of the operculum (Figure 2.17A). The avicularium is an extended acute form with a constricted orifice that is often obscured by a coating of organic material (Figure 2.17B). In contrast, the 
avicularia of $C$. watersi Stach, 1937 are smaller acute forms and variously located on the frontal surface of the autozooid (Figure 2.17C). The orifice is also obscured by a coating of organic material and epibionts (Figures 2.17D).

The adventitious avicularia of Hippomenella vellicata Hutton, 1873 (Schizoporellidae) are very small and variously located on the frontal surface of the autozooid (Figure 2.17E). The orifice is constricted and surrounded by organic material and epibionts (Figure 2.17F). The morphology of the avicularia from Microporella agonistes Gordon, 1989 (Microporellidae) is very different from the other members of the Schizoporelloidea examined. The avicularia are adventitious but have a setiform mandible and are consistently located just below the operculum of the autozooid (Figure 12.8A). The morphology of the orifice of the avicularia resembles the tubular structure found in the vibracula of Caberea species (Figure 2.18B, C and compare with Figures 2.7C, $2.8 \mathrm{C})$.

There is also a high degree of morphological variability within the Celleporoidea. Celleporina grandis Gordon, 1989, C. wellingtonensis Gordon, 2008, and Osthimosia sirena Gordon, 2008 (Celleporidae) all have small oval adventitious and spatulate vicarious types of avicularia (Figures 2.19A, C, E). In C. grandis the mandible of the adventitious avicularium is serrated and the orifice consists of a constricted pore (Figure 2.19B). No data were available for the vicarious types because all the mandibles were closed in the samples examined. The anatomy of the avicularia from $C$. wellingtonensis was unclear because the colony was in poor condition. A minimal amount of information was obtained from one adventitious type, the mandible of which had fractured and the palate torn away at the area of the orifice. Similarly to C. grandis, the orifice consists of a constricted pore (Figure 2.19D).

In $O$. sirena, the adventitious and vicarious avicularia possess a distinctive pore in the plane of the palate located near the mandibular cross-bar (Figures 2.19F, G). Stephanollona scintillans Hincks, 1885 (Phidoloporidae) has small oval adventitious and acute interzooidal avicularia (Figure 2.20A). The orifice of the adventitious type is in the plane of the palate with an organic structure emerging from the orifice (Figure $2.20 \mathrm{~B})$. The orifice of the interzooidal type is variable in morphology with an apparent bulbous projection with a terminal central pore that displays varying degrees of protrusion; from being in the plane of the palate (Figure 2.20C) to being extended beyond the rim of the basal cystid (Figure 2.20D). 
In confamilial Reteporella gracilis Gordon, 1989 (Celleporoidea), the avicularia are adventitious and acute, with a slightly raised constriction of the palate terminating in a pore (Figures 2.20E, F). In contrast, all avicularia in Reteporella aurantiace Gordon, 2008 are adventitious and predominantly frontally located or found at the edge of the fenestra (Figure 2.21A). The frontal avicularia could be roughly split into two size categories but all had a pore in the plane of the palate (Figures $2.21 \mathrm{~B}, \mathrm{D}$ ). In contrast, the fenestrula avicularium (only data from a single fenestrula avicularium was available) possesses a tubular extension of the palate (Figure 2.21C).

In the avicularia of confamilal Rhynchozoon zealandicum Gordon, 2008 the avicularia are small acute adventitious types (Figure 2.22A). Orifice morphology is highly variable among the avicularia and a protuberance was often observed emerging from the orifice which consists of circular pore in the plane of the palate (Figure 2.22B). The everted portion consisted of cilia and microvilli (Figures 2.22C, D). 
Figure 2.4. (A) Chaperiopsis cf. rubida colony. Scale bar, $500 \mu \mathrm{m}$; (B) Acute adventitious avicularium of $C$. cf. rubida with a relatively cryptic small orifice, or pore, with small amount of organic material being exuded. Scale bar, $50 \mu \mathrm{m}$; (C) Interzooidal avicularia of $C$. cf. rubida. Avicularium on left has mandible closed and avicularium on right has mandible open exposing the palate which consists of a bulbous orifice with central pore. Scale bar, $100 \mu \mathrm{m}$; (D) Odontionella cyclops colony. Scale bar, $500 \mu \mathrm{m}$; (E) Adventitious avicularium of $O$. cyclops with a bulbous protrusion of the palate, possibly the underlying vestigial polypide, with a terminal pore. Scale bar, $10 \mu \mathrm{m}$.

Figure 2.5. (A) Bicellariella ciliata colony. Scale bar, $100 \mu \mathrm{m}$; (B) Bird's-head form of adventitious avicularium of $B$. ciliata with a central mass of organic material being exuded from a pore in the plane of the palate. Scale bar, $10 \mu \mathrm{m}$; (C) organic material from (B). Scale bar, $1 \mu \mathrm{m}$; (D) Bugula flabellata colony. Scale bar, $100 \mu \mathrm{m}$; (E) Bird's-head form of adventitious avicularium of $B$. flabellata with a central tuft of cilia emerging from a pore in the plane of the palate. Scale bar, $30 \mu \mathrm{m}$; (F) Pore and cilia from (E). Scale bar, $2 \mu \mathrm{m}$.

Figure 2.6. (A) Nordgaardia cornucopioides colony. Scale bar, $200 \mu \mathrm{m}$; (B) Adventitious avicularium of $N$. cornucopioides with an embedded orifice resembling an elongated pore. Scale bar $50 \mu \mathrm{m}$; (C) Beania magellanica colony. Scale bar, $100 \mu \mathrm{m}$; (D) Bird's-head form of adventitious avicularia of $B$. magellanica with a small pore in the plane of the palate. Scale bar, $100 \mu \mathrm{m}$; (E) Tricellaria catalinensis colony. Scale bar, $100 \mu \mathrm{m}$; (F) Small lateral acute adventitious avicularium of $T$. catalinensis with a large pore in the plane of the palate. Scale bar $25 \mu \mathrm{m}$; (G) Larger lateral acute adventitious avicularium of $T$. catalinensis with large pore in the plane of the palate. Scale bar, $50 \mu \mathrm{m}$. 

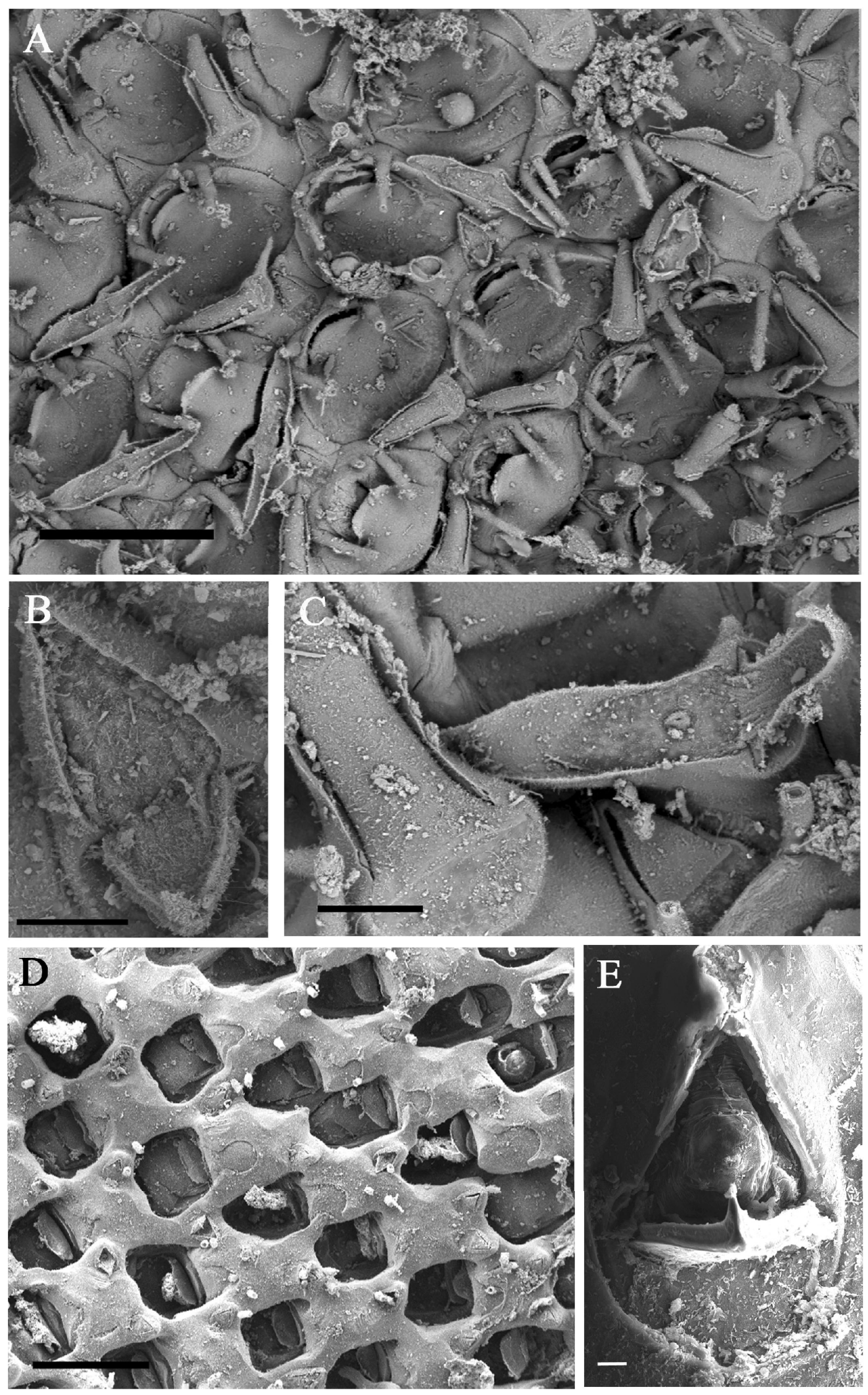

Fig. 2.4 

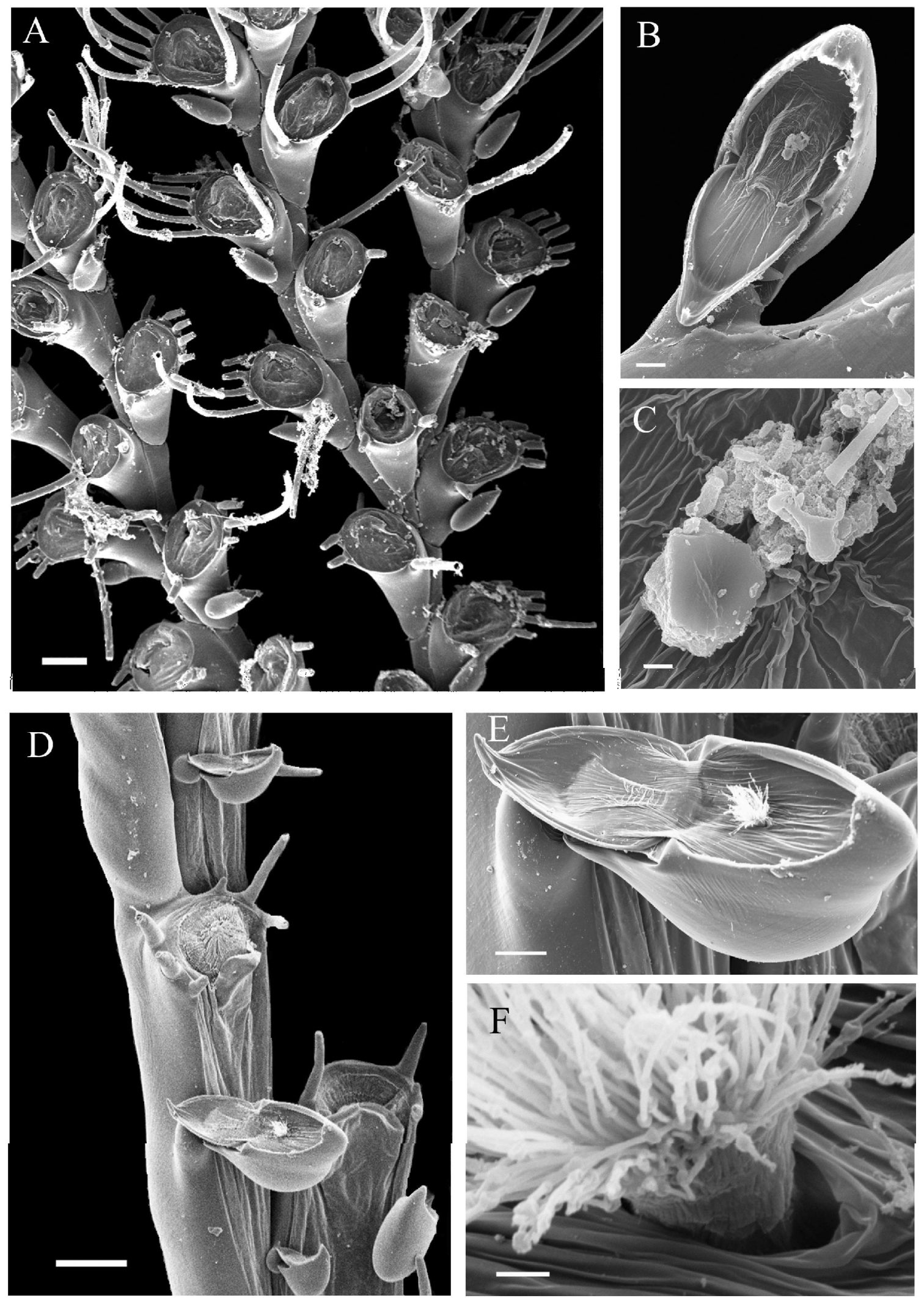

Fig 2.5 

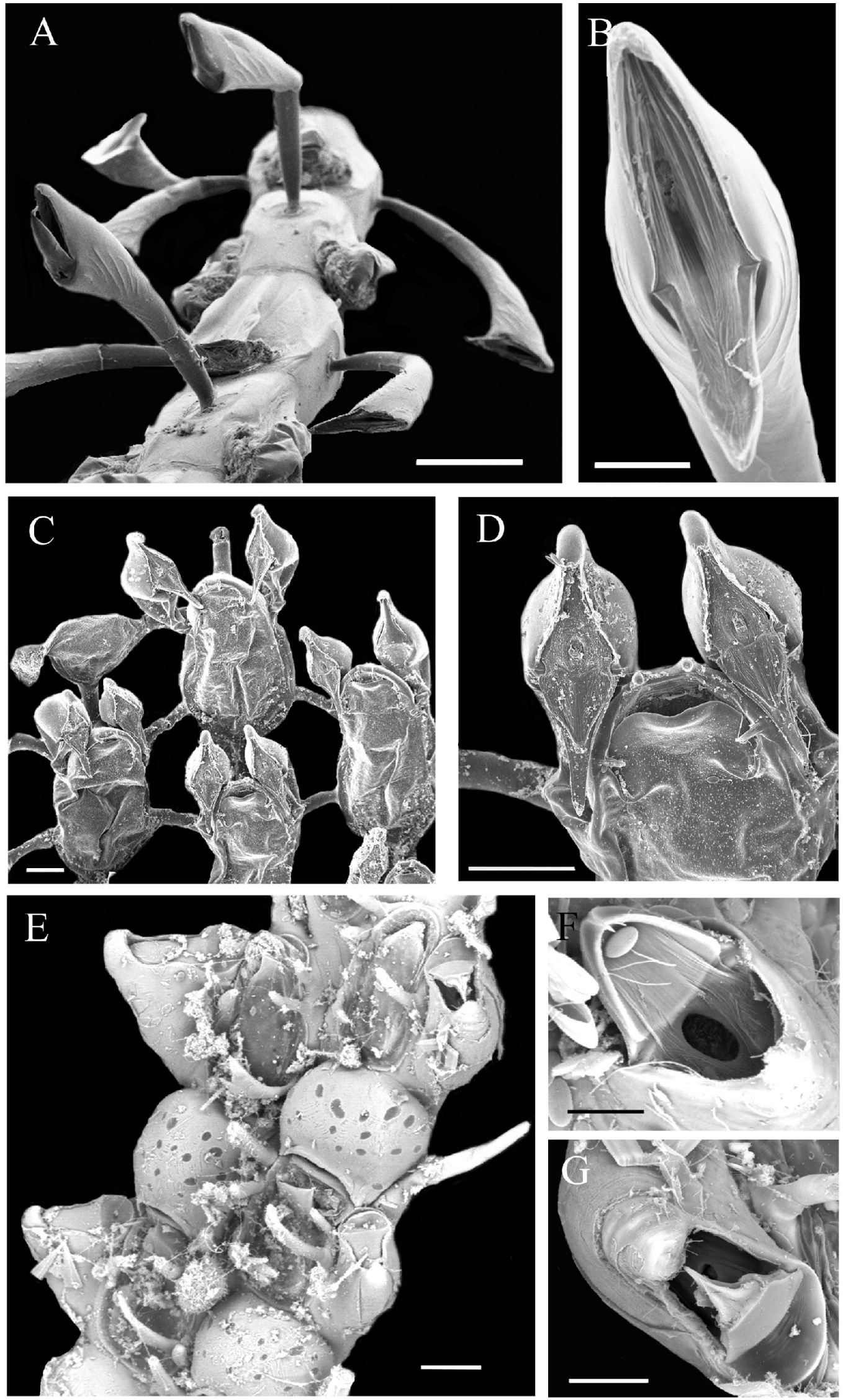

Fig 2.6 
Figure 2.7. (A) Caberea zelandica colony. Scale bar $100 \mu \mathrm{m}$; (B) Small acute frontal adventitious avicularium of $C$. zelandica with a slightly constricted pore in the plane of the palate. Scale bar $10 \mu \mathrm{m}$; (C) Palate of a vibraculum from $C$. zelandica with an orifice consisting of a tubular structure. Scale bar, $10 \mu \mathrm{m}$; (D) Caberea rostrata colony. Scale bar, $100 \mu \mathrm{m}$; (E) Small acute frontal adventitious avicularium of $C$. rostrata with a pore in the plane of the palate. Scale bar $10 \mu \mathrm{m}$.

Figure 2.8. (A) Caberea sp. colony. Scale bar, $100 \mu \mathrm{m}$; (B) Vibraculum of Caberea sp. Scale bar, $100 \mu \mathrm{m}$; (C) Orifice of vibraculum from (B) consisting of a tubular structure with a bulbous base inside. Scale bar, $5 \mu \mathrm{m}$; (D) Small acute frontal adventitious avicularium of Caberea sp. with a pore in the plane of the palate. Scale bar, $10 \mu \mathrm{m}$; (E) Scrupocellaria ornithorhyncus colony. Scale bar, $100 \mu \mathrm{m}$; (F) Lateral avicularium of $S$. ornithorhyncus with a pore in the plane of the palate. Scale bar, $20 \mu \mathrm{m}$; (G) Lateral vibraculum of $S$. ornithorhyncus with mandible closed. Scale bar, $10 \mu \mathrm{m}$.

Figure 2.9. (A) Opaeophora lepida colony. Scale bar, $100 \mu \mathrm{m}$; (B) Interzooidal avicularium of O. lepida with a slight raised extension of the palate forming an orifice. Scale bar, $100 \mu \mathrm{m}$; (C) Cellaria pilosa colony. Scale bar, $500 \mu \mathrm{m}$; (D) Vicarious avicularium of C. pilosa with a very small pore in the plane of the palate located at the mandibular cross-bar and with organic material being exuded from the pore. Scale bar $100 \mu \mathrm{m}$; (E) Cellaria tenuirostris colony. Scale bar, $100 \mu \mathrm{m}$; (F) Vicarious avicularium of $C$. tenuirostris with a circular protrusion of the palate with a central pore and located at the mandibular cross-bar. Scale bar $50 \mu \mathrm{m}$.

Figure 2.10. (A) Euthryoides jellyae colony. Scale bar, $500 \mu \mathrm{m}$; (B) Vicarious avicularium of E. jellyae. Scale bar $150 \mu \mathrm{m}$; (C) Orifice of E. jellyae with an organic matrix. Scale bar, $10 \mu \mathrm{m}$; (D) Parkermavella n. sp. colony. Scale bar, $500 \mu \mathrm{m}$; (E) Oval adventitious avicularium of Parkermavella n. sp. with a circular pore in the plane of the palate. Scale bar, $20 \mu \mathrm{m}$. 

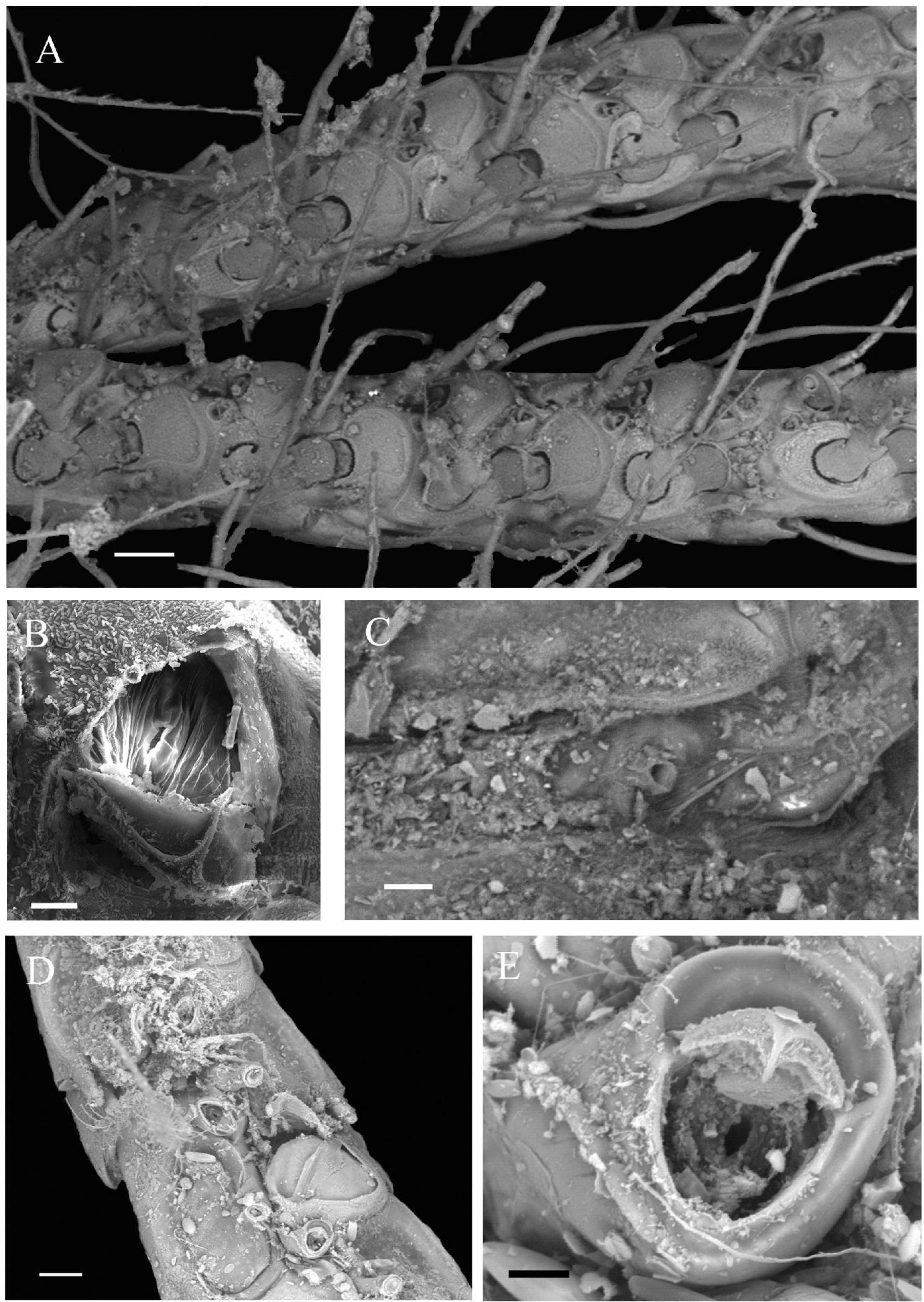

Fig 2.7 

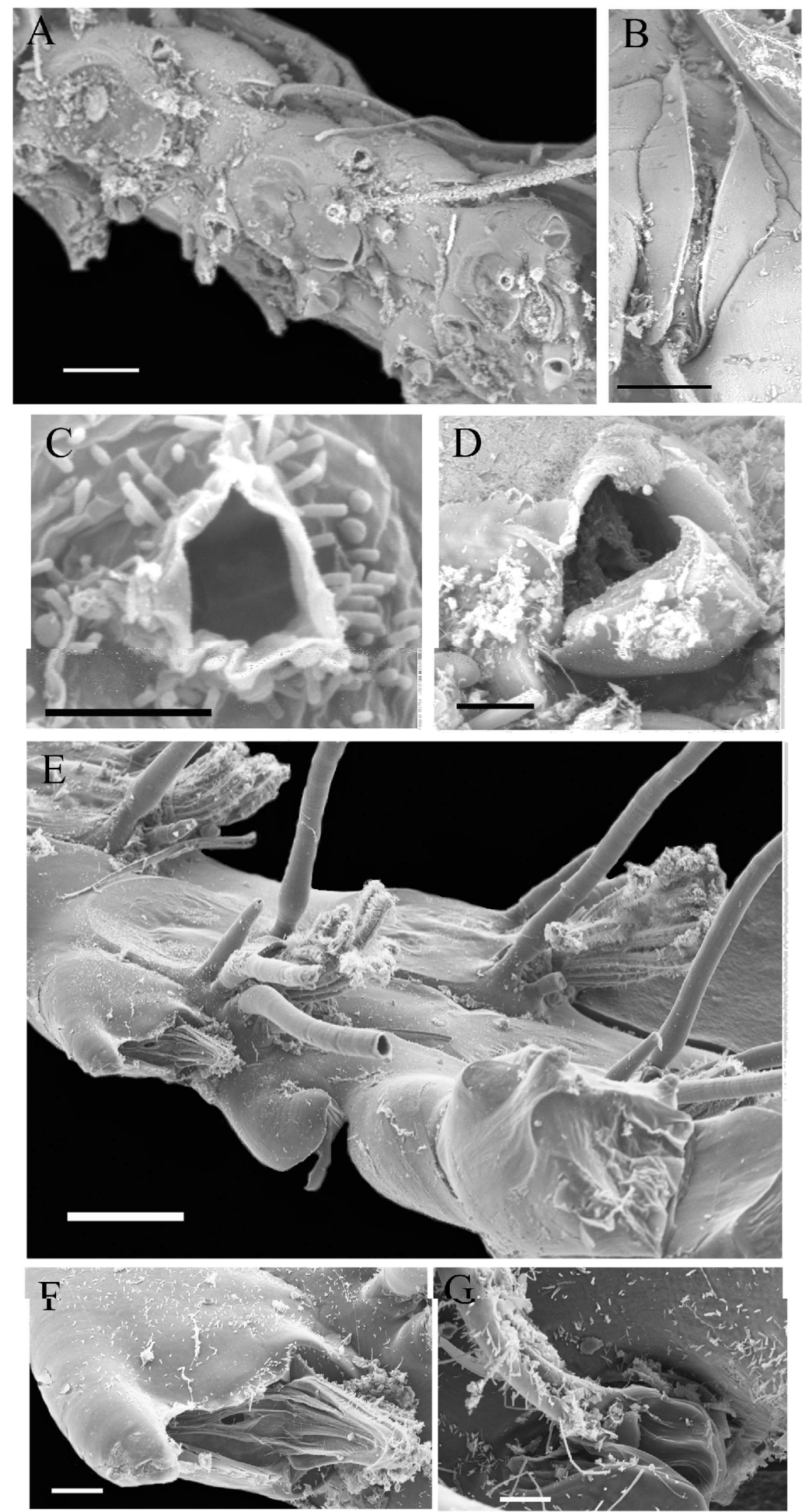

Fig 2.8 

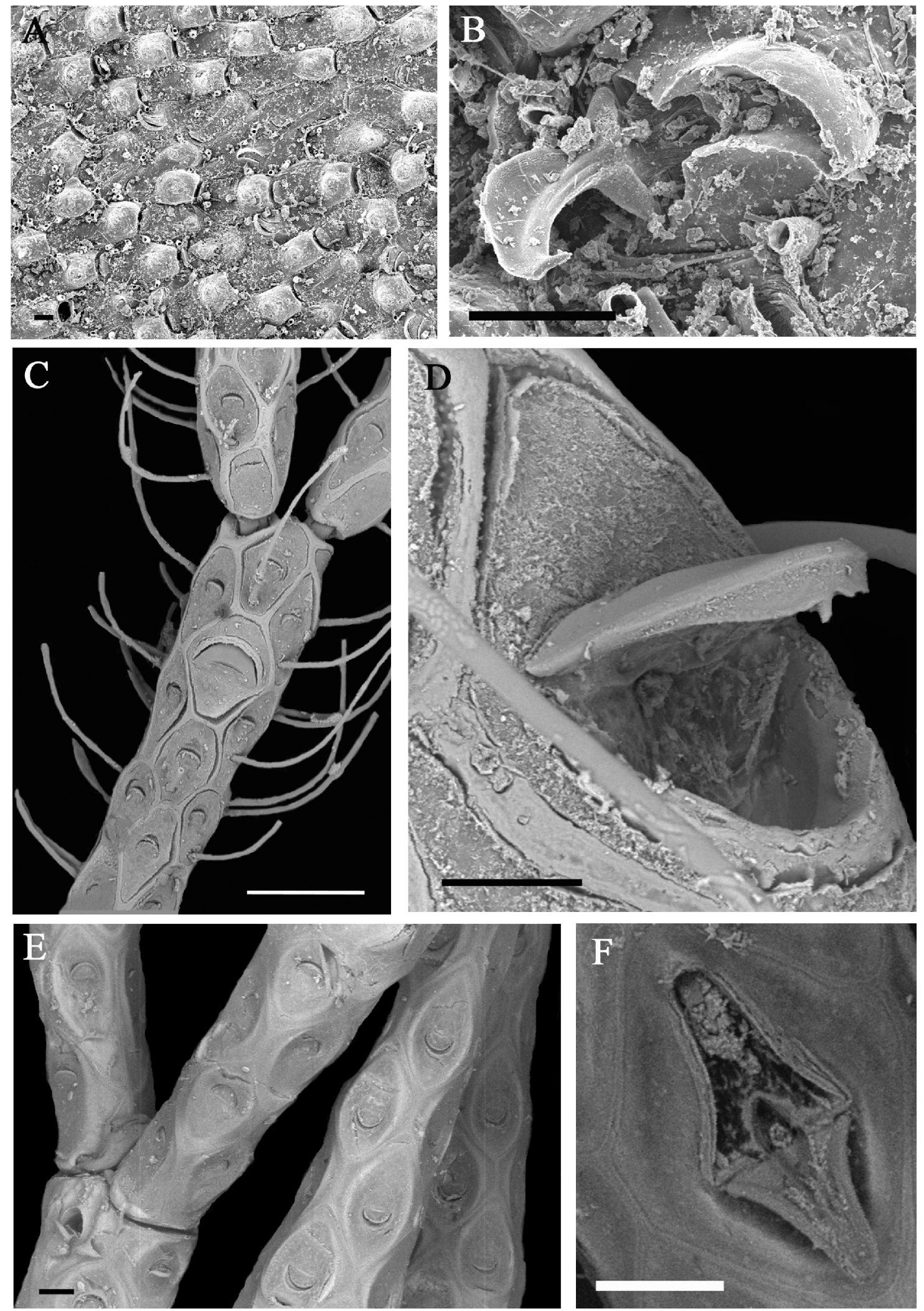

Fig 2.9 


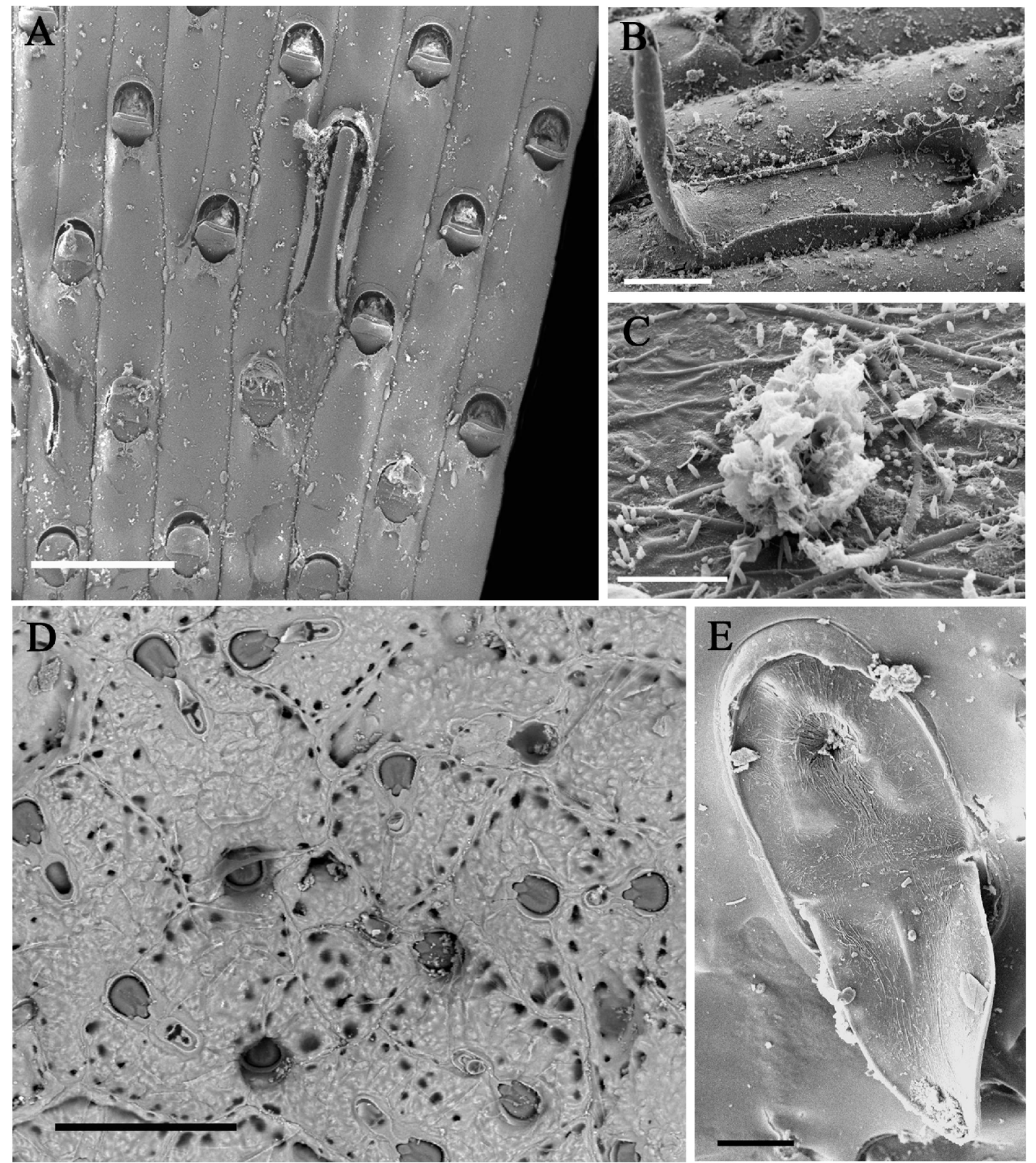

Fig. 2.10 
Figure 2.11. (A) Catenicella pseudoelegans colony. Scale bar, $100 \mu \mathrm{m}$; (B) Small lateral acute adventitious avicularium of Catenicella pseudoelegans with a circular pore in the plane of the palate and insert, cilia emerging slightly from the pore. Scale bar, $10 \mu \mathrm{m}$; (C) Cribricellina cribraria colony. Scale bar, $100 \mu \mathrm{m}$; (D) Autozooid orifice and adventitious avicularium illustrating the similarity between the orifice of the autozooid and avicularium. Scale bar, 50 $\mu \mathrm{m}$; (E) Avicularium from (D) illustrating the rosette-like morphology of the orifice. Scale bar, $16 \mu \mathrm{m}$.

Figure 2.12. Claviporella aurita. (A) Colony. Scale bar, $100 \mu \mathrm{m}$; (B) Orifice of an autozooid with rosette-like morphology. Scale bar, $50 \mu \mathrm{m}$; (C) Lateral acute adventitious avicularium with an orifice with a rosette-like morphology. Scale bar, $10 \mu \mathrm{m}$; (D) Large distolateral adventitious avicularium. Scale bar, $10 \mu \mathrm{m}$; (E) Lacuna-like orifice structure of (D). Scale bar, $10 \mu \mathrm{m}$.

Figure 2.13. (A) Autozooids of Costaticella bicuspis. Scale bar, $100 \mu \mathrm{m}$; (B) Lateral acute adventitious avicularium of $C$. bicuspis with an orifice with a rosette-like morphology. Scale bar $10 \mu \mathrm{m}$; (C) Costaticella solida colony. Scale bar, $100 \mu \mathrm{m}$; (D) Lateral acute adventitious avicularium with an orifice with a rosette-like morphology. Scale bar, $10 \mu \mathrm{m}$.

Figure 2.14. Arachnopusia unicornis. (A) Colony. Scale bar, $200 \mu \mathrm{m}$; (B) Adventitious avicularium located cryptically on a frontal foramen of an autozooid. Scale bar, $50 \mu \mathrm{m}$; (C) Adventitious acute avicularium with raised palate forming an orifice with cilia emerging from the pore. Scale bar, $10 \mu \mathrm{m}$; (D) Orifice and cilia from (C). Scale bar, $2 \mu \mathrm{m}$; (E) Interzooidal avicularium with a circular bulbous prominence of the palate terminating in a central pore. Scale bar, $100 \mu \mathrm{m}$; (F) Orifice of (E). Scale bar, $10 \mu \mathrm{m}$.

Figure 2.15. (A) Escharoides angela colony with two lateral spatulate adventitious avicularia each having an orifice comprised of raised tissue flaps with organic material being exuded from the central pore. Scale bar $100 \mu \mathrm{m}$; (B) Escharoides excavata with lateral spatulate adventitious avicularia with mandibles closed. Scale bar, $100 \mu \mathrm{m}$; (C) Oval adventitious avicularium of Escharoides excavata with organic material being exuded from a pore in the palate and numerous associated epibionts. Scale bar, $10 \mu \mathrm{m}$. 

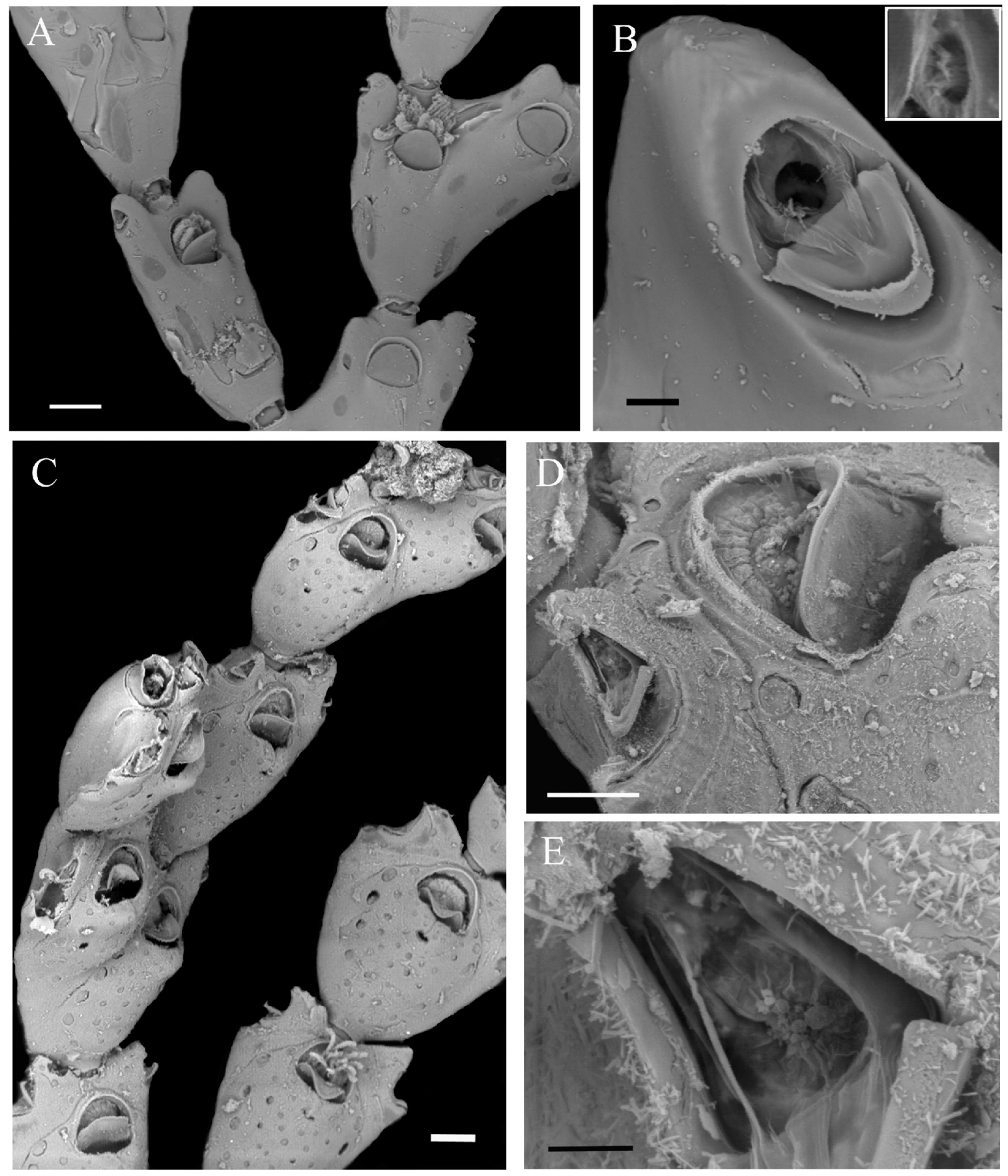

Fig. 2.11 

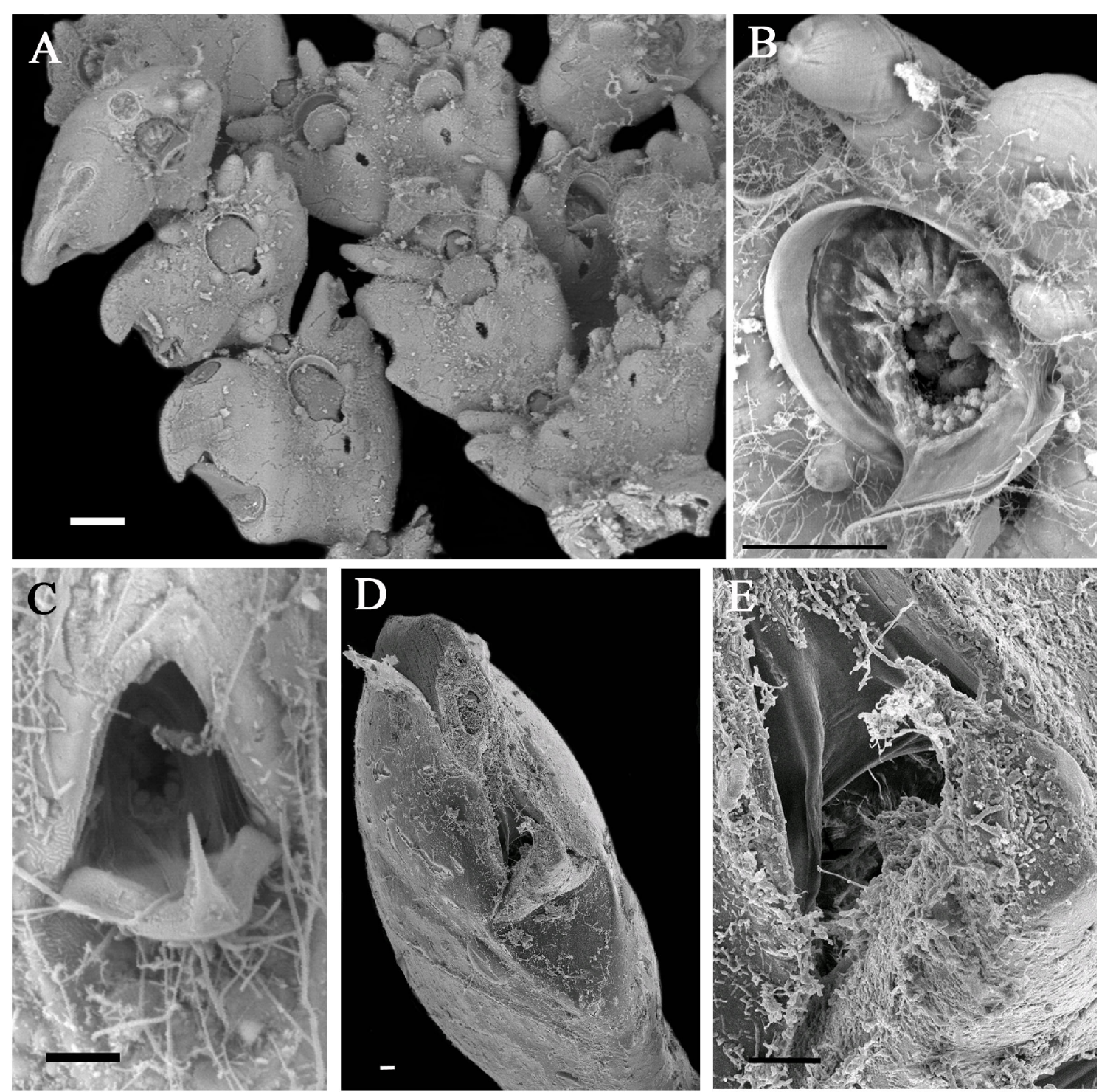

Fig. 2.12 

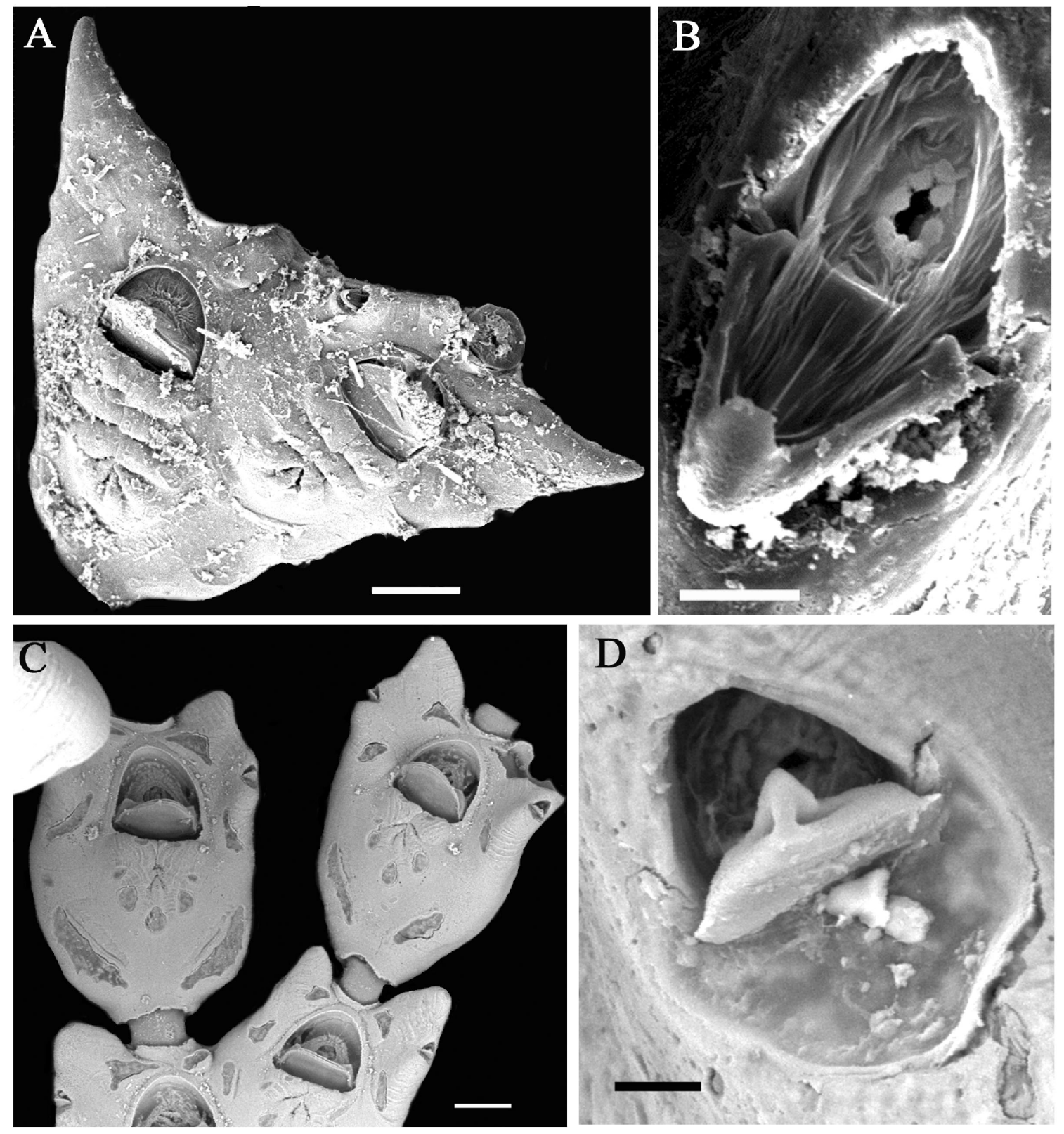

Fig 2.13 

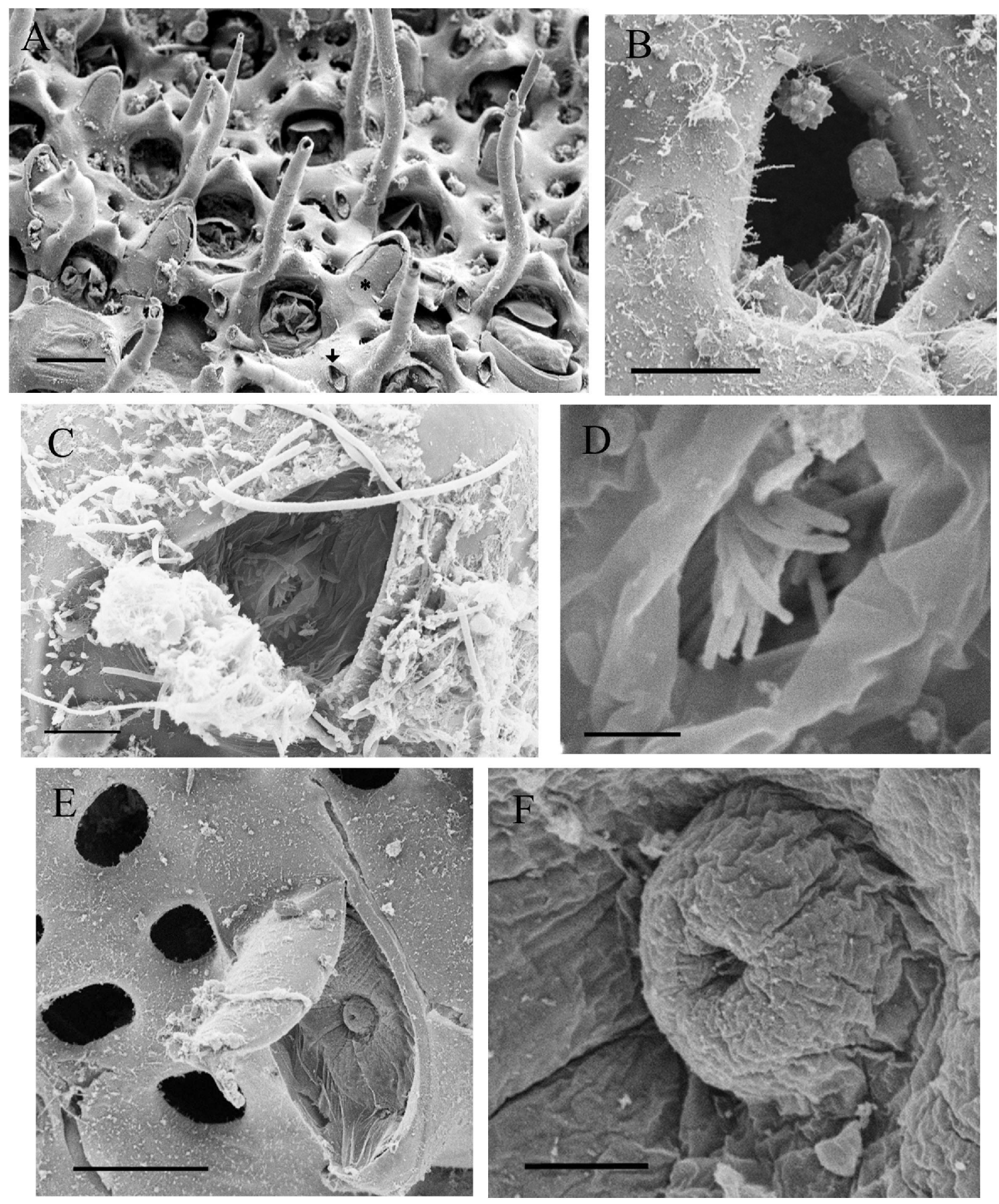

Fig. 2.14 

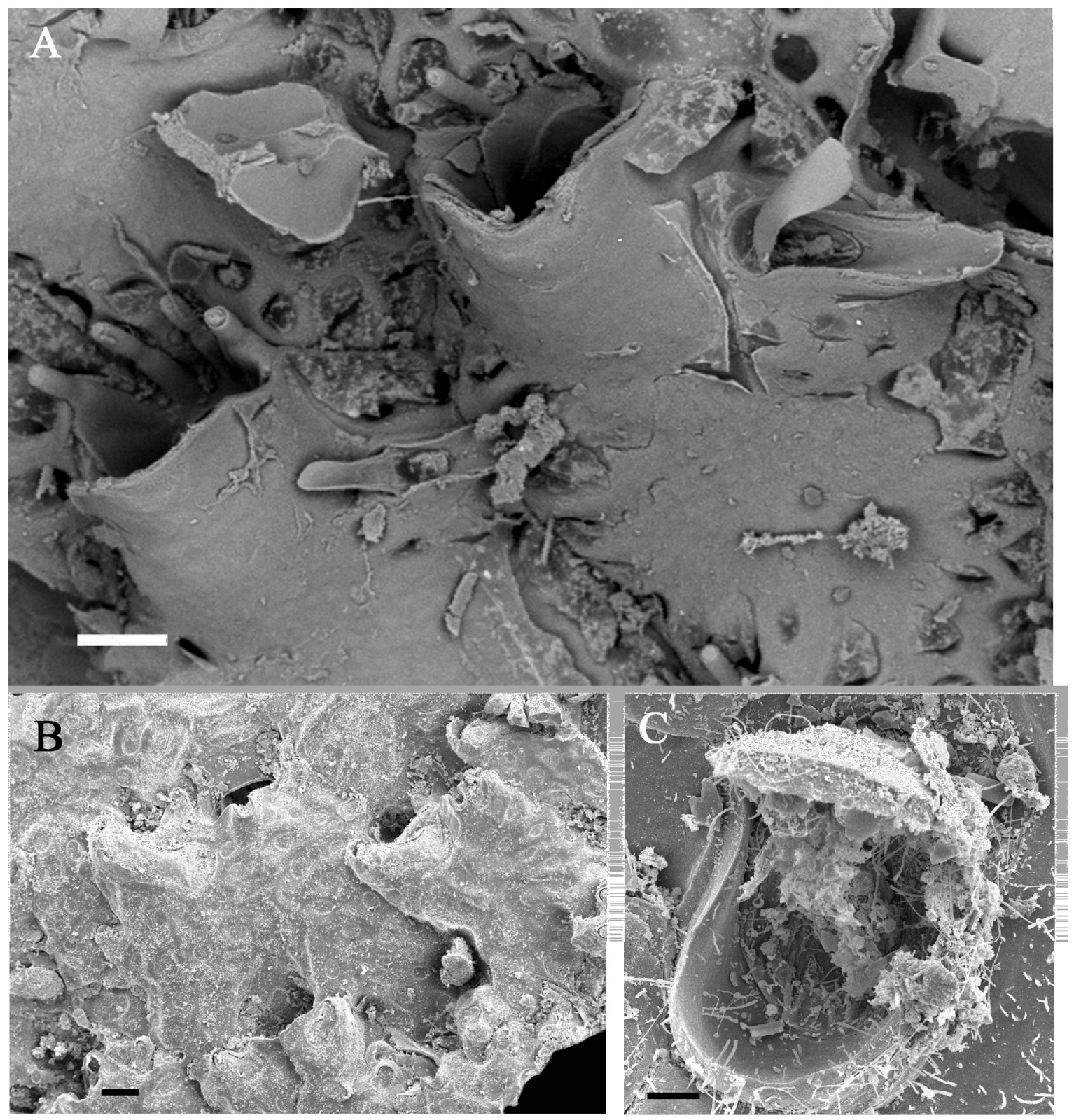

Fig. 2.15 
Figure 2.16. (A) Exochella armata colony. Scale bar, $100 \mu \mathrm{m}$; (B) Acute lateral adventitious avicularium of E. armata with a circular pore in the plane of the palate. Scale bar, $10 \mu \mathrm{m}$; (C) Exochella jullieni colony. Scale bar, $100 \mu \mathrm{m}$; (D) Elongated acute adventitious avicularium of E. jullieni with an orifice consisting of a constricted pore in the palate. Scale bar, $50 \mu \mathrm{m}$; (E) Mucropetraliella n. sp. colony. Scale bar, $500 \mu \mathrm{m}$; (F) Small oval adventitious avicularium of Mucropetraliella $\mathrm{n}$. sp. with a serrated mandible and circular pore in the plane of the palate. Scale bar, $10 \mu \mathrm{m}$.

Figure 2.17. (A) Chiastosella exuberans colony. Scale bar, $100 \mu \mathrm{m}$; (B) Elongated acute adventitious avicularium of $C$. exuberans with a circular pore in the plane of the palate. Scale bar, $100 \mu \mathrm{m}$; (C) Chiastosella watersi colony. Scale bar, $500 \mu \mathrm{m}$; (D) Adventitious avicularium of $C$. watersi with a constricted pore surrounded by organic material and epibionts. Scale bar, 50 $\mu \mathrm{m}$; (E) Hippomanella vellicata colony. Scale bar, $100 \mu \mathrm{m}$; (F) Adventitious avicularium of $H$. vellicata with a constricted pore. Scale bar, $10 \mu \mathrm{m}$.

Figure 2.18. Microporella agonistes. Pieces of fractured colony are scattered over the colony resulting from the physical removal of the colony from a rock. (A) Colony. Scale bar, $100 \mu \mathrm{m}$; (B) Adventitious avicularium with setiform mandible and a tubular orifice. Scale bar, $100 \mu \mathrm{m}$; (C) Tubular orifice of avicularium with a bulbous base inside. Scale bar, $1 \mu \mathrm{m}$.

Figure 2.19. (A) Celleporina grandis colony. Scale bar, $100 \mu \mathrm{m}$; (B) Oval adventitious avicularium of $C$. grandis with circular prominence in palate with a terminal pore. Scale bar, 10 $\mu \mathrm{m}$; (C) Celleporina wellingtonensis colony. Scale bar, $100 \mu \mathrm{m}$; (D) Oval adventitious avicularium of $C$. wellingtonensis with small protuberance of the palate with a terminal pore. Scale bar, $50 \mu \mathrm{m}$; (E) Osthimosia sirena colony. Scale bar, $100 \mu \mathrm{m}$; (F) Oval adventitious avicularium with small circular pore near the mandibular cross-bar. Scale bar, $10 \mu \mathrm{m}$; (G) Vicarious avicularium of Osthimosia sirena with small circular pore near mandibular cross-bar. Scale bar, $50 \mu \mathrm{m}$. 

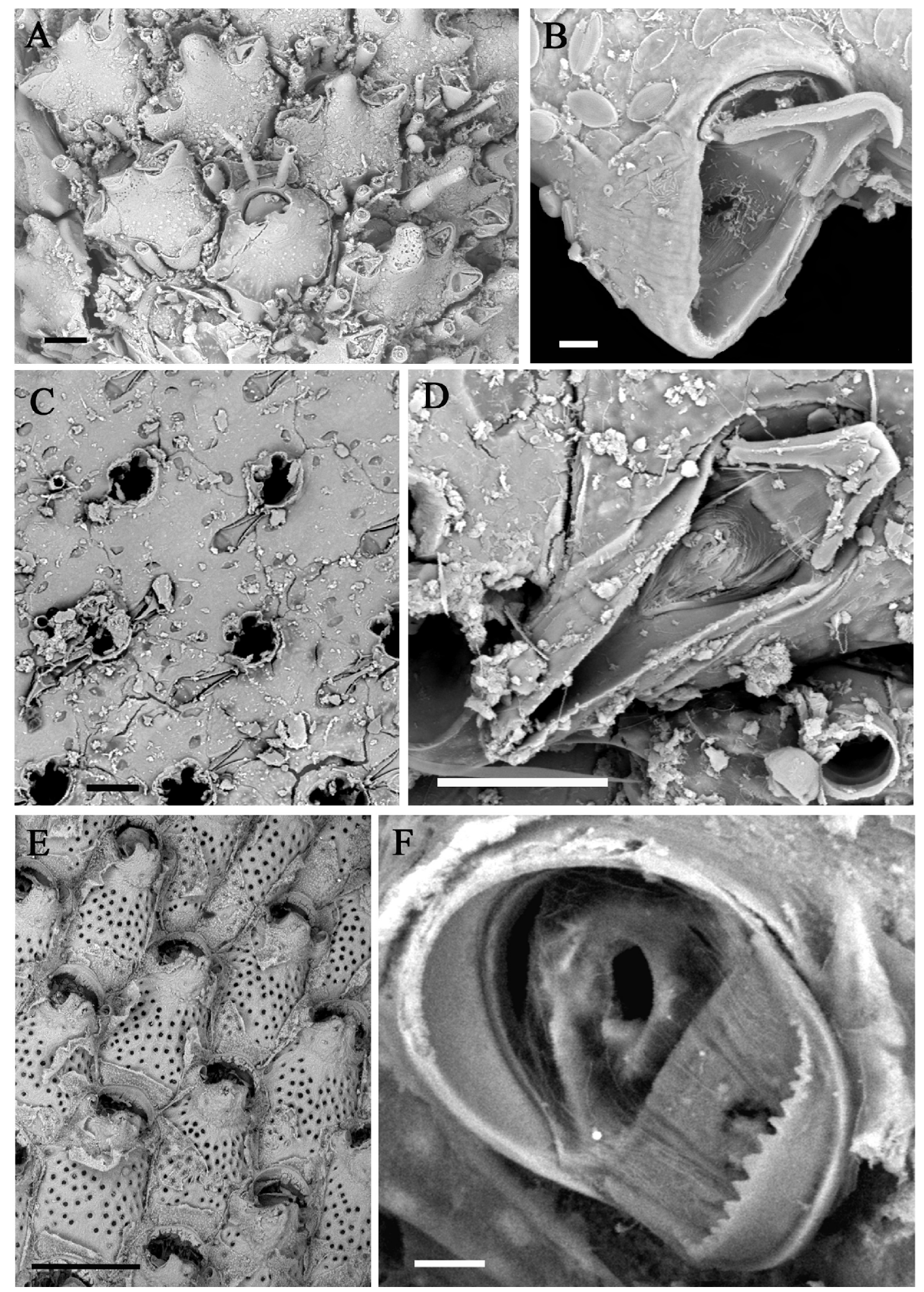

Fig. 2.16 

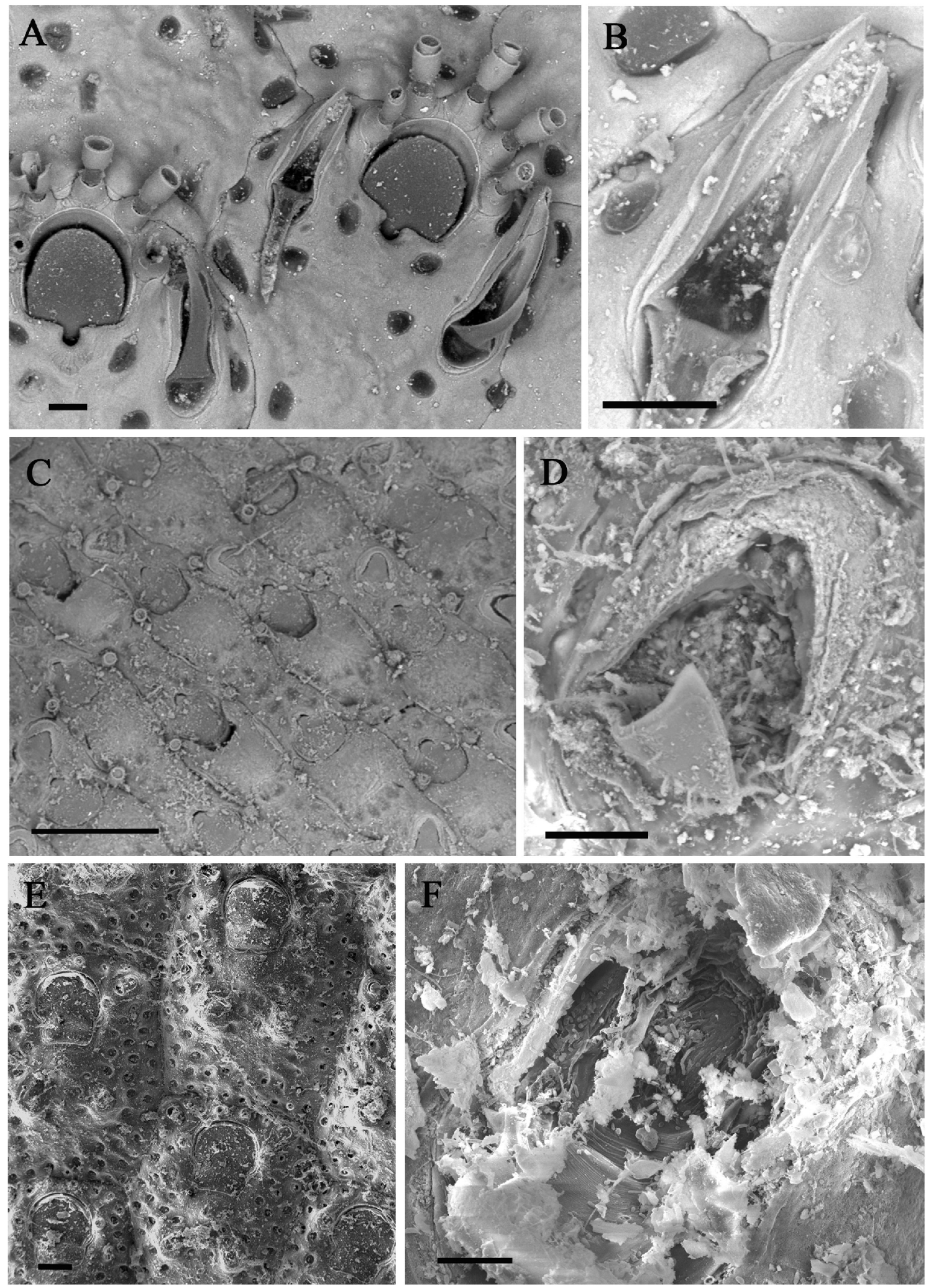

Fig 2.17 


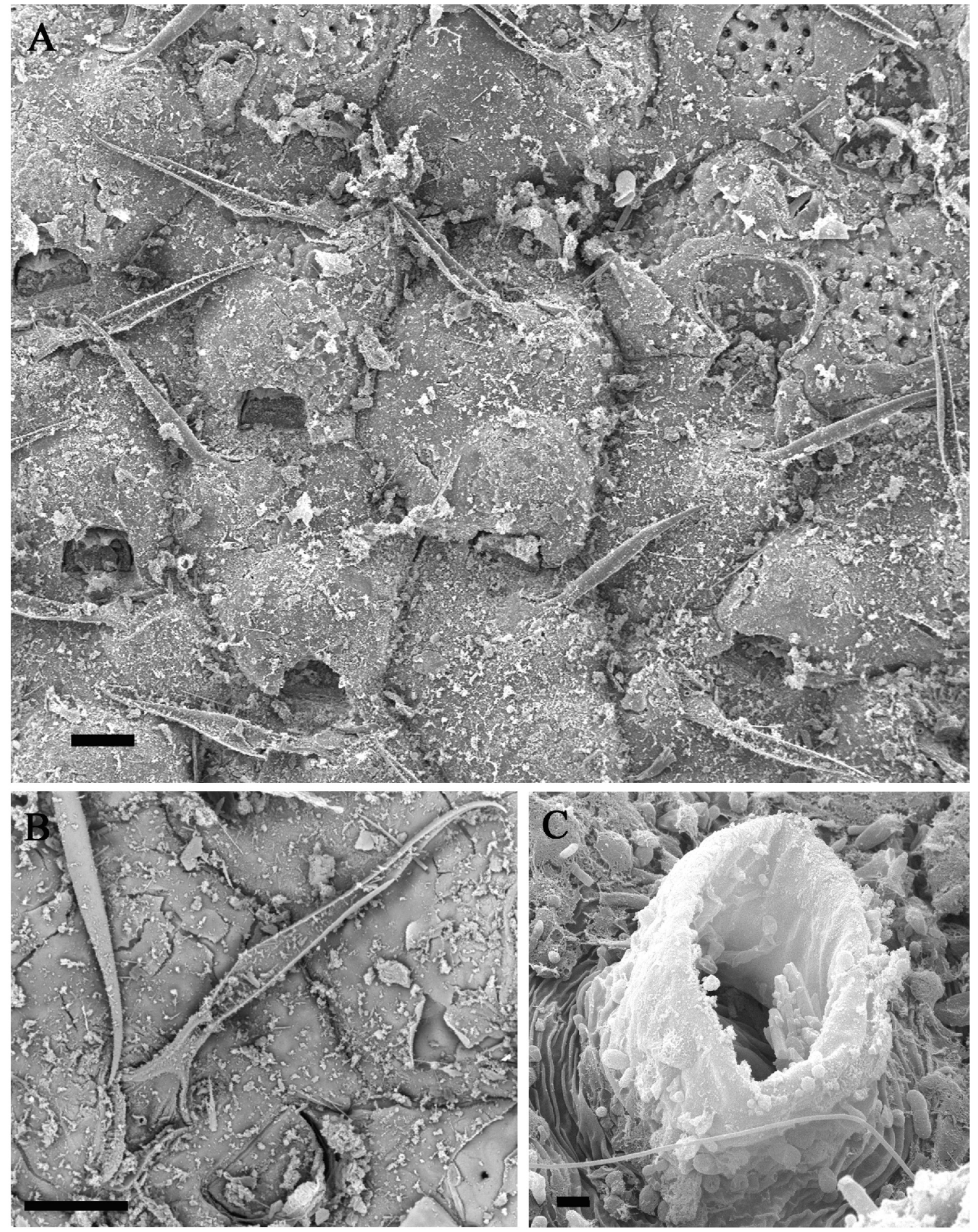

Fig 2.18 

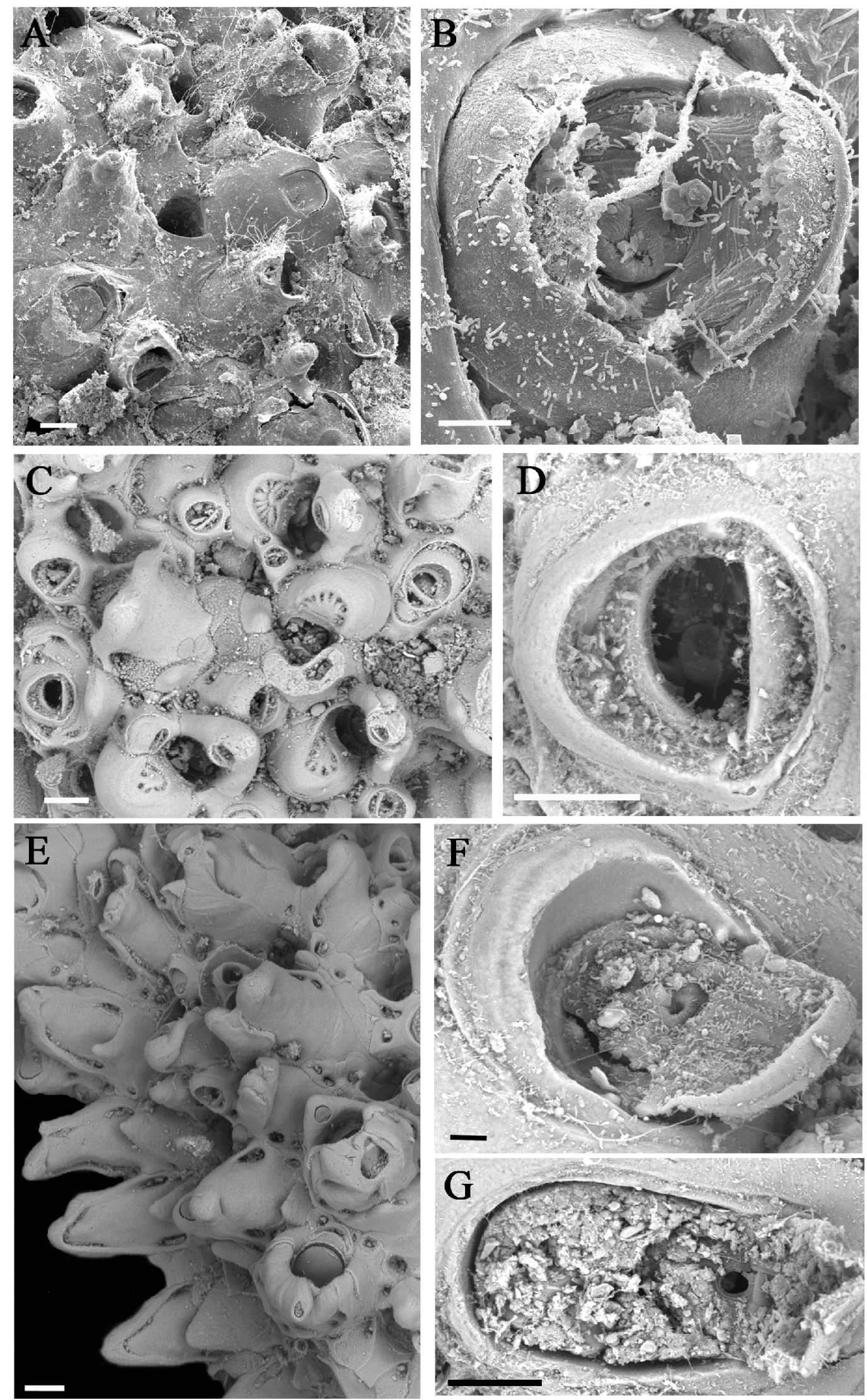

Fig 2.19 
Figure 2.20. (A) Stephanollona scintillans colony. Scale bar, $100 \mu \mathrm{m}$; (B) Small oval adventitious avicularium of $S$. scintillans with a pore in the plane of the palate and organic material being exuded from the pore. Scale bar, $10 \mu \mathrm{m}$; (C) Elongated acute interzooidal avicularium of $S$. scintillans with a small circular prominence in the palate that may lie in the plane of the palate. Scale bar $10 \mu \mathrm{m}$; (D) Interzooidal avicularium of $S$. scintillans illustrating the extensile ability of the orificial structure. Scale bar, $100 \mu \mathrm{m}$; (E) Reteporella gracilis colony. Scale bar $1 \mathrm{~mm}$; (F) Adventitious avicularium of $R$. gracilis with an orifice consisting of a circular constriction in the palate. Scale bar, $20 \mu \mathrm{m}$.

Figure 2.21. Reteporella aurantiaca (A) Colony of autozooids and a large adventitious avicularium with mandible open and an adventitious avicularium located at the fenestrula with mandible closed (arrow). Scale bar, $100 \mu \mathrm{m}$; (B) Autozooids and two small acute adventitious avicularia with pores in the plane of the palate. Scale bar, $100 \mu \mathrm{m} ;(C)$ Avicularium located at a fenestrula with an extensile orificial structure. Scale bar, $50 \mu \mathrm{m}$; (D) Larger adventitious avicularium with a pore in the plane of palate. Scale bar, $50 \mu \mathrm{m}$.

Figure 2.22. Rhynchozoon zealandicum (A) Colony. Scale bar, $100 \mu \mathrm{m}$; (B) Acute adventitious avicularium with a pore in the plane of the palate and vestigial polypide emerging from the pore. Scale bar, $10 \mu \mathrm{m}$; (C) Vestigial polypide of (B) with cilia and microvilli. Scale bar, $1 \mu \mathrm{m}$; (D) Cilia and microvilli from (C). Scale bar, $1 \mu \mathrm{m}$. 

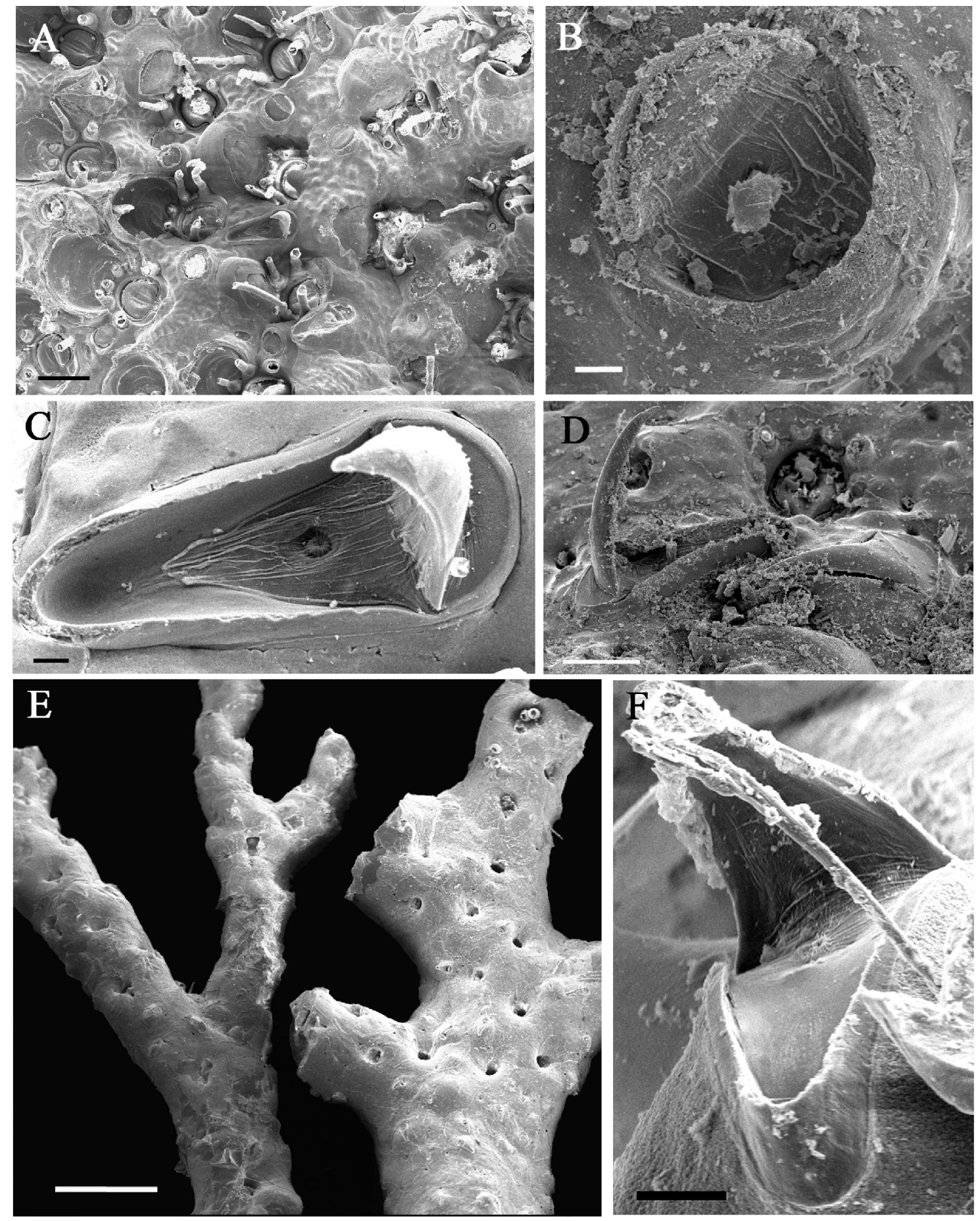

Fig. 2.20 

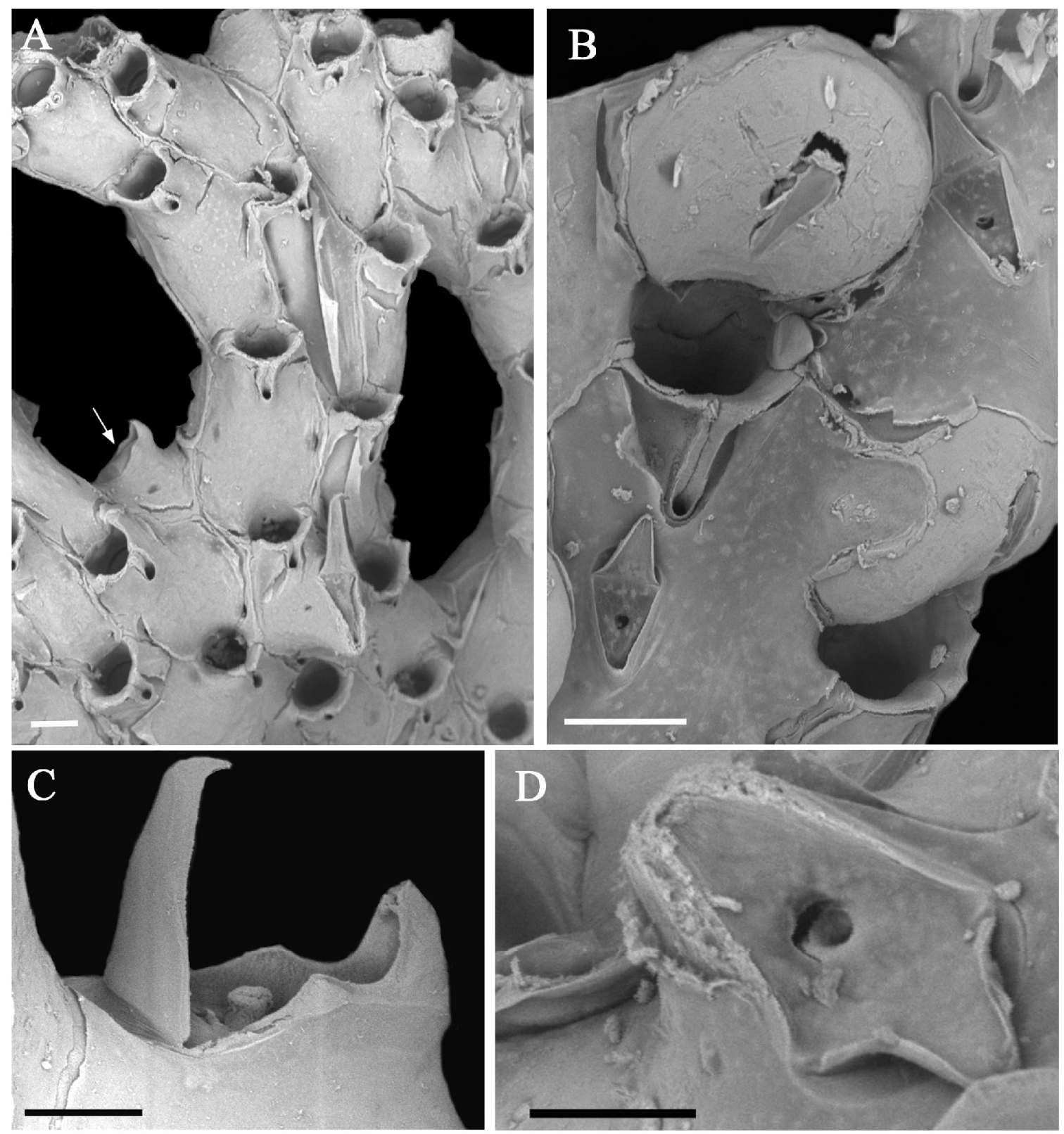

Fig. 2.21 

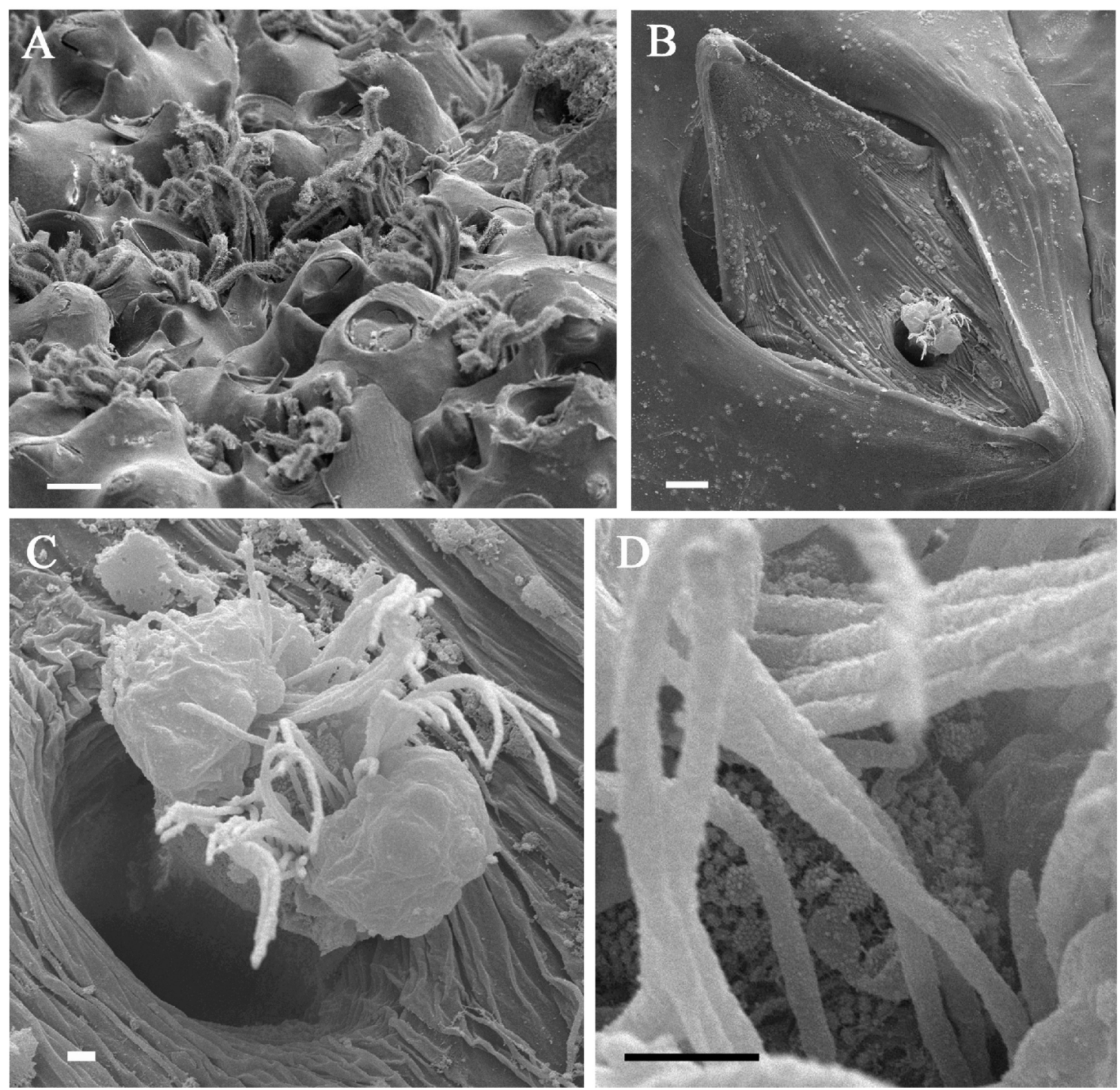

Fig. 2.22 
Table 2.1. Distribution of New Zealand bryozoans collected and their respective avicularian orifice morphologies. Key to avicularium type: Adv, adventitious; Intz, interzooidal; Vic, vicarious; Vib, vibracula.

SPECIES

SITE

DEPTH

(m)
AVICULARIAN

ORIFICE MORPHOLOGY

\section{CALLOPOROIDEA}

Chaperiopsis cf. rubida

Hincks, 1881

Odontionella cyclops

Busk, 1854

\section{BUGULOIDEA}

Beania magellanica

Busk, 1852

Bicellariella ciliata

Linnaeus, 1758

\section{Bugula flabellata}

Thompson in Gray, 1848

\section{Nordgaardia}

cornucopioides

d'Hondt, 1983

Tricellaria occidentalis

Robertson, 1905

Caberea rostrata

Busk, 1884

Caberea zelandica

Gray, 1843
Barrett Reef

$\sim 8$

Barrett Reef,

Cape Palliser \&

Foveaux Strait

$\begin{array}{ll}\text { Barrett Reef \& } & \sim 8 \\ \text { Island Bay } & 4-6\end{array}$

Foveaux Strait

Mahanga Bay

$\&$

Queens Wharf

0.5

0.1

Chatham Rise

$\sim 600-1000$

Mahanga Bay

$\sim 4$

Adv Pore in plane of palate

Barrett Reef \&

Island Bay

$\sim 8$

4-6

Barrett Reef,

Chatham Rise

\&

Foveaux Strait
Adv Small pore in the plane of the palate with organic material emerging from the orifice Intz Circular mass with a central pore

$\sim \quad$ Adv Bulbous extension in palate terminating in a pore
$8 \quad$ Adv Small pore in the centre of a rectangular protrusion of the palate

Adv Pore in plane of palate with organic material emerging from pore

Adv Pore in plane of palate with tuft of cilia extending from pore

Adv Sub-palatal pore

Adv Pore in plane of palate

$\sim 8$

Adv Pore in plane of palate 260-1000 Vib Tubular extension of palate 


\begin{tabular}{|c|c|c|c|}
\hline SPECIES & SITE & $\begin{array}{c}\text { DEPTH } \\
\text { (m) }\end{array}$ & $\begin{array}{l}\text { AVICULARIAN } \\
\text { ORIFICE } \\
\text { MORPHOLOGY }\end{array}$ \\
\hline
\end{tabular}

Caberea sp.

Scrupocellaria

ornithorhyncus

Thompson, 1858

\section{MICROPOROIDEA}

Opaeophora lepida

Hincks, 1881

\section{CELLARIOIDEA}

Cellaria pilosa

Kirchenpauer, 1869

Cellaria tenuirostris

Busk, 1852

\section{CRIBRILINOIDEA}

Euthyroides jellyae

Levinsen, 1909

\section{SMITTINOIDEA}

Parkermavella $\mathrm{n} . \mathrm{sp}$

\section{CATENICELLOIDEA}

Catenicella pseudoelegans

Gordon, 2008

Claviporella aurita

Busk, 1852

Costaticella bicuspis

Gray, 1843

Costaticella solida

Levinsen, 1909
Island Bay

Foveaux Strait

Princess Bay

Barrett Reef

Barrett Reef

Chatham Rise

$\sim 600-1000$

Princess Bay
4-6

0.2

Island Bay

Foveaux Strait

Island Bay \&

Queens Wharf

4-6

$-$

- 20.90

\section{4-6}

$\sim 8$

Drift

$\sim 8$

$\sim 8$

Vic Tiny, almost indistinguishable, pore with organic matrix
Adv Pore in plane of palate Vib Tubular extension of palate

Adv Pore in plane of palate
Intz Slightly raised extension of the palate

Vic Small pore at mandibular cross-bar with organic material emerging from pore

Vic Circular extension of the palate

Adv Pore in plane of palate

Adv Rosette-like

Adv (Large) Lacuna

Adv Large pore (proportional to size of the avicularium) in the plane of the palate

Drift Adv Pore in plane of palate 
SPECIES

SITE
DEPTH

(m)

\section{AVICULARIAN \\ ORIFICE \\ MORPHOLOGY}

Cribricellina cribraria

Busk, 1852

\section{ARACHNOPUSIOIDEA}

Arachnopusia unicornis

Hutton, 1873

Barrett Reef \&

Mahanga Bay

Greta Point \&

Island Bay

Hutton, 1873

Escharoides excavata

MacGillivray, 1860

Exochella armata

Hincks, 1882

Exochella jullieni

Gordon, 1989

\section{SCHIZOPORELLOIDEA}

Mucropetraliella n. sp.

Chiastosella exuberans

Gordon, 1989

Chiastosella watersi

Stach, 1937

Hippomenella vellicata

Hutton, 1873

Microporella agonistes Gordon, 1989

Barrett Reef
Island Bay \&

Princess Bay

Chatham Rise

\&

Foveaux Strait
Island Bay

4-6

Adv Rosette-like
0.3

4-6

$\sim 8$

$-$

Adv Slightly raised extension of palate, cilia emerging

Intz Bulbous protrusion with terminal pore
4-6

Drift

$\sim 600-1000$

Adv Constricted pore
Adv Extension of the palate with organic material emerging from the orifice

Adv Obscured by an extensive covering of organic material and epibionts

Adv Pore in plane of palate

\begin{tabular}{lcl} 
Barrett Reef & $\sim 8$ & Adv Pore in plane of palate \\
Chatham Rise & $\sim 600-1000$ & Adv Constricted orifice \\
$\begin{array}{l}\text { Barrett Reef } \\
\text { Foveaux Strait }\end{array}$ & -8 & $\begin{array}{l}\text { Adv Obscured by a covering of } \\
\text { organic material and epibionts }\end{array}$ \\
$\begin{array}{l}\text { Foveaux Strait } \\
\text { \& } \\
\text { Island Bay }\end{array}$ & - & $\begin{array}{l}\text { Adv Tubular extension of } \\
\text { palate }\end{array}$ \\
\hline
\end{tabular}


SPECIES

SITE

DEPTH

(m)

\section{AVICULARIAN \\ ORIFICE \\ MORPHOLOGY}

\section{CELLEPOROIDEA}

Celleporina grandis

Gordon, 1989

Celleporina wellingtonensis Princess Bay

Gordon, 1989

Osthimosia sirena Gordon, Princess Bay 2008

Stephanollona scintillans Hincks, 1885

Reteporella gracilis

Gordon, 1989

Reteporella aurantiaca

Gordon, 2008

Rhynchozoon zelandica

Gordon, 2008

Barrett Reef

Island Bay

Greta Point $\sim 8$

Adv Constricted pore

Drift $\quad$ Adv Constricted pore

Drift

Adv Pore at cross-bar of mandible

Vic Pore at cross-bar of mandible

Foveaux Strait

Chatham Rise

$\sim 600-1000$

Adv Pore in plane of palate

with organic material emerging from orifice

Intz Raised tubular prominence of palate

Chatham Rise

$\sim 600-1000$

Adv Raised constriction in the palate

4-6

Adv Pore in plane of palate

0.2

Adv Pore in plane of palate with ciliated vestigial polypide protruding through orifice 
Table 2.2. Distribution of the New Zealand deep-sea bryozoans collected from the Chatham Rise.

\section{Seamount Species}

Diabolical Nordgaardia cornucopioides d'Hondt, 1983

Graveyard Chiastosella exuberans Gordon, 1989

Reteporella gracilis Gordon, 1989

Main Knoll Caberea zelandica Gray, 1843

Parkermavella n. sp

Stephanollona scintillans Hincks, 1885

Zombie Nordgaardia cornucopioides d'Hondt, 1983

\subsubsection{Morphometric analyses}

\section{Colony density of avicularia}

The combination of adventitious and vicarious types or adventitious and vibracular types appeared to increase the total density of avicularia within the colony in some species (Figure 2.23). For example, Caberea sp. had the greatest density of avicularia by combining adventitious and vibracula $\left(44.8 \mathrm{~mm}^{-2}\right)$. Caberea rostrata $(15.6$ $\left.\mathrm{mm}^{-2}\right)$, C. zelandica $\left(20 \mathrm{~mm}^{-2}\right)$ and Scrupocellaria ornithorhyncus $\left(16 \mathrm{~mm}^{-2}\right)$ also had relatively high densities of avicularia by combining adventitious and vibracular types. There was an overall propensity for species with adventitious types to have a greater density of avicularia than those with either interzooidal or vicarious types only. Nordgaardia cornucopioides (adventitious only; $32 \mathrm{~mm}^{-2}$ ) had the greatest density of avicularia after Caberea sp. Exochella armata (adventitious only; $22 \mathrm{~mm}^{-2}$ ) also had a high density of avicularia. Opaeophora lepida has interzooidal type only and was among the species with the lowest density of avicularia $\left(4.3 \mathrm{~mm}^{-2}\right)$. All species that possess vicarious types only had the lowest density of avicularia; including Euthyroides jellyae $\left(0.09 \mathrm{~mm}^{-2}\right)$, Cellaria pilosa $\left(1.26 \mathrm{~mm}^{-2}\right)$, and C. tenuirostris $\left(1.87 \mathrm{~mm}^{-2}\right)$. 


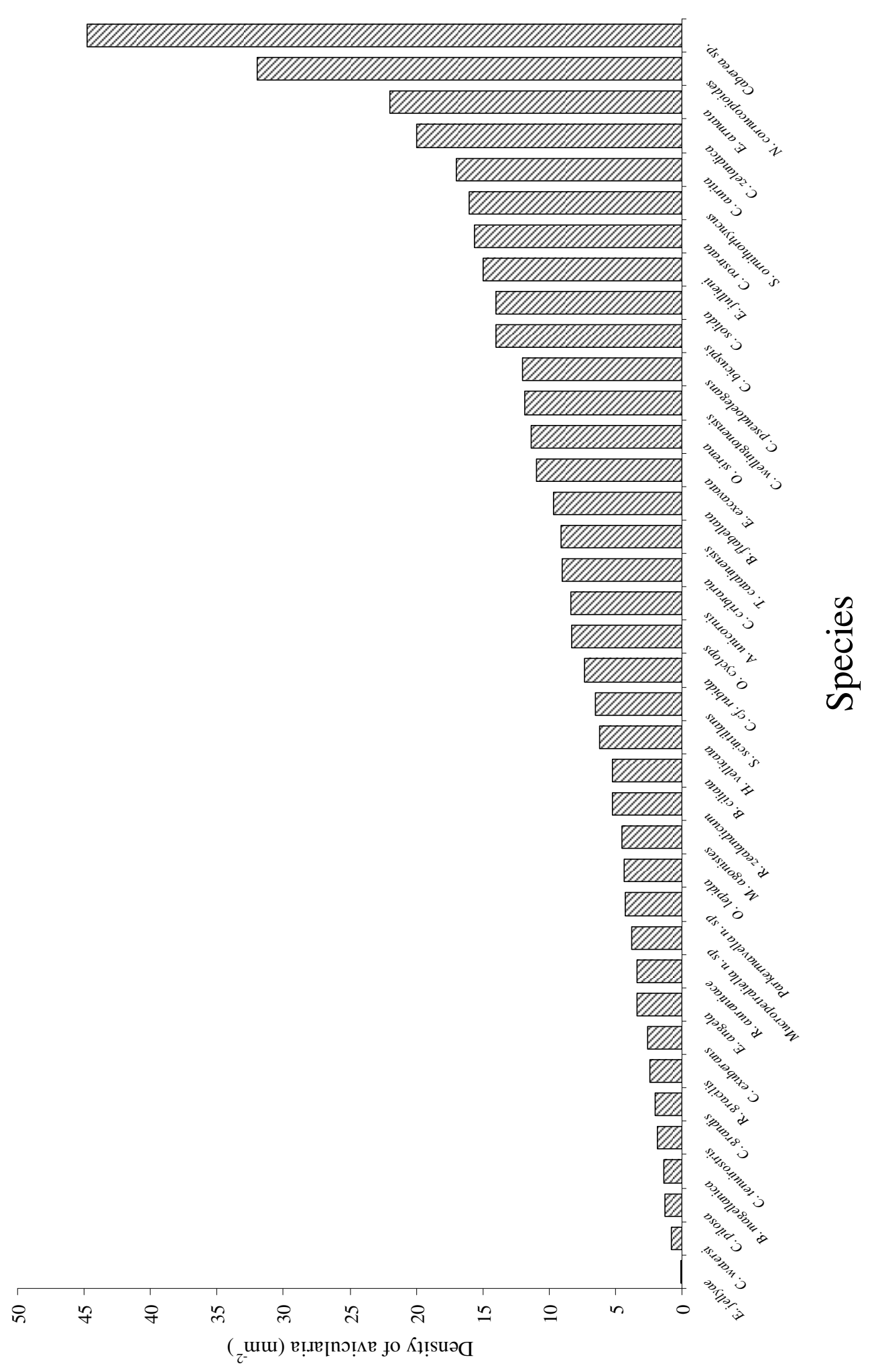

Figure 2.23. Density of avicularia $\left(\mathrm{mm}^{-2}\right)$ among species of cheilostome bryozoans. 


\section{Multivariate analyses of avicularian types}

The MDS ordination plot of the standardised multi-trait morphometric data for adventitious avicularia (34 species) showed a lowest level of $60 \%$ similarity in morphometrics (Figure 2.24A). The adventitious types were further split into four main groups at the $80 \%$ level based on morphometric similarity. One group comprised solely of the deep-sea bryozoan Nordgaardia cornucopioides and therefore was morphometrically distinct from other species with adventitious avicularia. Based on the combination of all morphometric data, the ANOSIM analysis supports the avicularian groupings, which were significantly different between species (Figure 2.24A; $P \leq 0.001$; Global $\mathrm{R}=0.474)$. Individual scores for the ANOSIM species pairwise comparison showed that morphometric dissimilarity was significantly greater between $N$. cornucopioides and Stephanollona scintillans $(P \leq 0.001, \mathrm{R}=0.99)$ and between $N$. cornucopioides and Costaticella bicuspis $(P \leq 0.001, \mathrm{R}=0.98)$. Species-specific clustering (where $\mathrm{n}>5$ ) was evident for S. scintillans, Parkermavella n. sp., Chiastosella exuberans, Exochella jullieni, and Mucropetraliella n. sp., indicating morphological constraint and a high degree of morphometric similarity among avicularia within these species. In contrast, intraspecific morphometric variability in avicularia was evident for Tricellaria catalinensis, C. bicuspis and Reteporella aurantiaca where the avicularia for each of these species were spread out along the width of the ordination plot. Reteporella aurantiaca for example, had two morphologically distinct adventitious avicularia (Figure 2.24A) which were clearly morphometrically distinct from the larger form lying outside the main cluster.

The MDS ordination plot for interzooidal types showed a lowest level of $60 \%$ similarity in morphometrics among avicularia (4 species). The interzooidal types were split into two main groups at the $80 \%$ level based on morphometric similarity. Interspecific morphometric similarities were greater for certain avicularia than intraspecifically at the $90 \%$ similarity level. These groupings were supported by the ANOSIM analysis, which were significantly different between species (Figure 2.24B; $P$ $\leq 0.001$; Global $\mathrm{R}=0.599)$. Individual scores for the ANOSIM species pairwise comparison showed that significant morphometric dissimilarity occurred between $A$. unicornis and Chaperiopsis cf. rubida $(P \leq 0.001, \mathrm{R}=0.70)$ and between Chaperiopsis cf. rubida and Opaeophora lepida $(P \leq 0.001, \mathrm{R}=0.91)$. 
The MDS ordination plot for vicarious types showed a lowest level of $60 \%$ similarity in morphometrics among avicularia (4 species) (Figure 2.24C). The vicarious types were split into two main groups at the $80 \%$ level based on morphometric similarity. These groupings were further supported by the ANOSIM analysis, which were significantly different at $P \leq 0.001$ (Figure 2.24C; Global $\mathrm{R}=0.835$ ). A high degree of morphometric similarity (90\%) was evident among the avicularia of $E$. jellyae, Cellaria pilosa, and C. tenuirostris each forming an intraspecific cluster. The clusters were distributed widely over the ordination plot implying extensive interspecific variability in morphometrics.

The MDS ordination plot for vibracular types showed a lowest level of $80 \%$ similarity in morphometric among avicularia. The two component species of this analysis were split into three groups. Caberea sp. appeared morphometrically distinct whilst $C$. zelandica was split into two morphometrically disparate groups. These groupings were further supported by the ANOSIM analysis, which were significantly different at $P<0.05$ (Figure 2.24D; Global $\mathrm{R}=0.505$ ).

The results from the ANOSIM analyses for avicularian type are highlighted in Table 2.3.

DFA revealed that the width of avicularium (sWav), length of orifice (sLo), width of orifice (sWo) and length of palate (sLpal) were all significant contributors to morphometric variability $(P<0.001$ in all cases; Table 2.4$)$ and less so, but still a significant contributor, width of palate (sWpal) $(P<0.05)$. A total of $83.9 \%$ of avicularia could be classified correctly (Table 2.5), with adventitious and vibracula classified correctly at $100 \%$. Notably, $3.5 \%$ of vicarious types were classified correctly (Cellaria tenuirostris) whilst the remaining were classified as adventitious. All pairwise comparisons of avicularian type using Mahalanobis Distance $\left(\mathrm{D}^{2}\right)$ were significantly different $(P<0.05$ in all cases) except for interzooidal $v s$ vicarious $(P>0.05)$ (Table 2.6). The largest difference was between adventitious $v s$ vibracular types $\left(D^{2}=42.79\right)$, followed by interzooidal $v s$ vibracular types $\left(\mathrm{D}^{2}=36.19\right)$. 


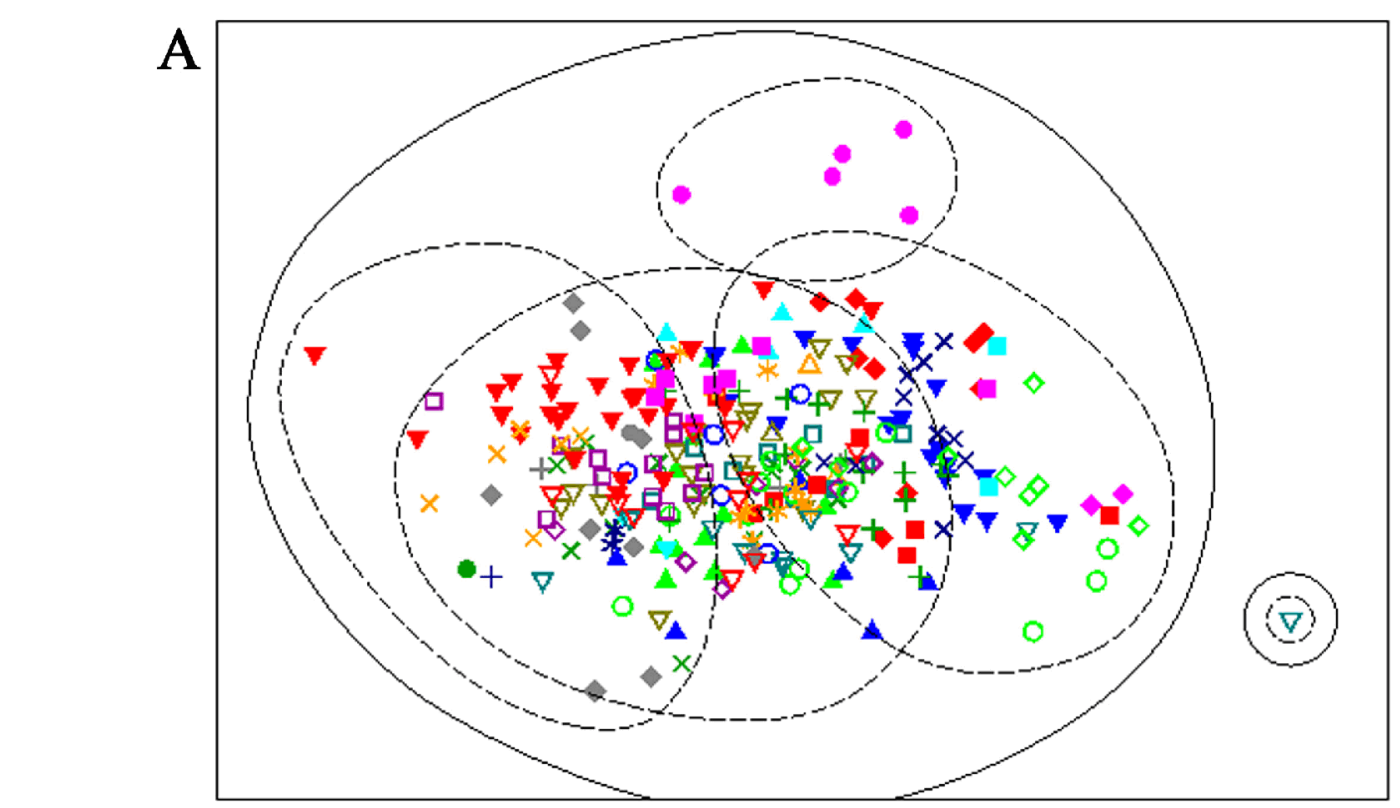

B

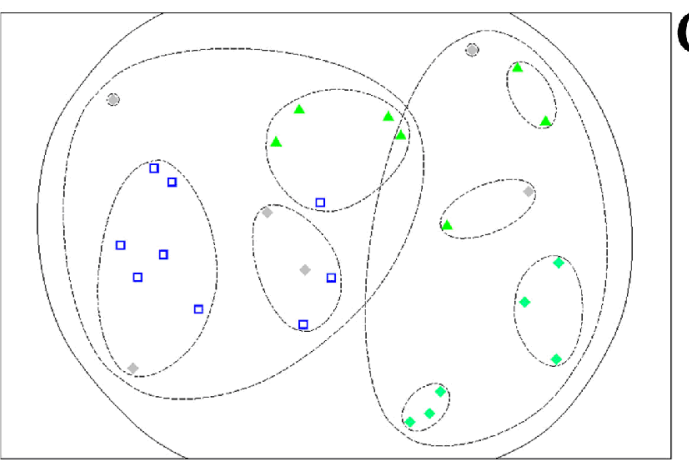

D

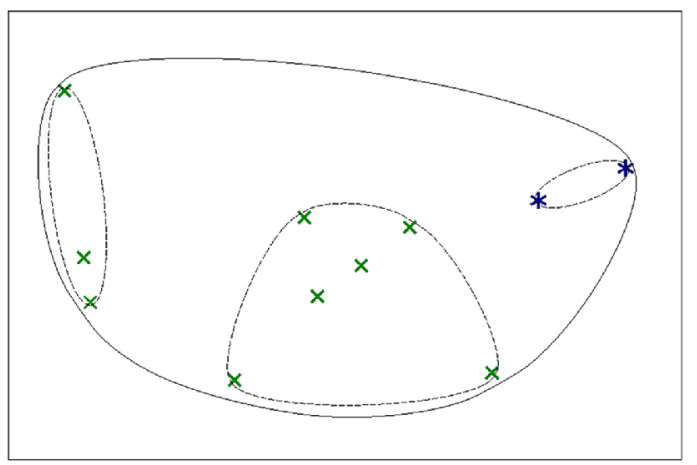

C

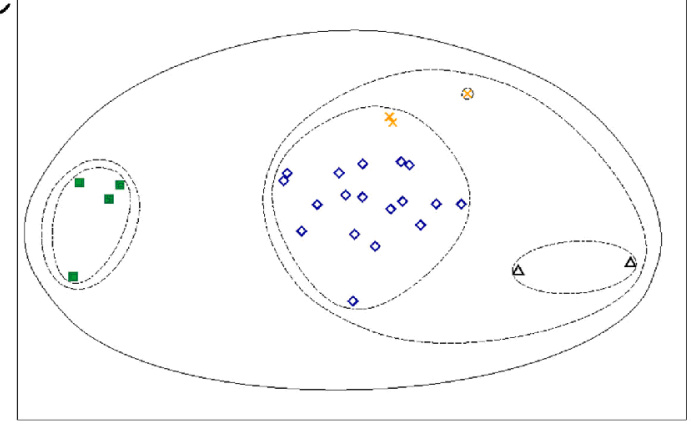

\section{KEY TO SPECIES}

A Arachnopusia unicornis

- Beania magellanica

- Bicellariella ciliata

- Bugula flabellata

- Nordgaardia cornucopioides

+ Caberea rostrata

$\times$ Caberea zelandica

* Caberea sp.

* Cabereasp.

$\nabla$ Tricellaria catalinensis

$\square$ Chaperiopsis cf. rubida

$\diamond$ Catenicella pseudoelegans

- Claviporella aurita

- Costaticella bicuspis

- Costaticella solida

- Cribricellina cribraria

- Escharoides angela

$\Delta$ Cellaria pilosa

$\Delta$ Cellaria tenuirostris

Euthyroides jellyae

$\times$ Osthimosia sirena
- Escharoides excavata

+ Exochella armata

$\times$ Exochella jullieni

* Parkermavella $\mathrm{n} . \mathrm{sp}$

$\triangle$ Hippomenella vellicata

$\nabla$ Microporella agonistes

$\checkmark$ Mucropetraliella n. sp.

$\checkmark$ Chiastosella exuberans

O Chiastosella watersi

$\triangle$ Reteporella gracilis

$\checkmark$ Reteporella aurantiace

Rhynchozoon zealandicum

- Stephanollona scintillans

- Celleporina grandis

+ Celleporina wellingtonensis

$\nabla$ Odontionella cyclops

- Opaeophora lepida 
Table 2.3. $P$ and Global $\mathrm{R}$ values for the species pairwise analysis of similarity (ANOSIM) test among avicularian types based on standardised (s) avicularian morphometrics (width of avicularia, sWav; length of palate, sLpal; width of palate, sWpal; length of orifice, sLo; width of orifice, $\mathrm{sWo}$ ). $\mathrm{N}=$ number of individual avicularium.

\begin{tabular}{ccccc}
\hline Avicularian type & $\mathrm{N}$ & $\begin{array}{c}\text { Overall } \\
\text { morphometric } \\
\text { similarity (\%) }\end{array}$ & $P$ & Global R \\
\hline Adventitious & 278 & 60 & $\leq 0.001$ & 0.437 \\
Interzooidal & 28 & 60 & $\leq 0.001$ & 0.599 \\
Vibracular & 11 & 80 & $<0.05$ & 0.505 \\
Vicarious & 28 & 60 & $\leq 0.001$ & 0.835 \\
\hline
\end{tabular}

Table 2.4. Discriminant function analysis of multi-trait morphometrics for avicularia, length of avicularium (Lav); width of avicularium (Wav); length of palate (Lpal); width of palate (Wpal); length of orifice (Lo); and width of orifice (Wo). Standardised Log10 transformed data.

\begin{tabular}{ccc}
\hline $\begin{array}{c}\text { Morphological } \\
\text { variables }\end{array}$ & Wilks' Lambda & $P$ \\
& 0.488 & $\leq 0.001$ \\
Wav & 0.403 & $\leq 0.001$ \\
Lpal & 0.394 & $<0.05$ \\
Wpal & 0.434 & $\leq 0.001$ \\
Lo & 0.400 & $\leq 0.001$ \\
Wo & & \\
\hline
\end{tabular}


Table 2.5. Percentage of individual avicularia identified correctly by discriminant function analysis. Standardised $\log 10$ transformed data.

Classified Group

\begin{tabular}{|c|c|c|c|c|c|c|}
\hline Avicularian & $\mathrm{N}$ & $\%$ & Adventitious & Interzooidal & Vibracula & Vicarious \\
\hline Type & & Classified & & & & \\
\hline & & Correctly & & & & \\
\hline
\end{tabular}

\begin{tabular}{ccccccc} 
Adventitious & 278 & 100 & 278 & 0 & 0 & 0 \\
Interzooidal & 28 & 0 & 28 & 0 & 0 & 0 \\
Vibracula & 11 & 100 & 0 & 0 & 11 & 0 \\
Vicarious & 28 & 3.5 & 27 & 0 & 0 & 1 \\
\hline
\end{tabular}

Table 2.6. Mahalanobis Distance and associated significance level $(P)$ for pairwise comparisons of avicularian types analysed by discriminant function analysis. Standardised Log10 transformed data.

\begin{tabular}{cccc}
\hline Pairwise Comparison & $\begin{array}{c}\text { Mahalanobis } \\
\text { Distance }\end{array}$ & $\mathrm{F}$ & $P$ \\
& 0.9 & 4.54 & $<0.001$ \\
Adventitious $v s$ Interzooidal & 1.8 & 9.36 & $<0.001$ \\
Adventitious $v s$ Vicarious & 42.79 & 89.51 & $<0.001$ \\
Adventitious $v s$ Vibracula & 0.60 & 1.67 & $>0.05$ \\
Interzooidal vs Vicarious & 36.19 & 56.49 & $<0.001$ \\
Interzooidal $v s$ Vibracula & 34.22 & 53.42 & $<0.001$ \\
Vicarious $v s$ Vibracula & & & \\
\hline
\end{tabular}




\section{Multivariate analyses among superfamilies}

The MDS ordination plot for the Calloporoidea showed a lowest level of $60 \%$ similarity in avicularian morphometrics. Chaperiopsis cf. rubida had adventitious and interzooidal avicularia whilst Odontionella cyclops had adventitious only (Figure $2.25 \mathrm{~A})$. The morphometrics of the avicularia of $O$. cyclops overlapped with the adventitious of $C$. cf. rubida at the $80 \%$ similarity level. The interzooidal avicularia of C. cf. rubida were morphometrically distinct and the majority formed a distinct second group (Figure 2.25B). These groupings were supported by the ANOSIM analysis, which were significantly different at $P \leq 0.001$ though the global $\mathrm{R}$ value is relatively low (0.388) and probably reflected the morphometric similarity between the adventitious avicularia of $C$. cf. rubida and of $O$. cyclops.

The MDS ordination plot for the Buguloidea showed avicularian-specific clustering with the adventitious types having an overall minimum $60 \%$ morphometric similarity and the vibracula $80 \%$. The adventitious avicularia were further split into three clusters, each with $80 \%$ morphometric similarity. These clusters were supported by the ANOSIM analysis, which were significantly different at $P \leq 0.001$ (Figures $2.25 \mathrm{C}$, $\mathrm{D}$; Global $\mathrm{R}=0.289$ ). The global $\mathrm{R}$ value was relatively low reflecting the collation of avicularian types in the between species ANOSIM analysis. However, the individual scores for the ANOSIM species pairwise comparison showed that morphometric dissimilarity was significantly greater between the avicularia of Nordgaardia cornucopioides and all other species $(P<0.05)$. There was a high degree of morphometric similarity between the bird's-head form of avicularia in Beania magellanica and Bicellariella ciliata $(P>0.05, \mathrm{R}=0)$ and between $B$. magellanica and the bird's-head form of Bugula flabellata $(P>0.05, \mathrm{R}=0)$. Similarly, there was no significant difference in morphometrics between the avicularia of Caberea zelandica and Caberea sp. $(P>0.05, \mathrm{R}=0)$.

Within the Cellarioidea there was a high degree of morphometric similarity $(80 \%)$ between the vicarious avicularia of Cellaria pilosa and C. tenuirostris. Two species-specific clusters emerged indicating a high degree of intraspecific morphometric similarity (90\%). The ANOSIM analysis supported the observed clusters, which were significantly different at $P<0.05$ (Figure 2.25E; Global $\mathrm{R}=0.924$ ).

The avicularia of the catenicellids are all adventitious with an overall minimum morphometric similarity of $60 \%$. Two further avicularian-specific clusters emerged each 
having a high degree of morphometric similarity $(80 \%)$. Based on the combination of all morphometric data, the ANOSIM analysis further supported the observed clusters with no significant difference in avicularian morphometrics between species (Figure 2.25F; $P$ $>0.05$; Global R=0). 

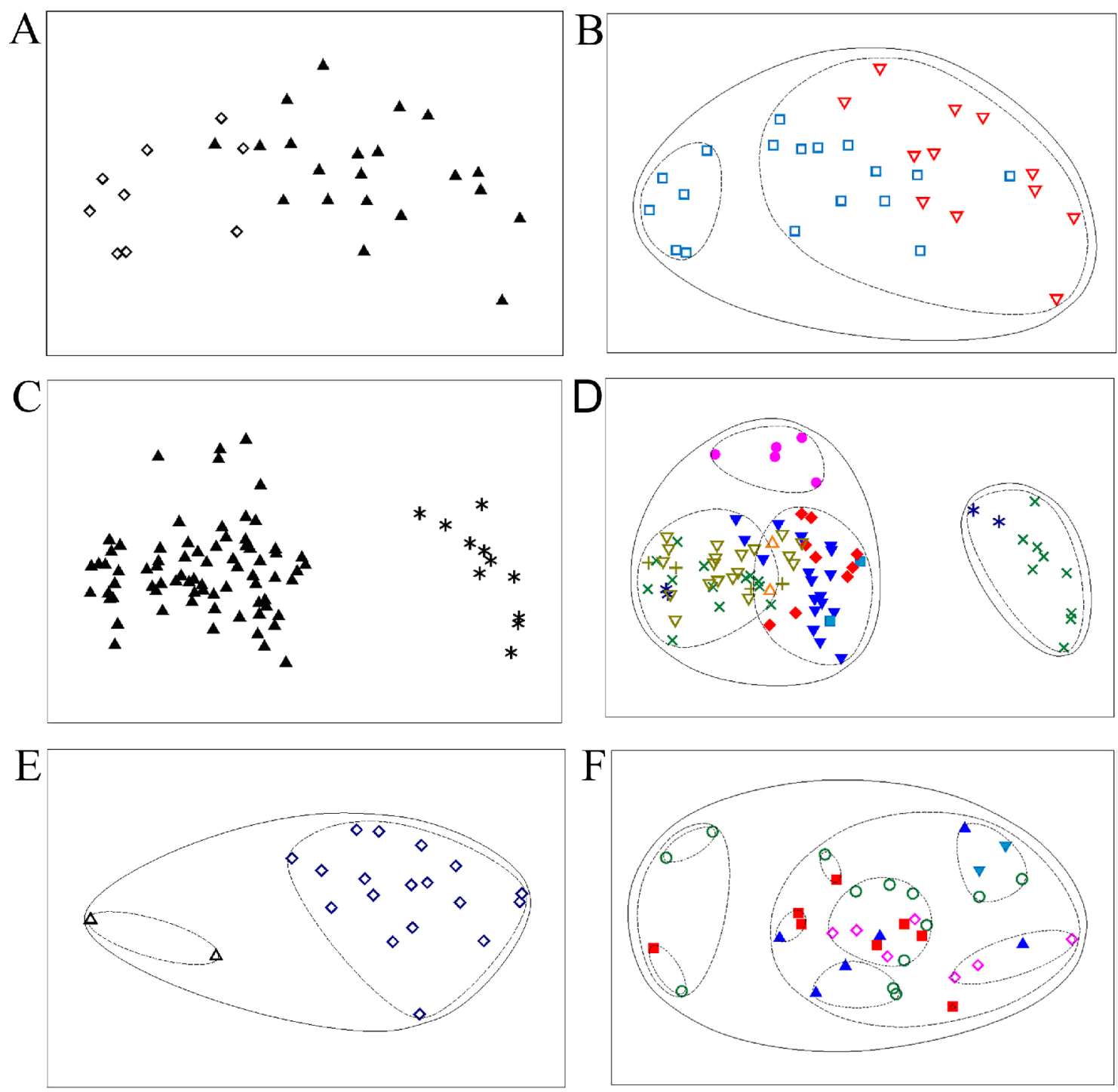

\section{AVICULARIUM TYPE}

$\Delta$ adventitious $\diamond$ Interzooidal

* vibraculum $\square$ vicarious

\section{KEY TO SPECIES}

A Arachnopusia unicornis Escharoides excavata

- Beania magellanica

Bicellariella ciliata

- Bugula flabellata

+ Exochella armata

$x$ Exochella jullieni

N Hippomenella vellicata

+ Caberea rostrata

$\checkmark$ Microporella agonistes

$\times$ Caberea zelandica

a Mucropetraliella n. sp.

* Caberea sp.

$\diamond$ Chiastosella exuberans

$\triangle$ Scrupacellaria ornithorhyncus $O$ Chiastosella watersi

$\checkmark$ Tricellaria catalinensis $\quad \Delta$ Reteporella gracilis

口 Chaperiopsis cf. rubida Reteporella aurantiace

$\diamond$ Catenicella pseudoelegans ERhynchozoon zealandicum

- Claviporella aurita

- Costaticella bicuspis

Rhynchozoon zealandicum
Stephanollona scintillans

- Costaticella solida

- Celleporina grandis

- Cribricellina cribraria

+ Celleporina wellingtonensis

- Escharoides angela

$\Delta$ Cellaria pilosa

$\nabla$ Odontionella cyclops

- Opaeophora lepida

$\diamond$ Cellaria tenuirostris

Euthyroides jellyae

$x$ Osthimosia sirena 
Figure 2.25 (previous page). Non-parametric MDS ordination plots for standardised (s) avicularian morphometrics (width of avicularia, sWav; length of palate, sLpal; width of palate, sWpal; length of orifice, sLo; width of orifice, sWo) among superfamilies. $\mathrm{N}=$ number of individual avicularia. (A) Calloporoidea avicularian type, and (B) species ( $\mathrm{N}=30)$, stress level, 0.08; (C) Buguloidea avicularian type, and (D) species $(\mathrm{N}=85)$, stress level, 0.07; (E) Cellarioidea $(\mathrm{N}=21)$, stress level, 0.06; (F) Catenicelloidea $(\mathrm{N}=36)$, stress level, 0.12 .

Arachnopusia unicornis was the sole representative for the Arachnopusioidea. The MDS ordination plot showed a high degree of similarity (80\%) between adventitious and interzooidal types. Based on the combination of all morphometric data, the ANOSIM analysis indicated there was no significant difference in morphometrics between the adventitious and interzooidal types (Figure 2.26A; $P>0.05$, Global $\mathrm{R}=$ 0.279).

Members of the Lepralielloidea all have adventitious avicularia and the MDS ordination plot showed an overall $60 \%$ morphometric similarity among avicularia. Two further clusters emerged each containing avicularia of $80 \%$ morphometric similarity. The groupings were supported by an ANOSIM analysis, which were significantly different at $P \leq 0.001$ (Figure 2.26B; Global $\mathrm{R}=0.501$ ). The individual scores for the ANOSIM species pairwise comparison showed that morphometric dissimilarity was significantly greater between the avicularia of Escharoides angela and Exochella jullieni $(P<0.05, \mathrm{R}=0.9)$. Intraspecific morphometric variability was evident for $E$. armata and E. jullieni as illustrated by the multi-grouping for E. armata and slight overlap in points between the two species. Despite this the individual pairwise scores showed the two species were significantly dissimilar in morphometrics $(P \leq 0.001$; Global $\mathrm{R}=0.339$ ).

The members of the Schizoporelloidea all have adventitious avicularia and the MDS ordination plot showed an overall $60 \%$ morphometric similarity among avicularia. Two further clusters emerged and each contained avicularia of $80 \%$ morphometric similarity. The observed clusters were supported by the ANOSIM analysis, which were significantly different at $P<0.001$ (Figure 2.26C; Global $\mathrm{R}=0.506$ ). The individual scores for the ANOSIM species pairwise comparison showed that morphometric dissimilarity was significantly greater between the avicularia of Chiastosella exuberans and $C$. watersi $(P<0.05, \mathrm{R}=0.70)$ and between Mucropetraliella n. sp. and $C$. exuberans $(P \leq 0.001, \mathrm{R}=0.902)$. 
The MDS ordination plot for the Celleporoidea showed an overall $60 \%$ morphometric similarity among avicularia. Two further clusters emerged each containing avicularia of $80 \%$ morphometric similarity. The observed clusters were supported by the ANOSIM analysis, which were significantly different at $P \leq 0.001$ (Figures 2.26D, E; Global $\mathrm{R}=0.29$ ). This superfamily consists of adventitious, interzooidal and vicarious types of avicularia and therefore an extensive morphometric range which presumably contributed to the low global $\mathrm{R}$. The individual scores for the ANOSIM species pairwise comparison showed that morphometric dissimilarity was significantly greater between the avicularia of Reteporella aurantiaca and Stephanollona scintillans $(P \leq 0.001, \mathrm{R}=0.40)$ and Reteporella aurantiaca and $R$. gracilis $(P<0.05, \mathrm{R}=0.4)$.

The results for the ANOSIM analyses among superfamilies are highlighted in Table 2.7. 

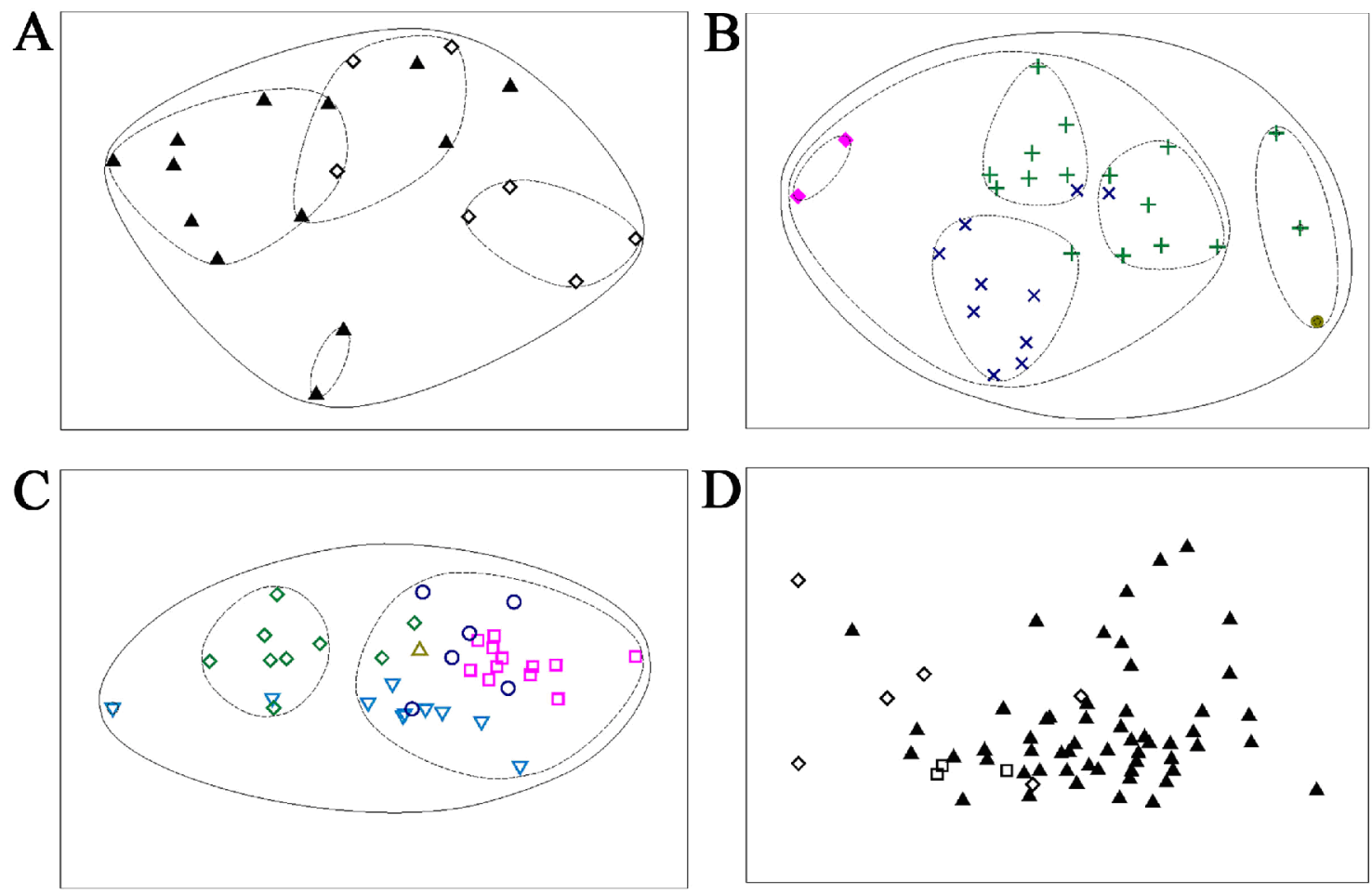

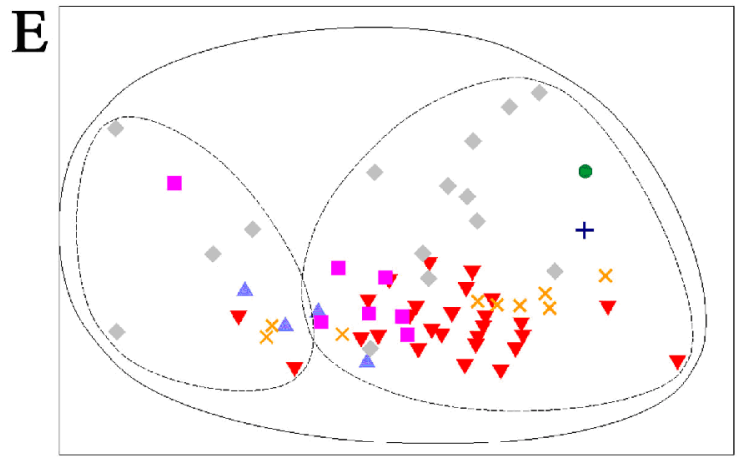

AVICULARIUM TYPE

$\boldsymbol{\Delta}$ adventitious $\boldsymbol{\Delta}$ Interzooidal

* vibraculum $\square$ vicarious

\section{KEY TO SPECIES}

Arachnopusia unicornis
Beania magellanica
Bicellariella ciliata
- Bugula flabellata
- Nordgaardia cornucopioides
+ Caberea rostrata
$\times$ Caberea zelandica
* Caberea sp.
A Scrupocellaria ornithorhyncus
$\nabla$ Tricellaria catalinensis
$\square$ Chaperiopsis cf. rubida
$\diamond$ Catenicella pseudoelegans
Claviporella aurita
C Costaticella bicuspis
$\nabla$ Costaticella solida
Cribricellina cribraria
Escharoides angela
$\Delta$ Cellaria pilosa
$\diamond$ Cellaria tenuirostris
Euthyroides jellyae
x Osthimosia sirena

- Escharoides excavata + Exochella armata $x$ Exochella jullieni * Parkermavella $\mathrm{n}$. sp

$\Delta$ Hippomenella vellicata $\nabla$ Microporella agonistes a Mucropetraliella n. sp. $\diamond$ Chiastosella exuberans so Chiastosella waters $\triangle$ Reteporella gracilis ₹ Reteporella aurantiace rhynchozoon zealandicum - Stephanollona scintillans - Celleporina grandis + Celleporina wellingtonensis $\nabla$ Odontionella cyclops $\checkmark$ Opaeophora lepida

Osthimosia sirena

Figure 2.26. Non-parametric MDS ordination plots for standardised (s) avicularian morphometrics (width of avicularia, sWav; length of palate, sLpal; width of palate, sWpal; length of orifice, sLo; width of orifice, sWo) among superfamilies. $\mathrm{N}=$ number of individual avicularia. (A) Arachnopusioidea avicularian type (Arachnopusia unicornis only, $\mathrm{N}=20$ ), stress level, 0.13; (B) Lepralielloidea ( $=29)$, stress level, 0.08; (C) Schizoporeloidea $(\mathrm{N}=38)$, stress level, 0.06; (D) Celleporoidea avicularian type, and (E) species $(\mathrm{N}=64)$, stress level, 0.11 . 
Table 2.7. $P$ and Global $\mathrm{R}$ values for the species pairwise analysis of similarity (ANOSIM) among superfamilies based on standardised (s) avicularian morphometrics (width of avicularia, sWav; length of palate, sLpal; width of palate, sWpal; length of orifice, sLo; width of orifice, $\mathrm{sWo}$ ). $\mathrm{N}=$ number of individual avicularia.

\begin{tabular}{|c|c|c|c|c|c|}
\hline Superfamily & $\mathrm{N}$ & $\begin{array}{l}\text { Avicularian } \\
\text { type(s) }\end{array}$ & $\begin{array}{c}\text { Overall } \\
\text { morphometric } \\
\text { similarity (\%) }\end{array}$ & $P$ & $\begin{array}{c}\text { Global } \\
\text { R }\end{array}$ \\
\hline Calloporoidea & 30 & $\begin{array}{l}\text { Adventitious } \\
\text { Interzooidal }\end{array}$ & 60 & $\leq 0.001$ & 0.388 \\
\hline Buguloidea & 85 & $\begin{array}{l}\text { Adventitious } \\
\text { Vibracular }\end{array}$ & 60 & $\leq 0.001$ & 0.289 \\
\hline Cellarioidea & 21 & Vicarious & 80 & $<0.05$ & 0.924 \\
\hline Catenicelloidea & 36 & Adventitious & 60 & $>0.05$ & 0 \\
\hline Arachnopusioidea & 20 & $\begin{array}{l}\text { Adventitious } \\
\text { Interzooidal }\end{array}$ & 80 & $>0.05$ & 0.279 \\
\hline Lepralielloidea & 29 & Adventitious & 60 & $\leq 0.001$ & 0.501 \\
\hline Schizoporelloidea & 38 & Adventitious & 60 & $\leq 0.001$ & 0.506 \\
\hline Celleporoidea & 64 & $\begin{array}{c}\text { Adventitious } \\
\text { Interzooidal } \\
\text { Vicarious }\end{array}$ & 60 & $\leq 0.001$ & 0.29 \\
\hline
\end{tabular}




\subsection{Discussion}

This extensive morphological survey of avicularia has failed to establish any consistent phylogenetic relationships based on morphology. An overall morphological similarity in closely related species or among avicularian types only existed in the catenicellids and in those species with vibracula. The orificial characters of the avicularia examined in this study were highly variable. The type of orifice structures observed included: tubular projections, bulbous extensions, tufts of cilia, and just a simple pore, or opening, in the plane of the palate. Such diversity may indicate a variety of biological roles and/or sensory capabilities even in species with similar forms of avicularia. For example, the bird's-head forms of Bugula flabellata and Bicellariella ciliata differ in avicularian orifice anatomy (B. flabellata- a tuft of cilia and B. ciliatapore with organic secretion). In contrast, there was a high degree of morphological similarity in orifice structure among the vibracula of Caberea sp. and Caberea zelandica suggesting extensive morphological constraint and possibly a similar functional role. Of particular significance is the occurrence of a vibracular-type orifice in Microporella agonistes (with setiform mandibles); the orifice of vibracula and setiform avicularia consisted of a tubular structure with a bulbous area within this structure, which may be the underlying vestigial polypide but needs further investigation to clarify. When phenotypic traits appear in seemingly unrelated taxa, the observed pattern could be attributable to either shared ancestry or independent evolution of that trait (Losos \& Miles 1994). Other examples of independent evolution in bryozoans exist in the genus Metrarabdotos where similar avicularian morphology occurred in different lineages (McKinney \& Jackson 1989).

The morphological disparities observed in this study may be correlated with different functional capacities, a subject that has been of immense speculation. Silén (1977) and Kaufmann (1971) commented that the mandibles of the bird's-head avicularium of Bugula flabellata are designed for grasping objects between mandible and rostrum whilst the setiform mandible of Microporella agonistes extends beyond the rostrum and lacks a fully rigid axial sclerite. It is therefore incapable of a grasping function and presumably has a different role. Certain species may possess more than one form such as the oval and acute mandibles of Stephanollona scintillans and the adventitious and vibracular types found in species of Caberea. Silén (1977) suggested that in such cases they may still have a similar defensive function but each form would 
be effective against different prey types. Kaufmann (1968) suggested that avicularia are specialised to fulfill a variety of roles that will differ among species. Certainly this study of avicularia concurs with Kauffman's theory in that my survey failed to discern any overall patterns in morphology among three of the four types (adventitious, interzooidal, and vicarious) and their respective avicularian orifices. A degree of morphological congruence was evident at superfamily level in some instances, such as the Catenicelloidea whereby in most species examined the lateral adventitious avicularia possessed a constricted, rosette-like orifice, morphologically similar to their respective autozooid orifice (Figures 2.11, 2.12). In contrast, morphological disparity was clearly evident in the avicularia in most superfamilies (e.g. Buguloidea; Figures 2.5, 2.6) and even within a species (e.g. the interzooidal and adventitious avicularia of Arachnopusia unicornis; Figures 2.14A-E).

A noteworthy observation from the survey of avicularia was the presence of what appeared to be organic material being exuded from the orifice of many avicularia (e.g. Figures $2.5 \mathrm{C}, 2.10 \mathrm{C}, 2.20 \mathrm{~B}$ ). The precise nature of this material and its significance requires further examination. The possibility of avicularian-derived chemical defence cannot be dismissed, particularly as research into bioactive compounds and marine natural products is currently prominent and has involved bryozoans (see Paul et al. 2007). Bioactive compounds are generally derived from symbiotic bacteria, the association of which can have wider ecological implications (Pukall et al. 2002). The presence of symbiotic bacteria in the pallial sinus of Bugula neritina larvae has been experimentally shown to provide chemical defence against predation (Lindquist 1996; Lindquist \& Hay 1996). Similarly, many species of sponge possess symbiotic bacteria that secrete bioactive compounds whilst offering the sponge defence against predation, overgrowth, and biofouling (Paul \& Puglisi 2004). In some species of bryozoans there is a negative correlation between surface bacterial densities and antimicrobial potency (Walls et al. 1993). Bacteria have been found in the glands of some avicularia (Lutaud 1964) and clearly this aspect requires further examination to determine the frequency of this association. In this study, avicularia were often observed biofouled by microbes (e.g. Figure $2.15 \mathrm{C}$ ), the density of which was highly variable between avicularia and often dense enough to obscure palatal anatomy whilst some avicularia (and respective autozooids) were relatively free of microbes (e.g. Figure 2.9 E). Further study in this area is certainly warranted with respect to examining the 
correlation between degree of biofouling and microbial potency and the presence/absence of avicularia.

\section{Morphometrics}

Despite collecting bryozoans from a variety of locations and depths, this study was dominated by adventitious types (34 species) whilst interzooidal (4 species), vicarious (4 species), and vibracular ( 3 species) formed the minority. There were basically two levels of rarity; firstly, the low number of species collected with either vicarious or interzooidal avicularia, and secondly, the low density of those types within any given colony. One explanation for the rarity of vicarious and interzooidal forms overall, is that they could be of greater cost than adventitious types in terms of energetic production and maintenance costs, a theory that requires testing. The density of avicularia within a colony could be considered to be of great significance and would depend on what the function of that avicularium is. If the avicularia act as deterrents to biofouling and/or predation then avicularia might be expected to occur in high densities. As this is the first study to examine the density of avicularia, the 38 species in this study provide a benchmark for further studies of avicularia in species from disparate environmental regimes. The correlation between the density of a putative defensive structure and its effectiveness has been examined in sea stars. The pedicellariae of Acanthaster planci (the Crown-of-thorns starfish) occur sporadically on the aboral surface. Densities of these pedicellariae are variable between individuals but overall the density is too low to be effective against biofouling of the larvae of Bugula neritina and must therefore have an alternative function (Guenther et al. 2007). Similar empirical studies would be useful on avicularia and include manipulation of avicularian densities among colonies and monitoring colony response.

It has been proposed that the duplication of a specialised structure increases performance capacity and has the potential to have a profound effect on the ecological potential and success of subsequent lineages and ultimately increase functional diversity. An example of duplicated structures is segmentation (e.g. arthropods) where slight modifications of each segment allow for functional diversification, such as walking and burst locomotion (Lauder 1981; Wainwright 2007). If one considers the occurrence of avicularia within any given colony as duplicated functional units offering enhanced performance capacity then any observable patterns in the occurrence of 
avicularia can offer insight into the functional capacity of that given colony. Therefore the density of avicularia within a given colony can be considered a proxy for estimating functional capacity. The general pattern indicates that species with a combination of avicularian types have the greatest density of avicularia. Specifically, species possessing a combination of vibracular or vicarious type and adventitious had the greatest density of avicularia (Figure 2.23). Of significance is that species with only adventitious avicularia were amongst those with the highest densities and those with only vicarious types, the lowest density. A possible explanation for this is that within a smaller spatial scale, functional performance can be enhanced by placing one to three avicularia on the frontal surface of an autozooid. Within a specified spatial scale, various functions may be catered for: nutrients provided by the autozooid; embryo nurturing by ovicells; defense or water-current manipulation by spines; space filling/structural reinforcement by kenozooids; and then up to three (possibly more) avicularia of uncertain function. The implications of this observed pattern suggests that the evolution of adventitious avicularia may have allowed for morphological and functional diversity.

Analysis of the multivariate morphometric data for avicularia enabled morphometric (dis)similarity to be quantified. MDS analyses have been successfully applied to morphometric data in ascertaining taxonomic distinctness in echinoids based on the morphological features of the tridentate pedicellariae (Coppard \& Campbell 2006). MDS has also been applied in establishing taxonomic distinction in congeneric species of bryozoans based on autozooid morphometrics (Carter \& Gordon 2007). With respect to the current study, MDS analyses revealed that morphometric similarity was greatest among vibracula (80\%), whilst adventitious, interzooidal and vicarious avicularia displayed extensive morphometric variability $(60 \%$ similarity among each avicularian type) (Figure 2.24). The morphometric analyses concur with the morphological survey where there was extensive anatomical diversity in orificial structure in adventitious types and therefore may reflect disparate functional requirements. In a similar way, the main types of echinoderm pedicellariae can be further categorised based on jaw characteristics with slight modifications in design reflecting the need for a specific bite strength (Coppard \& Campbell 2006). Further work on the morphology of adventitious types should examine the impact of environmental factors on their size, location in the colony, density, and morphological modifications at the level of the avicularian orifice. 
The morphometric relationship among superfamilies was variable with an overall $60 \%$ similarity in most superfamilies except for those with species possessing vicarious types only (Cellarioidea) where there was an overall $80 \%$ similarity. Generally there were species-specific similarities and avicularian type similarities in morphometrics though in some instances species with a similar avicularian type exhibited morphometric disparity (e.g. adventitious of Nordgaardia cornucopioides and Tricellaria catalinensis). The avicularia of the catenicellids displayed the greatest morphometric similarity. A recent phylogenetic analysis based on 16s rDNA sequencing placed the only catenicellid represented, Savignyella lafontii basal to all the other cheilostomes in a neighbour-joining tree yet when the data were treated by maximum parsimony, S. lafontii was placed amongst the ascophorans (Hao et al. 2005). The earliest recorded catenicellid dates back to the Late Cretaceous (Cheetham, pers. comm. in Banta 1979) implying avicularium evolution has been conserved in parallel with an apparent extensive diversification in frontal wall morphology (Banta 1979; Gordon \& Braga 1994). The genera used in the phylogenetic study by Hao et al. (2005) differed substantially from the genera examined in this study (only seven genera in common) and therefore no morphological comparison was compiled.

The length of avicularia is a significant contributor to morphometric variability (Carter et al. 2008) therefore the objective of this study was to reduce the severity of that factor by standardising the data. Standardisation enhances the effect of shape on avicularian morphometrics. The subsequent $\log _{10}$ of the standardised data homogenises group variances (Underwood 1997) and therefore meets the assumptions required for discriminant function analysis (DFA). The treatment of the data produced different outcomes in the classification results (DFA). No vicarious types were classified correctly using standardised $\log _{10}$ data (Table 2.5 ) yet $25 \%$ were classified correctly using standardised only data. Conversely, $99.6 \%$ of adventitious types were classified correctly using standardised $\log _{10}$ whilst $93 \%$ were correctly classified using standardised only. The significance of these findings illustrates the influence of avicularian length on morphometrics and by standardizing and $\log 10$-transforming the data, avicularia (except vibracula) are actually morphometrically constrained, i.e. avicularia are all the same shape. Another factor to consider is natural variability. Vicarious avicularia by definition take the place of an autozooid and are therefore the same size as or larger than the autozooid in the colony (Hyman 1959). The length of 
vicarious avicularia tends, therefore, to be a function of autozooid length. Just as autozooid length can be variable between species then so will the length of the vicarious avicularium (where they occur). In contrast, the length of adventitious avicularia is independent of autozooid length (Schopf \& Dutton 1976). The observed classification in the DFA could therefore reflect the extensive morphometric variability of adventitious avicularia, resulting in the morphometric distance between adventitious $v s$ interzooidal and adventitious $v s$ vicarious types being very small $\left(\mathrm{D}^{2}=0.99\right.$ and 0.1 .46 respectively).

The observed morphometric and morphological constraint in some species and variability in others may be indicative of the degree of constraint in the response of the observed phenotype to selective factors in the environment and the observed morphology represents aspects of the relationship between an organism and its environment (Ricklefs \& Miles 1994). Further work on avicularia should be based around this conceptual framework in order to understand their functional role and what the ecological implications are.

\section{Further research}

- Experimental manipulation of avicularian densities and monitoring of morphological response to an ecologically relevant cue, e.g. known predator, biofouling organisms

- Increase the anatomical and morphometric database, particularly of setiform and vibracular types in order to establish how ubiquitous is the tubular orifice

- Examine the correlation between bioactive compounds and biofouling of colonies in the presence/absence of avicularia. In species with potent bioactive compounds and avicularia, can the potency be experimentally enhanced in response to ecologically relevant cues?

\subsection{Conclusions}

In conclusion, avicularia display a range of orificial structures and with the exception of the Catenicelloidea and the vibracular of species of Caberea, no consistent phylogenetic relationships based on morphology existed. The orificial structures presented were variable and consisted of tubular and bulbous projections, pores in the plane of the palate, tufts of cilia, tubular extensions and constricted pores. Adventitious, vicarious 
and interzooidal types were morphometrically similar whilst the vibracular types were morphometrically distinct. Adventitious avicularia were common relative to the other three types and displayed the greatest divergence in morphometrics. These findings may be correlated with extensive functional divergence in avicularia, particularly in adventitious types indicating a strong evolutionary selection for adventitious types of avicularia, possibly in favour for maximised functional capacity over a smaller spatial scale in the colony.

\subsection{References}

Banta, W.C., 1973. Evolution of avicularia in cheilostome Bryozoa. In: Boardman, R.S., Cheetham, A. \& Oliver, W. (Eds), Animal colonies. Dowden, Hutchinson and Ross, Inc, Pennsylvania, pp. 295-303.

Banta, W.C., 1979. Catenicellid cheilostome Bryozoa I. Frontal walls. Australian Journal of Zoology Supplementary Series 68: 1-70.

Boardman, R.S. \& Cheetham, A.H., 1973. Degrees of colony dominance in stenolaemate and gymnolaemate Bryozoa. In: Boardman, R.S., Cheetham, A.H. \& Oliver, W.A. (Eds), Animal colonies. Development and function through time. Dowden, Hutchinson \& Ross, Inc, Stroudsburg, pp. 121-220.

Busk, G., 1854. Remarks on the structure and function of the avicularian organs of bryozoans; and on their value as diagnostic and vibracular characters in the classification of those creatures. Transactions of the Microscopical Society 2: 26-33.

Campbell, A.C., 1983. Form and function of pedicellariae. Echinoderm Studies 1: 139167.

Campbell, A.C. \& Jensen, M., 1993. Rostrate pedicellariae: A morphologically distinct form of echinoid test appendage. Journal of Morphology 218: 237-247.

Carter, M.C. \& Gordon, D.P., 2007. Substratum and morphometric relationships in the bryozoan genus Odontoporella, with a description of a new pagurideansymbiont species from New Zealand. Zoological Science 24: 47-56.

Carter, M.C., Gordon, D.P. \& Gardner, J.P.A., 2008. A preliminary analysis of avicularian morphology. In: Hageman, S.J., Key, M. \& Winston, J.E. (Eds), Bryozoan Research 2008. Proceedings of the 14th International Bryozoology Association Conference, July 1-8, 2007, Boone, North Carolina, pp. 19-30.

Cheetham, A.H., Sanner, J., Taylor, P.D. \& Ostrovsky, A.N., 2006. Morphological differentiation of avicularia and the proliferation of species in mid-Cretaceous Wilbertopora Cheetham, 1954 (Bryozoa: Cheilostomata). Journal of Paleontology 80: 49-71.

Clarke, K.R. \& Gorley, R.N., 2006. PRIMER v6: User manual/tutorial. PRIMER-E, Plymouth.

Cook, P.L., 1963. Observations on live lunulitiform zoaria of polyzoa. Cahiers de Biologie Marine 4: 407-413.

Coppard, S.E. \& Campbell, A.C., 2006. Systematic significance of tridentate pedicellariae in the echinoid genera Diadema and Echinothrix. Invertebrate Biology 125: 363-378. 
Darwin, C., 1845. Journal of researches into the natural history and geology of the countries visited during the voyage of H.M.S. 'Beagle' around the world, under the command of Capt. Fitzroy, R.N. Second edn., corrected with additions. Ward, Locke, and Co., London, 492 pp.

Darwin, C., 1872. On the origin of species by means of natural selection, or the preservation of favoured races in the struggle for life. Sixth edition with additions and corrections. John Murray, London, $458 \mathrm{pp}$.

Dzik, J., 1975. The origin and early phylogeny of the cheilostomatous Bryozoa. Acta Palaeontologica Polonica 20: 395-423.

Forbes, A., 1938. Conditions affecting the response of the avicularia of Bugula. Biological Bulletin 65: 469-479.

Gordon, D.P. \& Braga, G., 1994. Bryozoa: Living and fossil species of the catenicellid subfamilies Ditaxiporinae Stach and Vasignyellinae nov. In: Crosnier, A. (Ed.), Résultants des Campagnes MUSORSTOM. Mémoirs Des Muséum national d'Histoire naturelle, Paris, pp. 55-85.

Guenther, J., Heimann, K. \& de Nys, R., 2007. Pedicellariae of the crown-of-thorns sea star Acanthaster planci are not effective defence against fouling. Marine Ecology Progress Series 340: 101-108.

Hao, J., Li, C., Sun, X. \& Yang, Q., 2005. Phylogeny and divergence time estimation of cheilostome bryozoans based on mitochondrial 16s rRNA sequences. Chinese Science Bulletin 50: 1205-1211.

Harmer, S.F., 1900. A revision of the genus Steginoporella. Quarterly Journal of the Microscopical Society 43: 225-297.

Hyman, L.H., 1959. The invertebrates: Smaller coelomate groups Chaetognatha, Hemichordata, Pogonophora, Phoronida, Ectoprocta, Brachiopoda, Sipunculida. The coelomate bilateria. McGraw-Hill Book Company, Inc, New York, 783 pp.

James, M.A., 1997. Brachiopoda:Internal anatomy, embryology, and development. In: Harrison, F.W. \& Woollacott, R.M. (Eds), Microscopic anatomy of invertebrates. Lophophorates, enteprocta, and cycliophora. Wiley-Liss, New York, pp. 297-407.

Johnston, G., 1847. A history of the British zoophytes. Van Voorst, London.

Kaufmann, K.W., 1968. The biological role of Bugula-type avicularia (Bryozoa). In: Annoscia, E. (Ed.), Proceedings of the first international conference on Bryozoa. Atti della Società Italiana di Scienze Naturali e del Museo Civico di Storia Naturale di Milano 108, pp. 54-60.

Kaufmann, K.W., 1971. The form and functions of the avicularia of Bugula (Phylum Ectoprocta). Postilla 151: 1-26.

Lauder, G.V., 1981. Form and function: Structural analysis in evolutionary morphology. Paleobiology 7: 430-442.

Lewis, J.B. \& Saluja, G., 1967. The claviform pedicellariae and their stalk glands in the tropical sea urchin Diadema antillarum Philippi. Canadian Journal of Zoology 45: 1211-1214.

Lindquist, N., 1996. Palatability of invertebrate larvae to corals and sea anemones. Marine Biology 126: 745-755.

Lindquist, N. \& Hay, M.E., 1996. Palatability and chemical defense of marine invertebrate larvae. Ecological Monographs 66: 431-450.

Lindsay, S.M., Riordan, T.J. \& Forest, D., 2004. Identification and activity-dependent labeling of peripheral sensory structures on a spionid polychaete. Biological Bulletin 206: 65-77. 
Losos, J.B. \& Miles, D.B., 1994. Adaptation, constraint, and the comparative method: Phylogenetic issues and methods. In: Wainwright, P.C. \& Reilly, S.M. (Eds), Ecological morphology. Integrative organismal biology. The University of Chicago Ltd, Chicago, pp. 60-98.

Lutaud, G., 1964. Sur la structure et le rôle des glandes vestibulaires et sur la nature de certains organes de la cavité cystidienne chez les Bryozaires chilostomes. Cahiers de Biologie Marine 5: 201-231.

Marcus, E., 1939. Bryozoarios marinhos Brasileiros. III. BoletiMs da Faculdade de Filosofia, Ciências e Letras, Universidade de São Paulo, Zoologia 3: 111-353.

McKinney, F.K. \& Jackson, J.B.C., 1989. Bryozoan Evolution. Unwin Hyman, Boston, $287 \mathrm{pp}$.

Minnich, B., Leeb, H., Bernroider, E.W.N. \& Lametschwandtner, A., 1999. Threedimensional morphometry in scanning electron microscopy: A technique for accurate dimensional and angular measurements of microstructures using stereopaired digitized images and digital image analysis. Journal of Microscopy 195: 23-33.

Nielsen, C., 2002. Ciliary filter-feeding structures in adult and larval gymnolaemate bryozoans. Invertebrate Biology 121: 255-261.

Nielsen, C. \& Riisgård, H.U., 1998. Tentacle structure and filter-feeding in Crisia eburnea and other cyclostomatous bryozoans, with a review of upstreamcollecting mechanisms. Marine Ecology Progress Series 168: 163-186.

Paul, V.J. \& Puglisi, M.P., 2004. Chemical mediation of interactions among marine organisms. Natural Products Report 21: 189-209.

Paul, V.J., Arthur, K.E., Ritson-Williams, R., Ross, C. \& Sharp, K., 2007. Chemical defenses: from compounds to communities. Biological Bulletin 213: 226-251.

Pukall, R., Kramer, I., Rohde, M. \& Stackebrandt, E., 2002. Microbial diversity of cultivatable bacteria associated with the North Sea bryozoan Flustra foliacea. Systematic and Applied Microbiology 24: 623-633.

Purschke, G. \& Hausen, H., 2007. Lateral organs in sedentary polychaetes (Annelida)ultrastructure and phylogenetic significance of an insufficiently known sense organ. Acta Zoologica 88: 23-39.

Ricklefs, R.E. \& Miles, D.B., 1994. Ecological and evolutionary inferences from morphology: An ecological perspective. In: Wainwright, P.C. \& Reilly, S.M. (Eds), Ecological morphology. Integrative organismal biology. The University of Chicago Ltd, Chicago, pp. 13-41.

Ryland, J.S., 1970. Bryozoans. Hutchinson University Library, London, 175 pp.

Sandberg, P.A., 1971. Scanning electron microscopy of cheilostome bryozoan skeletons; Techniques and preliminary observations. Micropaleontology 17: 129-151.

Santagata, S., 2002. Structure and metamorphic remodeling of the larval nervous system and musculature of Phoronis pallida (Phoronida). Evolution and Development 4: $28-42$.

Santagata, S., 2004. Larval development of Phoronis pallida (Phoronida): Implications for morphological convergence and diverence among larval body plans. Journal of Morphology 259: 347-358.

Schopf, T.J.M. \& Dutton, A.R., 1976. Parallel clines in morphologic and genetic differentiation in a coastal zone marine invertebrate: the bryozoan Schizoporella errata. Paleobiology 2: 255-264. 
Shunatova, N. \& Nielsen, C., 2002. Putative sensory structures in marine bryozoans. Invertebrate Biology 121: 262-270.

Silén, L., 1945. The main features of the development of the ovum, embryo and ooecium in the ooeciferous Bryozoa Gymnolaemata. Arkiv fur Zoologi 35A: 134.

Silén, L., 1977. Polymorphism. In: Woollacott, R.M. \& Zimmer, R.L. (Eds), Biology of bryozoans. Academic Press, New York, pp. 184-231.

StatSoft Inc., 2005. STATISTICA (data analysis software system), version 7.1.www.statsoft.com.

Taylor, P.D., 1990. The impact of the SEM in studies of living and fossil bryozoans. In: Claughter, D. (Ed.), Scanning electron microscopy in taxonomy and functional morphology Clarendon Press, Oxford, pp. 259-280.

Taylor, P.D., 1994. An early cheilostome bryozoan from the Upper Jurassic of Yemen. Neues Jahrbuch für Geologie und Paläontologie Abhandlungen 191: 331-344.

Taylor, P.D. \& Jones, C.G., 1996. Use of the environmental chamber in uncoated SEM of recent and fossil bryozoans. Microscopy and Analysis March issue: 27-29.

Underwood, A.J., 1997. Experiments in ecology. Cambridge University Press, Cambridge, 504 pp.

Valdecasas, A.G. \& Camacho, A.I., 2005. On the environmental scanning electron microscope for taxonomic purposes. Invertebrate Biology 124: 66-73.

Wainwright, P.C., 1994. Functional morphology as a tool in ecological research. In: Wainwright, P.C. \& Reilly, S.M. (Eds), Ecological morphology. Integrative organismal biology. The University of Chicago Press, Ltd, Chicago, pp. 42-59.

Wainwright, P.C., 2007. Functional versus morphological diversity in macroevolution. Annual Review of Ecology, Evolution, and Systematics 38: 381-401.

Walls, J.T., Ritz, D.A. \& Blackman, A.J., 1993. Fouling, surface bacteria and antibacterial agents of four bryozoan species found in Tasmania, Australia. Journal of Experimental Marine Biology and Ecology 169: 1-13.

Winston, J.E., 1984. Why bryozoans have avicularia - A review of the evidence. American Museum Novitates 2789: 1-26.

Winston, J.E., 1986. Victims of avicularia. Marine Ecology 7: 193-199.

Winston, J.E., 1991. Avicularian behaviour - A progress report. In: Bigey, F.P. (Ed.), Bryozoa Living and Fossil. Bulletin de la Société des Sciences Naturelles de l'Ouest de France, Mémoire, H.S, Nantes, pp. 531-540. 


\section{CHAPTER 3}

\section{A Comparative Ultrastructural Study of the Avicularia from Two Species of Bugulidae from Disparate Environments}

\subsection{Introduction}

Marine bryozoans have a wide bathymetric distribution and can be found from the intertidal to $8300 \mathrm{~m}$ and include many avicularium-bearing taxa (Schopf 1969; Hayward 1981). This study provides an opportunity to examine the ultrastructural anatomy of the avicularia from two confamilial taxa inhabiting different depths. One of the species is an adventive and has a wide geographic distribution whilst the other is restricted to deep-sea seamounts. Whilst this work is not an ecological study, the functional morphology of the avicularia from two species of Buguloidea will be examined and their ecology discussed in a general context in order to highlight their habitat differences. This study will provide essential insight into adaptive modifications in avicularian anatomy in closely related taxa each possessing a bird's-head form of avicularia. Despite similarities, the internal anatomy will provide insight into the degree of anatomical and functional divergence in avicularia. The objective of this study, therefore, is to examine the ultrastructural anatomy of the avicularium from a subtidal (Bugula flabellata) and deep-sea (Nordgaardia cornucopioides) bryozoan. A critical consideration when selecting suitable taxa for an ultrastructural study is the ease with which the avicularia can be isolated from the rest of the colony. The two species chosen for this study fit that criterion. B. flabellata is a successful adventive species and has been selected in order to determine whether the function of this avicularium could be considered conducive to its adventive success. The next two sections will present current knowledge of the systems and ecology associated with a deep-sea and adventive existence providing an overall ecological perspective in the context of understanding functional morphology. 


\subsubsection{Deep-sea bryozoans}

Overall, the biological and physical properties of the deep-sea environment are considered to be relatively constant, or have a degree of predictability. Temperatures usually range between $4^{\circ} \mathrm{C}$ and $-1{ }^{\circ} \mathrm{C}$, salinity is $\sim 34.8 \mathrm{PSU}$, there is no light beyond $200 \mathrm{~m}$, phytoplankton productivity decreases with depth and hydrostatic pressure increases 1 bar with every $10 \mathrm{~m}$ increase in depth (Gage \& Tyler 1991; Childress 1995). Since the discovery of oceanographic features such as hydrothermal vents and seeps, it is increasingly clear that some parts of the deep-sea are more variable (e.g. hydrothermal vents and seeps) (Van Dover et al. 2002; Shillito et al. 2006; Mills et al. 2007).

Bryozoan diversity in the deep-sea is great (Gage \& Tyler 1991). In New Zealand, there are 240 species of deep-sea bryozoans, more than $80 \%$ of these species are endemic (Gordon 1987). Maximum diversity of bryozoans occurs in the first $200 \mathrm{~m}$ (Gordon 1999); peaks of 'bryodiversity' occur at 10-40 $\mathrm{m}$ and 800-1000 $\mathrm{m}$ though the overall trend is towards a decrease in biodiversity with increasing depth (Rowden et al. 2004). The most speciose family in the deep-sea waters surrounding New Zealand is the Bugulidae (Gordon 1987). The main contributing factors to bryozoan diversity in the deep-sea are availability of hard substrata and flow regime, whereby upwelling can increase primary productivity and in turn increase the availability of food (Mullineaux 1988; Hughes 2001; Rowden et al. 2004). Whereas shallow water bryozoans feed on photosynthetic flagellates and other microalgae (Winston 1977), deep-sea species presumably rely on a combination of heterotrophic protists, non-living particulate detritus and dissolved organic matter (Hughes 2001). Water currents play a crucial role in maintaining a supply of resuspended detritus. Oceanographic features such as undersea mountains, or seamounts are places of relatively high productivity and current speeds (Gage \& Tyler 1991; Rogers 1994) and alongside the limited availability of hard substrata, is a possible explanation for the observed biodiversity peak of bryozoans on seamounts (Rowden et al. 2004).

Bryozoans have developed morphological adaptations that enable them to inhabit regions deficient in hard substrata and thereby enhance their success in the deepsea. Strategies may involve the production of kenozooids at the base of the colony, anchoring rootlets, or setiform avicularia (Cook 1981). By producing such specialised structures, bryozoans can inhabit soft-sediment sea floors and the substratum is 
therefore limited to small grain sizes that may nevertheless be large enough for the ancestrula to settle upon (Hayward 1981) or rootlets to attach to (Gordon 1987). An example of such specialisation exists in the free-living lunulitiform bryozoans that inhabit soft sea floors. The ancestrula of these bryozoans settles on a sand grain and colony growth then extends beyond the grain. Specialised avicularia called vibracula enable the colony to remain above the sediment by virtue of their long bristle-like mandibles (Cook 1963; Cook \& Chimonides 1978). Erect colony forms in the deep-sea typically possess a descending cluster of rootlet tubes surrounding the base of the colony; these are a type of kenozooid and they function to attach the colony to fine sediment grains (Schopf 1969; Marshall 1979). Another characteristic feature of deepsea bryozoans appears to be their longer tentacles than in comparable shelf species (Schopf 1969; Ryland 1970).

Cheilostome bryozoans tend to dominate the deep-sea (Schopf 1969; Hughes 2001) and anascans tend to outnumber the ascophorans within the cheilostomes (Hayward 1981; Gordon 1987). Both erect and encrusting growth forms are represented in the deep-sea. In the New Zealand region, encrusting bryozoans that form discrete patchy colonies tend to dominate (45\%) followed by upright arborescent growth forms (19\%) (Gordon 1987). Encrusting forms dominated the Hebridean continental slope (Hughes 2001) whilst only upright forms were collected during the Galathea Expedition (Covering an area that included the western Indian Ocean and western Pacific Ocean) (Hayward 1981). The occurrence of erect forms only in the Galathea Expedition suggests a sampling bias. A significant finding from this Expedition, is that out of the 44 species where systematic descriptions were given, 38 species had avicularia (Hayward 1981). This finding suggests that avicularia may well be an important component of colony functioning among deep-sea bryozoans.

\subsubsection{Adventive bryozoans}

The introduction of adventive marine organisms is primarily through hull fouling and/or the ballast water of vessels. These invasive species usually remain confined to the harbour once colonised rather than colonising naturally occurring substrata (Cranfield et al. 1998). In fact, invasive species have experimentally demonstrated a preference for artificial structures such as wharf pilings and pontoons over natural reefs as a suitable substratum for colonisation (Glasby et al. 2007). The 
major contributors in the development of fouling communities are species recruitment onto a surface, competitive interactions and disturbance by predation and/or environmental factors (Richmond \& Seed 1991). Research on various global localities indicate that pollution is a significant issue in harbours and often have elevated levels of organic matter, nutrients, trace metals and hydrocarbons (Guerra-García \& GarcíaGómez 2005). Despite the high levels of pollution in harbours, an extensive biofouling community exists (Cranfield et al. 1998). Generally, hull-fouling species display a high level of tolerance for environmental stress (e.g. blue mussel Mytilus galloprovincialis) (Apte et al. 2000) and therefore readily adapt to new environments (Mooney \& Cleland 2001).

Bryozoans are major contributors to the biofouling community (Ryland 1965; Gordon \& Mawatari 1992; Cranfield et al. 1998) and are more tolerant to a wider range in temperature, salinity, turbidity and pollution than open-coastal species (Gordon \& Mawatari 1992). In New Zealand, the most ubiquitous fouling bryozoans are Cryptosula pallasiana, Tricellaria catalinensis, Conopeum seurati, Watersipora subtorquata, Bugula neritina, Bugula stolonifera and Bugula flabellata (Gordon \& Mawatari 1992). Bugula flabellata has a wide global distribution and was first recorded in New Zealand around 1949 in Wellington Harbour (Gordon 1986; Gordon \& Mawatari 1992). B. flabellata is particularly common on the wharf pilings at Queens Wharf and can be found in abundance between May and March (Ralph \& Hurley 1952). The hydrological regime around Wellington Harbour (Figure 2.1 Chapter 2) can be variable depending on location: the salinity at Queens Wharf is fairly stable (34.1- 35.9 PSU) yet can be as low as 21.9 PSU at Matiu-Somes Island where the salinity is influenced by the freshwater input of the Hutt River during heavy rain (Booth 1975; Northcote 1998). Tidal flow in the harbour entrance can vary between $0.10 \mathrm{~m} \mathrm{~s}^{-1}$ and $0.46 \mathrm{~m} \mathrm{~s}^{-1}$ within the harbour (Northcote 1998). The turbidity of the harbour waters increases as a result of such heavy rain but is also increased as a result of shipping activities (Booth 1975). Wellington Harbour is exposed to regular traffic of marine vessels of commercial and recreational origin as well as domestic ferries (Smith 1996). It is such shipping activities that are responsible for the arrival of Bugula flabellata into Wellington Harbour and for its conspicuous presence at the majority of ports and harbours around New Zealand (Gordon \& Mawatari 1992). 


\subsubsection{Ecological role of avicularia}

B. flabellata and $N$. cornucopioides form upright branching colonies. This morphology mitigates spatial competition on the substratum by reducing the hard surface area required for growth (Jackson 1979). Bugula flabellata is perennial and overwinters as dormant holdfasts. During favourable conditions, initial growth and reproductive output is rapid. Larval production is maximised through successive generations (degeneration and regeneration of polypides) of branches (Dyrynda \& Ryland 1982). It is believed that avicularia undergo degeneration and regeneration also (Winston 1984). The initial autozooids following dormancy have to allocate resources into rapid branch growth, spermatogenesis, oogenesis, initial embryogenesis (Dyrynda \& Ryland 1982) and production of avicularia. The energetic demands of $B$. flabellata are therefore large and the energy allocated to the production and maintenance of avicularia can only be assumed to be of some significance. The functional morphology, or even the functional capacity, of the avicularium would be largely influenced by its ecological niche and the functional requirements of the colony in order to respond to relevant ecological cues. The production of avicularia in B. flabellata may play a key role in the success of its colonisation into new habitats.

Similarly, the avicularia of $N$. cornucopioides would also be influenced by ecological cues relevant to the deep-sea-seamount environment. Phenotypic differences among organisms can provide useful information regarding the relationship between that organism and its environment based on the observed morphology (Ricklefs \& Miles 1994). Therefore, the disparate environmental regimes and habitat structure (Table 3.1) would presumably promote anatomical and physiological differences in the respective avicularia of $B$. flabellata and $N$. cornucopioides irrespective of their evolutionary relationship. The functional capacity of each of those types will be examined ultrastructurally using transmission electron microscopy (TEM). 
Table 3.1. Habitat comparison between Bugula flabellata and Nordgaardia cornucopioides.

Habitat

\begin{tabular}{|c|c|c|}
\hline Habitat & Bugula flabellata & $\begin{array}{l}\text { Nordgaardia } \\
\text { cornucopioides }\end{array}$ \\
\hline Depth (m) & 0.2 & $\sim 1000$ \\
\hline Substratum & Wharf pilings & Seamount \\
\hline Abiotic environment & $\begin{array}{l}\text { Pollution; photic zone; } \\
\text { turbidity fluctuations; } \\
\text { seasonal temperature } \\
\text { variations }\end{array}$ & $\begin{array}{l}\text { Upwelling; stable } \\
\text { temperature; no light }\end{array}$ \\
\hline Biotic environment & $\begin{array}{l}\text { Co-occur with other } \\
\text { cosmopolitan and/or } \\
\text { invasives; epibionts; } \\
\text { feed on phytoplankton }\end{array}$ & $\begin{array}{l}\text { High productivity due to } \\
\text { upwelling which re-suspends } \\
\text { OM; co-occur with other } \\
\text { seamount fauna; colony free } \\
\text { of epibionts; feed on } \\
\text { inorganic detritus, } \\
\text { heterotrophic protists and } \\
\text { possibly dissolved OM }\end{array}$ \\
\hline
\end{tabular}

\subsubsection{Transmission electron microscopy (TEM)}

In order for cell structure to be observed under TEM, ultrathin tissue sections (10-100 nm thick) need to be cut on an ultramicrotome using a diamond knife (Hayat 1981). Before actually getting to the stage of being able to cut the tissue, there are several steps involved in preparing the tissue for TEM, namely fixation, dehydration, and resin embedding. Fixation of biological samples can often result in the loss of cell constituents. In order to reduce such loss, the best fixation method is a double fixation with glutaraldehyde followed by osmium tetroxide $\left(\mathrm{OsO}_{4}\right)$ (Glauert 1965; Hayat 1981). Once fixed the tissue is then dehydrated and finally embedded in resin (Glauert 1965; Humason 1972).

TEM has been extensively used in examining the functional morphology of a range of invertebrates including bryozoans. Ultrastructural studies of various anatomical structures such as the stomach, lophophore, reproductive organs (Figure 3.1A), and the various brooding methods have enabled a greater understanding of their cellular composition, functional capacity, and evolutionary development (e.g. Mukai et al. 1997). Ultrastructural examination of the tentacles revealed the presence of numerous 
cells surrounding a central lumen. Basally to these cells is a collagen-based basement membrane. Ciliated cells are concentrated in the frontal area of the tentacle with a few lateral ciliated cells (Lutaud 1973; Mukai et al. 1997; Nielsen 2002) (Figure 3.1B). These cilia play a crucial role in creating a localised water current for the entrainment of food particles. Edible and inedible particles are differentiated by the specialised lateral cilia with inedible particles being deflected away by reverse flicking of the cilia (Mukai et al. 1997). The epidermal cells of the tentacle are covered by a layer of microvilli and mucopolysaccharide coating, or glycocalyx (Smith 1973; Gordon 1974b).

The digestive tract of all bryozoans is similar in gross morphology with a Ushaped appearance and is divided into the pharynx, stomach, and rectum (Silén 1944; Bullivant \& Bils 1968; Figure 3.1A). Ultrastructural features of the digestive tract have been studied by various authors (Gordon 1975; Ryland 1976; Lutaud 1985; Mukai et al. 1997). Studies have shown that the pharyngeal cells of the ctenostome Zoobotryon verticillatum are ciliated with a microvillous border (Bullivant \& Bils 1968). Food particles pass through the mouth into the ciliated pharynx and into the stomach. The stomach contains acidophilic and basophilic cells, neither of which are ciliated but have a microvillous border (Mukai et al. 1997). Previous anatomical studies on avicularia have involved light microscopy only and therefore ultrastructural anatomy has not yet been described for any avicularium. Ultrastructural details can be obtained using TEM and therefore it is currently unknown as to what anatomical details of the autozooid have been conserved or modified at the ultrastructural level in the avicularium. 

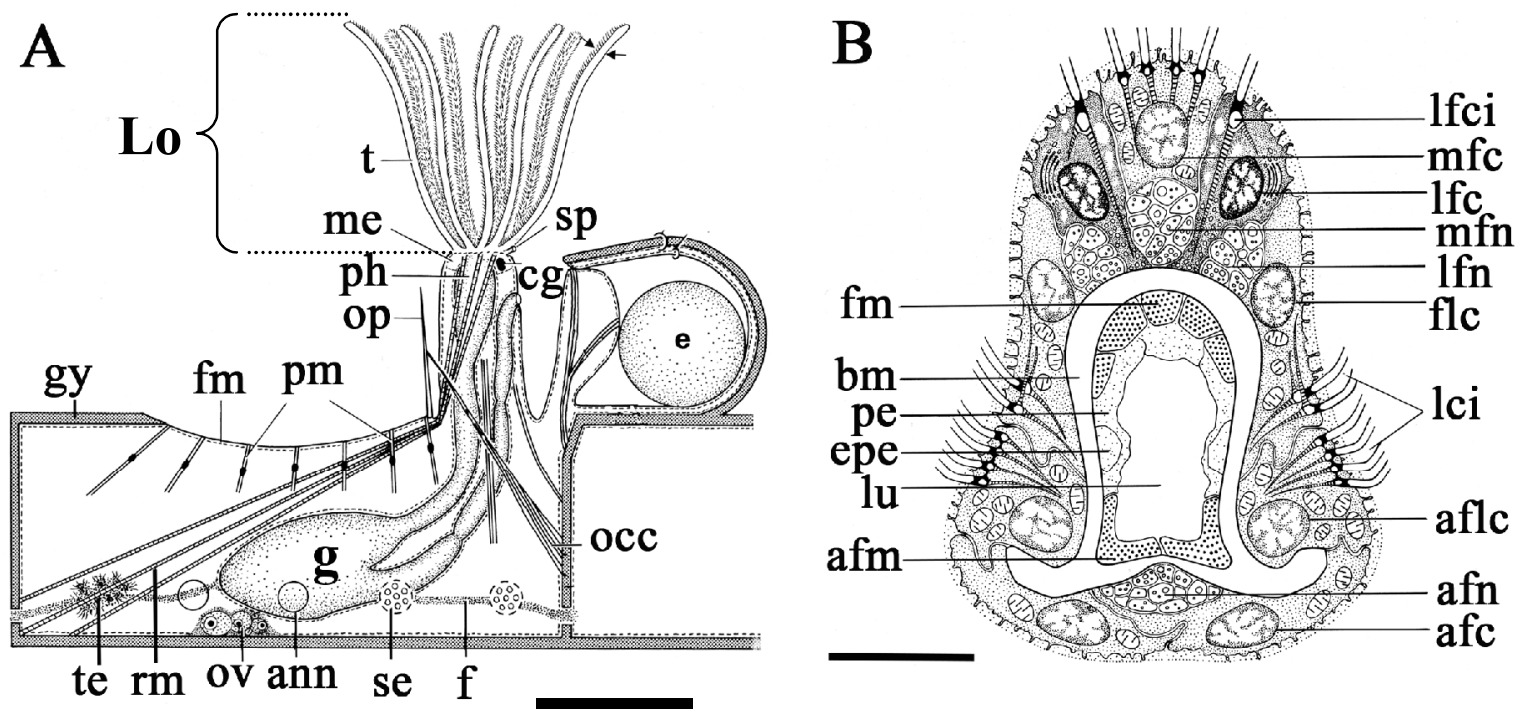

Figure 3.1. (A) Diagram of a generalised cheilostome autozooid. Arrows indicate plane of section through the tentacle as represented by (B) (Modified from Ryland 1970). Scale bar 250 $\mu \mathrm{m}$. ann, annulus of pore chamber; cg, cerebral ganglion; e, embryo; f, funicular system; fm, frontal membrane; g gut; gy, gymnocyst; Lo, lophophore; me, mesocoel; occ, occlusor muscle; op, operculum; ov, ovaries; ph, pharynx; pm, parietal muscles; rm, retractor muscles; se, septulum; sp, supraneural pore; $t$, tentacle; te, testes; Gut and lophophore = polypide; (B) Transverse section through an autozooid tentacle of Electra pilosa (From Lutaud 1973). Scale bar, $3 \mu \mathrm{m}$. afc, abfrontal cell; aflc, abfrontolateral cell; afm, abfrontal muscles; afn, abfrontal nerve; bm, basement membrane; epe, enclosed part of peritoneal cell; fm, frontal muscle; flc, frontolateral cell; lci, lateral cilia; lfn, lateral frontal nerve; lfc, laterofrontal cell; lfci, laterofrontal cilium; lu, lumen; mfc, median frontal cell; $\mathrm{mfn}$, median frontal nerve; pe, peritoneal cell.

\subsubsection{Research objectives}

This study will provide essential insight into adaptive modifications in avicularian anatomy in confamilial taxa each possessing a bird's-head form of avicularia. Despite phylogenetic and gross morphological relatedness, the internal anatomy will provide insight into the degree of anatomical and functional divergence in avicularia. The objective therefore is to examine the functional morphology of the avicularium from two species of Bugulidae from disparate environments: Bugula flabellata, a subtidal marine-fouling species and Nordgaardia cornucopioides, a seamount inhabitant of the deep-sea. Both species possess a bird's-head form of avicularium.

This study will greatly advance our knowledge of the functional morphology and evolutionary development of avicularia in an ecological context. The aim, therefore, 
is to compare the ultrastructural anatomy of the avicularia from B. flabellata and $N$. cornucopioides using transmission electron microscopy (TEM).

\subsection{Materials and Methods}

\subsubsection{Distribution and sample collection}

\section{Bugula flabellata}

In Wellington, New Zealand, B. flabellata can be found growing on wharf pilings at Queens Wharf (berthing for vessels of international and national origin), Chaffers Marina (berthing for recreational vessels), Burnham Wharf (berthing for vessels of international and national origin), and on offshore floating rafts belonging to the aquaculture research centre at Mahanga Bay (National Institute of Water and Atmospheric research, NIWA). All colonies were found subtidally. For this study colonies were collected from Queens Wharf and Mahanga Bay (Figure 2.1, Chapter 2) between September 2006 and March 2007. At Queens Wharf, access to colonies was achieved by climbing onto the floating pontoons and picking colonies off the wharf pilings or off the mussels that were attached to the piling (Figures 3.2A, B). At Mahanga Bay, access to colonies was achieved by boat and then climbing onto the floating rafts and pulling up the various suspended nets and ropes from the rafts. The colonies were placed into sealed containers with seawater collected from their respective site.

During the sectioning of tissue, particles of grit and sand were found to be caught between the mandible and rostrum of the avicularium causing extensive scouring through the $1 \mu \mathrm{m}$ sections and preventing progression onto the diamond knife in order to obtain ultrathin sections. To reduce the problem of trapped sand and grit, dormant stolons of B. flabellata were collected from Mahanga Bay during the winter of July and August, 2006. In order for B. flabellata to survive, the colony had to remain attached to the substratum, therefore pieces of rope or net were cut around the colony and placed into sealed containers with seawater from the site of collection and taken back to the Mahanga Bay aquaculture facility for culturing. The colonies were maintained in a $40 \mathrm{~L}$ tank of $1 \mu \mathrm{m}$ filtered seawater ran on a semi-closed system. The seawater was kept at a constant temperature of $18^{\circ} \mathrm{C}$ by a thermal coil. The colonies were fed $\sim 50 \mathrm{~mL}$ 
Isochrysis galbana once a day. Once sufficient growth of B. flabellata was obtained, colonies were fixed for TEM.
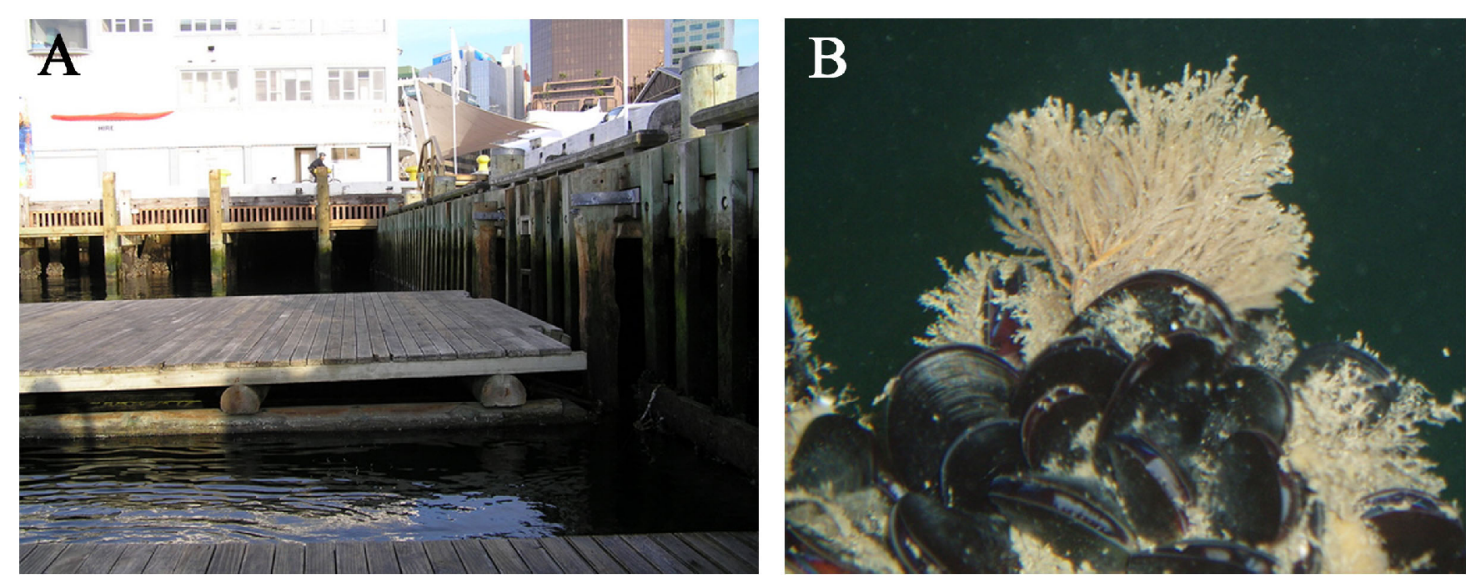

Figure 3.2. (A) Collection site for Bugula flabellata. Floating pontoons and pilings at Queens Wharf, Wellington; (B) B. flabellata in-situ growing on the blue mussel Mytilus galloprovincialis which is attached to a wharf piling. Colony length approximately $6 \mathrm{~cm}$.

\section{Nordgaardia cornucopioides}

Colonies of $N$. cornucopioides were collected from the Graveyard Seamount Complex on the Chatham Rise, New Zealand (Figure 2.2, Chapter 2) by epibenthic sled during a scientific voyage onboard the $R V$ Tangaroa during May and June 2006. Benthic tows were deployed at the majority of the mounts in the Graveyard Seamount Complex but colonies were only collected from Zombie (-42.766 180.0737; Depth at summit, $891 \mathrm{~m}$ ) and Diabolical (-42.7898 180.0127; Depth at summit, $894 \mathrm{~m})$. The environment on the seamounts consisted mainly of silty-covered volcanic rock and sessile invertebrates such as corals, hydroids, sea anemones, and sponges (Figure 3.3A). The contents of the epibenthic sleds were sorted immediately following release onto the deck. Once found, colonies were placed into filtered seawater and fixed as soon as possible following collection. Brief observations were made under a dissecting microscope. The avicularia are very conspicuous and are visible even without the aid of microscopy (Figure 3.3B). 

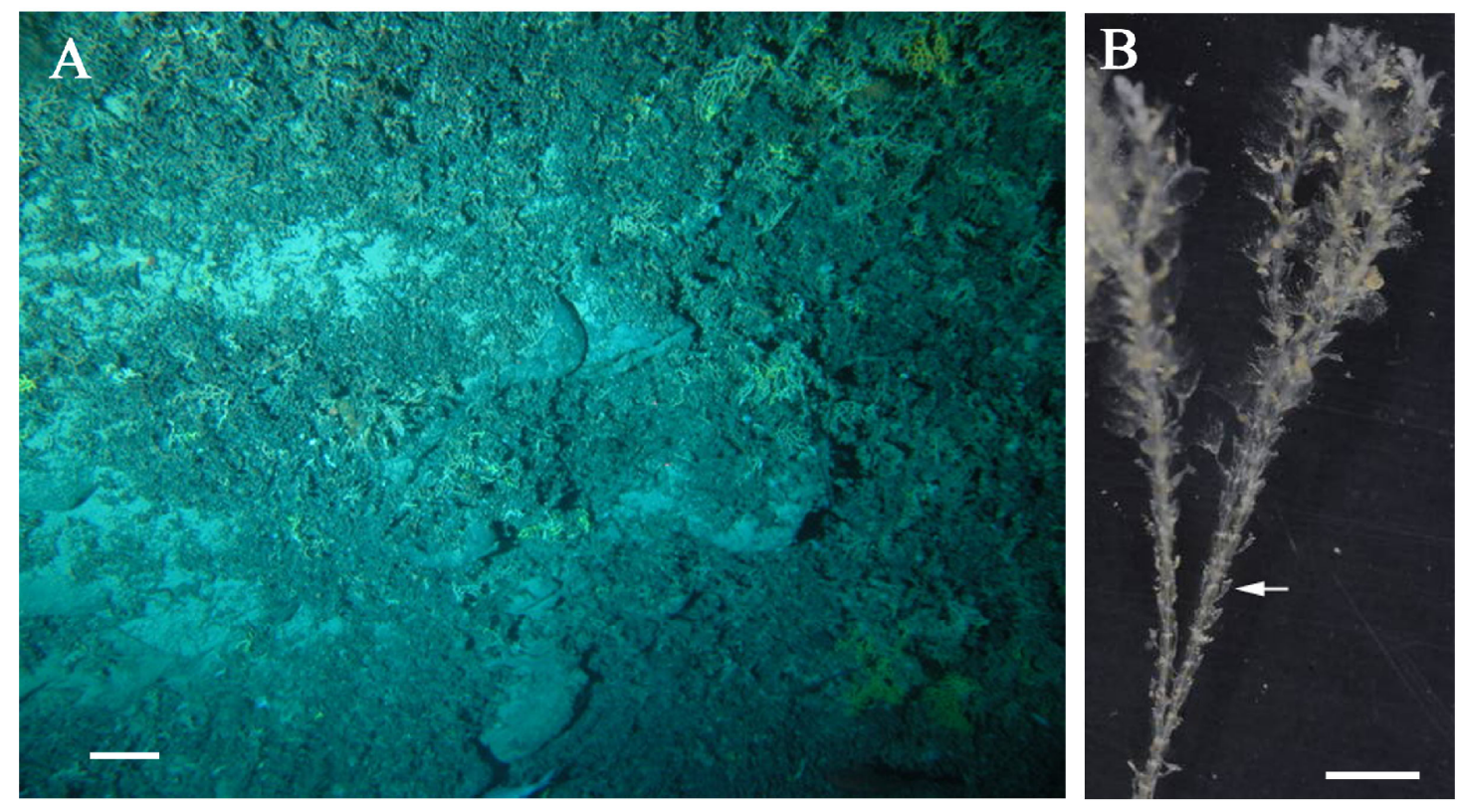

Figure 3.3. (A) Collection site for Nordgaardia cornucopioides. Zombie seamount, part of the Graveyard seamount complex, Chatham Rise. Scale bar $20 \mathrm{~cm}$. Image taken with a "seamount/scampi" still camera system designed by NIWA; (B) N. cornucopioides following collection. The avicularia are clearly seen without the aid of microscopy (Arrow). Scale bar 13 $\mathrm{mm}$. Image courtesy of P. Marriott (NIWA).

\subsubsection{Scanning electron microscopy (SEM)}

SEM images were acquired and utilised here purely for orientation purposes.

The relevant protocols for the fixation of subtidal and deep-sea bryozoans have been described in Chapter 2.

\subsubsection{Photomicroscopy}

Gross-anatomical details were examined by a Nikon Microphot FX-A compound microscope and light and Differential Interference Contrast (DIC) images captured using a Pixielink PL-A686C colour firewire video camera.

\subsubsection{Transmission electron microscopy (TEM)}

The methods and solutions required for the following protocols are documented in Appendix 2.

\section{Bugula flabellata}

The following protocol is based on that of Shunatova \& Nielsen (2002) but the black osmium was developed by Prof. S.J. Wakefield (Pathology Dept, Wellington 
School of Medicine). Colonies were fixed in $2.5 \%$ glutaraldehyde in $0.1 \mathrm{M}$ sodium cacodylate buffer $(7.4 \mathrm{pH})$ and $10.26 \%$ sucrose $(\mathrm{CAB})$ (750 mOsMol). Colonies were then washed in $\mathrm{CAB}$ for $10 \mathrm{~min}$ then decalcified in 10\% EDTA (in CAB) for up to four wk and kept rotated at $5^{\circ} \mathrm{C}$ with solution changes every 3-5 d. Once decalcified, samples were post-fixed in either $1 \%$ standard or black $\mathrm{OsO}_{4}$ in $\mathrm{CAB}$ for $2 \mathrm{~h}$, washed three times in $\mathrm{CAB}$ for $10 \mathrm{~min}$ each wash, and then dehydrated in a graded ethanol/acetone series ending in $100 \%$ acetone. The samples were then placed in propylene oxide for 20 min followed by a gradual introduction of epon resin over a period of $24 \mathrm{~h}$ with a final exposure to $100 \%$ resin for $4 \mathrm{~h}$ before being embedded in Beam ${ }^{\mathrm{TM}}$ capsules containing $100 \%$ resin and left overnight to harden at $60^{\circ} \mathrm{C}$. For orientation purposes, $1 \mu \mathrm{m}$ thick sections were cut on a microtome and stained with Toluidine Blue and viewed under a compound microscope. Ultrathin sections (70-90 $\mathrm{nm})$ were cut using a Diatome diamond knife, placed onto microadhesive coated copper grids, stained in uranyl acetate followed by lead citrate staining, then viewed under a Philips CM100 TEM. The negatives produced were then scanned and converted to positive images using the SilverFast-SE v6.4.4r7 software and edited in Photoshop Elements v3.

\section{Nordgaardia cornucopioides}

No protocol exists for the fixation of deep-sea bryozoans intended for TEM. The following protocol is a modified version of the protocol of Shunatova \& Nielsen (2002) using the black osmium solution developed by Prof. S.J Wakefield. The protocol involved two fixation stages; an initial onboard fixation stage following collection of colonies, an interim storage period and finally the post-fixation stage at an onshore laboratory.

Following collection onboard the research vessel, colonies were initially relaxed in $7 \% \mathrm{MgCl}_{2}$ (20-60 min) prior to fixation in $2.5 \%$ glutaraldehyde in $\mathrm{CAB}$ for $2-3 \mathrm{~h}$ and then placed in airtight plastic containers with filtered seawater for storage purposes. Seawater is a natural buffer and therefore a suitable medium for the extended storage period (5-25 d). During storage, the samples were kept cool simply by placing the containers in a cool place on the ship (e.g. below deck). Once back onshore, colonies were decalcified, post-fixed in black $\mathrm{OsO}_{4}$ in $\mathrm{CAB}$ then taken through the dehydration and embedding process as described for B. flabellata. For orientation purposes, $1 \mu \mathrm{m}$ 
thick sections were cut on a microtome using a glass knife and stained as described previously. Subsequent procedures were carried out as for B. flabellata.

\subsection{Results}

\subsubsection{Bugula flabellata}

When the mandible of the avicularium is open the cilia extend from the palate and into the external environment (Figure 3.4A). The cilia arise from the vestigial polypide whilst the highly augmented adductor muscles are the dominant tissue structure in the avicularium (Figure 3.4B). The vestigial polypide is encased by the palatal membrane that extends from the palate (Figure 3.4C), and comprises approximately 18 elongated cells with a pseudostratification of component organelles (Figures 3.4D, E, 3.5A, B). The cells can either be ciliated or unciliated (Figure 3.6). The anterior portion of these cells contains short cilia (if present) of $\sim 2 \mu \mathrm{m}$ in length (Mean, $1.6 \mu \mathrm{m} ; \mathrm{N}=3$ ) and a 9x2+2 microtubule arrangement (Figures 3.5C, D). Most cells have finger-like projections, or cellular extensions, on the cell surface (Figures 3.4E, 3.5B). A few bacteria were found within a pocket of the vestigial polypide (Figures 3.4D, 3.7A). Widely distributed throughout the cells are mitochondria and well developed Golgi apparatus. The median region of all cells contains numerous granulated vesicles. These vesicles are closely associated with various lacuna that are located between the cells (Figures 3.4D, 3.5A, B, 3.7A). The Golgi apparatus are responsible for the formation of these granulated vesicles (Figures 3.5A, B). Each cell has a basal nucleus and lipid-like vesicles occur alongside these basal nuclei. A retractor muscle attaches either side of the vestigial polypide (Figures 3.7 A, B).

Basally to the vestigial polypide is the cerebral ganglion (Figures 3.4C, D, 3.8). Its cells contain mitochondria, lysosomes and basal nuclei (Figure 3.8). The ganglion is semi-circular and tightly associated with the vestigial polypide and the adductor muscles (Figures 3.4C, D). The ganglion comprises numerous axonal cells containing dense-cored, double-membrane, neurosecretory vesicles of $\sim 55-100 \mathrm{~nm}$ in diameter (Figures 3.9A, B). 

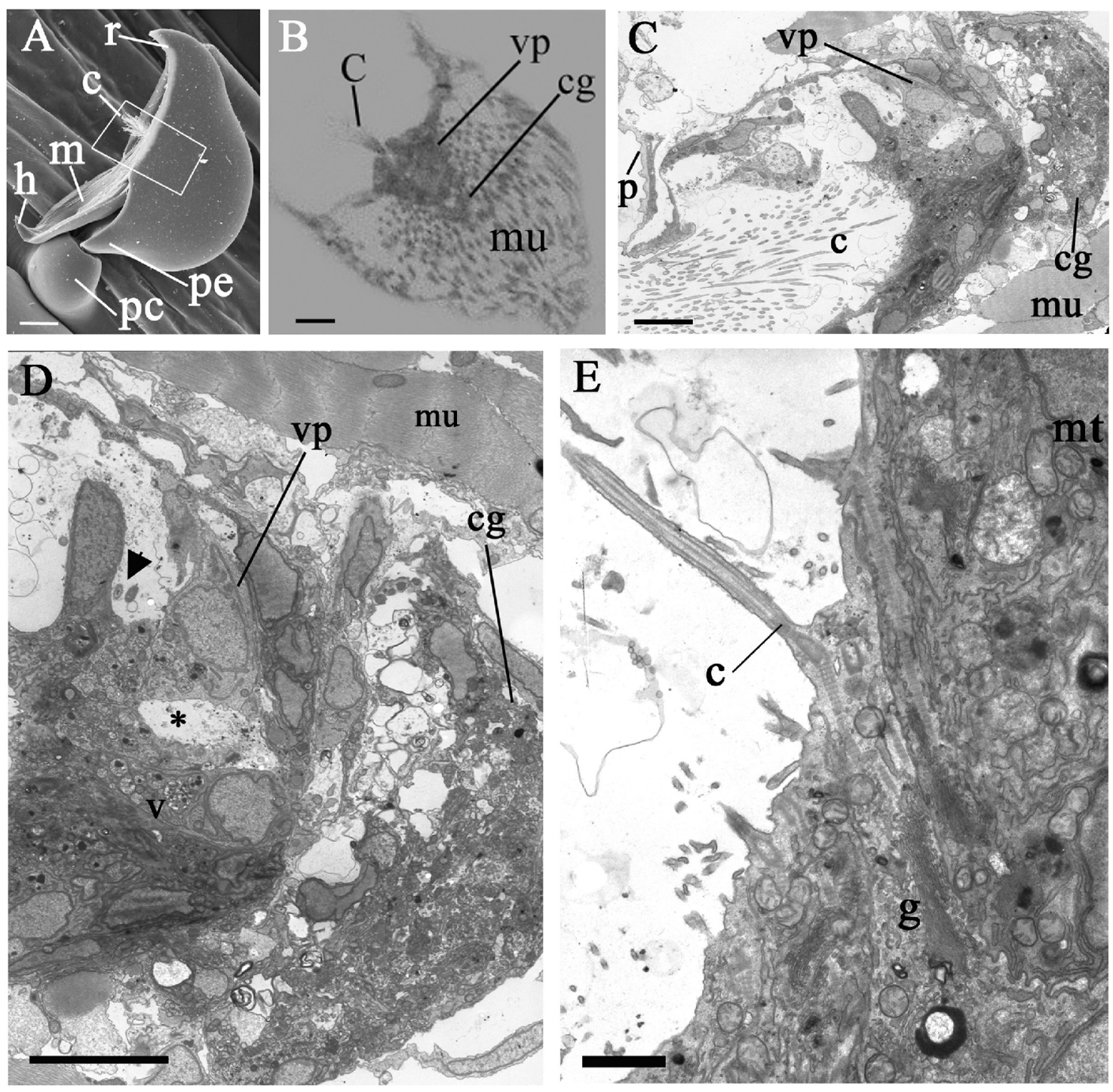

Figure 3.4. Avicularium of Bugula flabellata. (A) SEM of an avicularium in lateral view. Rectangle indicates area of vestigial polypide that is represented in B-E. Scale bar, $20 \mu \mathrm{m}$; (B) 1 $\mu \mathrm{m}$ thick resin embedded section of an avicularium stained with Toluidine Blue and in longitudinal plane. Scale bar, $20 \mu \mathrm{m}$; (C) TEM of the vestigial polypide and cerebral ganglion in a slightly oblique, longitudinal plane. Scale bar, $5 \mu \mathrm{m}$; (D) TEM of the vestigial polypide in a slightly oblique, longitudinal plane. A lacuna within the vestigial polypide $(*)$ and a pocket in the vestigial polypide contain bacteria (arrow head). Scale bar, $2.5 \mu \mathrm{m}$; (E) TEM of the anterior region of the cells of the vestigial polypide. Scale bar, $1 \mu \mathrm{m}$. c, cilia/cilium; cg, cerebral ganglion; g, golgi apparatus; $h$, hook; $\mathrm{m}$, mandible; $\mathrm{mt}$, mitochondria; mu, muscle; $\mathrm{p}$, palate; $\mathrm{pc}$, peduncle cushion; pe, peduncle; $r$, rostrum; $v$, secretory vesicles; vp, vestigial polypide. 

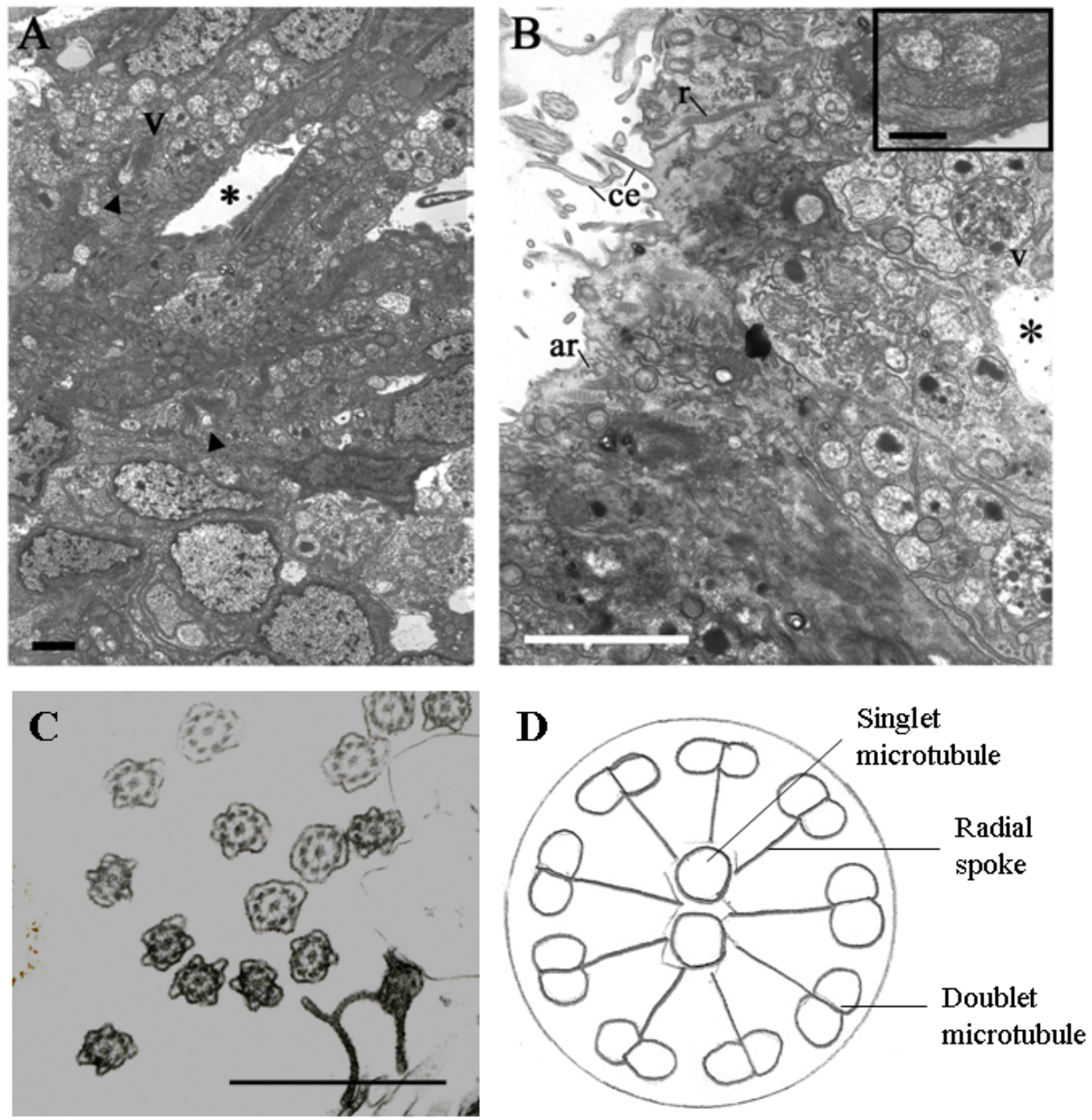

Figure 3.5. TEM of the avicularium of Bugula flabellata in longitudinal section. (A) Median region of the cells from the vestigial polypide with numerous granular secretory vesicles closely associated with a lacuna $(*)$. The numerous and well developed Golgi apparatus are responsible for vesicle formation (arrow heads). Scale bar, $1 \mu \mathrm{m}$; (B) Ciliated and unciliated cells that comprise the vestigial polypide. The constituent organelles are organised in a pseudostratified arrangement. The cell surface possesses numerous cellular extensions. Scale bar, $1 \mu \mathrm{m}$; Insert, secretory vesicle formation. Scale bar, $0.5 \mu \mathrm{m}$; (C) Cross-section of cilia with $9 \times 2+2$ microtubule arrangement. Scale bar, $1 \mu \mathrm{m}$; (D) Diagram of the main components of a cilium in cross-section. ar, agranular reticulum; ce, cellular extensions; r, ciliary rootlet; v, secretory vesicles. 


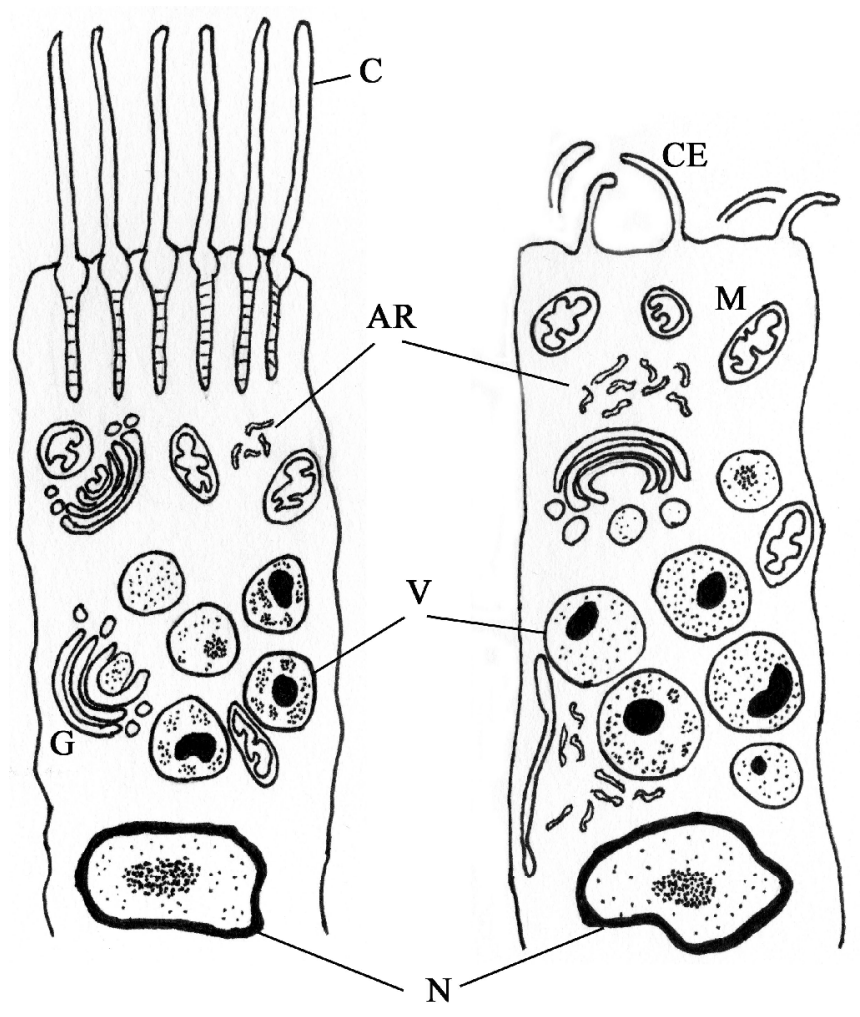

Figure 3.6. Diagram of a ciliated (Left) and unciliated (Right) cell of the vestigial polypide of the avicularium from Bugula flabellata. AR, agranular reticulum; C, cilia; CE, cellular extensions; G, Golgi apparatus; M, mitochondria; N, nuclei; V, granular secretory vesicles.
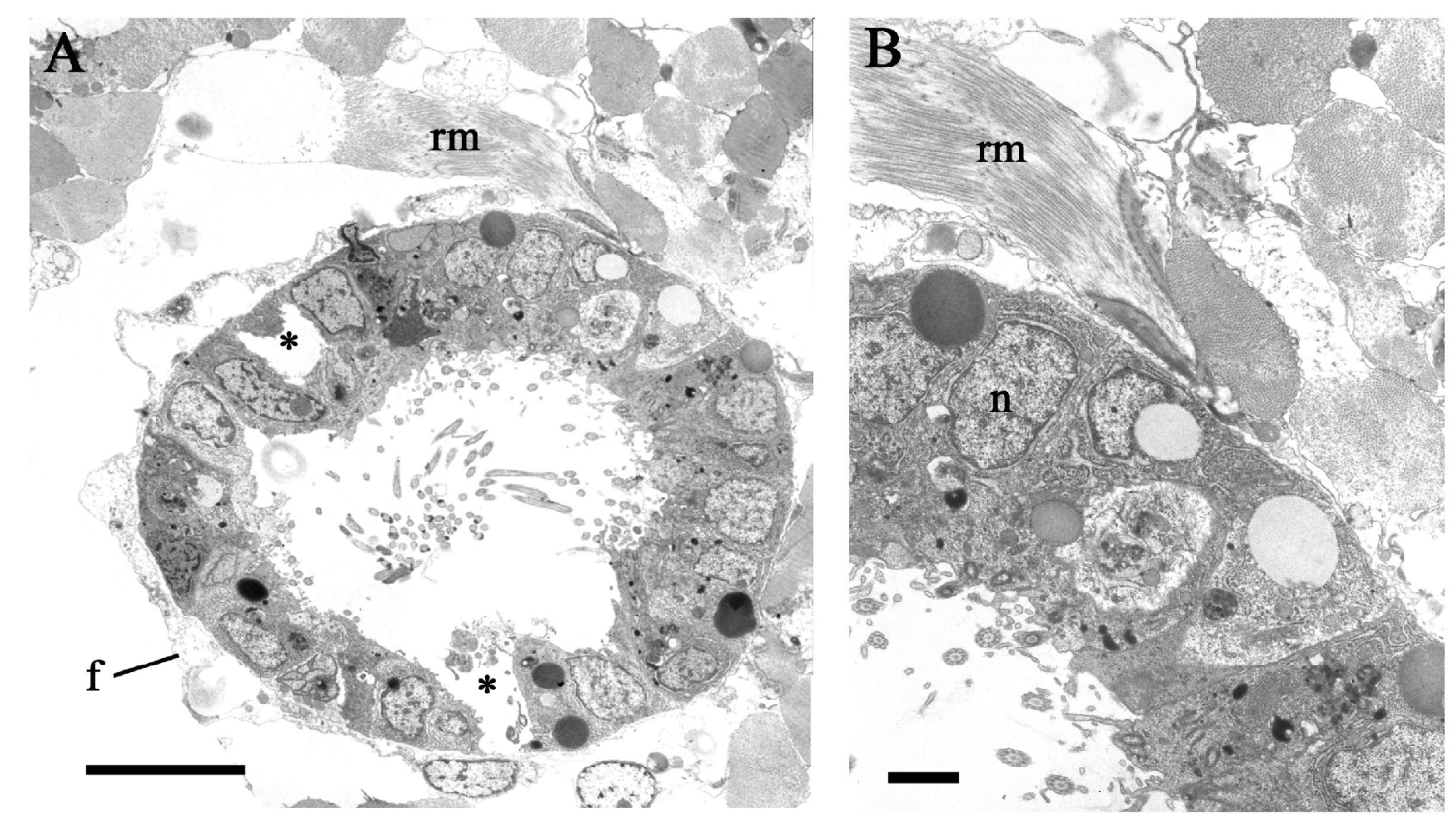

Figure 3.7. TEM of the avicularium of Bugula flabellata. (A) Transverse section of the vestigial polypide showing basal nuclei, central cilia, lacuna $(*)$, retractor muscle and funicular system. Scale bar, $5 \mu \mathrm{m}$; (B) Retractor muscle and portion of vestigial polypide from (A). Scale bar, 1 $\mu \mathrm{m}$. f, funicular system; $\mathrm{n}$, nucleus; rm, retractor muscle. 


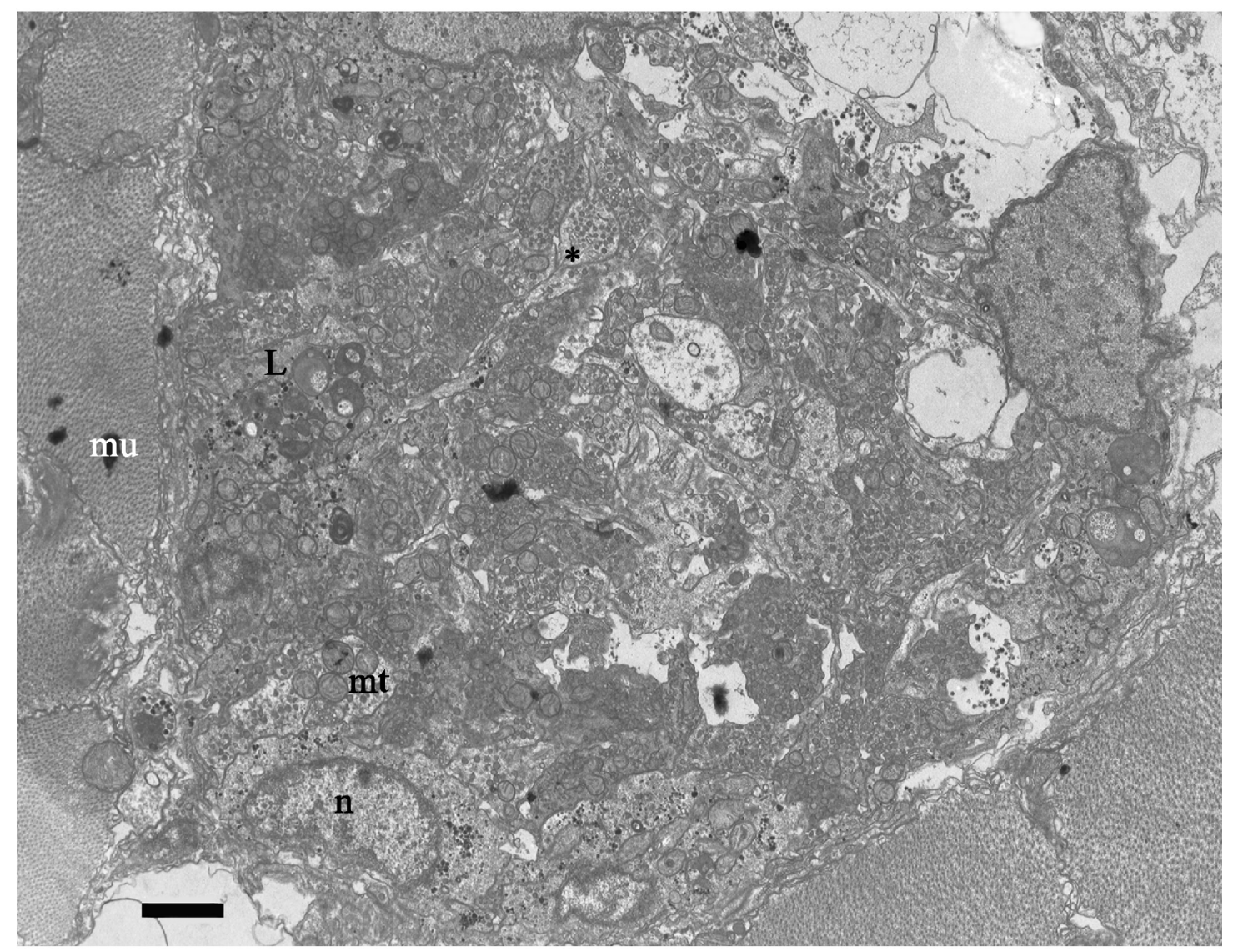

Figure 3.8. TEM of the cerebral ganglion from the avicularium of Bugula flabellata in transverse plane of section. Scale bar, $1 \mu \mathrm{m}$. L, lysosomes; mt, mitochondria; mu, muscle; $\mathrm{n}$, nucleus; asterisk, neurovesicles cell. 
Chapter 3 TEM study on the avicularia from two bugulids
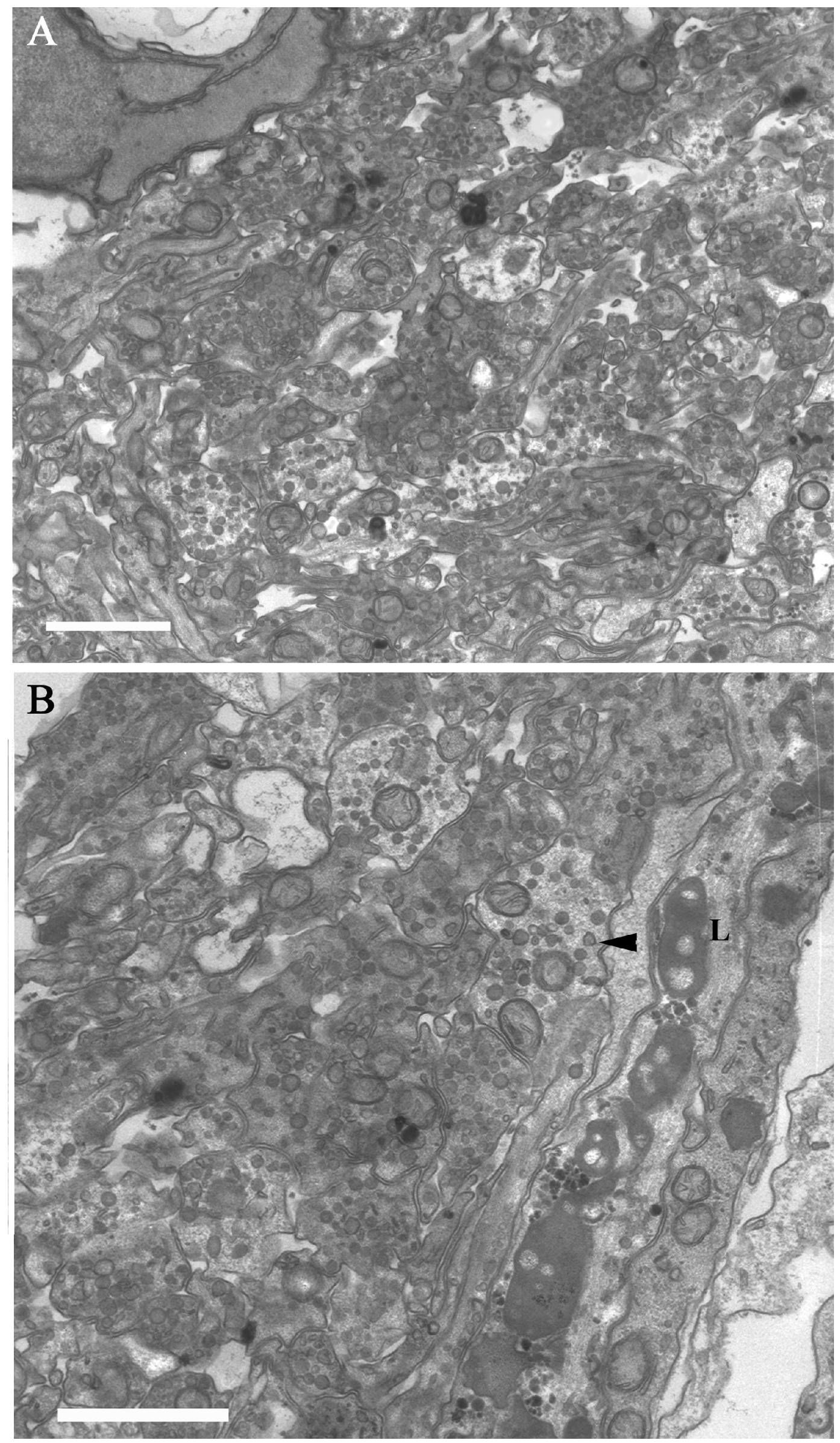
Figure 3.9 (Previous page). TEM of the cerebral ganglion from the avicularium of Bugula flabellata in transverse plane of section. (A) Axonal cells and electron-dense neurosecretory vesicles. Scale bar, $1 \mu \mathrm{m}$; (B) Axonal cells with electron-dense neurosecretory vesicles (Arrow head). Scale bar, $1 \mu \mathrm{m}$. L, lysosomes.

A funicular system (nutrient transport system) originating from the parental autozooid extends through the peduncle cushion and peduncle and surrounds the vestigial polypide (Figure 3.10A). The funicular system contains evidence of semidegraded organelles (Figure 3.10B). The funicular system diverges at the vestigial polypide and continue towards the calcified bar at the rostrum. There is a very narrow constriction where this bar of the rostrum and the palatal surface meet (Figure 3.10C). Here the funicular system constricts and emerges into the rostrum and encapsulates a spherical body of uncertain function (Figures 3.10C, D). This spherical body is approximately $4.4 \mu \mathrm{m}$ in diameter and lies alongside the calcified bar (Figures 3.11AD). The spherical body contains material that resembles degraded organelles and cellular particles (Figures 3.11E, F). The funicular system extends from this spherical body and continues towards cells located distally and basally of the rostrum which contain a mucous-like substance (Figures 3.12A, B).

The peduncle cushion, upon which the peduncle or stalk rotates (Figure 3.13A) contains an electron-dense region in the centre. This electron-dense region is surrounded by a layer of epithelium and a small number of bacteria ( 7 in $31.5 \mu \mathrm{m}^{-2}$ (Figure 3.13B). 

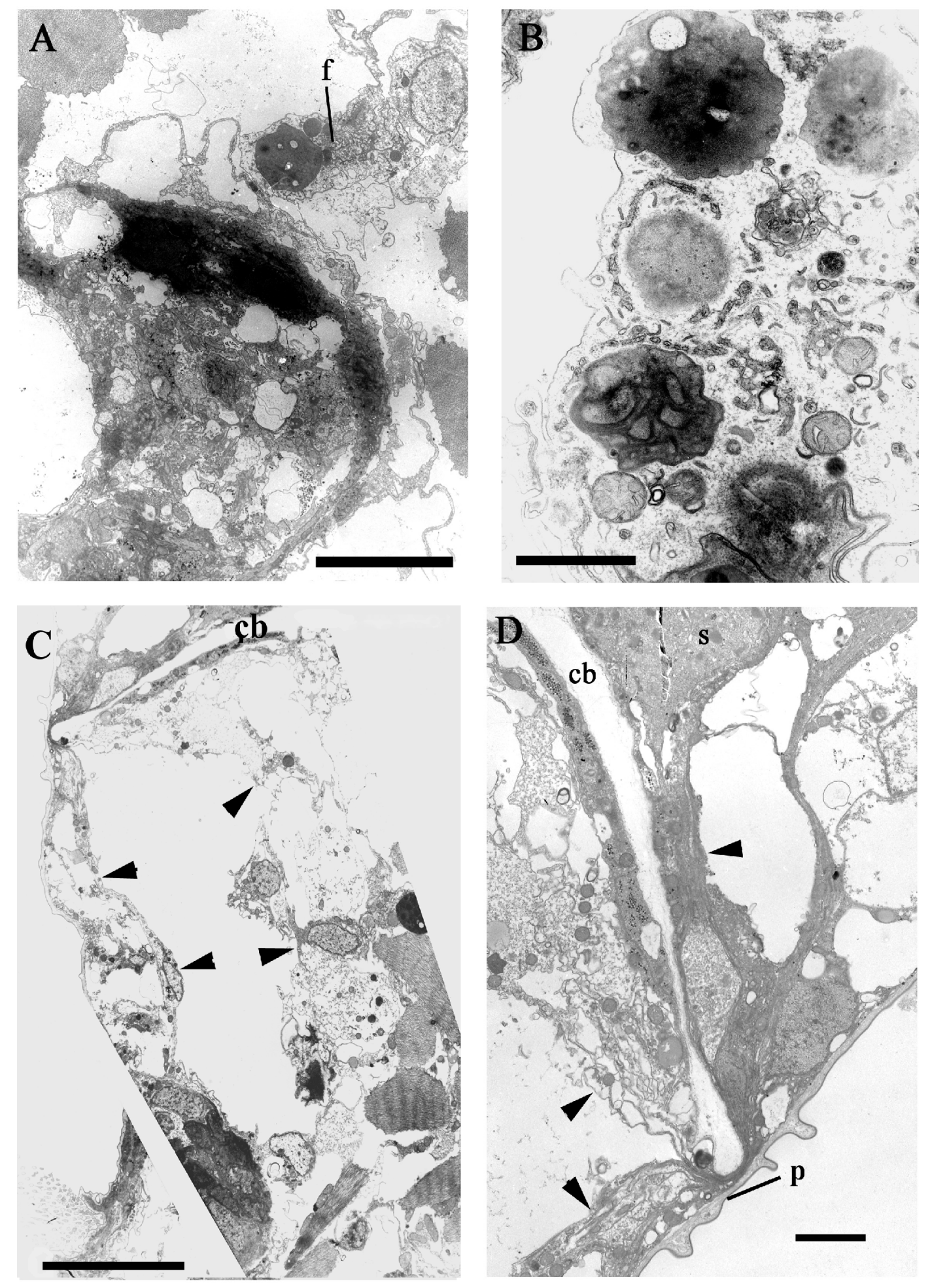

Figure 3.10. Transmission electron micrographs of the avicularium of Bugula flabellata. (A) Funicular system encasing the vestigial polypide. Scale bar, $5 \mu \mathrm{m}$; (B) Funicular system containing degraded organelles. Scale bar, $1 \mu \mathrm{m}$; (C) Funicular system extending from the vestigial polypide to the rostrum though a constriction at the calcified bar of the rostrum (Arrows) (see Figure 3.11 for detail of the calcified bar). Scale bar, $10 \mu \mathrm{m}$; (D) Narrow constriction between the palate and calcified bar of the rostrum where the funicular system (Arrows) enters from the vestigial polypide and surrounds a spherical body. Scale bar, $2 \mu \mathrm{m} . \mathrm{cb}$, calcified bar; f, funicular system; $p$, palate; s, spherical body. 
Chapter 3 TEM study on the avicularia from two bugulids
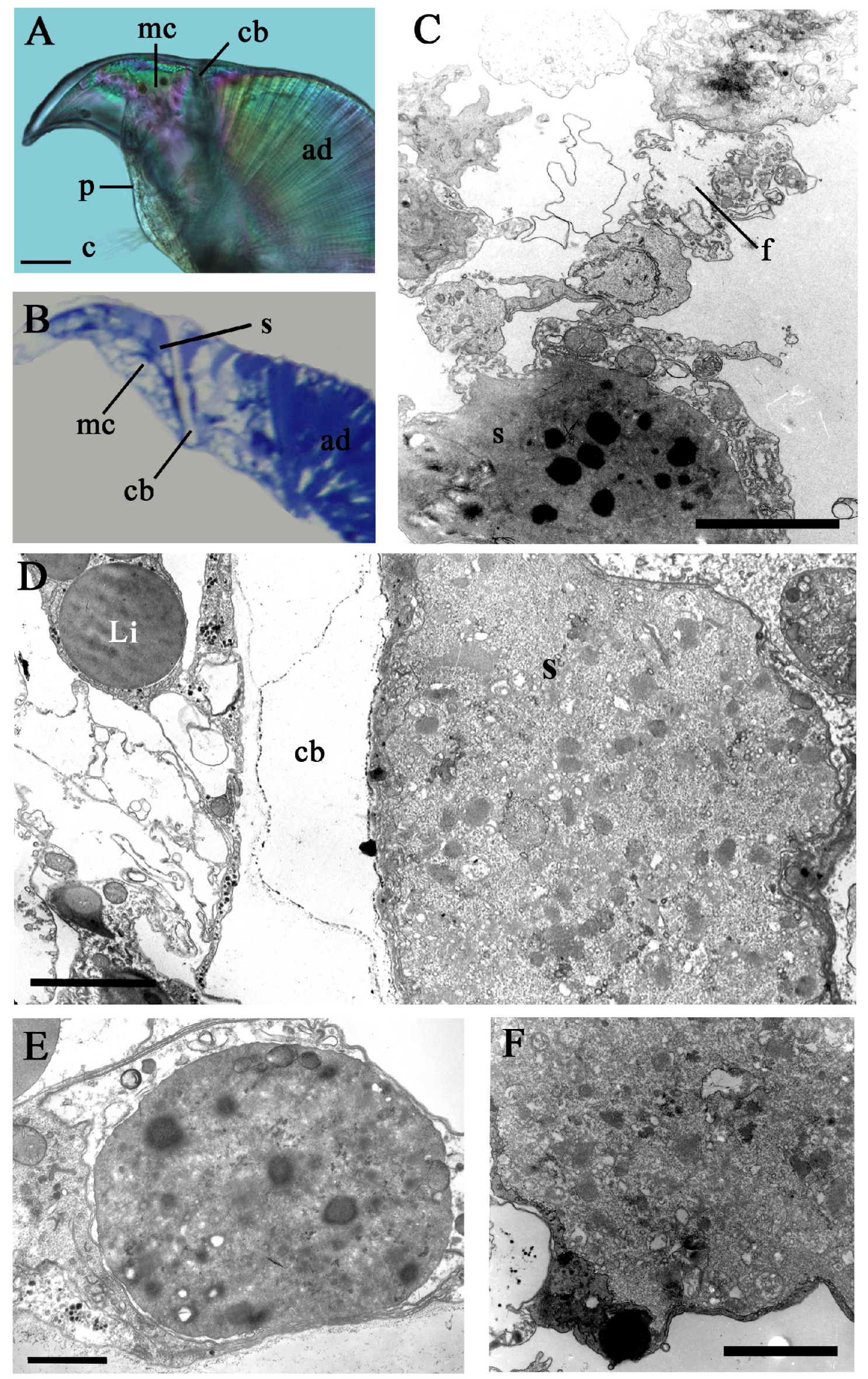
Figure 3.11 (Previous page). Avicularium of Bugula flabellata. (A) Differential Interference Contrast (DIC) of the distal region of an avicularium in lateral view. Scale bar, $25 \mu \mathrm{m}$; (B) $1 \mu \mathrm{m}$ thick resin embedded section of the rostrum stained with Toluidine Blue. Longitudinal plane and in lateral view; (C) Transmission electron micrograph of the funicular system encasing the spherical body in the rostrum. Scale bar, $2 \mu \mathrm{m}$; (D) Transmission electron micrograph of the spherical body in the rostrum. Scale bar, $2 \mu \mathrm{m}$; (E) Transmission electron micrograph of the spherical body in the rostrum showing degraded organelles and the funicular system surrounding it. Scale bar, $1 \mu \mathrm{m}$; (F) Transmission electron micrograph of the spherical body in the rostrum showing degraded organelles. Scale bar, $2 \mu \mathrm{m}$. ad, adductor muscles; c, cilia; cb, calcified bar; f, funicular; Li, lipid; mc, mucous cells; $p$, palate; s, spherical body.

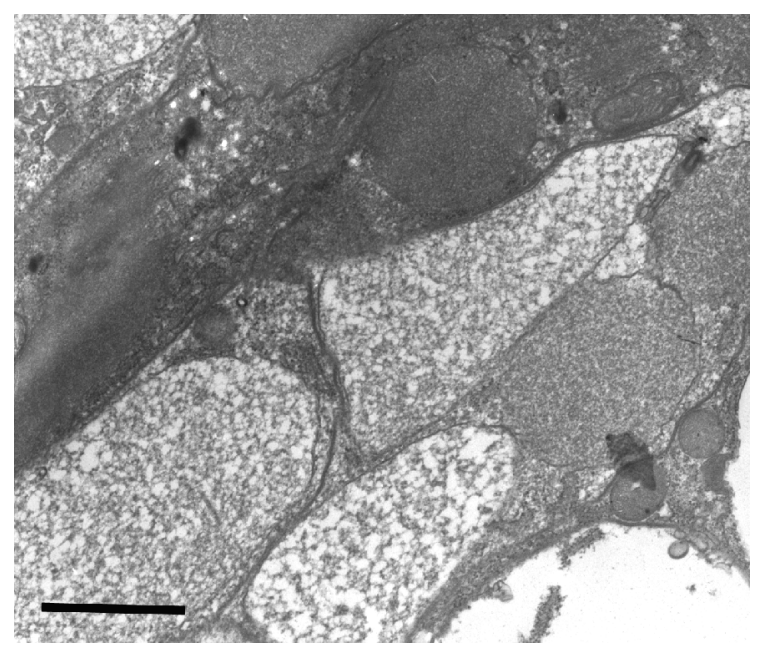

Figure 3.12. Transmission electron micrograph of the mucous cells in the rostrum. Scale bar, 1 $\mu \mathrm{m}$.
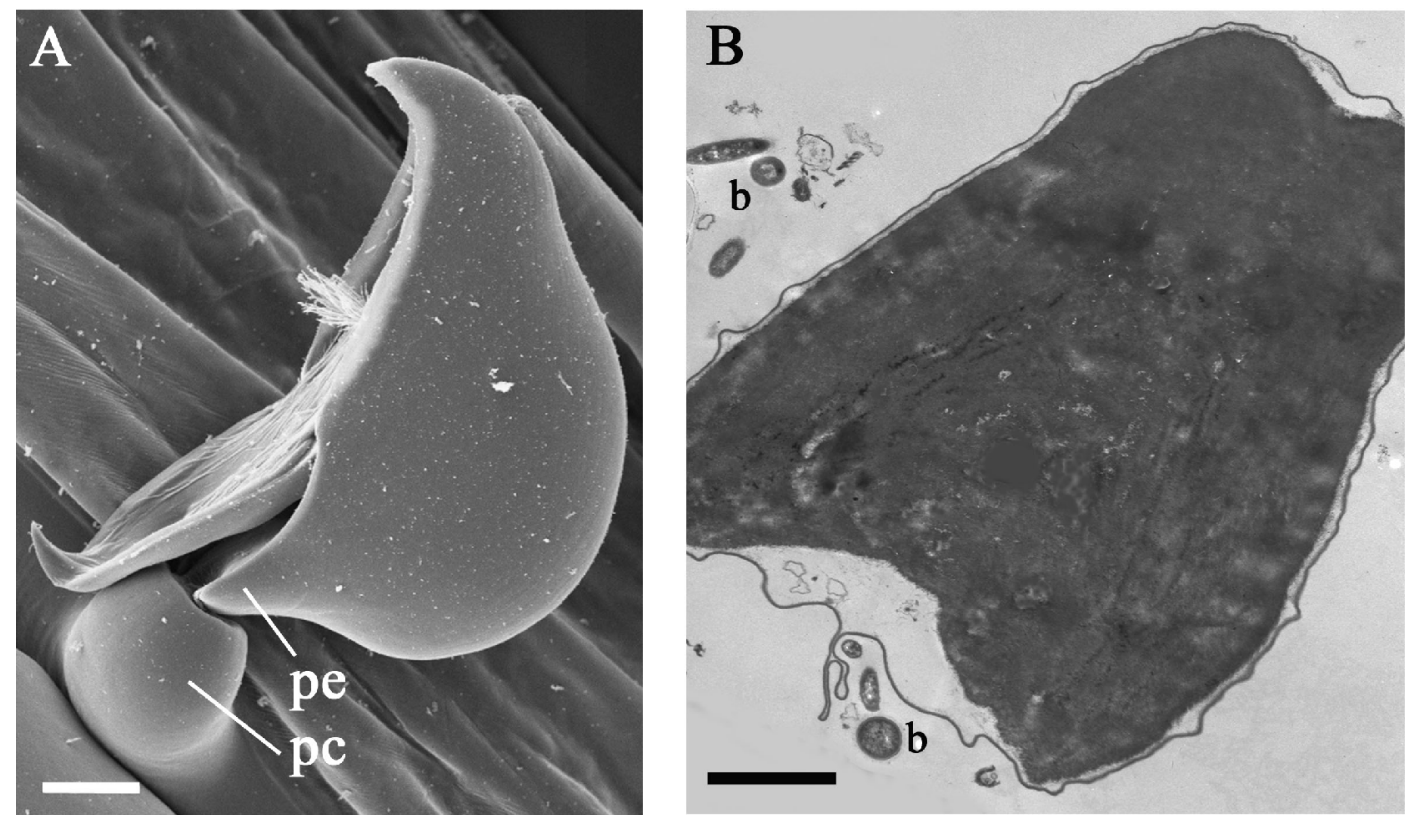

Figure 3.13. Avicularium of Bugula flabellata. (A) Scanning electron micrograph in lateral view. Scale bar, $20 \mu \mathrm{m}$; (B) Transmission electron micrograph of the peduncle cushion with an electron-dense area surrounded by an epithelium and bacteria. Scale bar, $2 \mu \mathrm{m}$. b, bacteria; pc, peduncle cushion; pe, peduncle. 
A

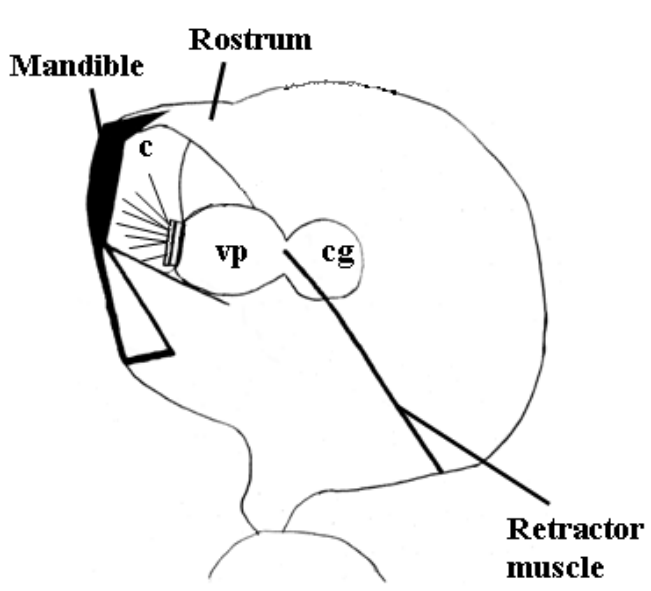

B

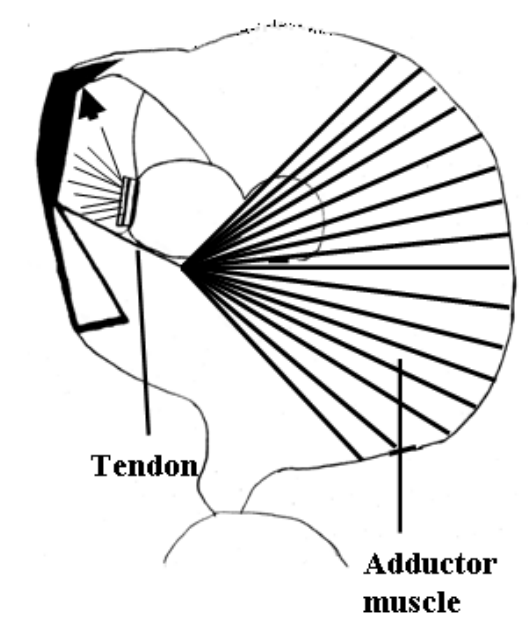

$\mathbf{C}$

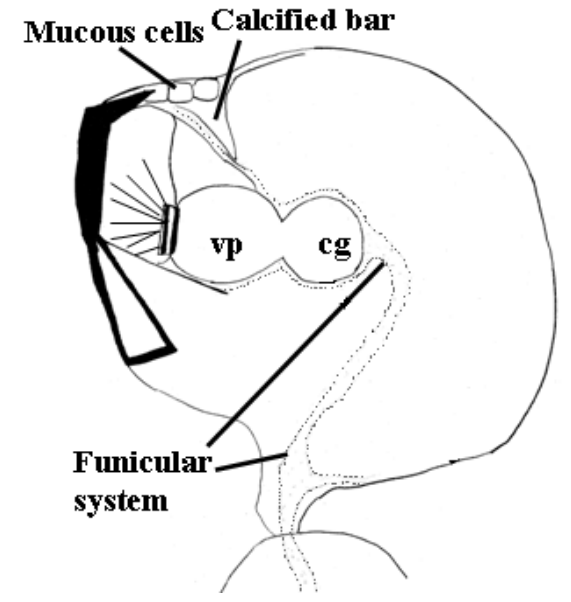

Figure 3.1.4. Diagrammatic representation of a bird's-head avicularium of Bugula flabellata in lateral view. (A) The retractor muscle inserts at the central constriction of the vestigial polypide; (B) The adductor muscle and tendon inserting into the mandible. Arrow, indicates the lacuna where the hook of the mandible inserts into the rostrum; (C) The funicular system originating from the parental autozooid extends up the avicularium and surrounds the vestigial polypide. The funicular system extends from the vestigial polypide and through the constriction of the calcified bar and into the rostrum where the mucous cells are located. c, cilia; cg, cerebral ganglion; vp, vestigial polypide. Scale bar, $50 \mu \mathrm{m}$.

\subsubsection{Nordgaardia cornucopioides}

Each autozooid has one or two avicularia arising either proximal to the opesia (frontal surface) or on the basal wall surfaces. The avicularia are tubular overall in morphology with the subrostral chamber extended to such an extent that it resembles a stalk, or extended peduncle. Terminally, the rostrum is beaked, and when closed, the mandible slots into the extended rim of this beak (Figures 3.15A, 3.16A). The peduncle base is derived from the autozooid extending approximately $200 \mu \mathrm{m}$ from the colony surface. The transition between the peduncle base and peduncle of the avicularium is 
continual; however, a point of demarcation can be located (Figures 3.15A, B). In the parent autozooid, two sets of muscle fibres attach from the wall of the autozooid to the peduncle base (Figure 3.16B). Colonies were observed briefly following collection under a dissecting microscope. In contrast to the characteristic rapid swinging to and fro of the avicularia of $B$. flabellata, the avicularia of $N$. cornucopioides appeared to sway over the colony in a gentle motion.
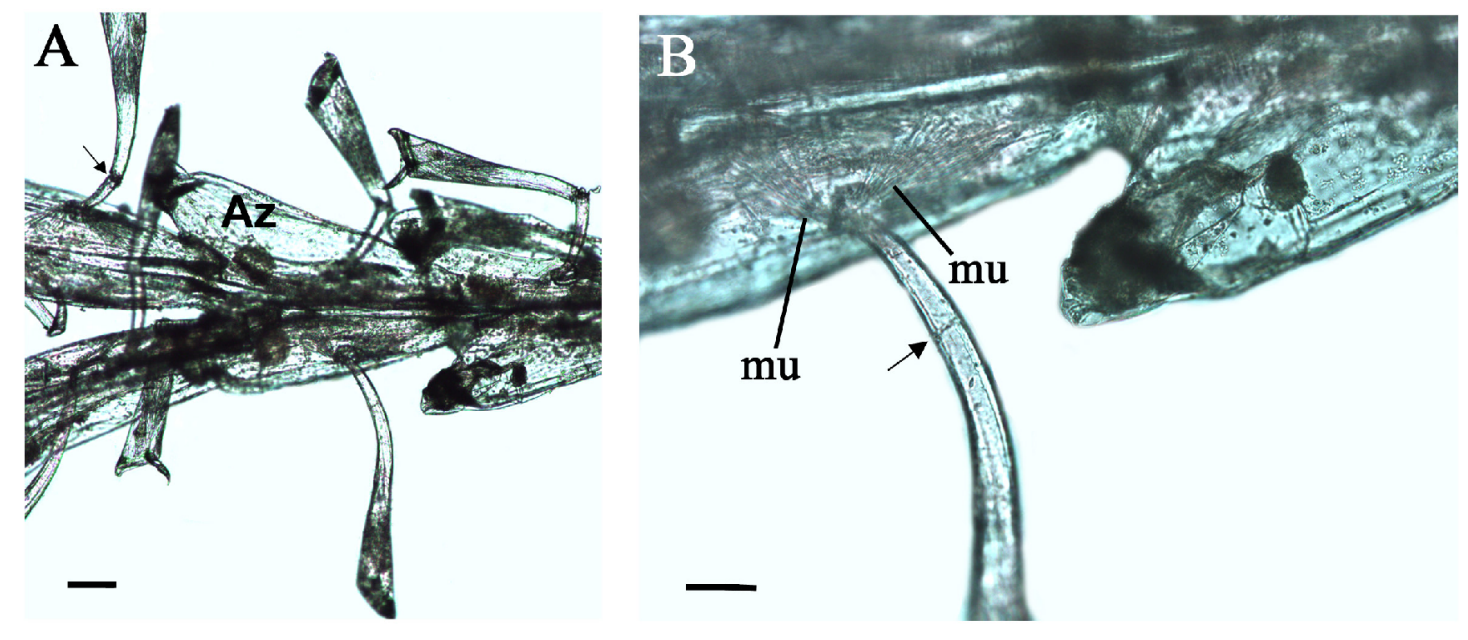

Figure 3.15. Photomicrographs of Nordgaardia cornucopioides. (A) Autozooids and avicularia. The point of demarcation between the peduncle cushion, or base, and peduncle of the avicularium is annotated with an arrow. Scale bar $200 \mu \mathrm{m}$; (B) Peduncle and peduncle base (Arrow indicates point of demarcation between the two) of an avicularium illustrating the muscle attachment from the autozooid wall inserting into the peduncle base. Scale bar $100 \mu \mathrm{m}$. $\mathrm{Az}$, autozooid; mu, muscle.

The vestigial polypide of $N$. cornucopioides is located basally in the avicularian cystid and is bulbous and slightly elongated (Figures 3.16A-C, 3.17A, B). The palate of the avicularium is submerged and the palatal membrane then extends into the avicularium and encases the vestigial polypide (Figure 3.17D). This vestigial polypide sheath is hypertrophied into glandular cells containing secretory vesicles which are released into a vestibule. The vestibule is continual with the avicularian orifice and therefore the external environment (Figures 3.17B, C, 3.18B). This glandular region of the vestigial polypide encases a single vestigial tentacle which is terminated distally by numerous ciliated cells containing basal nuclei and very few organelles. The cilia possess long ( $\sim \mu \mathrm{m}$; Mean, $4.1 \mu \mathrm{m} ; \mathrm{N}=4)$ slender rootlets and a $9 \times 2+2$ microtubule arrangement. The cilia extend into the vestibule and are in close association with the glandular secretions (Figures 3.18C, 3.19A-C). 
The vestigial tentacle possesses a basement membrane comprising of collagen fibres upon which a series of smooth muscles attach on the internal surface. The basement membrane can be either elongated (Figure 3.17B) or convoluted (Figures $3.18 \mathrm{D}, \mathrm{E})$. On the outer surface of the basement membrane, and covering the vestigial tentacle, is a layer of microvilli and glycocalyx. This microvilli-glycocalyx border opposes the glandular cells and is therefore in contact with the glandular secretions. The glandular cells and the cell surface of the vestigial tentacle eventually connect at the base of the vestigial tentacle (Figure 3.18D).

The basement membrane extends to encase the cerebral ganglion which is located at the base of the vestigial polypide (Figure 3.20A). The retractor muscle attaches to the basement membrane surrounding the cerebral ganglion (Figures 3.20A, B). The ganglion is spherical and roughly $6 \mu \mathrm{m}$ in diameter with numerous axonal cells rich with neurosecretory vesicles (Figures 3.20B, C). There are two types of neurosecretory vesicles, smaller agranular vesicles $(\sim 50 \mathrm{~nm}$ in diameter) and larger electron-dense double membrane-bound vesicles $(\sim 75-100 \mathrm{~nm}$ in diameter) (Figure 3.20C).
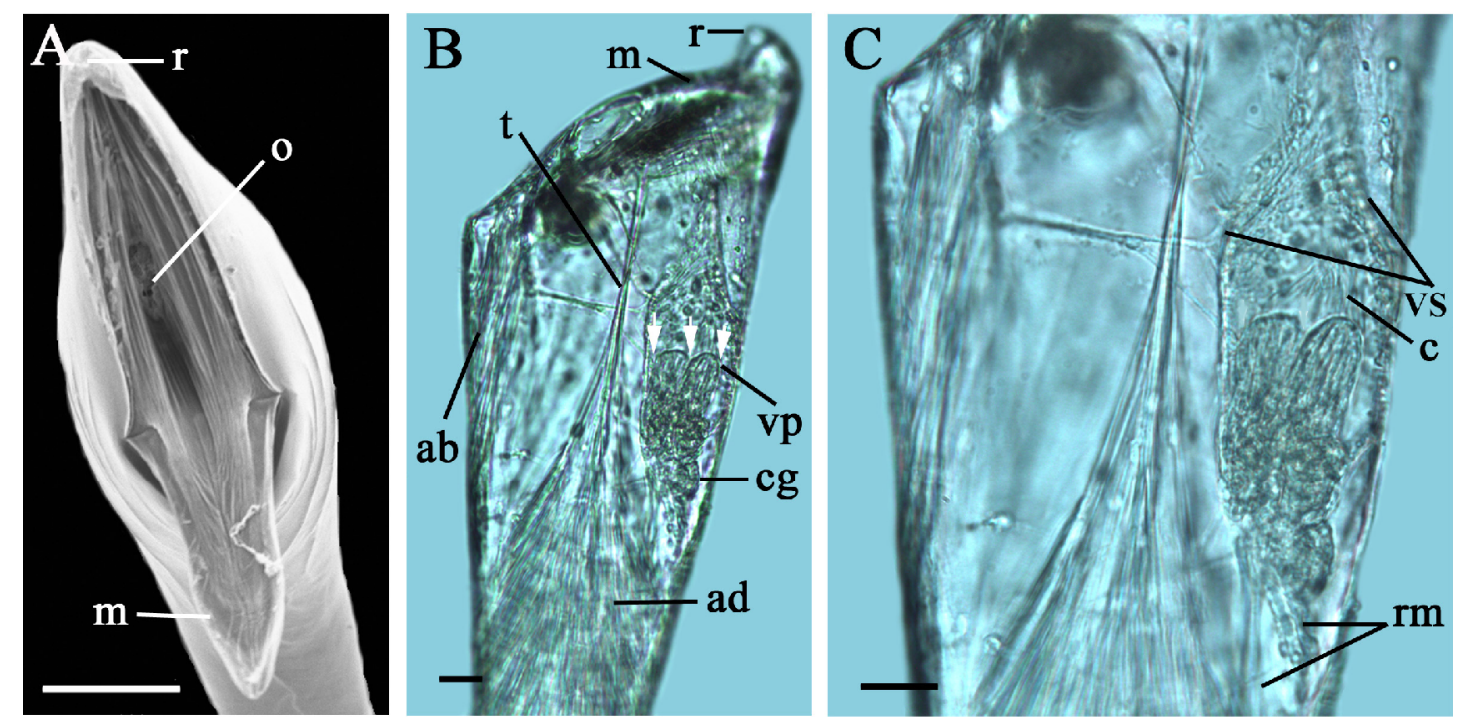

Figure 3.16. Avicularium of Nordgaardia cornucopioides. (A) SEM in frontal view. Scale bar $50 \mu \mathrm{m}$; (B) Photomicrograph illustrating the vestigial polypide and associated muscles in lateral view. The white arrows highlight the undulations in the glandular cells that are represented in Figure 3.17B. Scale bar $16 \mu \mathrm{m}$; (C) Photomicrograph illustrating the vestigial polypide and retractor muscles in lateral view. Scale bar $16 \mu \mathrm{m}$. ab, abductor muscle; ad, adductor muscle; c, cilia; cg, cerebral ganglion; $\mathrm{m}$, mandible; $\mathrm{o}$, orifice; $r$, rostrum; rm, retractor muscle; $t$, tendon; vp, vestigial polypide; vs, vestigial polypide sheath. 

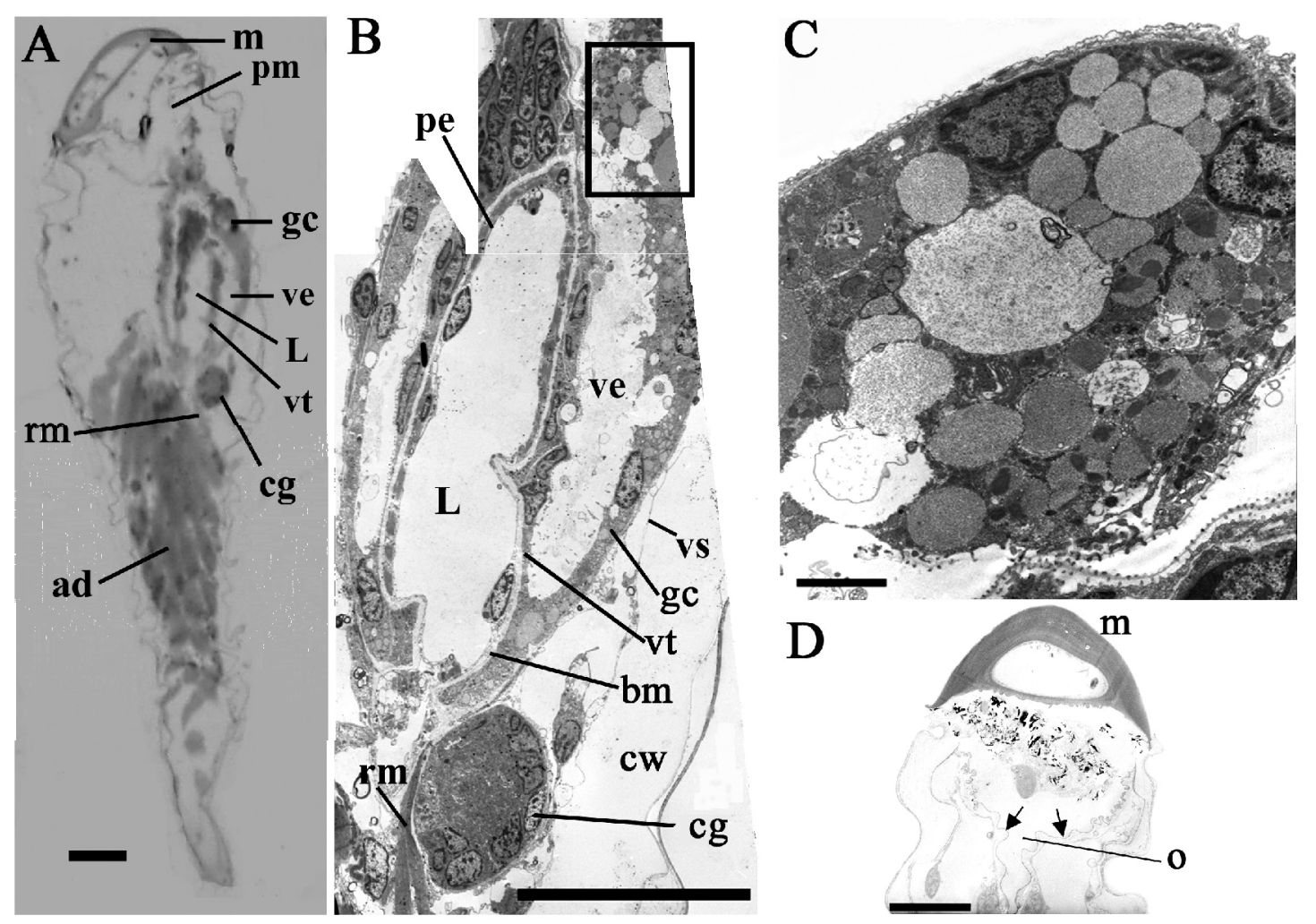

Figure 3.17. Avicularium of Nordgaardia cornucopioides. (A) $1 \mu \mathrm{m}$ thick resin-embedded, longitudinal section stained with Toluidine Blue. Scale bar $10 \mu \mathrm{m}$; (B) TEM of the vestigial polypide from (A). Scale bar $10 \mu \mathrm{m}$; (C) Area of the glandular cells as indicated by the square in (B) containing numerous secretory vesicles the contents of which are released into the vestibule between the glandular region and vestigial tentacle. Scale bar $2 \mu \mathrm{m}$; (D) TEM of the mandible area in longitudinal plane through the frontal surface. Arrows indicate the palatal membrane. Scale bar $10 \mu \mathrm{m}$. ad, adductor muscle; bm, basement membrane; cg, cerebral ganglion; cw, calcified wall; gc, glandular cells; L, lumen of vestigial tentacle; m, mandible; o, orifice; pe, peritoneal layer; pm, palatal membrane; rm, retractor muscle; ve, vestibule; vs, vestigial polypide sheath; vt, vestigial tentacle. 

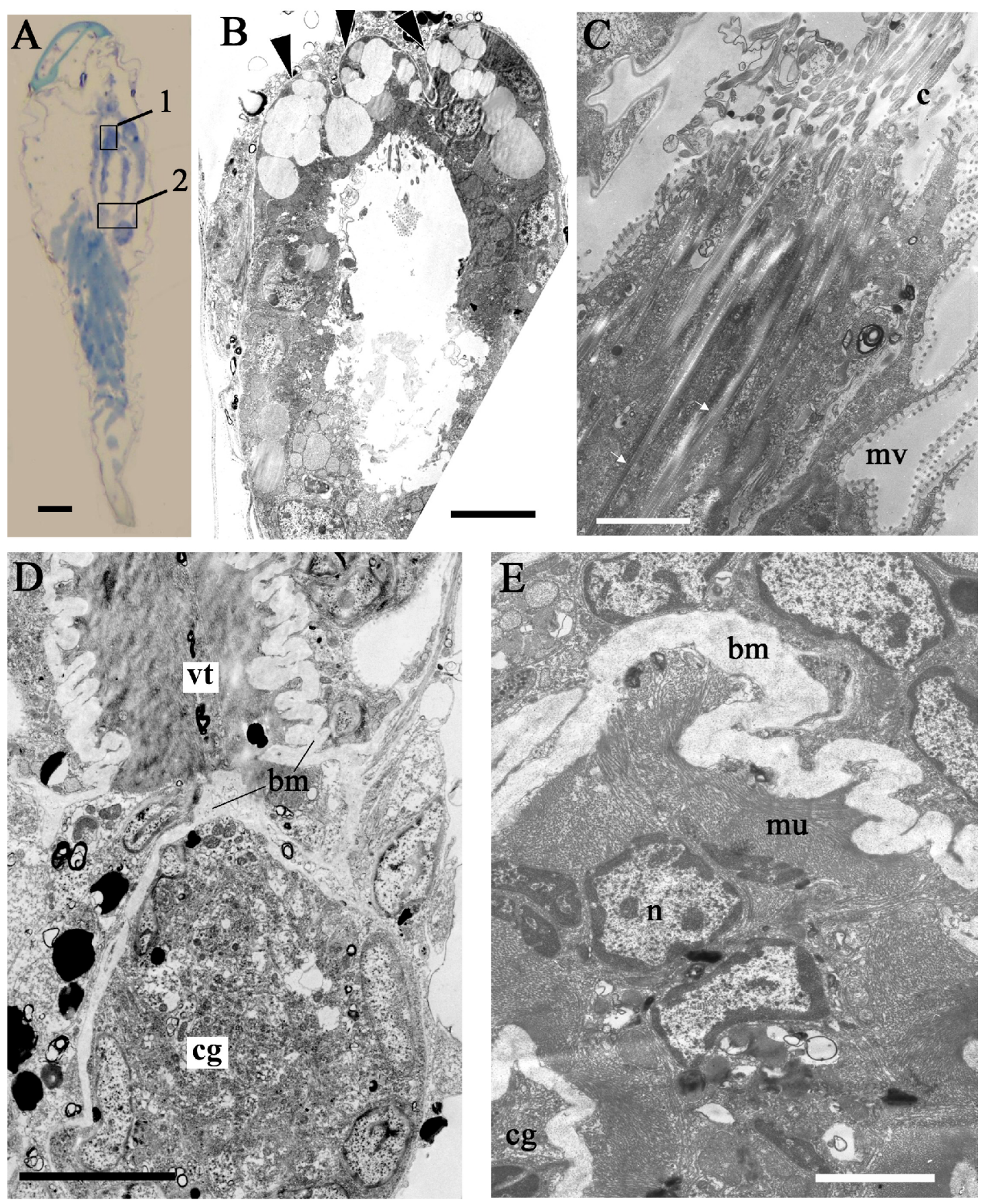

Figure 3.18. Avicularium of Nordgaardia cornucopioides. (A) $1 \mu \mathrm{m}$ thick resin-embedded, longitudinal section stained with Toluidine Blue. The boxes numbered $1 \& 2$ represent regions examined by TEM in (C) and (D). Scale bar $10 \mu \mathrm{m}$; (B) TEM of a longitudinal section through the vestigial polypide revealing the glandular cells only. The arrows represent the undulations shown in Figure 3.16B. Scale bar $5 \mu \mathrm{m}$; (C) TEM of the distal ciliated cells of the vestigial tentacle as indicated by box 1 in (A). Scale bar $2 \mu \mathrm{m}$; (D) TEM of box 2 from (A) showing the base of the vestigial tentacle and cerebral ganglion. The glandular cells and the cells of the vestigial tentacle meet at the base of the vestigial polypide. An extensive convoluted basement membrane separates the internal muscles and the cells of the vestigial tentacle on the outside surface of the membrane. Scale bar $5 \mu \mathrm{m}$; (E) TEM of the muscles that line the internal surface of the basement membrane. Scale bar $2 \mu \mathrm{m}$. bm, basement membrane; c, cilia; cg, cerebral ganglion; mu, muscle; mv, microvilli; $\mathrm{n}$, nucleus; vt, vestigial tentacle. 
A
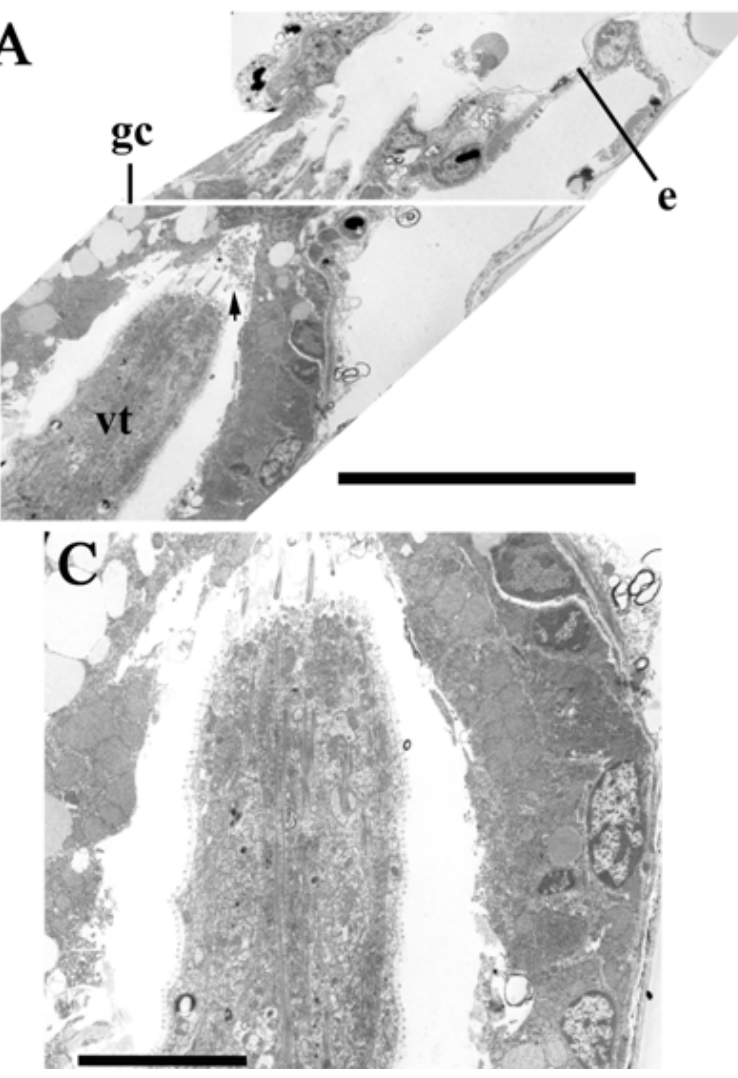

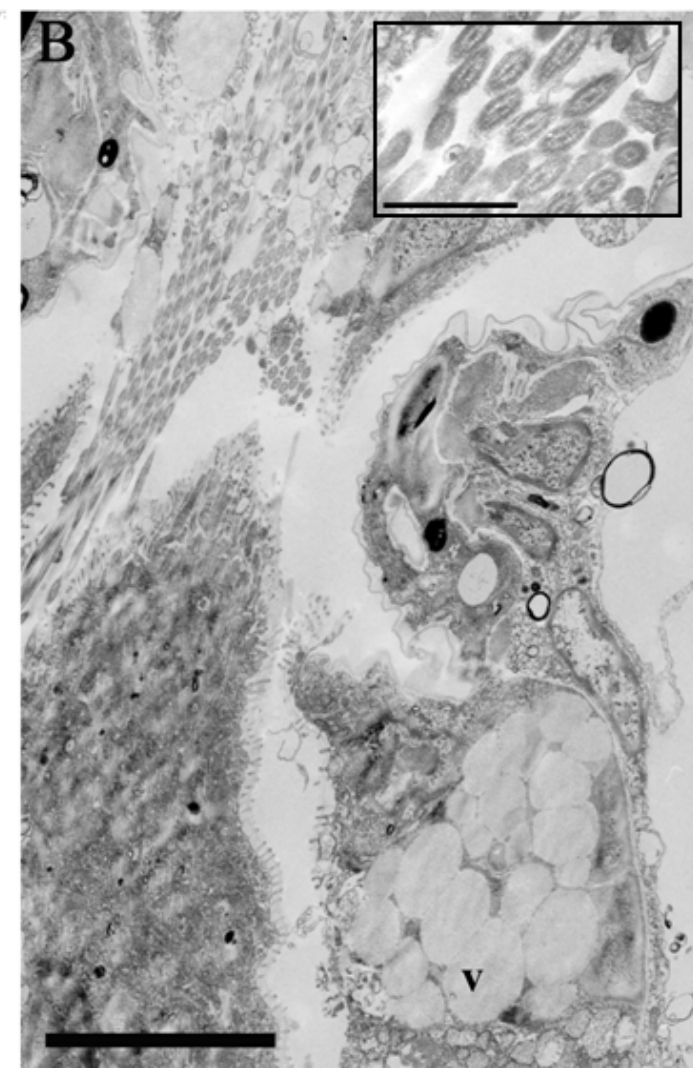

Figure 3.19. TEM of the vestigial polypide of the avicularium of Nordgaardia cornucopioides. (A) Distal area of vestigial polypide with glandular cells and vestigial tentacle with microvilliglycocalyx border and terminal cilia (Arrow). The palatal membrane extends from the palate of the avicularium and extends to form a sheath that encases the vestigial polypide. Scale bar 20 $\mu \mathrm{m}$; (B) Distal area of vestigial tentacle with microvilli-glycocalyx border and cilia in close association with the glandular secretions. Scale bar $5 \mu \mathrm{m}$. Insert, cross-section of cilia. Scale bar $1 \mu \mathrm{m}$; (C) Vestigial tentacle in the vestibule surrounded by glandular cells. Scale bar $5 \mu \mathrm{m}$. pm, palatal membrane; gc, glandular cells; ve, vestibule; vt, vestigial tentacle; v, secretory vesicles. 
Chapter 3 TEM study on the avicularia from two bugulids
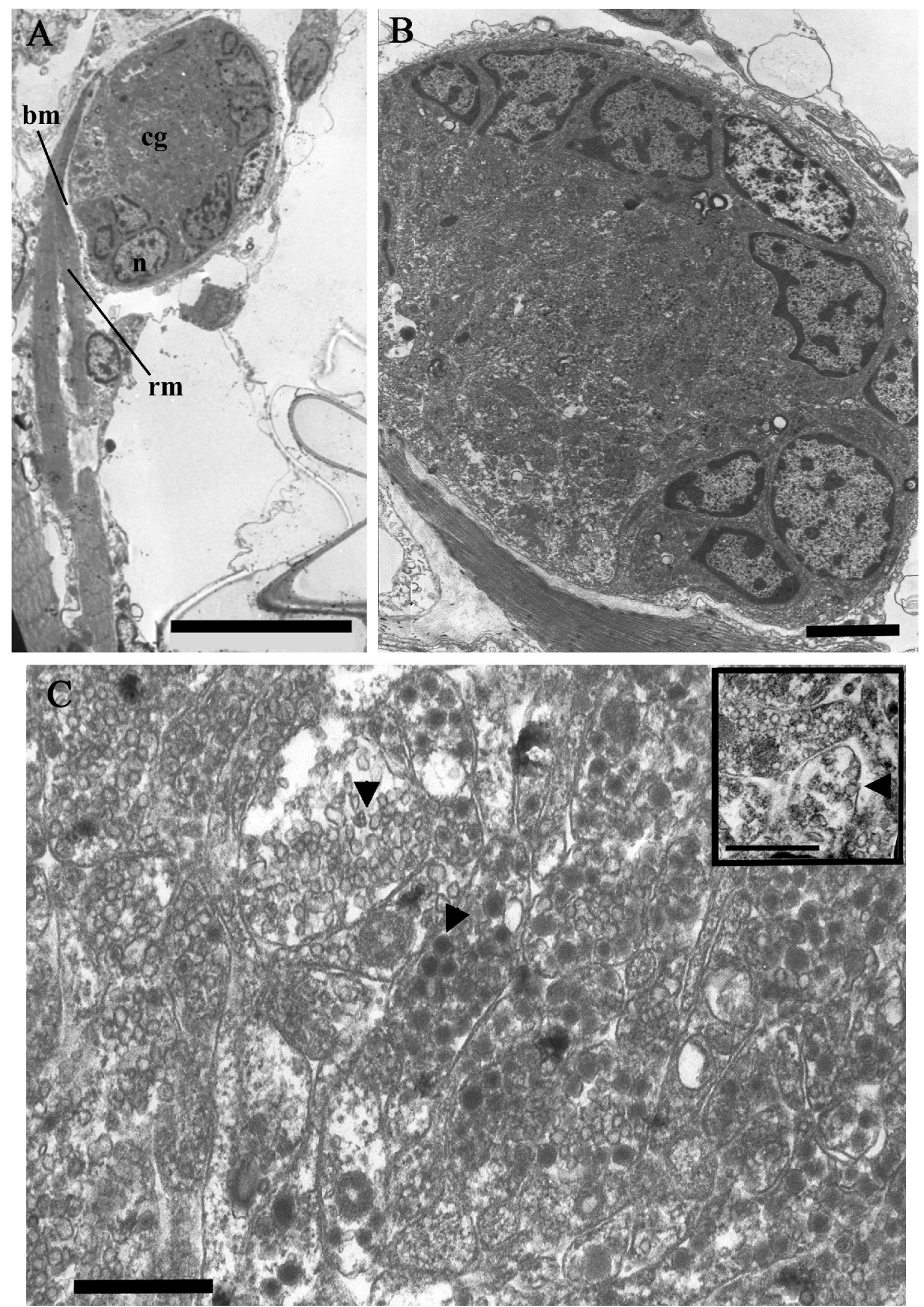

Figure 3.20. Transmission electron micrographs of the cerebral ganglion of Nordgaardia cornucopioides. (A) Cerebral ganglion with basal nuclei and a retractor muscle inserting onto the surrounding basement membrane. Scale bar $20 \mu \mathrm{m}$; (B) Retractor muscle and cerebral ganglion. Scale bar $2 \mu \mathrm{m}$; (C) Axonal cells with agranular and electron dense neurosecretory vesicles (Arrows). Scale bar $500 \mathrm{~nm}$. Insert, excytosis of a neurosecretory vesicle. Scale bar, $500 \mathrm{~nm}$. bm, basement membrane; cg, cerebral ganglion; $\mathrm{n}$, nucleus; rm, retractor muscle. 


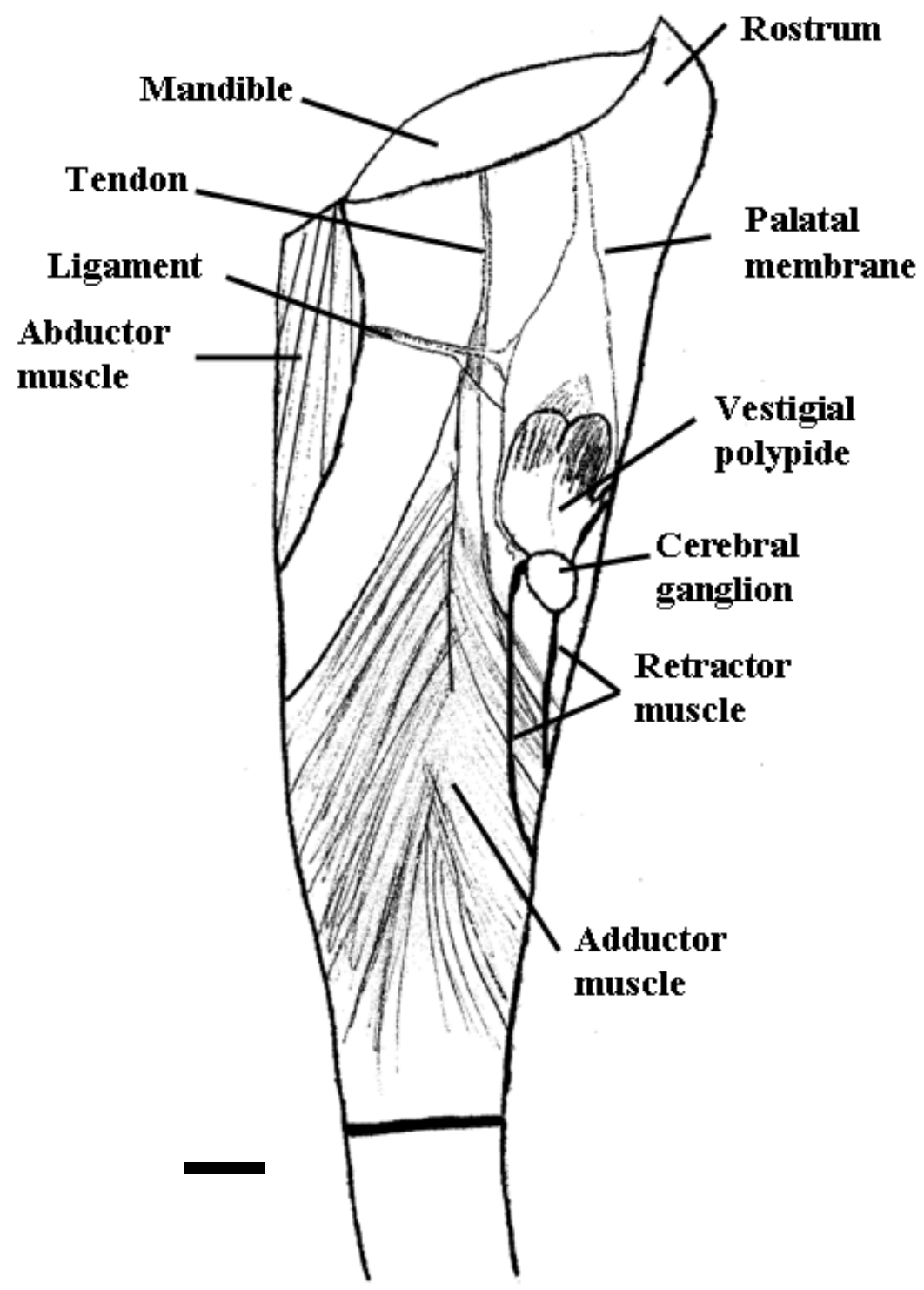

Figure 3.21. Diagrammatic representation of an avicularium from Nordgaardia cornucopioides in lateral view. Scale bar $20 \mu \mathrm{m}$. 
Table 3.2. Comparative ultrastructural and behavioural characteristics of the avicularia of Bugula flabellata and Nordgaardia cornucopioides.

Characteristics

\section{Bugula flabellata}

\section{Nordgaardia cornucopioides}

\section{$\underline{\text { Biology }}$}

Highly derived, mass of cells

Mechanoreceptor

Primary

receptor/sensory

function

Secretory capacity

Cilia

Adductor muscle

Granular vesicles in mucous vesicles in rostrum

Extend into external environment, $9 \times 2+2$ microtubule arrangement, $\sim 2 \mu \mathrm{m}$ long and flexible rootlets vestigial polypide and

\section{Condensed but extensive within the avicularian cystid for rapid and immediate closure of the mandible} ganglionsecretory vesicles

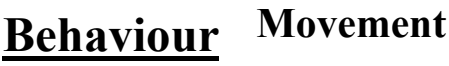

Less derived, comprising vestigial tentacle and large area of glandular cells

Chemoreceptor

Large glandular region comprising secretory vesicles

Internal, 9x2+2 microtubule arrangement, long $(\sim 4 \mu \mathrm{m})$ slender, and straight rootlets

Concentrated in the peduncle. Long tendon to attach to mandible
55-100 nm diameter

$\sim 50 \mathrm{~nm} \& \sim 75-100 \mathrm{~nm}$ in diameter

Active, swings to and fro on peduncle, mandible closes rapidly onto stray organisms
Passive, swings by gentle motion very subtly

\subsection{Discussion}

This is the first known study to examine the ultrastructural anatomy of avicularia and is also the first to conduct an anatomical study on a deep-sea bryozoan. This study found significant differences in the ultrastructural anatomy of the vestigial polypide of 
the avicularium between Nordgaardia cornucopioides and Bugula flabellata (Bugulidae) (Table 3.2). The vestigial polypide of $N$. cornucopioides consists of two cytologically distinct regions. The internal region possesses many characteristics of an autozooid tentacle (Figure 3.16B). The second region comprises an extension of the sheath that encases the vestigial polypide, the cells of which are hypertrophied into a large area of glandular secretory cells that completely encases the vestigial tentacle (Figures $3.17 \mathrm{~B}, \mathrm{C}$ ). In contrast, the vestigial polypide of $B$. flabellata comprises a differentiated mass of cells having little structural form (Figure 3.4D). The differential anatomy in two confamilial species may be due to: (1) environmentally-driven (nondepth related) phenotypic responses to their respective habitats (Ricklefs \& Miles 1994); (2) phylogenetic differences and therefore the anatomical differences represent differing stages of evolutionary development; (3) morphological and physiological divergence as a function of depth (Childress 1995); and/or (4) depth-related differential rates of evolution (Wilson \& Hessler 1987). The arrival of bryozoans into the deep-sea is certainly not recent, with the first deep-sea bryozoans recorded from the Eocene $(\sim 37$ 58 my bp) with Scrupocellaria (Buguloidea) representing one of the earliest inhabitants (Schopf 1969). To identify whether the observed ultrastructural anatomy is a result of either depth-related evolutionary rates, a time-span related split in the lineage (e.g. Bugula flabellata split early on in evolutionary time), or an environmentally-driven difference requires data from molecular phylogeny studies that currently do not exist.

Despite possessing the overall anatomical characteristics of an autozooid (see Lutaud 1973), the vestigial tentacle of $N$. cornucopioides displays modifications in the development of the internal muscles and a highly convoluted arrangement in the basement membrane (Figures 3.18D, E). A possible explanation for the presence of these muscles and convoluted basement membrane is the need for some degree of flexibility in the movement in the tentacle. Contraction and relaxation of the internal muscles may manipulate movement of the basement membrane and thereby stimulate glandular secretion. The extensive convolution of the basement membrane implies a requirement for an increase in surface area or greater flexibility in movement. The presence of the convoluted basement membrane, internal muscles and the attachment of a retractor muscle implies the vestigial polypide is capable of some degree of contraction and extension. Observations on live colonies may provide further insight. 
The glandular cells of $N$. cornucopioides cover a large region of the vestigial polypide and completely encase the vestigial tentacle (Figure 3.17B) and can therefore be considered of particular significance in the function of the avicularium. The secretory vesicles of these glandular cells closely resemble the vesicles found in the periopercular glands of Membranipora membranacea (Hageman \& Lutaud 1982). Glands commonly occur in the autozooids of cheilostome bryozoans and are located in the vestibule and arise as an out-pocket of the tentacle sheath (Hyman 1959; Lutaud 1964). Similar glands have been described in some avicularia through histological sections (Marcus 1939; Lutaud 1964; Figure 1.5 in Chapter 1). The avicularian glands arise from a sheath containing the vestigial polypide and there are interspecific variations in size and shape (Waters 1889; Marcus 1939). The glands contain a protidic or mucoidic substance, the function of which is unknown. The mucous secretions of the autozooids are thought to either coat the everting lophophores and act as a lubricant, or provide a medium for the retention of food particles in the lophophore crown (Lutaud 1964). The function of mucous is to act as a solvent for impinging substances and the maintenance of a constant environment (Farnesi et al. 1982). The function of the mucous-like secretions in $N$. cornucopioides is unclear. The internal cilia of the avicularium are clearly embedded in the glandular secretions (Figure 3.19A) and could therefore be implicated in the translocation of secretions to the external environment. Cilia can have three main functions, namely moving a mucous sheet, providing locomotion, or producing a local water current (Lundin \& Schander 1999, 2001a, b, 2003). Similarly, the location and characteristics of the cilia in the avicularium may offer insight into its functional role and receptive capabilities. Long slender cilia are associated with a water- and mucousmoving function in members of various metazoan phyla (Lundin \& Schander 1999, 2001a). The main characteristics of a chemoreceptor indicate the cilia should be modified but do not contribute to locomotion, or the generation of water currents, and are embedded within the secretion of glandular cells, and protected from mechanical injury (Altner \& Prillinger 1980). The cilia of the avicularium of N. cornucopioides certainly fit these criteria and the next logical step would be to ascertain the chemical constituents of the mucous-like vesicles. The possibility of avicularian-derived chemical defence has been proposed (Marcus 1939; Winston 1984) and should be considered.

Conversely, the vestigial polypide of $B$. flabellata does not possess the extensive glandular region observed in $N$. cornucopioides. Mucous-like vesicles were observed in 
B. flabellata but were located in a different part of the rostrum from the vestigial polypide (Figure 3.12B). Marcus (1939) noted a vestibular epithelium in the rostrum of Bugula ditrupae and actual glands in the rostrum of the sessile bird's-head avicularium of Synnotum aegyptiacum. The rostrum of avicularia is homologous to the outer vestibular region in autozooids (Lutaud 1977a), thus if the vestibular glands were to be retained in the avicularium then it is not surprising they are located in the rostrum in some species. Of the avicularia examined, most appear to have glands located in close proximity to the vestigial polypide (Marcus 1939), as in N. cornucopioides. Lutaud (1977a) examined the nervous system and polypide anatomy of the bird's-head avicularia from Bugula simplex, B. turbinata, and B. flabellata but did not mention the presence of vestibular glands in the rostrum and indicated that the posterior cells of the vestigial polypide had a glandular function and proposed this area as the homologue to a functional gut. Two cytologically distinct regions of the vestigial polypide were noted by Lutaud (1977a) who interpreted the anterior ciliated cells as the lophophore homologue, with a central constriction where the cerebral ganglion is located and a posterior vestigial gut containing digestive-like vesicles. Examination by TEM of the vestigial polypide of $B$. flabellata allowed a cellular-level perspective of this region and the interpretation based on this study does not fully concur with that of Lutaud (1977a). The area of the vestigial polypide does have two cytologically distinct regions, comprising of an anterior region of ciliated and unciliated cells which make up the vestigial polypide proper, but the proximal area is actually the cerebral ganglion based on the presence of axonal cells containing neurosecretory vesicles (Figure 3.4C). The nature of the 'digestive vesicles' noted by Lutaud (1977) is unclear. There are what appear to be digestive-like vesicles in abundance in the vestigial polypide (Figures 3.5A, B). Their heterogeneous, granular appearance implies that these vesicles may contain proteolytic enzymes. The appearance of these vesicles suggests they could be lysosomes, the contents of which can be highly variable (Toner \& Carr 1968). They do not however contain organelle remnants characteristic of the stomach digestive vacuoles of the marine bryozoan Cryptosula pallasiana (Gordon 1975) or the freshwater bryozoan Asajirella gelatinosa (Mukai et al. 1997), or any evidence at all of partial degradation of organelles as typically presented in lysosomes (Smith \& Farquhar 1966; Pitt 1975). The heterogeneous vesicles of the vestigial polypide of B. flabellata are produced by the Golgi apparatus and initially have a relatively even distribution of 
granules, becoming more concentrated as the vesicle matures (Figure 3.5B). If these vesicles are lysosomes, their production is unusually high and are a dominant morphological feature of these cells. It seems more likely that these granular vesicles are secretory vesicles based on their close association with the lacuna that arises within the vestigial polypide and their abundance. Secretory granules play crucial roles related to communication, digestion and defence (Arvan \& Castle 1998): further work is required to establish the function of these secretory vesicles.

Where $N$. cornucopioides has internal cilia, the cilia of B. flabellata are directed externally and in contact with the external environment (Figure 3.4A). The characteristic of a mechanical receptor is the presence of a projection, whether it be hairs or cilia, from the surface of the body and innervated directly or through a secondary structure which is innervated itself by a neuron (Laverack 1968). The ciliated cells are in close association with the cerebral ganglion (Figure 3.4C). The location of the cilia, the close association of the cerebral ganglion to the ciliated cells and the highly augmented adductor system, and the continual and often rapid movements of the bird'shead avicularium, all strongly indicate a primary mechanoreceptive function. A response (e.g. the closing of the mandible) would be initiated, presumably, by the distortion of the cilia. A distinctive feature of tactile sensors is the ability to detect a deflection or distortion of a body part, such as cilia (Laverack 1968; Keil 1997). Such an organ is considered to be highly specialised and a very sensitive structure (Laverack 1968).

A noteworthy addition to the cell surface anatomy of the vestigial polypide of Bugula flabellata is the presence of cellular extensions (Figure 3.5B). These irregular projections differ from the uniformity and vertical orientation of microvilli (Fawcett 1966). Similar structures appear on the cell surfaces of the limiting cells of the rosette, or communication pore, of the ctenostome Bowerbankia imbricata and are thought to entrain water in order to enhance the absorption of ions (Gordon 1974a). The surface of the peritoneal cells in the funicular system of Asajirella gelatinosa has cytoplasmic extensions that are interdigitated though their function was not discussed (Mukai et al. 1997). Generally, the functional significance of cellular processes is that they greatly increase the area of the membrane required for the absorption of substances (Fawcett 1966). The function of the cellular extensions in the vestigial polypide of the avicularium of Bugula flabellata is unclear. Another puzzling feature of B. flabellata 
was the presence of a spherical body located next to the calcified bar of the rostrum (Figures $3.11 \mathrm{~A}-\mathrm{F})$. This structure was relatively large $(\sim 4.4 \mu \mathrm{m})$ and contained what appeared to be degraded organelles. The funicular system, which is derived from the parental autozooid, surrounds the vestigial polypide and then diverges and constricts at the calcified bar, entering the rostrum and surrounding the unspecific structure. Cellular extensions then continue towards the mucous secretory cells. Partially degraded organelles appear to be transported to this unspecific structure and what function it has is unknown. The funicular system, or cellular strands, extends from the unspecific structure to the mucous-forming rostrum. On this basis, this structure may be implicated in the biochemical maintenance of the mucous-like cells.

A significant difference also in the vestigial polypide ultrastructure between $B$. flabellata and $N$. cornucopioides is the presence of a microvilli-glycocalyx border around the vestigial tentacle of $N$. cornucopioides (Figure 3.19C). There was no microvilli-glycocalyx border associated with the vestigial polypide of $B$. flabellata. In autozooids, the epidermal cells of the individual tentacles are coated by a layer of microvilli-glycocayx (Smith 1973; Gordon 1974b) and may act as a cushion against mechanical abrasion during polypide retraction (Smith 1973). A microvilli-glycocalyx border of the tentacles has also been documented in the sipunculid Phascolion strombus (Lundin \& Schander 2003), many holothurian species (McKenzie 1987), the brachiopod Terebratalia transversa (Reed \& Cloney 1977), the hydrozoan polyp of Hydra vulgaris (Gulz \& Thurm 1991), and the entoproct Loxosomella elegans (Nielsen \& Rostgaard 1976). The purpose of microvilli borders in animal systems (in a similar way to cellular processes) is to increase surface area, particularly in the intestine where they increase the surface area for absorption. Biochemical investigations of the membrane covering the microvilli in human intestines suggests that a coating of enzymes is built into the structure thereby increasing the surface area of digestive enzymes on the absorptive surface between cell and lumen (Toner \& Carr 1968). Microvilli borders can also be associated with cells whose primary function is secretory (Fawcett 1966). In the case of $N$. cornucopioides the microvilli-glycocalyx border may therefore provide a surface area for protection by creating a chemical barrier, or may also be a site of absorption. During this study there was no evidence of microbial invasion and presumably the combination of glandular secretions and cilia creates an adequate cleaning mechanism if microbial invasion is problematic. Alternatively, the avicularia of $N$. cornucopioides 
may be producing a toxic chemical to provide chemical defence against predation. Toxicity appears to be highly correlated with a sessile benthic habit and implicated in the prevention of predation or biofouling (Bakus 1981; Dyrynda 1986). In $N$. cornucopioides, the glandular cells cover a large area, therefore the production of secretions is an important function of this avicularium and whether they are intended for chemical defence is unclear. A few bacteria were associated with B. flabellata and located in a pocket of the vestigial polypide and in the peduncle cushion (Figures 3.4D, 3.13B). Clusters of bacteria have been found in the funicular system of the autozooids of Bugula turbinata (Lutaud 1969b), Bugula neritina (Woollacott \& Zimmer 1975) and Epistomia bursaria (Dyrynda \& King 1982). The funicular system lacks an exit to the exterior therefore it is not entirely clear how the bacteria enter the funicular system or what their purpose is (Mukai et al. 1997). Based on these findings, it would appear likely that bacteria would be transported interzooidally via the funicular system yet the bacteria found in $B$. flabellata were free within coelomic spaces such as the peduncle cushion and not in membrane-bounded clusters as observed in B. turbinata (Lutaud 1969b). Bacteria were also often located on the surface of the avicularia and the colony as a whole but this is not unusual as intertidal and subtidal bryozoans are often coated in a microbial film (Scholz \& Krumbein 1996). The bacteria located in the avicularium or in the pocket of the vestigial polypide were present in very small numbers ( 7 in 31.5 $\mu \mathrm{m}^{-2}$ ) and therefore of limited significance to suggest a symbiotic association. However, their presence is puzzling as is the ability of the bacteria to enter the coelomic space of the peduncle cushion.

In autozooids, the cerebral ganglion is a small, heart-shaped or oval structure located in the pharyngeal constriction between the base of the lophophore and the first esophageal subdivision of the digestive tract (Lutaud 1977b; Mukai et al. 1997). In the avicularium of $B$. flabellata and $N$. cornucopioides, the ganglion lies at the base of the vestigial polypide. Significant differences in the anatomy of the cerebral ganglion were evident between $B$. flabellata and $N$. cornucopioides. In $B$. flabellata the ganglion was concave and tightly associated with the vestigial polypide. The dense neurosecretory vesicles were all roughly similar in size $(55-100 \mathrm{~nm}$ in diameter) and morphology (Figure 3.9B). In contrast, the ganglion of $N$. cornucopioides was spherical and contained numerous neurosecretory vesicles which were either small clear vesicles $(\sim 50$ $\mathrm{nm})$, or large $(\sim 100 \mathrm{~nm})$ electron-dense vesicles (Figure 3.20D). The cerebral ganglion 
of the phylactolaemate Asajirella gelatinosa contains dense neurosecretory vesicles (100-150 $\mathrm{nm}$ in diameter) and small clear vesicles (50-70 $\mathrm{nm}$ in diameter) (Mukai et al. 1997). The cerebral ganglion of Electra pilosa has two different types of neurovesicles also, consisting of small clear vesicles (30-50 $\mathrm{nm}$ in diameter) and larger dense vesicles (80-270 nm) (Lutaud 1969a). The vestigial polypide of B. flabellata is clearly a more derived structure than that of $N$. cornucopioides. The smaller clear vesicles of $B$. flabellata may have become redundant in function through evolutionary time and therefore no longer present or required in the communication system of the vestigial polypide of $B$. flabellata. This study indicates that the vestigial polypide of $N$. cornucopioides is less-derived in appearance and until other ultrastructural studies emerge, it is unclear at what stage of evolutionary development this structure is. The avicularia of Crassimarginatella exilimargo have been described as being the same size as neighbouring autozooids (and therefore vicarious) and possessing an incomplete cross-bar, a miniature polypide with functional gut, tentacle sheath, diaphragm and 2-4 thick short tentacles (Hastings 1945). Marcus (1939) described two types of vicarious avicularia in Antropora leucocypha (as Crassimarginatella), one with a full polypide and the other with a vestigial polypide. The avicularium with the full polypide is considered an incipient avicularium. Similarly, the B-zooids of most Steginoporella spp. have lophophores and are also considered incipient avicularia (Harmer 1900; Banta 1972; Cook 1977). A more holistic approach would, ideally, incorporate an extensive molecular phylogeny study of cheilostome bryozoans to superimpose onto the observed morphological data.

Phylogeny is not the only factor to be considered in piecing together the evolutionary development of the vestigial polypide. Phenotypic differences among individuals and species are related to differences in their respective ecology (Wainwright 1994). An unambiguous interpretation of the observed morphologies is greatly confounded by potential environmentally-driven phenotypic responses. $B$. flabellata is an invasive cosmopolitan species commonly found at ports and harbours. In contrast $N$. cornucopioides is a seamount-inhabiting species of the deep-sea. Each is exposed to differing environmental regimes that may well have been instrumental in the evolution of their respective avicularia. 


\subsection{Conclusions}

This study is the first to examine the ultrastructural anatomy of avicularia and offers immense insight into their functional morphology. The anatomy of the vestigial polypide differs substantially between the avicularia of the two bugulids Bugula flabellata and Nordgaardia cornucopiodes. The avicularium of B. flabellata consists of external cilia, the cells of which are closely associated with a cerebral ganglion. Combined with the behavioural observations, the anatomy of this bird's-head avicularium is strongly correlated with a mechanoreceptive function. In contrast, the avicularium of Nordgaardia cornucopioides consists of a vestigial tentacle with internal cilia and a basal cerebral ganglion. A large glandular region surrounds the vestigial tentacle. The close association of the glandular region and cilia indicates the primary function of this avicularium is of a chemosensory nature. The added habitat differences between the two bugulids is of real value when correlating anatomy and behaviour and indicates that bryozoans inhabiting subtidal, or harbour environments may be under threat of damage or predation by more mobile and/or tactile organisms. The disparate anatomy is indicative of substantial phylogenetic and functional divergence in these two species of bugulids. The possibility of depth related selection pressures cannot be excluded and implicit in this is the potential for anatomical differentiation, offering a unique insight into adaptive responses in bryozoans to differing environmental conditions.

\subsection{References}

Altner, H. \& Prillinger, L., 1980. Ultrastructure of invertebrate chemo-, thermo-, and hygroreceptors and its functional significance. International Review of Cytology 67: 69-139.

Apte, S., Holland, B.S., Godwin, L.S. \& Gardner, J.P.A., 2000. Jumping ship: a stepping stone event mediating transfer of a non-indigenous species via a potentially unsuitable environment. Biological Invasions 2: 75-79.

Arvan, P. \& Castle, D., 1998. Sorting and storage during secretory granule biogenesis: looking backward and looking forward. Biochemical Journal 332: 593-610.

Bakus, G.J., 1981. Chemical defense mechanisms on the Great Barrier Reef, Australia. Science 211: 497-499.

Banta, W.C., 1972. The body wall of cheilostome Bryozoa, V, Frontal budding in Schizoporella unicornis floridana. Marine Biology 14: 63-71.

Booth, J.D., 1975. Seasonal and tidal variations in the hydrology of Wellington Harbour. New Zealand Journal of Marine and Freshwater Research 9: 333-354. 
Bullivant, J.S. \& Bils, R.F., 1968. The pharyngeal cells of Zoobotryn verticillatum (delle Chiaje), a gymnolaemate bryozoan. New Zealand Journal of Marine and Freshwater Research 2: 438-446.

Childress, J.J., 1995. Are there physiological and biochemical adaptations of metabolism in deep-sea animals? Trends in Evolution and Ecology 10: 30-36.

Cook, P.L., 1963. Observations on live lunulitiform zoaria of polyzoa. Cahiers de Biologie Marine 4: 407-413.

Cook, P.L., 1977. Colony-wide water currents in living Bryozoa. Cahiers de Biologie Marine 18: 31-47.

Cook, P.L., 1981. The potential of minute bryozoan colonies in analysis of deep-sea sediments. Cahiers de Biologie Marine 22: 89-106.

Cook, P.L. \& Chimonides, P.J., 1978. Observations on living colonies of Selenaria (Bryozoa, Cheilostomata). I. Cahiers de Biologie Marine 19: 147-158.

Cranfield, H.J., Gordon, D.P., Willan, R.C., Marshall, B.A., Battershill, C.N., Francis, M.P., Nelson, W.A., Glasby, C.J. \& Read, G.B., 1998. Adventive marine species in New Zealand, NIWA Technical Report. NIWA, Wellington, pp. 48.

Dyrynda, P.E.J., 1986. Defensive strategies of modular organisms. Philosophical Transactions of the Royal Society of London. Series B 313: 227-243.

Dyrynda, P.E.J. \& Ryland, J.S., 1982. Reproductive strategies and life histories in the cheilostome marine bryozoans Chartella papyracea and Bugula flabellata. Marine Biology 71: 241-256.

Dyrynda, P.E.J. \& King, P.E., 1982. Sexual reproduction in Epistomia bursaria (Bryozoa: Cheilostomata), an endozooidal brooder without polypide recycling. Journal of Zoology 198: 337-352.

Farnesi, R.M., Marinelli, M., Tei, S. \& Vagnetti, D., 1982. Ultrastructural aspects of mechano- and chemoreceptors in Branchiobdella pentodonta (Annelida, Oligochaeta). Journal of Morphology 173: 237-245.

Fawcett, D.W., 1966. An atlas of fine structure. The cell. Its organelles and inclusions. W.B. Saunders Company, Philadelphia, 448 pp.

Gage, J.D. \& Tyler, P., 1991. Deep-sea biology: A natural history of organisms at the deep-sea floor. Cambridge University Press, Cambridge, 504 pp.

Glasby, T.M., Connell, S.D., Holloway, M.G. \& Hewitt, C.L., 2007. Nonindigenous biota on artificial structures: could habitat creation facilitate biological invasion? Marine Biology 151: 887-895.

Glauert, A.M., 1965. The fixation and embedding of biological specimens. In: Kay, D. (Ed.), Techniques for electron microscopy. Alden Press, Oxford, pp. 166-212.

Gordon, D.P., 1974a. Ultrastructure of communication pore areas in two bryozoans. In: Pouyet, S. (Ed.), Bryozoa. Proceedings of the third conference of the International Bryozoology Association. Documents des Laboratoires de Geologie de la Faculte des Sciences de Lyon. H.S.3 (fasc. 1). Université Claude Bernard, Lyon, pp. 187-192.

Gordon, D.P., 1974b. Microarchitecture and function of the lophophore in the bryozoan Cryptosula pallasiana. Marine Biology 27: 147-163.

Gordon, D.P., 1975. Ultrastructure and function of the gut of a marine bryozoan. Cahiers de Biologie Marine 16: 367-382.

Gordon, D.P., 1986. The marine fauna of New Zealand: Bryozoa: Gymnolaemata (Ctenostomat and Cheilostomata Anasca) from the western South Island continental shelf and slope. New Zealand Oceanographic Institute, Wellington, $121 \mathrm{pp}$. 
Gordon, D.P., 1987. The deep-sea Bryozoa of New Zealand. In: Ross, J.R.P. (Ed.), Bryozoa: Present and Past. Western Washington University, Bellingham, pp. 97104.

Gordon, D.P., 1999. Bryozoan diversity in New Zealand and Australia. In: Ponder, W. \& Lunney, D. (Eds), The other 99\%. The conservation and biodiversity of invertebrates. The Royal Zoological Society of New South Wales, Mosman, pp. 199-204.

Gordon, D.P. \& Mawatari, S.F., 1992. Atlas of marine-fouling bryozoans of New Zealand ports and harbours, Miscellaneous Publications New Zealand Oceanographic Institute. DSIR, Wellington.

Guerra-García, J.M. \& García-Gómez, J.C., 2005. Assessing pollution levels in sediments of a harbour with two opposing entrances. Environmental implications. Journal of Environmental Management 77: 1-11.

Gulz, R. \& Thurm, U., 1991. Cytoskeletal modifications of the sensorimotor interneurons of Hydra vulgaris (Cnidaria, Hydrozoa), indicating a sensory function similar to chordotonal receptors of insects. Zoomorphology 111: 113118.

Hageman, G.S. \& Lutaud, G., 1982. La structure des organes périoperculaires des Chilostomes Malacostèges et leur relation avec le réseau nerveux pariétal chez Membranipora. Cahiers de Biologie Marine 24: 347-357.

Harmer, S.F., 1900. A revision of the genus Steginoporella. Quarterly Journal of the Microscopical Society 43: 225-297.

Hastings, A.B., 1945. Notes on Polyzoa (Bryozoa).-II. Membranipora crassimarginata auctt., with remarks on some genera. Annals and Magazine of Natural History, series 11 12: 69-103.

Hayat, M.A., 1981. Principles and techniques of electron microscopy. Biological applications. Edward Arnold, London, 522 pp.

Hayward, P.J., 1981. The cheilostomata (Bryozoa) of the deep sea. Galathea Reports 15: 21-68.

Hughes, D.J., 2001. Quantitative analysis of a deep-water bryozoan collection from the Hebridean continental slope. Journal of the Marine Biological Association 81: 987-993.

Humason, G.L., 1972. Animal tissue techniques. W.H. Freeman and Company, San Francisco.

Hyman, L.H., 1959. The invertebrates: Smaller coelomate groups Chaetognatha, Hemichordata, Pogonophora, Phoronida, Ectoprocta, Brachiopoda, Sipunculida. The coelomate bilateria. McGraw-Hill Book Company, Inc, New York, 783 pp.

Jackson, J.B.C., 1979. Morphological strategies of sessile animals. In: Larwood, G.P. \& Nielsen, C. (Eds), Biology and systematics of colonial animals. Academic Press, London, pp. 499-555.

Keil, T., 1997. Functional morphology of insect mechanoreceptors. Microscopy Research and Technique 39: 506-531.

Laverack, M.S., 1968. On the receptors of marine invertebrates. Oceanography and Marine Biology Annual Review 6: 249-324.

Lundin, K. \& Schander, C., 1999. Ultrastructure of gill cilia and ciliary rootlets of Chaetoderma nitidulum Loven 1844 (Mollusca, Chaetodermomorpha). Acta Zoologica 80: 185-191.

Lundin, K. \& Schander, C., 2001a. Ciliary ultrastructure of protobranchs (Mollusca, Bivalvia). Invertebrate Biology 120: 350-357. 
Lundin, K. \& Schander, C., 2001b. Ciliary ultrastructure of neomeniomorphs (Mollusca, Neomeniomorpha= Solenogastres). Invertebrate Biology 120: 342349.

Lundin, K. \& Schander, C., 2003. Epidermal ciliary ultrastructure of adult and larval sipunculids (Sipunculida). Acta Zoologica 84: 113-119.

Lutaud, G., 1964. Sur la structure et le rôle des glandes vestibulaires et sur la nature de certains organes de la cavité cystidienne chez les Bryozaires chilostomes. Cahiers de Biologie Marine 5: 201-231.

Lutaud, G., 1969a. Le plexus pariétal de Hiller et la coloration du système nerveux par le bleu méthylène chez quelques Bryozoaires Chilostomes. Zeitschrift feur Zeilforschung und Mikroskopische Anatomie 99: 302-314.

Lutaud, G., 1969b. La nature des corps funiculaires des cellularines Bryozoaires chilostomes. Archives de Zoologie Expérimentale et Générale 110: 2-30.

Lutaud, G., 1973. L'innervation du lophophore chez le Bryozoaire Chilostome Electra pilosa (L.). Zeitschrift feur Zeilforschung und Mikroskopische Anatomie 140: 217-234.

Lutaud, G., 1977a. L'innervation de l'aviculaire pédonculé en Bicellariidae (Bryozoaires Chilostomes). Cahiers de Biologie Marine 18: 435-448.

Lutaud, G., 1977b. The bryozoan nervous system. In: Woollacott, R.M. \& Zimmer, R.L. (Eds), Biology of bryozoans. Academic Press, New York, pp. 377-410.

Lutaud, G., 1985. Preliminary experiments on interzooidal metabolic transfer in anascan bryozoans. In: Nielsen, C. \& Larwood, G.P. (Eds), Bryozoa: Ordovician to Recent. Olsen \& Olsen, Fredensborg, pp. 183-191.

Marcus, E., 1939. Bryozoarios marinhos Brasileiros. III. BoletiMs da Faculdade de Filosofia, Ciências e Letras, Universidade de São Paulo, Zoologia 3: 111-353.

Marshall, N.B., 1979. Developments in deep-sea biology. Blandford Press, Poole, 566 pp.

McKenzie, J.D., 1987. The ultrastructure of the tentacles of eleven species of dendrochirote holothurians studied with special reference to the surface coats and papillae. Cell and Tissue Research 248: 187-199.

Mills, S.W., Mullineaux, L.S. \& Tyler, P.A., 2007. Habitat associations in gastropod species at East Pacific Rise hydrothermal vents $\left(9^{\circ} 50^{\prime} \mathrm{N}\right)$. Biological Bulletin 212: 185-194.

Mooney, H.A. \& Cleland, E.E., 2001. The evolutionary impact of invasive species. Proceedings of the National Academy of Science 98: 5446-5451.

Mukai, H., Terakado, K. \& Reed, C., 1997. Bryozoa. In: Harrison, F.W. \& Woollacott, R.M. (Eds), Microscopic anatomy of invertebrates. John Wiley \& sons Inc, New York, pp. 45-206.

Mullineaux, L.S., 1988. The role of settlement in structuring a hard-substratum community in the deep sea. Journal of Experimental Marine Biology and Ecology 120: 247-261.

Nielsen, C., 2002. Ciliary filter-feeding structures in adult and larval gymnolaemate bryozoans. Invertebrate Biology 121: 255-261.

Nielsen, C. \& Rostgaard, J., 1976. Structure and function of an entoproct tentacle with a discussion of ciliary feeding types. Ophelia 15: 115-140.

Northcote, L., 1998. Te Whanganui a Tara Wellington Harbour. Review of Scientific and technical studies of Wellington Harbour, New Zealand, to 1997. East Harbour Environmental Association, Eastbourne, Wellington, 200 pp.

Pitt, D., 1975. Lysosomes and cell function. Longman Group Ltd, London, 165 pp. 
Ralph, P.M. \& Hurley, D.E., 1952. The settling and growth of wharf-pile fauna in Port Nicholson, Wellington, New Zealand, Wellington, 22 pp.

Reed, C. \& Cloney, R.A., 1977. Brachiopod tentacles: Ultrastructure and functional significance of the connective tissue and myoepithelial cells in Terebratalia. Cell and Tissue Research 185: 17-42.

Richmond, M.D. \& Seed, R., 1991. A review of marine macrofouling communities with special reference to animal fouling. Biofouling 3: 151-168.

Ricklefs, R.E. \& Miles, D.B., 1994. Ecological and evolutionary inferences from morphology: An ecological perspective. In: Wainwright, P.C. \& Reilly, S.M. (Eds), Ecological morphology. Integrative organismal biology. The University of Chicago Ltd, Chicago, pp. 13-41.

Rogers, A.D., 1994. The biology of seamounts. Advances in Marine Biology 30: $305-$ 350.

Rowden, A.A., Warwick, R.M. \& Gordon, D.P., 2004. Bryozoan biodiversity in the New Zealand region and implications for marine conservation. Biodiversity and Conservation 13: 2695-2721.

Ryland, J.S., 1965. Catalogue of the main marine fouling organisms (found on ships coming into European waters). Vol. 2: Polyzoa. Organisation for Economic Cooperation and Development, Paris.

Ryland, J.S., 1970. Bryozoans. Hutchinson University Library, London, 175 pp.

Ryland, J.S., 1976. Physiology and ecology of marine bryozoans. Advances in Marine Biology 14: 285- 443.

Scholz, J. \& Krumbein, W.E., 1996. Microbial mats and biofilms associated with bryozoans. In: Gordon, D.P., Smith, A.M. \& Grant-Mackie, J.A. (Eds), Bryozoans in space and time. Proceedings of the 10th International Bryozoology Conference. NIWA, Wellington.

Schopf, T.J.M., 1969. Geographic and depth distribution of the phylum Ectoprocta from 200 to 6,000 meters. Proceedings of the American Philosophical Society 113: 464-474.

Shillito, B., Le Bris, N., Hourdez, S., Ravaux, J., Cottin, D., Caprais, J., Jollivet, D. \& Gaill, F., 2006. Temperature resistance studies on the deep-sea vent shrimp Mirocaris fortunata. Journal of Experimental Biology 209: 945-955.

Shunatova, N. \& Nielsen, C., 2002. Putative sensory structures in marine bryozoans. Invertebrate Biology 121: 262-270.

Silén, L., 1944. On the division and movements of the alimentary canal of the Bryozoa. Arkiv för Zoologi 35A: 1-40.

Smith, L.W., 1973. Ultrastructure of the tentacles of Flustrellidra hispida (Fabricius). In: Larwood, G.P. (Ed.), Living and fossil Bryozoa. Academic Press, London, pp. 335-342.

Smith, P.J., 1996. Selective decline in imposex levels in the dogwhelk Lepsiella scobina following a ban on the use of TBT antifoulants in New Zealand. Marine Pollution Bulletin 32: 362-365.

Smith, R.E. \& Farquhar, M.G., 1966. Lysosome function in the regulation of the secretory process in cells of the anterior pituitary gland. Journal of Cell Biology 31: 319-347.

Toner, P.G. \& Carr, K.E., 1968. Cell structure. E \& S Livingstone Ltd, Edinburgh.

Van Dover, C.L., German, C.R., Spear, K.G., Parson, L.M. \& Vrijenhoek, R.C., 2002. Evolution and biogeography of deep-sea vent and seep invertebrates. Science 295: 1253. 
Wainwright, P.C., 1994. Functional morphology as a tool in ecological research. In: Wainwright, P.C. \& Reilly, S.M. (Eds), Ecological morphology. Integrative organismal biology. The University of Chicago Press, Ltd, Chicago, pp. 42-59.

Waters, A.W., 1889. Supplementary report on the Polyzoa. Report of the Scientific Results of the Voyage of H.M.S Challenger, Zoology 31: 1-41.

Wilson, G.D.F. \& Hessler, R.R., 1987. Speciation in the deep sea. Annual Review of Ecology and Systematics 18: 185-207.

Winston, J.E., 1977. Feeding in marine bryozoans. In: Woollacott, R.M. \& Zimmer, R.L. (Eds), Biology of bryozoans. Academic Press, London, pp. 233-271.

Winston, J.E., 1984. Why bryozoans have avicularia - A review of the evidence. American Museum Novitates 2789: 1-26.

Woollacott, R.M. \& Zimmer, R.L., 1975. A simplified placenta-like system for the transport of extra-embryonic nutrients during embryogenesis of Bugula neritina (Bryozoa). Journal of Morphology 147: 355-376. 


\section{CHAPTER 4}

\section{Immunocytochemistry of the Nervous System and the Musculature of the Bird's-Head Avicularium of Bugula flabellata}

\subsection{Introduction}

The bird's-head avicularium is considered to be the most highly developed of all avicularian forms (Harmer 1930; Kaufmann 1971; Winston 1986). Instead of being fused with the parent autozooid, as other forms of adventitious avicularia are, the basal cystid is free and attachment to the parent autozooid is via a stalk, or peduncle. Such freedom enables some avicularia to swing to and fro in an almost $180^{\circ}$ arc. It is through this peduncle that the avicularium maintains continuity with the parent autozooid, from which a supply of nutrients is derived via the funicular system (nutrient transport system) (Kaufmann 1971). Devoid of any functional gut, the avicularium is highly dependent on this supply of nutrients and therefore constitutes a significant energy cost in production and maintenance to the parent autozooid, and possibly the colony as a unit (Schopf 1973). Avicularia must perform some reciprocal function in order to justify this expenditure.

The bird's-head avicularium has been the subject of immense speculation and interest since Charles Darwin first described its behaviour in a species of Bugula over 150 years ago (Darwin 1845, 1872). During his observations, Darwin tickled the exposed palate of an avicularium and found the mandible closed rapidly onto the needle to such an extent he was able to lift the whole colony out of the water. On this basis Darwin deduced they had some form of sensory capabilities and suggested that such a grasping action would be best suited for trapping predators and prey. This theory was also endorsed by many subsequent workers well into the $20^{\text {th }}$ Century (Busk 1854; 
Harmer 1909; Kaufmann 1968, 1971; Silén 1977; Winston 1984; Winston 1986; McKinney \& Jackson 1989; Winston 1991).

Evidence for a defensive function is primarily anecdotal and no real empirical evidence exists to support this suggestion. Much of the research on avicularia has largely been based on light microscopy observations. However, recent advances in confocal microscopy now permit investigation of biological structures, the results of which can be complemented with behavioural observations to gain a broader knowledge of functional morphology. Avicularian functional biology represents a substantial gap in the overall knowledge of cheilostome biology, therefore it is critical to close the gap, test hypotheses, and begin understanding how bryozoans function as a total unit (colony-level functioning).

Due to the numerous avicularian morphologies that exist (Silén 1977; Winston 1984) the degree of muscular modification cannot be assumed to be consistent and conserved through all forms. If we assume that differential forms equate to disparate functions then presumably the muscular anatomy would be modified in order to complement the specific physiology of the avicularium in question. Therefore, it cannot be assumed that the diagrammatic representation of the muscular system of the $F$. foliacea avicularium (Figure 1.1 Chapter 1) is a true representation for all avicularia: differences may become apparent among taxa depending on which muscles have become hypertrophied and which are reduced. On this basis, an extensive study of the muscular anatomy of avicularia is certainly warranted. Recent anatomical studies of other taxa (e.g. annelids Filippova et al. 2005; Muller \& Worsaae 2006) that employed histochemical and confocal microscopy techniques have reconstructed muscular anatomy to far more accuracy than earlier studies had achieved by light microscopy and histological techniques.

The bird's-head avicularium of Bugula flabellata has been chosen for this study due to the availability and accessibility of this species around ports and harbours. Also, their size (100-200 $\mu \mathrm{m}$ length), light calcification, and accessibility on branch edges, mean they are well suited for confocal microscopy. Therefore, the objective of this study is to examine the muscular anatomy and nervous system of the avicularium of Bugula flabellata using immunohistochemistry and confocal microscopy. In addition the muscular system of the avicularium and autozooid will be compared in order to understand the evolutionary development of the muscular system. 


\subsubsection{Laser scanning confocal microscopy}

The confocal scanning microscope was invented by Marvin Minsky in 1961 (see Minsky 1988) in a quest to try and understand how the brain works. The structural complexity of the brain in addition to light contamination under optical microscopy, made ascertaining the fine structure of the cells and nerves difficult. Minsky's solution to these problems was to eliminate background light and brightly illuminate a single spot in a tissue sample at one time. Minsky's microscope was modified over time by several workers through the 1970's and 1980's with the first commercial instrument appearing in 1987 (Claxton et al. 2006).

The fundamental principle of confocal microscopy is based on the emission of coherent light from the excitation source (laser) which passes through a pinhole aperture located in confocal plane with a scanning point on the specimen and a second pinhole aperture located at the front of the detector (a photomultiplier tube). The laser is reflected by a dichromatic mirror and scanned across the specimen in a defined plane (x, $\mathrm{y}$ or $\mathrm{z}$ ). Secondary fluorescence emitted from points on the specimen (in the same focal plane) are emitted back through the dichromatic mirror and focused as a confocal point at the detector pinhole aperture (Claxton et al. 2006).

The advantages of confocal microscopy are numerous but primarily microscopes can be equipped with multiple light sources or lasers. Common excitation sources in laser-based systems include argon (488 and $514 \mathrm{~nm}$ ), krypton (568 nm), argon-krypton (488, 514 and $568 \mathrm{~nm}$ ), and helium-neon (633 nm) lasers (Dailey et al. 1999). This variety of excitation wavelengths on a single microscope offers incredible scope and convenience. By using a range of fluorescent probes on a single specimen it is possible to locate several target molecules simultaneously (Dailey et al. 1999; Claxton et al. 2006).

Not achievable by optical microscopy, is the ability to view thick specimens and to collect 2-D images from different depths within the specimen (Dailey et al. 1999; Webb 1999) and/or obtain serial thin (0.5-1.5 $\mu \mathrm{m})$ optical sections (Claxton et al. 2006). A typical stack of optical sections is obtained by combining $x-y$ (perpendicular lateral) scans taken along the $\mathrm{z}$ axis with the computer software and projecting a view of fluorescence intensity as if the microscope hardware had been physically capable of performing a vertical section (Claxton et al. 2006). 
The confocal microscope is an extremely useful tool in the study of cell structure and function (Bkaily et al. 1999) particularly in thick specimens whereby optical sections can be obtained without physically sectioning the tissue (Sun 1999; Webb 1999) and reconstructed to produce a 3-D overview of the targeted molecule or tissue within the specimen (Sun 1999; Claxton et al. 2006). For these reasons, confocal microscopy is especially useful for reconstructing complex 3-D neuroanatomy (Sun 1999).

A commonly used stain for labelling muscle tissue in confocal microscopy is phalloidin. Phallotoxins are bicyclic peptides isolated from the deadly Amanita phalloides mushroom that selectively bind to the muscle protein F-actin (Haugland 1996). Combined with confocal laser scanning microscopy, phalloidin staining allows a 3-D reconstruction of muscles and is therefore a valuable tool to complement other microscopic methods.

Phalloidin histochemical methods have been utilised in many studies examining the phylogenetic relationships and evolutionary relatedness of taxa based on similarities and differentiation of body plans. Recent studies have reconstructed larval neural and muscular traits in the Lophotrochozoa with respect to assessing the evolutionary origins of larval body plans (Hay-Schmidt 2000; Santagata 2002; Santagata \& Zimmer 2002). A data set is also being compiled on the muscular anatomy of annelids in order to determine the plesiomorphic condition (Filippova et al. 2005; Muller \& Worsaae 2006; Ruchel \& Muller 2007). Wanninger (2005) used phalloidin and confocal microscopy to describe the muscular anatomy of the chordoid larva of Symbion pandora (Cycliophora) to discover that the body-wall musculature exhibits similarities to the body plan of rotifers. Phalloidin histochemistry has also been employed in describing the musculature of gastrotrichs (Leasi et al. 2006); kinorhynchs (Muller \& Schmidt-Rhaesa 2003); phoronids (Santagata 2002, 2004); rotifers (Kotikova et al. 2001) and platyhelminthes (Mair et al. 1998; Pfistermuller \& Tyler 2002; Raikova et al. 2006).

\subsubsection{The muscular anatomy of cheilostome bryozoans}

The most prominent muscles found in bryozoans are the retractors of the polypide, which are located both sides of the digestive tract and attach to the cystid wall of the autozooid. Contraction of the retractors withdraws the everted tentacles back into the cystid (Ryland 1970). Other muscles include the dilator muscles of the vestibule, 
diaphragm, and tentacle sheath; together with the muscles operating the operculum (including the occlusors), they are often referred to collectively as apertural muscles. Apertural muscles are considered to be modifications of the transverse parietal muscles (e.g. parietodepressors). The term parietal muscles is often used in the literature in its broad sense to include both parietodepressors and apertural muscles (Ryland 1970; Mukai et al. 1997). Hence, the descriptive inconsistency evident in the literature requires careful scrutiny.

The parietal muscles are found only in the gymnolaemates and in anascan bryozoans (e.g. Bugula) they are located on the lateral walls and frontal membranes. In ascophorans the parietal muscles are located on the lateral walls and basal cystid (Hyman 1959; Ryland 1970; Mukai et al. 1997). The most distal sets of transverse parietal muscles are associated with the musculature of the operculum. A pair of adductor (also known as occlusor) muscles is responsible for closing the operculum and when relaxed, the operculum is pushed open with a concomitant increase in coelomic pressure. In anascans, parietal contraction pulls in the frontal membrane causing a depression in the membrane which in turn raises the coelomic hydrostatic pressure, and forces the polypide to evert through the opened operculum. Opening of the operculum may also be assisted by a set of divaricator muscles which extend from the lateral walls and insert behind the hinge line of the operculum (Ryland 1970; Mukai et al. 1997).

The muscle anatomy of avicularia has been studied in only a few taxa using light microscopy and staining techniques (e.g. Marcus 1939). The predominant muscular modification from an autozooid appears to be the augmentation of the adductors responsible for closing the mandible (Harmer 1930; Marcus 1939; Hyman 1959; Kaufmann 1971; Silén 1977; Winston 1984). The homology of other muscles associated with the avicularium remains unclear, possibly due to functional transformation, even redundancy, which makes a comparative analysis based on morphology difficult. Figure 1.1 (in Chapter 1) is an example of the morphological modification of an avicularium from an autozooid in Flustra foliacea. The parietal muscle system of the autozooid has become a highly condensed system of abductors in the avicularium (Marcus 1939; Silén 1977; Winston 1984) though their precise function is unclear. In addition, there appears to be some ambiguity about the actual existence of the abductor muscles in some taxa. This is particularly evident in the Buguloidea. A distal pair and proximal pair of abductors have been described for Bugula flabellata, B. ditrupae, and Cornucopina 
conica (Harmer 1926; Marcus 1939; Lutaud 1977b) and only one proximal pair for Synnotum aegyptiacum, B. cucullata, and C. moluccensis (Harmer 1926; Marcus 1939). Clearly, the existence of such ambiguity even between congenerics implies an extensive examination of avicularian muscle anatomy is required. Establishing the precise location of the muscles in an avicularium can provide essential information on its functional capacity based on which muscles are developed and which are redundant.

\subsubsection{The bryozoan nervous system}

The nervous system of bryozoans has been studied in a variety of taxa (Mukai et al. 1997). The main techniques employed were TEM and light microscopy observations of Methylene blue vital-stained and silver-impregnated tissue sections (Lutaud 1969, 1977b, 1979; Mukai et al. 1997). The nerve centre in bryozoans is the cerebral ganglion located at the base of the lophophore, resting against the dorsal surface of the pharynx (Lutaud 1977a; Mukai et al. 1997). Neurons branching from the cerebral ganglion go on to innervate the tentacles and associated muscles of the aperture, and the pharynx and gut (visceral nerves). From the cerebral ganglion there is extensive peripheral innervation with intermittent branching of motor and sensory nerves to the various parietal muscles as well as the diaphragm and tentacle sheath (Lutaud 1979). Interzooidal communication has been confirmed in the Phylactolaemata and in stoloniferous ctenostomes (Lutaud 1977a). In the cheilostome Electra pilosa the parietal plexus extended towards the interconnecting pore plates forming a synapse with the parietal filaments of adjacent autozooids thereby ensuring nervous continuity (Lutaud 1979).

Lutaud (1977b) examined the nervous system of four species from the family Bugulidae using vital-staining techniques and light microscopy. The patterns of innervation are similar in the avicularia (in this case the bird's-head avicularia) and in the autozooid. The avicularian nerves appear to diverge from a ganglion located in the median constriction of the vestigial polypide. The main muscles of the avicularium (adductors and abductors) are all innervated with motor nerves originating from the ganglion. No interconnecting neurons appear to exist between the autozooids and avicularia in Bugula flabellata and B. turbinata, whilst positive Methylene blue staining was evident in partitions of B. simplex and Bicellariella ciliata. The general consensus in the literature indicates an extensive study is required to ascertain the true extent of 
neural continuity between autozooids, and between autozooids and heterozooids in the context of establishing the extent of intracolony integration and communication (Ryland 1970; Lutaud 1977a, b, 1979; Mukai et al. 1997). Confocal microscopy offers immense scope for novel research in establishing a 3-D perspective of the nervous system in bryozoans which the 2-D perspective techniques of histology and TEM are unable to construct.

\subsubsection{The serotonergic nervous system}

Serotonin is an ancient and ubiquitous neurotransmitter found throughout the animal kingdom, suggesting an early origin in invertebrate ancestors (Hay-Schmidt 2000; Tierney 2001). Due to the ancient origins of the serotonergic nervous system, homologous relationships exist between invertebrate and vertebrate serotonin receptor types. Numerous subtypes of serotonin receptors exist that mediate a diverse array of functions in vertebrates and invertebrates (Tierney 2001). Phylogenetic studies indicate the existence of three main classes of serotonin receptors 750 Mya, predating the split between invertebrates and vertebrates. Since this time these receptors have undergone independent differentiation giving rise to numerous sub-types and a variety of phenotypic expressions (Tierney 2001; Barbas et al. 2003).

In vertebrates, serotonin is involved in several basal brain functions including feeding (Yokoyama et al. 2007), psychological state (Owens \& Nemeroff 1994; Kapur \& Remington 1996), circadian rhythms (Edgar \& Miller 1993; Morin 1999), and sleep (Portas et al. 2000). In invertebrates, serotonin plays multiple roles in modulating behaviour and development (Sudlow et al. 1998). Serotonin may regulate ciliary activity by means of serotonergic neurons in the pedal ganglia in the embryos of the pond snail Helisoma trivolvis (Kuang \& Goldberg 2001; Kuang et al. 2002; Koss et al. 2003) and in the ciliary band region of the larvae of the sea urchin Hemicentrotus pulcherrimus (Katow et al. 2007). Serotonin plays a vital role in the locomotion and metamorphosis of larvae of the gastropod Ilyanassa obsoleta (Leise et al. 2001; Page 2002; Braubach et al. 2006); regulates feeding rates in larvae of the bivalve Mytilus edulis (Beiras \& Widdows 1995); and regulates settlement and metamorphosis in the larvae of the barnacle Balanus amphitrite (Yamamoto et al. 1996; Yamamoto et al. 2000). Serotonin has also been implicated in gamete maturation and spawning in bivalve molluscs such as the zebra mussel Dreissena polymorpha (Ram et al. 1996; Fong 1998; Fong et al. 
2003), fingernail clam Sphaerium striatinum (Fong et al. 2003), and the European clam Macoma balthica (Honkoop et al. 1999), as well as increasing ciliary pumping in the mussels Mytilus edulis, Perna viridis, Modiolus demissus and the clam Anodonta sp. (Gosselin 1961; Wang 2002; Cadet 2004). In nemertean worms, serotonin has been implicated in the maturation of oocytes by stimulating an increase in intra-oocytic cAMP (Stricker \& Smythe 2001).

Only two studies have been documented that map the serotonergic nervous system in bryozoans using confocal microscopy and immunocytochemical techniques. These two studies were conducted on the larvae of Membranipora sp. (Hay-Schmidt 2000) and Triphyllozoon mucronatum (Wanninger et al. 2005). The occurrence and distribution of serotonin in T. mucronatum was followed through metamorphosis from newly released larva to ancestrula. In the larval stage, the serotonergic nervous system exhibits a larval commissure located underneath the apical plate and innervation of the ciliary band responsible for locomotion. After 15-30 minutes from the induction of metamorphosis, serotonin expression is lost as the serotonergic nerve net begins to break down (Wanninger et al. 2005). Bryozoan larvae appear to be unique, certainly within the lophophorates, by undergoing radical morphological changes whereby most larval structures are lost and juvenile/adult organs appear to form de novo (Zimmer \& Woollacott 1977). Whilst undergoing such dramatic metamorphosis the larvae of Triphyllozoon mucronatum had lost the entire serotonergic nervous system but it reappeared, de novo, in the ancestrula. In the ancestrula, immunoreactivity was evident in the cerebral commissure, in cell bodies at the base of the lophophore, and in neurites connecting these cell bodies to the commissure (Wanninger et al. 2005).

The existence and anatomy of the serotonergic nervous system in the ancestrula may be a reliable representation of adult neuroanatomy, but until further data are available adult bryozoan neuroanatomy remains unmapped by immunohistochemical means. Similarly, the serotonergic nervous system of avicularia has not been studied. Mapping the serotonergic nervous system in the bird's-head avicularium is a vital component in completing the biological reconstruction of this avicularium. By determining precisely the avicularium structures that are innervated by serotonergic neurons it will then be possible to gain insight into the neuroethology of the avicularium based on information gained from previous studies on other invertebrates. The best 
technique to map structures at a molecular level in whole organisms is laser scanning confocal microscopy.

Serotonin can be targeted by an indirect method of identification, or immunocytochemistry, involving an antigen-antibody interaction where the antibody has been tagged with a visible label or fluorophore (Mao 1999). This protocol is highly sensitive and involves incubation of the tissue in the primary, unlabelled antibody then a second labelled antibody from another species, but raised against the immunoglobulin of the animal donating the first antibody, is applied (Mao 1999). The primary antigenic site, on the serotonin molecule, is thus revealed under confocal microscopy.

\subsubsection{Research objectives}

This study takes an integrated and focused approach by utilising a suite of techniques to examine the functional morphology and development of the avicularium in a single species within an evolutionary contextual framework. Bugula flabellata has been chosen for this study because it is easily available around the Wellington coast and the avicularia are lightly calcified and conspicuous. In addition, this study will complement the TEM work on this species (Chapter 3). Behavioural observations on $B$. flabellata will also be conducted in order to gain a complete understanding of the functional morphology of the bird's-head avicularium. This component will be achieved by SEM in order to record the behavioural responses.

On that basis the objective of this study is as follows:

i. To examine the gross-structural morphology of the avicularia and relate their morphology to behavioural observations. Information will be derived by scanning electron microscopy (SEM).

ii. To reconstruct the muscular anatomy of the avicularium and autozooids using fluorescent phalloidin histochemical techniques. The results will enable a comparative analysis of homologous traits.

iii. To map the serotonergic nervous system in the avicularium. Serotonin has been implicated in ciliary and motor activity in a range of taxa, therefore the location 
of serotonin within the avicularium can provide crucial evidence in deciphering the functional biology of avicularia.

\subsection{Materials and Methods}

\subsubsection{Collection of Bugula flabellata}

Colonies of $B$. flabellata required for behavioural observations were collected off pilings from Queens Wharf and floating rafts at Mahanga Bay, Wellington Harbour. Collections from Queens Wharf were made at low tide, whilst those from Mahanga Bay required boat access: collections were made at both sites in January 2007. Three colonies from each site were individually placed into a snap-lock plastic bag and then each colony was placed into a container of $100 \%$ ethanol (i.e. six containers of ethanol preserved colonies, three colonies from each of the two sites). These ethanol-preserved colonies were examined at a later date and any avicularia observed with organisms caught between their mandible and rostrum were isolated and placed immediately in a glass vial of $100 \%$ ethanol for SEM analysis. One additional colony was collected from each site and placed in a container of seawater and used for live behavioural observations. Observations on live and preserved colonies were made under a dissecting microscope.

Colonies of B. flabellata required for confocal and optical microscopy were collected from wharf pilings at Queens Wharf, Wellington (Figure 2.1 in Chapter 2) during low tide in October 2006 and February 2008. Colonies collected in 2006 were placed in an insulated container with seawater and taken to the laboratory at Victoria University of Wellington and maintained in aerated seawater at $18^{\circ} \mathrm{C}$. Colonies required for histochemistry were fixed within four hours of collection. Colonies collected in 2008 were held in a container overnight. The following morning these colonies were used for optical and Differential Interference Contrast (DIC) imaging using a Nikon Microphot FX-A compound microscope and images were captured using a Pixielink PL-A686C colour firewire video camera. 


\subsubsection{Scanning Electron Microscopy (SEM)}

SEM images were acquired in order to discern morphological details. Whilst the palate morphology has been described in Chapter 2 it is pertinent to highlight such details in this Chapter for contextual and orientation purposes. In addition, this SEM study provided an opportunity to discover newly described characteristics in the bird'shead avicularium. The protocol for the fixation of subtidal bryozoans has already been described in Chapter 2. Avicularia were viewed in a Leo 440 or Jeol 5300LV SEM. All images were annotated in Adobe Photoshop Elements v3.0.

\subsubsection{Histochemistry of the muscular anatomy}

Colonies were initially relaxed in $7 \% \mathrm{MgCl}$ for $20 \mathrm{~min}$ and then fixed in $4 \%$ paraformaldehyde in $0.1 \mathrm{M}$ PBS for $4 \mathrm{~h}$ at room temperature. The samples were then permeabilised in $0.1 \mathrm{M}$ PBS with $0.1 \% \mathrm{NaN}_{3}$ and $0.1 \%$ Triton $\mathrm{X}-100$ (PBT) for $1 \mathrm{~h}$ at room temperature, stained in Phalloidin Alexa Fluor 568 (Invitrogen Catalogue number: A12380) in a 1:20 dilution (in $0.1 \mathrm{M}$ PBS) for $1 \mathrm{~h}$, and then rinsed three times (15 min each wash) in 0.1 M PBS (Santagata 2002). The samples were then mounted on glass microscope slides in DABCO antifade, covered with a size 1 cover-slip and sealed with clear nail varnish. Slides were kept in the dark by wrapping them in black plastic to reduce the possibility of bleaching of the fluorophore and refrigerated until required. Samples were viewed either under a Leica SP2 or an Olympus FV1000 Confocal laser scanning microscope.

\subsubsection{Serotonergic neuroanatomy of the bird's-head avicularium}

Colonies were fixed in 4\% paraformaldehyde in $0.1 \mathrm{M}$ PBS for $4 \mathrm{~h}$ at room temperature. To aid antibody penetration, samples were decalcified in 10\% EDTA in 0.1 M PBS for up to 4 weeks whilst being kept rotated at $4^{\circ} \mathrm{C}$. Once decalcified, samples were permeabilised in PBS with $0.1 \% \mathrm{NaN}_{3}$ and $0.1 \%$ Triton $\mathrm{X}-100$ (PBT) for $1 \mathrm{~h}$ at room temperature, then incubated overnight in $6 \%$ goat serum (GS; Invitrogen Catalogue number: PCN5000) in PBT (GS-PBT) in order to prevent non-specific binding. For this and subsequent stages, the samples were placed in glass vials and kept rotated in their respective solutions whilst being maintained at $4^{\circ} \mathrm{C}$. Samples were then incubated in rabbit serotonin primary antibody (Invitrogen Catalogue number: 18-0077) 
in GS-PBT in a 1: 800 dilution for 20-24 h, washed four times over 6-8 $\mathrm{h}$ in GS-PBT then incubated in goat anti-rabbit Alexa Fluor 555 (Invitrogen Catalogue number: A31629) for $48 \mathrm{~h}$ in a 1:500 dilution (modified from Wanninger, 2005). The glass vials were wrapped in black plastic for subsequent stages to reduce the possibility of bleaching of the fluorophore. Finally, the samples were rinsed in 0.1M PBS for 24 hours and mounted on glass microscope slides in DABCO antifade mounting media and covered with a size 1 cover-slip and sealed with clear nail varnish. Negative controls were produced by deleting the primary antibody. Slides were kept in the dark and refrigerated until required. Samples were viewed under a Leica SP2 Confocal laser scanning microscope.

See Appendix 2 for the protocols for each of the solutions used in this study.

\subsubsection{Behavioural observations}

Live colonies of Bugula flabellata provided a habitat for various organisms including gammarid amphipods, copepods, ostracods, nematodes, nudibranchs, platyhelminths, hydroids, pycnogonids, colonial ascidians, other bryozoans, and errant polychaetes. Notably, colonies also seemed to provide a nursery habitat for juvenile mussels and decapods. On one occasion a juvenile decorator crab was found not only within a colony but with small colonies of $B$. flabellata attached to its carapace and appendages (Figure 4.1).

A site-specific difference in faunal composition was observed (but not quantified) between the Queens Wharf population and colonies from Mahanga Bay. For example, amphipods and tanaids were observed on the Mahanga Bay colonies, whereas these groups were absent in the Queens Wharf population. During observations of a colony from Mahanga Bay, an amphipod was trapped for over a period of five days during which time its strong movements became subdued and on day five only gentle beating of the pleopods was evident. During the five days there was also a build up of detritus over the amphipod. Observations were not made beyond the five days.

The ethanol-preserved samples from Queens Wharf and Mahanga Bay revealed several avicularia (c. 5\% in a colony) with organisms, from a variety of phyla, trapped between their mandibles and rostra. Figures $4.2 \& 4.3$ illustrate a sample of the various 
organisms that were captured by the avicularia from each site, including objects of a non-biological origin (Figure 4.2D). The bird's-head avicularium has the potential to capture organisms of sizes that far exceed their own by trapping stray appendages between the mandible and rostrum. In one instance, the appendage of a podolpean copepod was trapped; the body length of the copepod was ten times greater than the width and three times greater than the length of the avicularium (Figure 4.3C). In other instances, the terminal hook of the mandible actually penetrated soft-bodied organisms. Trapped organisms included a nematode (Figure 4.2A), hydroid (Figure 4.2B), the palp of a spionid worm (Figure 4.3A), an unidentified worm (Figure 4.3G), and a polychaete (Figure 4.3H).

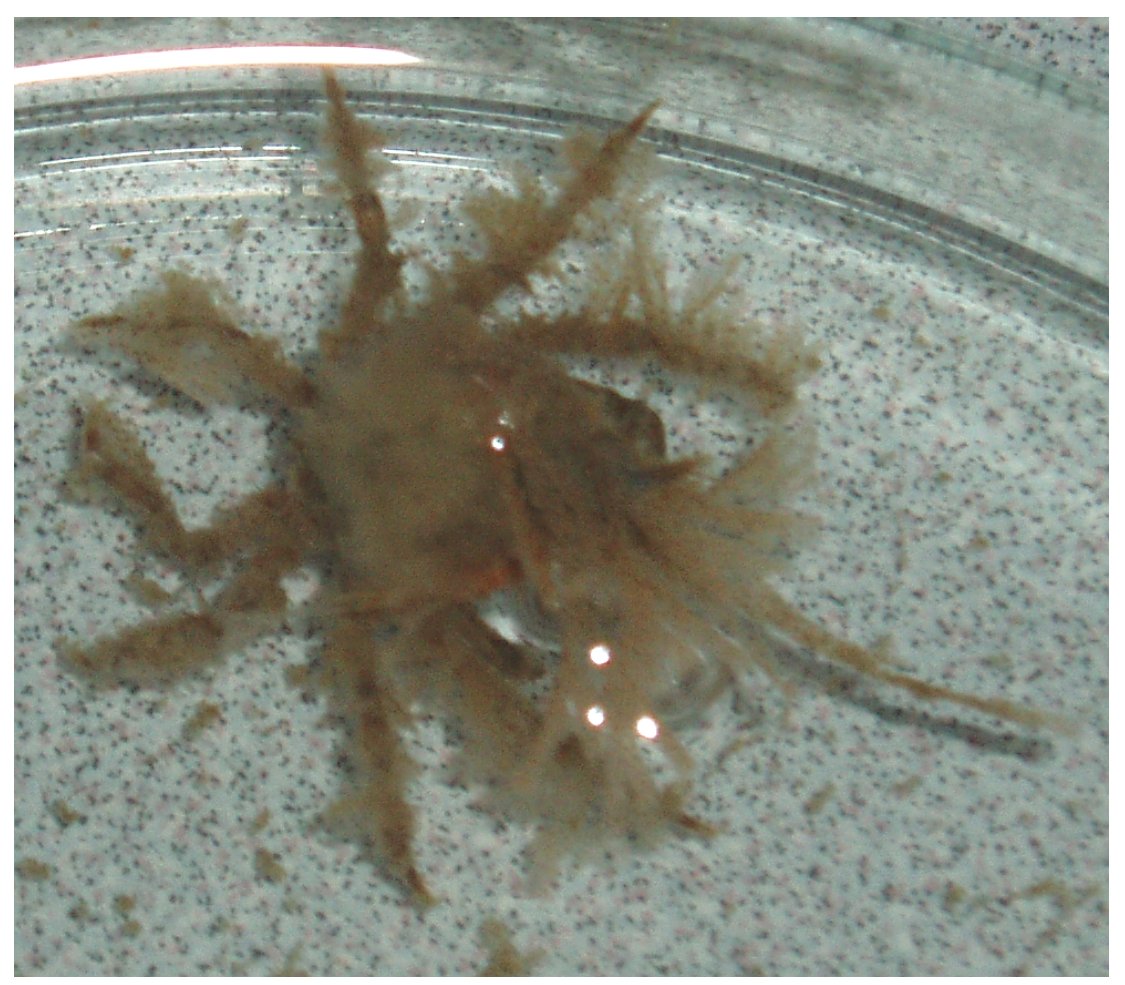

Figure 4.1. Juvenile decorator crab with colonies of Bugula flabellata attached to its carapace and appendages. Actual size ca. $1 \mathrm{~cm}$ in carapace diameter. Image taken with an Olympus Stylus 410 digital camera. 

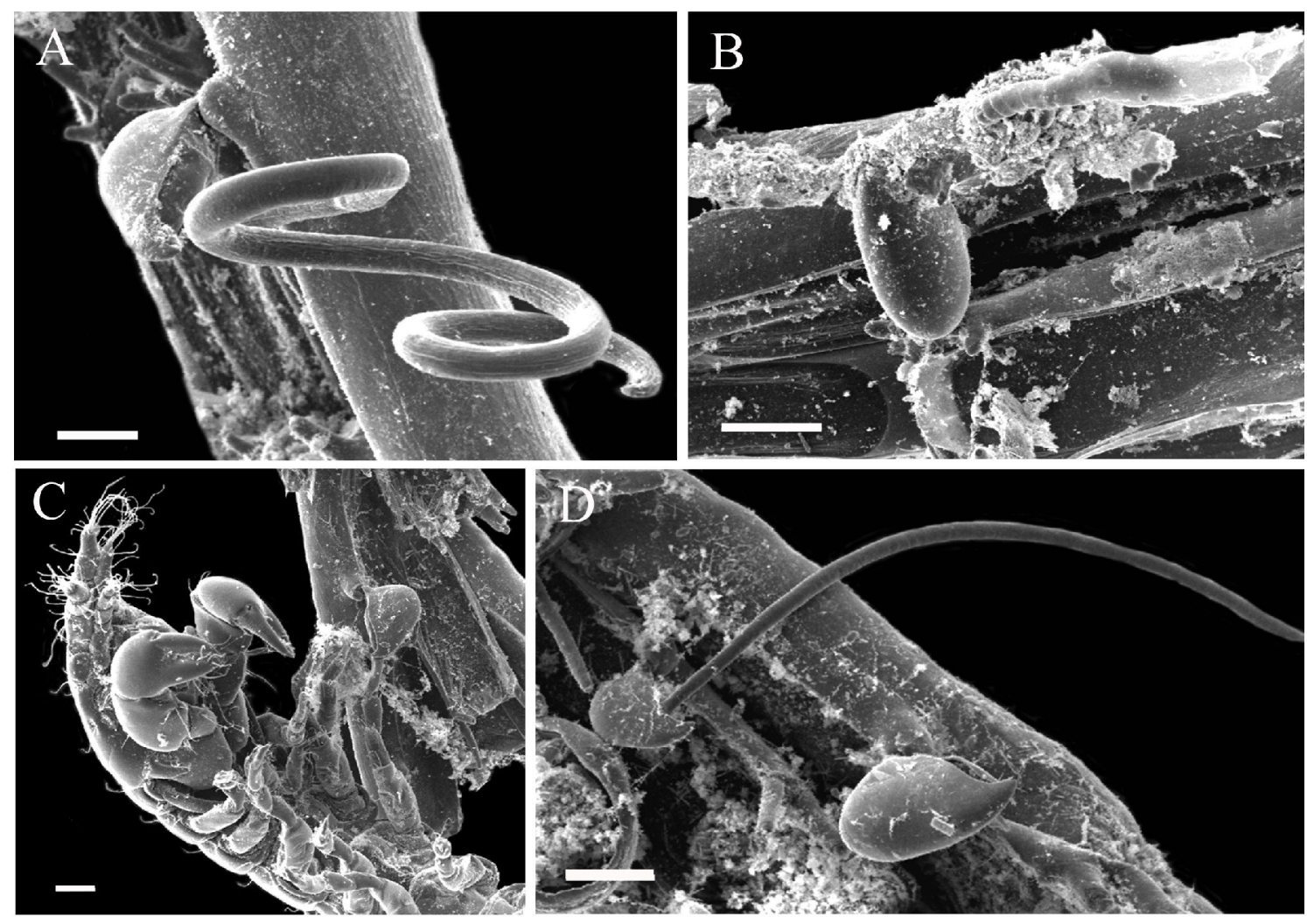

Figure 4.2. Scanning electron micrographs of Bugula flabellata from Mahanga Bay, Wellington. Bird's-head avicularia with (A) a nematode; (B) a portion of a hydroid that was growing over and between branches of the colony; (C) a tanaid; and (D) a non-biological object. Scale bars: all $100 \mu \mathrm{m}$.

Figure 4.3 (Next page). Scanning electron micrographs of Bugula flabellata from Queens Wharf, Wellington. Bird's-head avicularia with (A) and (B) a palp from a Polydora sp. (Spionidae); (C) and (D) a podolpean copepod; (E) and (F) harpacticoid copepod; (G) a piece from a worm; and (H) a polychaete. Scale bars: (A), (B), (C), (E), (G), and (H) $100 \mu \mathrm{m}$; (D) and (F) $50 \mu \mathrm{m}$. 
Chapter 4 Biology of the bird's-head avicularium

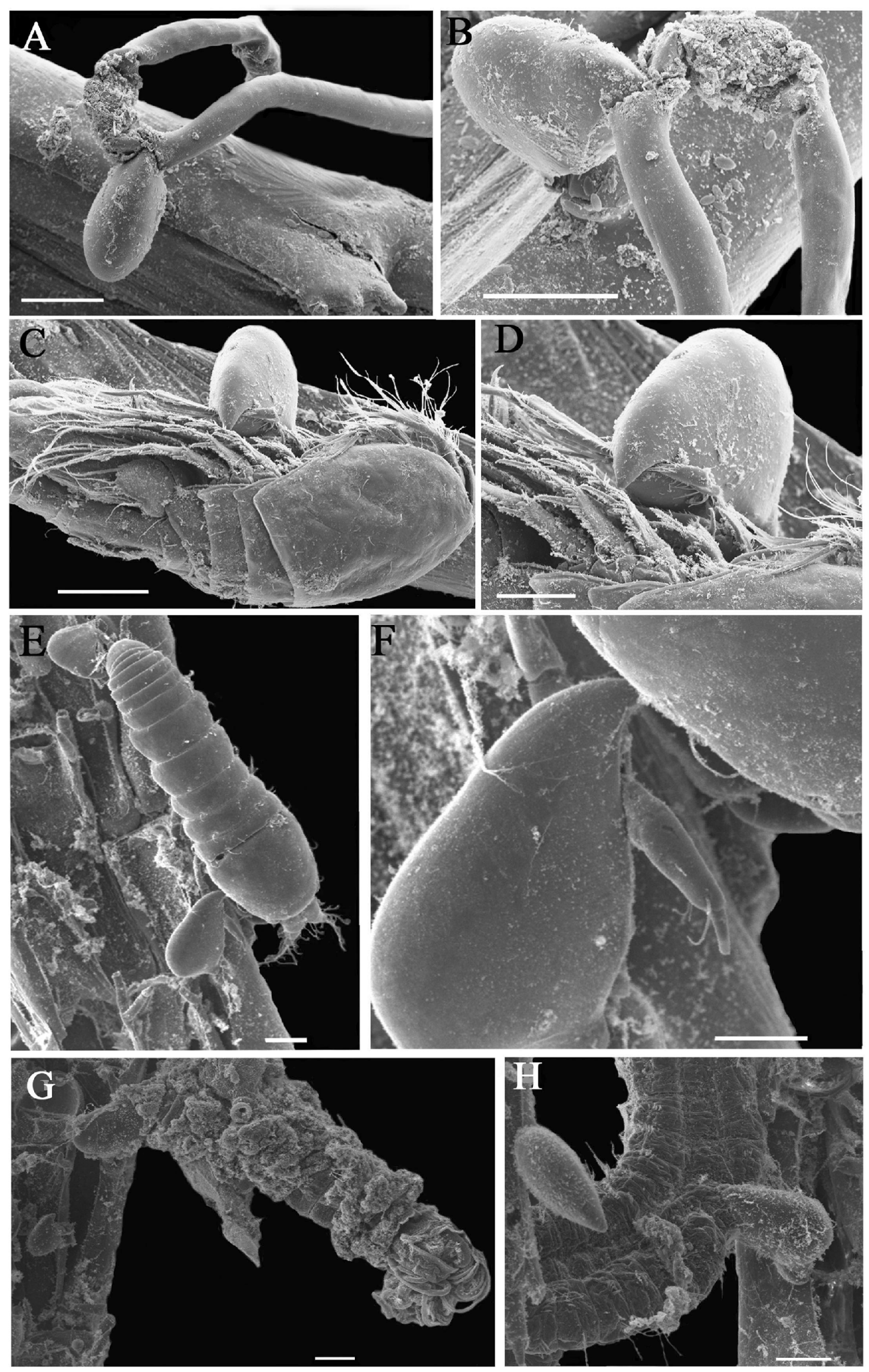


Chapter 4 Biology of the bird's-head avicularium
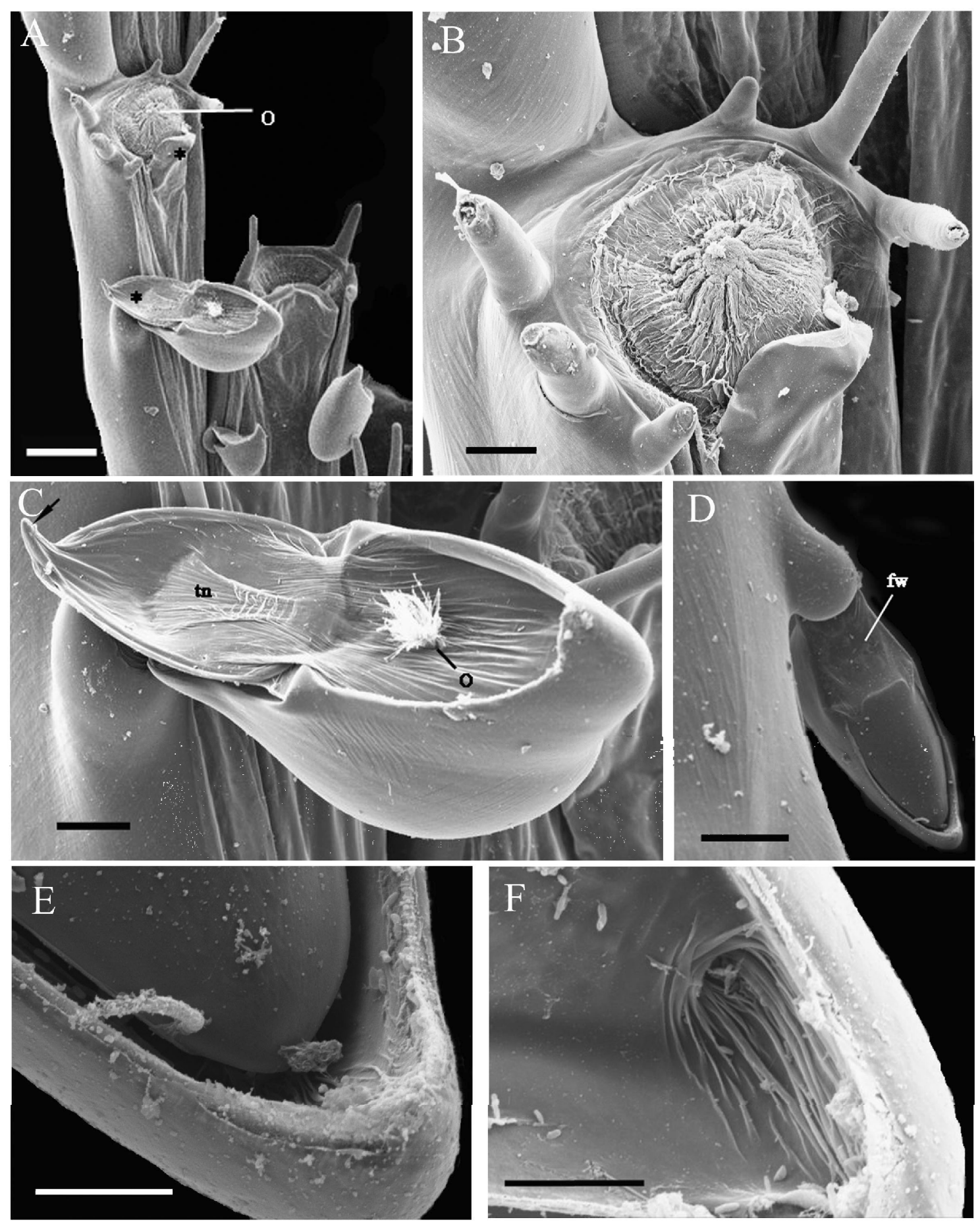
Figure 4.4 (previous page). Scanning electron micrographs of Bugula flabellata. (A) autozooids and avicularia. *Denotes pseudo-operculum in autozooid and corresponding homologue, the mandible, in the avicularium. O, orifice. Scale bar, $100 \mu \mathrm{m}$; (B) orifice of an autozooid with pseudo-operculum. The orifice is surrounded by six oral spines. Scale bar, $30 \mu \mathrm{m}$; (C) bird'shead avicularium with a central tuft of cilia emerging from the avicularian orifice (O). Arrow, terminal hook of mandible. Scale bar, $30 \mu \mathrm{m}$; (D) an avicularium with mandible closed. Proximal to the mandible is the frontal membrane underlain by a cryptocyst; this membrane extends to the peduncle and provides the flexibility required for the peduncle to articulate on the peduncle cushion. The peduncle cushion is derived from the parental autozooid and the peduncle is an extension of the avicularium. Scale bar $50 \mu \mathrm{m}$; (E) avicularium from (D) illustrating the position of the mandible inside the rostrum. Scale bar $10 \mu \mathrm{m}$; (F) the lacuna of the rostrum (hollow depression in the frontal membrane). Scale bar $5 \mu \mathrm{m}$.

\subsubsection{SEM and optical microscopy}

Every autozooid in a colony has one avicularium and occasionally two. The frontal membrane of the autozooid extends distally ending in a reinforced flap resembling an incomplete operculum. This pseudo-operculum fails to enclose the orifice and instead the orifice (an extension of the tentacle sheath) constricts tightly to encase the polypide (Figures $4.4 \mathrm{~A}, \mathrm{~B}$ ).

The operculum homologue in the avicularium is the mandible, which ends in a prominent hook (Figure 4.4C). This hook fits inside the rostrum when the mandible is closed thereby creating a seal (Figures 4.4D, E). The hook slips into a hollow depression in the membrane covering the cryptocyst of the rostrum, the lacuna (Figure 4.4F). The lacuna is surrounded by several folds in the membrane. Within the rostrum is a pouch where the hook rests when the mandible is closed and is innervated by nerves proximally and distally of the pouch (Figure 4.5).

The tendon of the adductor muscles emerges at the cross-bar and attaches midway down the mandible where it splays outward (Figures 4.4C, 4.6).

Articulation of the avicularium originates at the contact point between peduncle and the peduncle cushion. The peduncle cushion is derived from the parental autozooid (Figure 4.4D, though coelomic continuity is more apparent in Figure 4.8I), whilst the peduncle is a continuation of the avicularium. Whilst moving, the frontal membrane of the peduncle distorts in order to withstand stresses imposed upon the avicularium during normal motion as well as during erratic motion whilst 'restraining' a captured organism. 


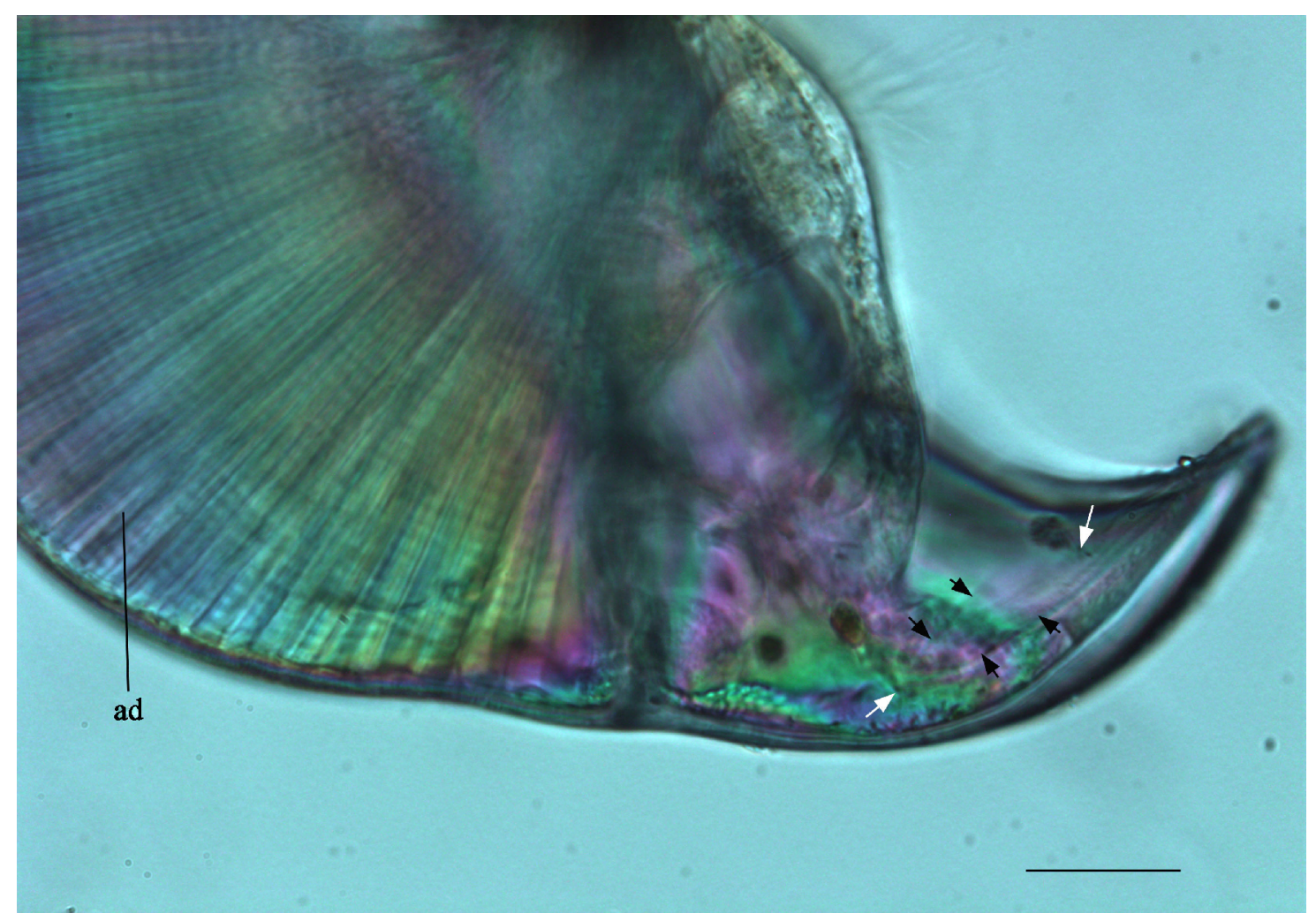

Figure 4.5. A Differential Interference Contrast (DIC) image of the distal end of an avicularium in lateral view. An internal pouch in the rostrum where the hook of the mandible rests whilst closed (black arrows) is innervated with nerves distally and proximally (white arrows). ad, adductor. Scale bar $25 \mu \mathrm{m}$. 


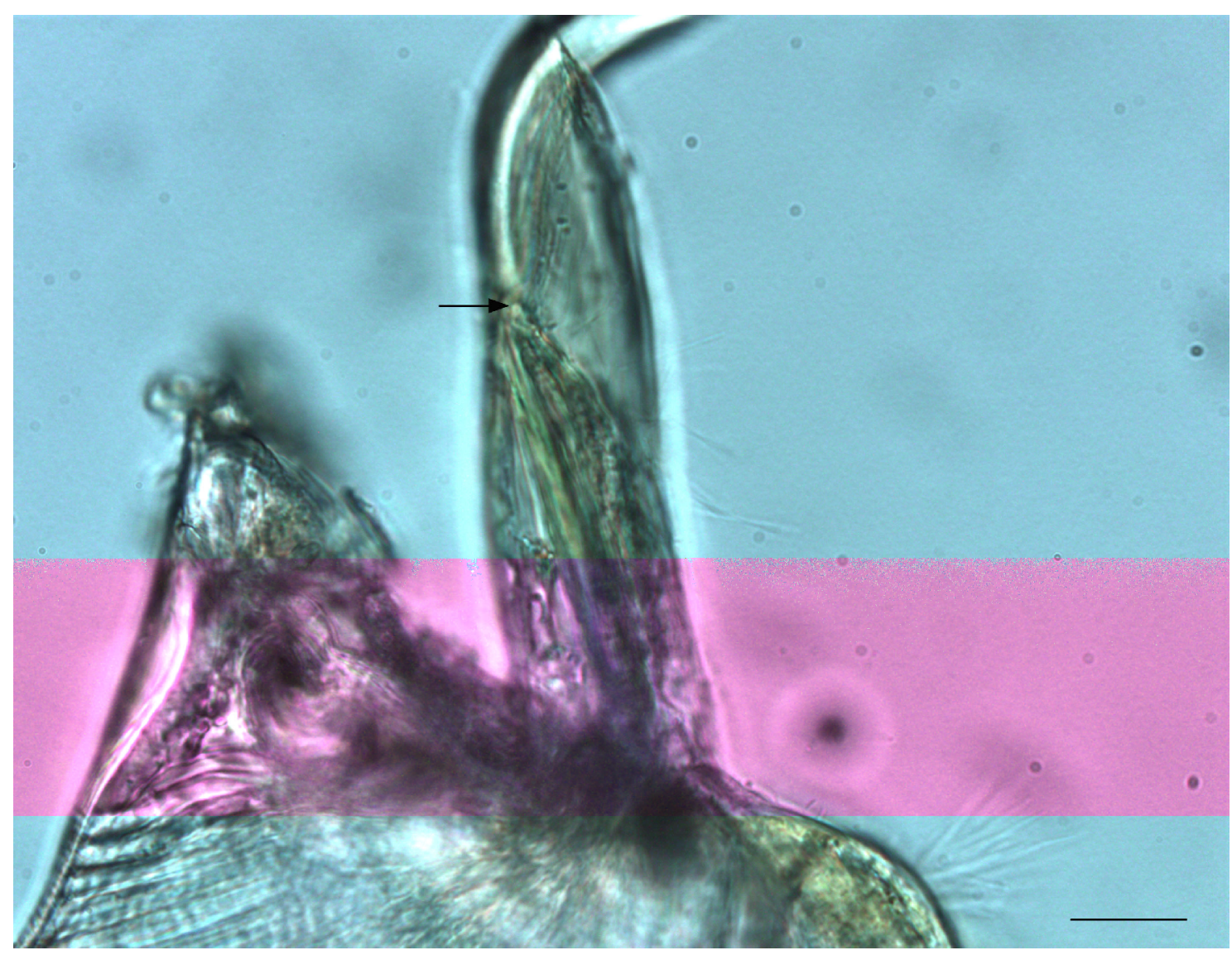

Figure 4.6. Optical image of the mandible of an avicularium (open) in lateral view. Arrow indicates the point of tendon attachment to base of the mandible. Scale bar $20 \mu \mathrm{m}$.

\subsubsection{Muscular anatomy of Bugula flabellata}

The anatomical deviations of an avicularium from an autozooid are given in Table 4.1. The orifice of the autozooid consists of a series of circular muscles with adductor muscles attaching either side of the orifice (Figure 4.7). In the avicularium, the adductors are far more extensive. They arise on each lateral side starting at the mid-line of the basal cystid, extend around each side of the vestigial polypide, and converge into a tendon which inserts into the mandible through the cross-bar. The mechanism involved in closing the mandible starts with the contraction of the striated fibres of the adductor muscles which then pull on the tendon that attaches to the middle of the mandible, pulling it to the closed position (Figures 4.8D, E, 4.9B). When the mandible is open the adductor muscles are relaxed, the tendon then lies in the plane of the open mandible and the connection point between the tendon and adductors then lies juxtaposed with the cross-bar (Figures $4.8 \mathrm{H}, \mathrm{I}$ ). 
The retractor muscles of the avicularium are significantly reduced compared to the system evident in the autozooid. In the autozooid the retractor muscles insert at various places along the polypide and extend to the proximal end of the basal cystid (Figure 4.7, 4.9A). In the avicularium, a single retractor fibre emerges from each side of the median constriction of the vestigial polypide and attach to the basal cystid along with the adductor system (Figures 4.8D, E).

The autozooid has a series of circular muscles starting with a pair at the esophagus and continuing down through the gut and caecum (Figure 4.7). In the avicularium this system is highly reduced with only a pair of circular muscles located at the orifice of the vestigial polypide (Figure 4.8D, 4.9A).

The parietal muscles of the autozooid attach the polypide to the frontal membrane. In the avicularium these muscles are now the abductors. There are two pairs of abductor muscles in the avicularium; a smaller proximal pair, consisting of a single fibre extends from the basal cystid to the frontal wall anteriorly to the peduncle (Figure $4.8 \mathrm{~F}, 4.9 \mathrm{C})$. A second larger pair extends proximally from the basal cystid, just before the cryptocystal reinforcement of the rostrum and attach to the frontal wall just proximal to the mandibular cross-bar (Figure 4.8G, 4.9C).

No F-actin fluorescence was evident in the peduncle or peduncle cushion of the avicularium. The peduncle cushion is a continuation of the autozooid, constricting distally at the point where the peduncle itself connects. The funicular system extends through the peduncle cushion, into the peduncle, and branches dichotomously along the periphery of the avicularium (Figure 4.8I). 
Table 4.1. Anatomical deviations of an avicularium from an autozooid in Bugula flabellata.

Anatomical

Autozooid

Avicularium

Structure

Retractor muscles

Polypide

Operculum

Orifice

Mouth

Tentacle sheath

Parietal muscles

Adductor muscles

Cerebral ganglion
Extensive system arising each side of the polypide, extending to the proximal base of cystid. Responsible for retraction of polypide

Fully functional digestive gut and lophophore (with ciliated tentacles)

Secondarily absent and has a reinforced 'flap' or pseudo-operculum

Consists of circular muscles that constrict to encase the polypide. Arises as an extension of the tentacle sheath

Sphincter of circular muscles

Epithelial membrane encasing the polypide, extends to form the orifice
Reduced to a single muscle fibre attaching on each side of the median constriction of the vestigial polypide. Possibly retract the vestigial polypide to some extent or provides support/stability

Polypide vestigial, comprising of ciliated sensory cells

Highly modified, comprising of a heavily reinforced and hinged mandible

A pore in the palate for eversion of cilia. Derived from an epithelial membrane with a possible tentacle sheath origin

Circular muscles of vestigial polypide

Epithelial membrane encasing the vestigial polypide, extends to form the orifice, palate, and mandibular layer (c.f palatal membrane)

Insert on the lateral and frontal walls. Proximal and distal abductors. Responsible for eversion of the Combined, these muscles may lophophore by increasing internal provide the mechanical force hydrostatic pressure during contraction enabling avicularium to swing to and fro

A small bundle of muscle on either side of the orifice

Highly augmented system responsible for closing the mandible

Neural convergence point proximal to the lophophore
Neural convergence point proximal to ciliated cells of the vestigial polypide 


\subsubsection{Serotonergic neuroanatomy of the bird's-head avicularium}

The results presented here represent the most successful outcome from a series of attempts to optimise this protocol. Problems encountered included: Non-specific binding, lack of signal or immunoreactivity, and contamination of the control samples with secondary antibody. With respect to the results presented here, though immunoreactivity was evident in the avicularium, there was extensive non-specific binding on the surface of the avicularium making a definitive neuroanatomical description difficult.

Serotonergic immunoreactivity was evident basally to the vestigial polypide and specifically the cerebral ganglion (Figures 4.10A, B). From this ganglion, one axon emerges either side and runs along the lateral margins of the avicularium (Figures 4.10B, F), then branches abrostrally to give rise to the vestibular sensory neurons (Figure 4.10C). A small network of vestibular nerves exists within the rostrum (Figure 4.10 ), terminating in a circular ring (the lacuna nerve ring) (Figure 4.10E). 


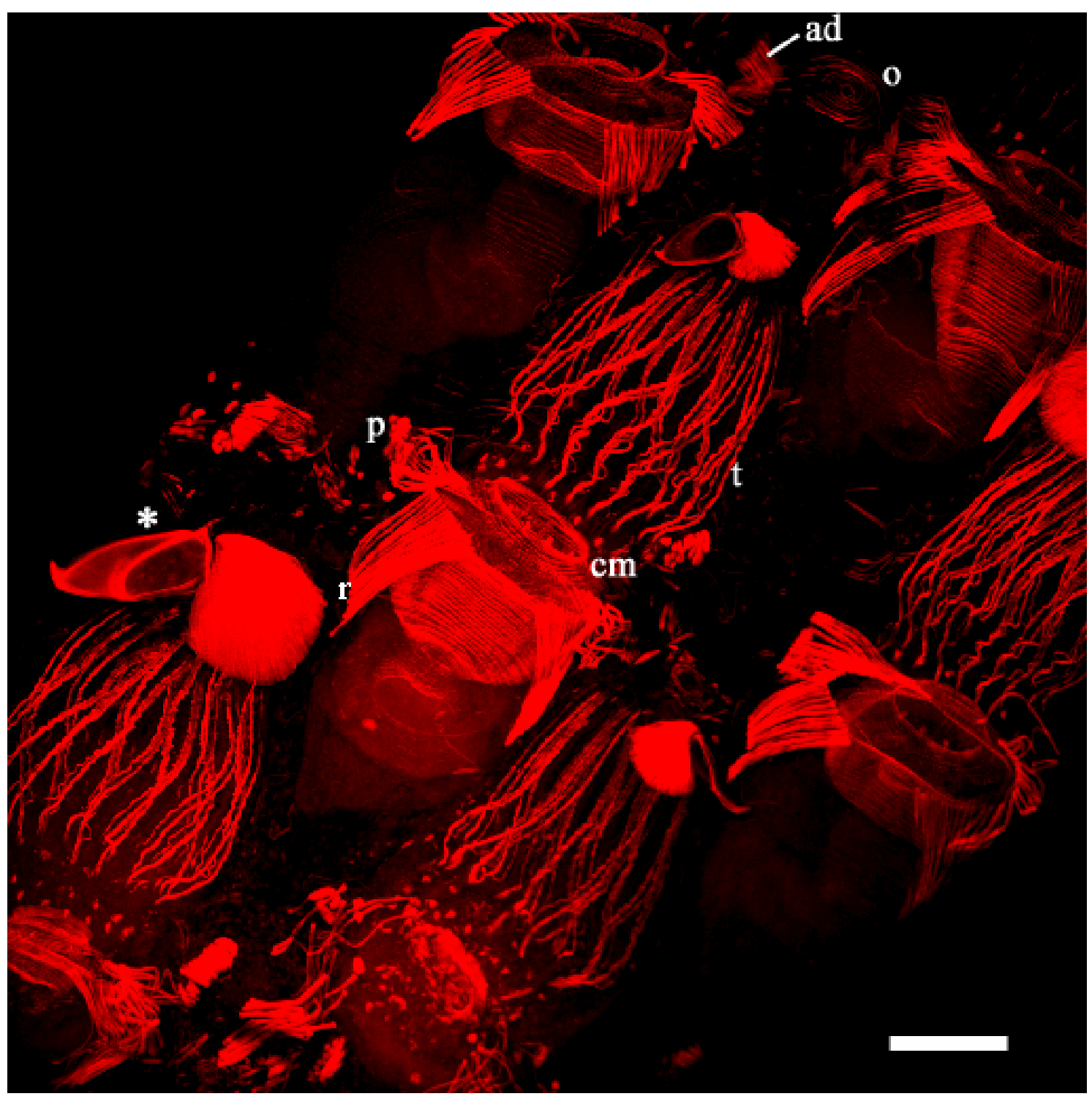

Figure 4.7. Laser scanning confocal z-projection of Bugula flabellata (autozooids with avicularia) stained with Phalloidin conjugated with an Alexa Fluor 568 fluorescent dye to target F-actin. Frontal view of colony with autozooids distally directed angled slightly to the right. ad, adductor muscles; cm, circular muscles of oesophogus; o, orifice; $p$, parietal muscle; r, retractor muscles; t, tentacles; * denotes avicularium in Figure 4.8G. Scale bar $75 \mu \mathrm{m}$. 
Chapter 4 Biology of the bird's-head avicularium
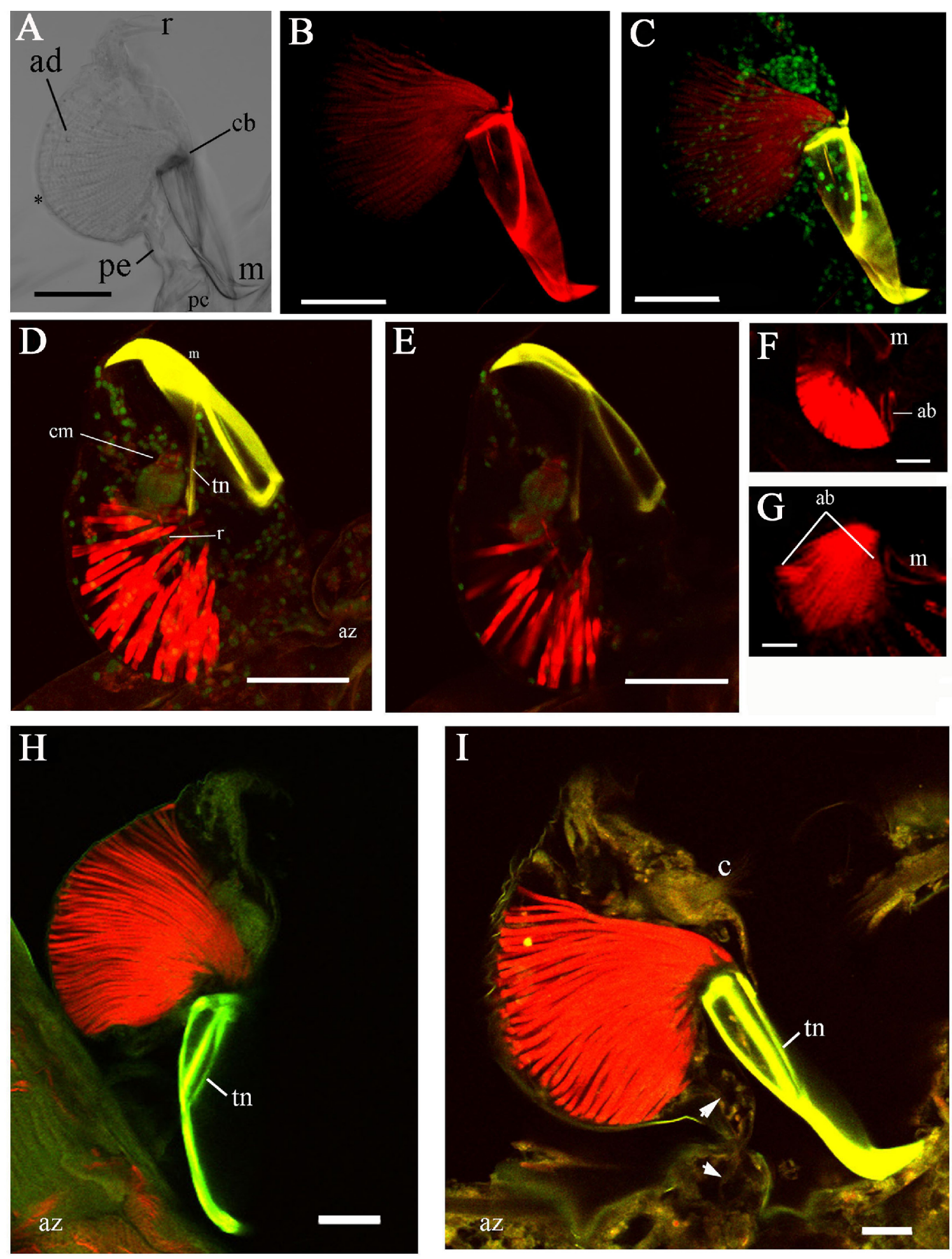
Figure 4.8 (previous page). Bird's-head avicularium of Bugula flabellata. (A) Optical micrograph of an avicularium in lateral view annotated with relevant anatomy. ad, adductor muscles; cb, cross-bar; m, mandible; pc, peduncle cushion; pe, peduncle; and $\mathrm{r}$, rostrum. * Denotes basal cystid wall. (B) to (I) are laser scanning confocal z-projections of avicularia stained with phalloidin conjugated with an Alexa Fluor 568 fluorescent dye to target F-actin in muscle (Red) and are orientated as close as possible to (A). Green and yellow fluorescence indicates autofluorescence; (B) z-projection of avicularium from (A) showing the large adductor muscles converging at the cross-bar of the open mandible; (C) avicularium from (A) and (B) placing the adductors (red) in context with the vestigial polypide (green); (D) avicularium with mandible closed, the adductor muscles converge and attach to a tendon (yellow), which then attaches to the middle portion of the mandible. A pair of circular muscles encircles the orifice of the vestigial polypide. A pair of retractor fibres attach either side of the vestigial polypide; (E) avicularium of (D) illustrating clearly the insertion of retractor fibres onto the median constriction of the vestigial polypide; (F) Avicularium with mandible closed. The proximal abductor fibres extend from each side of the basal cystid and attach to the frontal wall; (G) avicularium from Figure 4.7 (with mandible open) with the larger distal abductor muscles emerging distally, just before the cross-bar of the rostrum, and attaching to the frontal wall, just proximal of the mandibular cross-bar; $(\mathrm{H})$ avicularium in lateral view with mandible open placing the tendon in the plane of the open mandible and extending the adductor muscles to the cross-bar; (I) avicularium in lateral view with mandible open. The peduncle cushion is outlined as a continuation of the autozooid. The funicular system extends from the parental autozooid, through the peduncle cushion, and into the peduncle (Arrows). ab, abductor muscle; az, autozooid; c, cilia; cm, circular muscles; $m$, mandible; $t$, tentacles of autozooid; tn, tendon. Scale bars $50 \mu \mathrm{m}$. 
A

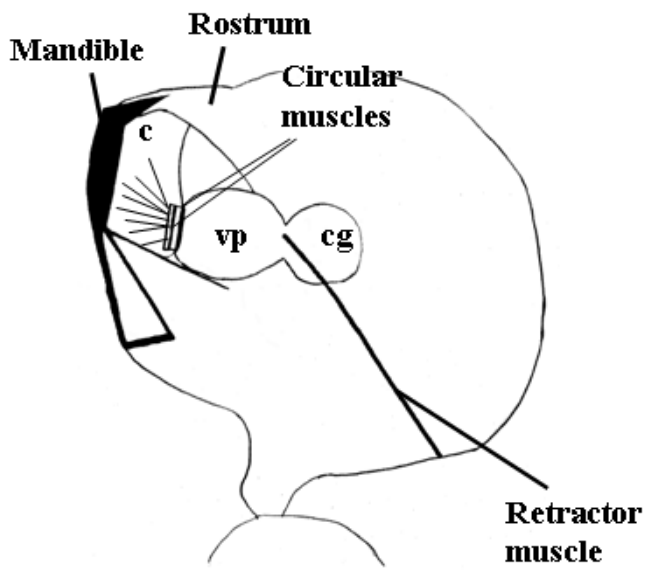

C

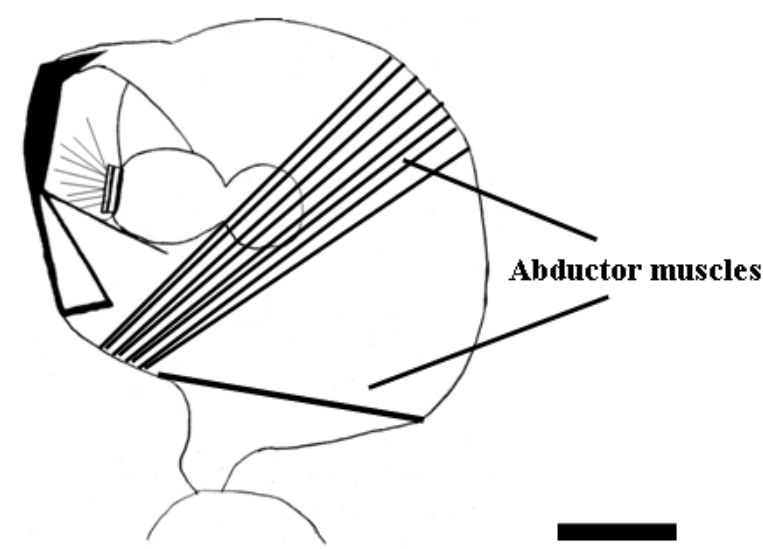

B

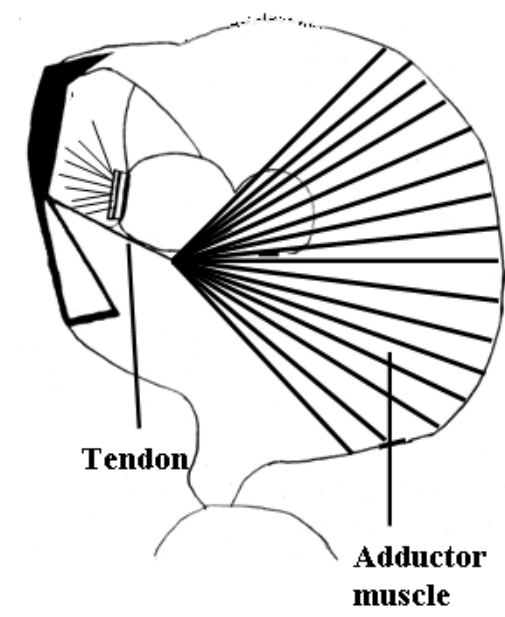

Figure 4.9. Diagrammatic representations of the muscular system in the avicularium of Bugula flabellata. Scale bar $50 \mu \mathrm{m}$. (A) Avicularium showing the insertion of the retractor muscle on the median constriction of the vestigial polypide and two circular muscles of the vestigial polypide orifice; (B) Adductor muscles attach at the basal cystid and converge at the vestigial polypide into a tendon which then attaches to the centre of the mandible; (C) A series of fibres forms the anterior abductor muscles whilst a single fibre forms the posterior abductor muscle, each insert on the frontal wall. 

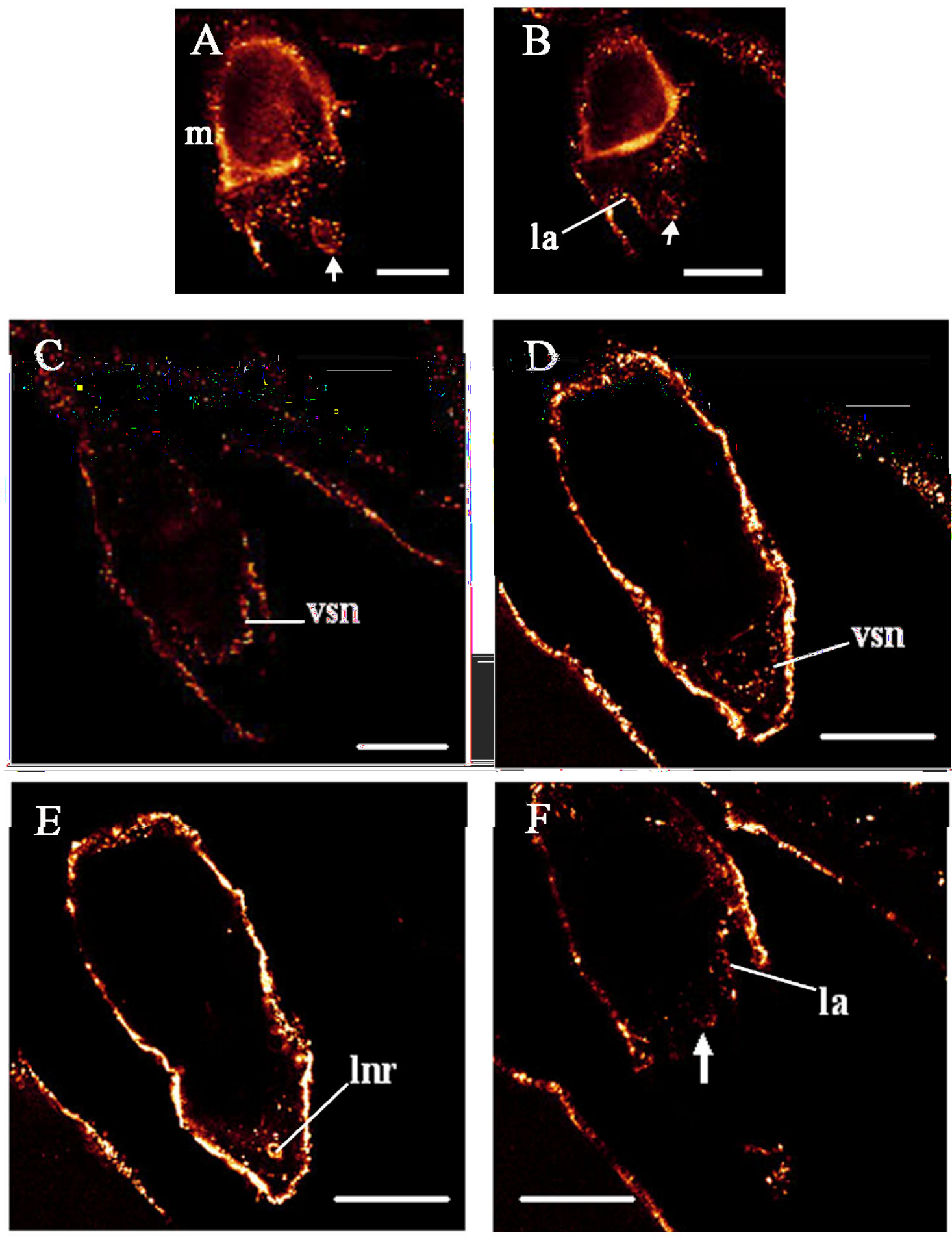
Figure 4.10 (previous page). Laser scanning confocal z-projections of the serotonergic nervous system of the avicularium of Bugula flabellata. Z-sections were taken along the longitudinal plane (but transverse through vestigial polypide), in a frontal to basal direction with (A) to (E) representing serial sections from the same avicularium. (A) z-projection of vestigial polypide area showing the cerebral ganglion; (B) z-projection of the vestigial polypide showing a lateral axon branching from the cerebral ganglion; (C) z-projection of the distal area showing the sensory nerves of the vestibule of the rostrum; (D) z-projection of the rostrum showing the vestibular sensory nerves; (E) z-projection of the rostrum showing the nerve ring of the lacuna; (F) z-projections of the vestigial polypide showing bilateral nerve axons branching from the cerebral ganglion. Solid arrows annotate the cerebral ganglion in all images; la, lateral axon; lnr, lacuna nerve ring; $\mathrm{m}$, mandible; vsn, vestibular sensory nerve. Scale bars $50 \mu \mathrm{m}$.

\subsection{Discussion}

\section{Behavioural observations}

The bird's-head avicularium, characteristic of the family Bugulidae, is considered the most complex and derived type, anatomically and behaviourally (Harmer 1930; Winston 1986). The bird's-head avicularium has stimulated immense speculation as to its function. The consensus appears to indicate they have a defensive role in the colony in light of their ability to capture the stray appendages of organisms (Busk 1854), yet no evidence had been documented of a bird's-head avicularium "caught in the act". Winston (1986) provided evidence of the capture of a syllid polychaete by a large spatulate interzooidal avicularium in Celleporaria albirostris. This study is the first to document the behaviour of the bird's-head avicularium: the appendages of small crustaceans (e.g. tanaids, copepods) were often trapped in the mandibles of an avicularium (Figures 4.2, 4.3). Small crustaceans such as copepods and amphipods are considered specialist consumers of bryozoans by feeding on individual autozooids (Lidgard 2008). The bird's-head avicularium may therefore be implicated in the capture of these predators. The main predators of bryozoans at the level of the zooid also include pycnogonids and nudibranchs whilst more generalist predators include fishes, decapods and echinoids which tend to consume bryozoans incidentally whilst pursuing other invertebrates (Lidgard 2008). Larval predators are not so well documented; however an amphipod of approximately $2.5 \mathrm{~cm}$ in length has been observed consuming the newly released larvae of Celleporella hyalina (J. Cancino, pers. comm).

Kaufmann (1971) detailed the functional parameters of the avicularia of Bugula simplex and $B$. stolonifera in terms of ascertaining the size of organism that could potentially be trapped based on the angle of the open mandible. He concluded that the 
avicularia have the ability to trap objects of 0.1-0.5 $\mathrm{mm}$ in diameter. The avicularia of $B$. simplex and B. stolonifera are apparently well suited for grasping hold of the many appendages of the gammaridean amphipods Corophium insidiosum and Jassa falcata. These amphipods were present in high numbers on the colony and built their detritus based tubes over the colony, often obstructing the orifice of the autozooid and preventing the lophophores everting to feed. By calculating the angle at which the mandible of the avicularium can open, and measuring the length of the amphipods, Kaufmann conjectured that the biological role of Bugula is defence against tubebuilding amphipods (Kaufmann 1968, 1971). In order to test this hypothesis an empirical investigation would be required that involves manipulating avicularia and amphipod densities in a controlled experiment.

\section{Gross morphology}

The transition from autozooid to avicularium in B. flabellata is quite remarkable. On a gross level, the morphology of the avicularium is such that it could prove to be a formidable threat to any stray invertebrate, and has provoked much discussion since Charles Darwin's (Darwin 1845, 1872) observations. The terminal hook of the mandible is one aspect of the avicularium that has caused speculation. Kaufmann (1971) suggested that the function of the 'spike' is to prevent objects from slipping out past the end of the mandible as it closes or to puncture any objects that are small enough to fit between the spike and the rostrum. Certainly, the hook has the potential to pierce any soft-bodied organism (Figures 4.2A, B, 4.3A, G, H) but it may simply be an extension of the mandible in order to create a seal once it is closed (Figure 4.4D) by placing the hook into the lacuna (Figure 4.4F). Surprisingly, the lacuna, or any other form of depression in the rostrum, has never been documented before. Many authors have described and annotated the closed mandible of a bird's-head avicularium with an overbite of the rostrum to mandible, yet no comment has been made regarding the final resting place of the terminal hook (e.g. Harmer 1926; Hyman 1959; Kaufmann 1968, 1971; Lutaud 1977b; Winston 1984). Further examination of other taxa will reveal whether or not the lacuna of the rostrum is a ubiquitous feature of avicularia, specifically those morphologies possessing a terminal hook. 


\section{Musculature anatomy of Bugula flabellata}

The evolution of the muscular system from functional autozooid to avicularium has involved substantial augmentation in the development of the adductor muscles. This development really equates to a co-evolution of muscle development and allometric design of the avicularium. The adductors are highly augmented as a response to an increase in size and strength of what is now the heavily reinforced mandible. In the case of Bugula the transformation from 'operculum' to avicularian mandible is quite remarkable. Bugula is considered exceptional in that a definitive operculum is secondarily absent (Ryland 1970) and instead comprises a reinforced raised 'flap' or pseudo-operculum and series of circular muscles that constrict to close the orifice (Figures 4.4B, 4.7). The operculum is a unique structure in cheilostome bryozoans and is considered the only characteristic that is a prerequisite for the occurrence of avicularia because it is the operculum that is hypertrophied into the avicularian mandible, or seta of vibracula (Silén 1977).

The retractor muscles have also undergone extensive modification. In autozooids, the retractor muscles are considered the most prominent muscles in bryozoans and are responsible for retracting the polypide (Mukai et al. 1997). In the avicularium of $B$. flabellata the retractors have become reduced to a pair of single fibres and it is unclear whether they have any functional role other than support. Presumably the reduction of the retractor muscles over evolutionary time is a function of the vestigial status of the polypide, which no longer has any digestive capacity and therefore does not require any extensile capability. Marcus (1939) examined the muscular anatomy of avicularia from a range of taxa using basic staining and optical microscopy techniques. Using these methods, Marcus noted the presence of the retractor muscles in the avicularia of Rhynchozoon phrynoglossum, Celleporina costazii, and Securiflustra securifrons but not in any of the bird's-head forms of Bugula avicularia, Beania intermedia, or Bugula ditrupae.

This study, which contains the first confocal images of bryozoan avicularia, reveals numerous previously unknown features of avicularian anatomy. Thus the previously undetected retractor muscles attaching at the median constriction of the vestigial polypide and inserting on the basal wall of the cystid amongst the extensive adductor fibres. 
Similarly, confocal microscopy has revealed circular muscles at the orifice of the vestigial polypide that have not been documented before. The presence of these muscles implies that the orifice is capable of some degree of constriction (Figure 4.8D). Likewise, the retractor muscles could potentially retract the vestigial polypide, to some extent, deeper into the avicularium and in turn retract the cilia (Figures 4.8D, E2). When an organism is trapped, the mandible is capable of closing tightly and creating a seal so that by retracting the cilia slightly, the avicularium could prevent any potential damage or severe mechanical distortion of the cilia.

The parietal muscles of the anascan autozooid are located on the lateral walls and frontal membranes. Contraction of the parietal muscles pulls the frontal membrane down and thereby increases the hydrostatic pressure within the coelomic cavity of the autozooid, which in turn everts the polypide (Ryland 1970; Mukai et al. 1997). The presence of muscle fibres attaching to the frontal membrane of the avicularium of $B$. flabellata to the basal cystid wall indicates the abductors are the parietal homologues. In B. flabellata the distal abductors attach just before the reinforced cryptocystal-bar of the rostrum and extend to the frontal membrane, just proximal of the mandible. A second set of abductors attaches at the proximal end of the basal cystid wall, just before the peduncle, and extends to the proximal base of the frontal membrane. The high degree of specificity of phalloidin staining combined with confocal microscopy enabled the abductor anatomy to be discerned in greater detail than previous studies have achieved. During a study of the nervous system of B. flabellata, Lutaud (1977b) was able to distinguish two sets of abductor muscles and whilst the description of the proximal set concurs with the current study, the distal set was described as located centrally of the avicularium and not the extreme distal location detected by confocal microscopy. The location of the distal abductors in B. flabellata concurs with B. ditrupae (Marcus 1939), Cornucopina conica, and C. geniculata (Harmer 1926). C. conica differs from $C$. geniculata by having an extra set of abductors located distally plus a proximal set not present in $C$. genicullata. The congener $C$. moluccensis is described as just having one set of proximal abductors (Harmer 1926). Overall abductor anatomy in the genus Cornucopina remains unclear as the insertion points on the frontal membrane remain obscure in Harmer's (1926) description.

The precise mechanism involved in the opening of the mandible in B. flabellata is unclear. A dichotomy of opinion exists that suggests that either both sets of abductors 
(Kaufmann 1971) or the distal set only (Hyman 1959; Winston 1984) are responsible for opening the mandible. Regardless of which muscles function to open the mandible, the mystery still remains regarding how this is achieved. The abductors actually attach to the frontal membrane and not the mandible, an arrangement that concurs with the avicularia from taxa studied to date (for examples see Harmer 1926; Marcus 1939; Hyman 1959; Silén 1977). If it is assumed that the abductors are the parietal homologue then presumably one or both sets of abductors must pull on the frontal membrane of the avicularium during contraction and in doing so, force the mandible open. Alternatively, the relaxation of the adductors may simply be enough to open the mandible. Resolution of this uncertainty may lie in the field of electrophysiology and is therefore beyond the scope of this study.

Based on observations by Marcus (1939), developmental pathways leading to the formation of the peduncle may be variable between taxa. By using hematoxylinbased stains, Marcus noted an avicularium-derived peduncle for Bugula ditrupae and $B$. avicularia. In contrast, an autozooid-derived peduncle was described for Synnotum aegyptiacum and Beania intermedia. In B. flabellata, the peduncle is aviculariumderived and the cushion is autozooid-derived (Figure 4.8I). Clearly, this is an area that requires further investigation as such disparities in developmental pathways could potentially offer insight into the evolutionary development of avicularia, particularly in members of the same superfamily (i.e. Bugula, Beania, and Synnotum). Marcus (1939) also noted that muscle fibres occurred in the peduncle cushion but not in the peduncle of the avicularium of Bugula ditrupae whereas Kaufmann (1971) was unable to find muscle fibres in either the peduncle or cushion in B. simplex and B. stolonifera. By employing a technique that involves specific staining of F-actin it is possible to ascertain the presence or absence of muscle fibres. B. flabellata has no muscles in the peduncle cushion or peduncle; therefore it is possible that the generic stain used for $B$. ditrupae highlighted the funicular system which can be seen in the cushion and peduncle of B. flabellata (Figure 4.8I). Silén (1977) also noted the absence of any muscles in the peduncle of the bird's-head avicularia of Bugula and Bicellariella and remained perplexed over the mechanism involved in the back and forth movement characteristic of these avicularia. The contraction of the two sets of abductor muscles may provide enough mechanical force to swing the avicularium back and forth on the peduncle cushion, but this idea is highly speculative. 
The highly augmented adductor system has to provide sufficient force to close the heavily reinforced mandible. The adductors converge into a tendon which attaches to the middle of the mandible (Figures 4.8D, E). The tendon can be observed on the external surface of the open mandible in an SEM image but appears to splay across the mandible rather than appear as a single fibre (see Figure 4.4C). The phalloidin protocol used in this study would not be able to discern individual tendon fibres as tendons are composed of collagen-rich connective fibres (Campbell 1996) and not F-actin.

\section{Serotonergic nervous system of the bird's-head avicularium}

Serotonin has been implicated in modulating the general arousal state associated with locomotor, feeding, defensive and other behaviours in a range of invertebrates based on its ability to up-regulate spontaneous activity and reactivity in neural and muscular systems (Weiger 1997; Sudlow et al. 1998). Nudibranchs particularly are an accessible experimental system owing to the presence of giant neurons and ganglia. In Pleurobranchaea, the metacerebral giant neurons are the major source of serotonin activity providing innervation of the feeding network in the buccal ganglion and the feeding musculature of the buccal mass in the mouth area. These giant neurons are activated by touch, chemosensory stimuli and activity in the feeding oscillator motor network. Also in Pleurobranchaea, immunoreactivity occurred in areas responsible for modulating escape swimming, and creeping locomotion (Sudlow et al. 1998).

The physiological control of ciliary activity in many invertebrates is mediated by serotonin (Gosselin 1961). For example, the beating of the lateral cilia on lamellibranch gills of molluscs is mediated by serotonin (Gosselin 1961; Schor 1965; Scheide \& Dietz 1986; Beiras \& Widdows 1995). In the echinoplutei of Hemicentrotus pulcherrimus, serotonin receptors are located in the ciliary band region. Serotonin is secreted from the apical ganglion and stimulates the elevation of intracellular $\left[\mathrm{Ca}^{2+}\right]$ in the larval ectodermal cells through the serotonin receptor network (Katow et al. 2007). Studies on the larvae and juveniles of brachiopods and phoronids have shown serotonin immunoreactivity in the apical ganglion with innervation extending to the tentacles and around ciliary bands of lophophores (Hay-Schmidt 1990, 1992; Santagata 2002). Similarly, in the bryozoan larva of Triphyllozoon mucronatum, serotonergic nerves underlie the locomotory ciliary band (Wanninger et al. 2005). In fact serotonergic nerves appear to underlie the ciliary bands of most lophotrochozoans (Hay-Schmidt 
2000). In the planktonic rotifers, Conochilus coenobasis and C. dossuarius, serotonin immunoreactivity was located in the cerebral ganglion and along the border of the coronal cilia and implicated in modulating ciliary activity (Hochberg 2006). In the avicularium of $B$. flabellata serotonin immunoreactivity was localised in the cerebral ganglion, which is closely associated with the ciliated cells of the vestigial polypide. There is strong evidence to suggest that serotonin plays a major role in mediating ciliary beating in the bird's-head avicularium of $B$. flabellata. The lophophore of adult bryozoans has ciliated tentacles responsible for creating localised water currents and directing food particles to the mouth (Ryland 1976; Nielsen 2002). Serotonin was discovered in the cerebral commissure (or ganglion) at the base of the lophophore in the ancestrula of Triphyllozoon mucronatum (Wanninger et al. 2005) and the possibility of serotonin mediated ciliary activity of the tentacles cannot be excluded and may well be implicated in modulating feeding rates in bryozoans.

The vestibular sensory nerves have been identified in B. flabellata by Lutaud (1977b) using silver-impregnation staining techniques. Peripheral axons appear to branch and extend to various parts of the rostrum (or vestibule) but no terminal nerve ring was described. Serotonin immunoreactivity was evident within the rostrum and vestibular sensory nerves identified accordingly. The presence of serotonergic immunoreactivity in the newly described lacuna nerve ring indicates that the closed position of the mandible is an integral part in the communication system of the avicularium. The terminal hook of the avicularium would appear to slot into the lacuna of the rostrum in order to create a tight seal when closed (Figures $4.4 \mathrm{D}-\mathrm{F}$ ). The hook itself would appear to be the actual communicating structure of reference, presumably, to the open or closed status of the mandible. In terms of homology, in an autozooid, the transopercular branch of nerves runs along the hinge of the operculum in Electra pilosa (Lutaud 1977a), but no nerves appear to exist proximally where the operculum would sit when closed.

\section{Future work}

Further work is required to optimise the serotonin immunocytochemistry protocol utilising the modifications proposed below. Immunocytochemistry has enormous potential in bryozoan studies particularly in mapping nervous and musculature development in larvae, ancestrulae and adult zooids. This technique is best 
suited for anascans due to their light calcification whereas the heavy calcification of the ascophorans may present a significant barrier to antibody penetration. The serotonin distribution in B. flabellata requires further work in order to locate specific neurites as well as confirm the distribution of the axons.

Similarly, anascans are well suited for histochemistry and an extensive survey of avicularian muscular anatomy would provide useful information into the evolutionary development of body plans in bryozoans. Not only would it be possible to map the muscle system but a myriad of stains are available that target specific molecules or organelles, even in the same specimen. The potential is there to examine in detail the origin of the peduncle and peduncle cushion in the Buguloidea, gross morphology of the vestigial polypide, overall morphological deviation of avicularium from autozooid, and the presence of bacterial symbionts.

\subsection{Conclusions}

This study is the first to describe the morphology of an avicularium using confocal microscopy. Also, the behaviour of the bird's-head avicularium has been captured and documented for the first time. The integrated approach and utilisation of various techniques has enabled a greater understanding of the functional morphology of this avicularium. The evolution of the muscular system from autozooid to avicularium has involved substantial augmentation and co-reduction in the development of the muscular system. This development really equates to a co-evolution of muscle development and allometric design of the avicularium. The augmented adductor system functions to rapidly close the mandible whilst the abductor system closes the mandible. The close association between the vestigial polypide and adductor system as well as the presence of serotonin in the avicularium, supports a mechanoreceptive function where the detection and rapid response to a tactile stimulus is critical.

\subsection{References}

Barbas, D., Des Groseillers, L., Castellucci, V.F., Carew, T.J. \& Marinesco, S., 2003. Multiple serotonergic mechanisms contributing to sensitization in Aplysia: Evidence of diverse serotonin receptor subtypes. Learning and Memory 10: 373-386. 
Beiras, R. \& Widdows, J., 1995. Effect of the neurotransmitters dopamine, serotonin and norepinephrine on the ciliary activity of mussel (Mytilus edulis) larvae. Marine Biology 122: 597-603.

Bkaily, G., Jacques, D. \& Pothier, P., 1999. Use of confocal microscopy to investigate cell structure and function. Methods in Enzymology 307: 119-135.

Braubach, O.R., Dickinson, A.J.G., Evans, C.C.E. \& Croll, R.P., 2006. Neural control of the velum in larvae of the gastropod, Ilyanassa obsoleta. The Journal of Experimental Biology 209: 4676-4689.

Busk, G., 1854. Remarks on the structure and function of the avicularian organs of bryozoans; and on their value as diagnostic and vibracular characters in the classification of those creatures. Transactions of the Microscopical Society 2: 26-33.

Cadet, P., 2004. Nitric oxide modulates the physiological control of ciliary activity in the marine mussel Mytilus edulis via morphine: Novel mu opiate receptor splice variants. Neuroendocrinology Letters 25: 184-190.

Campbell, N.A., 1996. Biology. The Benjamin/Cummings Publishing Company, Inc, California, $1206 \mathrm{pp}$.

Claxton, N.S., Fellers, T.J. \& Davidson, M.W., 2006. Laser scanning confocal microscopy. In: Webster, J.G. (Ed.), Encyclopedia of Medical Devices and Instrumentation. John Wiley and Sons Inc, New York, pp. 1-37.

Dailey, M., Marrs, G., Satz, J. \& Waite, M., 1999. Concepts in imaging and microscopy: Exploring biological structure and function with confocal microscopy. Biological Bulletin 197: 115-122.

Darwin, C., 1845. Journal of researches into the natural history and geology of the countries visited during the voyage of H.M.S. 'Beagle' around the world, under the command of Capt. Fitzroy, R.N. Second edn., corrected with additions. Ward, Locke, and Co., London, $492 \mathrm{pp}$.

Darwin, C., 1872. On the origin of species by means of natural selection, or the preservation of favoured races in the struggle for life. Sixth edition with additions and corrections. John Murray, London, $458 \mathrm{pp}$.

Edgar, D.M. \& Miller, J.D., 1993. Serotonin and the mammalian circadian system: II. Phase-shifting rat behavioral rhythms with serotonergic agonists. Journal of Biological Rhythms 8: 17-31.

Filippova, A., Purschke, G., Tzetlin, A.B. \& Muller, M.C.M., 2005. Reconstruction of the musculature of Magelona cf. mirabilis (Magelonidae) and Prionospio cirrifera (Spionidae) (Polychaeta, Annelida) by phalloidin labeling and cLSM. Zoomorphology 124: 1-8.

Fong, P.P., 1998. Zebra mussel spawning is induced in low concentrations of putative serotonin reuptake inhibitors. Biological Bulletin 194: 143-149.

Fong, P.P., Philbert, C.M. \& Roberts, B.J., 2003. Putative serotonin reuptake inhibitorinduced spawning and parturition in freshwater bivalves is inhibited by mammalian 5- $\mathrm{HT}_{2}$ receptor antagonists. Journal of Experimental Zoology 298A: 67-72.

Gosselin, R.E., 1961. The cilioexcitatory activity of serotonin. Journal of Cellular and Comparative Physiology 58: 17-25.

Harmer, S.F., 1909. Presidential address, Report, 78th meeting of the British Association for the Advancement for Science, 1908, pp. 715-731.

Harmer, S.F., 1926. The Polyzoa of the Siboga expedition. Part II, Cheilostomata Anasca. Siboga-Expeditie 28b: viii, 181-501, pls 113-134. 
Harmer, S.F., 1930. Polyzoa. Proceedings of the Linnean Society of London 141: 68118.

Haugland, R.P., 1996. Handbook of fluorescent probes and research chemicals. Molecular Probes, Eugene.

Hay-Schmidt, A., 1990. Distribution of catecholamine-containing, serotonin-like and neuropeptide FMRFamide-like immunoreactive neurons and processes in the nervous system of the actinotroch larva of Phoronis muelleri (Phoronida). Cell Tissue Research 259: 105-118.

Hay-Schmidt, A., 1992. Ultrastructure and immunocytochemistry of the nervous system of the larvae of Lingula anatina and Glottidia sp. (Brachiopoda). Zoomorphology 112: 189-205.

Hay-Schmidt, A., 2000. The evolution of the serotonergic nervous system. Proceedings of the Royal Society, London, B 267: 1071-1079.

Hochberg, R., 2006. On the serotonergic nervous system of two planktonic rotifers, Conochilus coenobasis and C. dossuarius (Monogononta, Flosculariacea, Conochilidae). Zoologische Anzeiger 245: 53-62.

Honkoop, P.J.C., Luttikhuize, P.C. \& Piersma, T., 1999. Experimentally extending the spawning season of a marine bivalve using temperature change and fluoxetine as synergistic triggers. Marine Ecology Progress Series 180: 297300.

Hyman, L.H., 1959. The invertebrates: Smaller coelomate groups Chaetognatha, Hemichordata, Pogonophora, Phoronida, Ectoprocta, Brachiopoda, Sipunculida. The coelomate bilateria. McGraw-Hill Book Company, Inc, New York, 783 pp.

Kapur, S. \& Remington, G., 1996. Serotonin-dopamine interaction and its relevance to schizophrenia. American Journal of Psychiatry 153: 466-476.

Katow, H., Yaguchi, S. \& Kyozuka, K., 2007. Serotonin stimulates [Ca2+]i elevation in ciliary ectodermal cells of echinoplutei through a serotonin receptor cell network in the blastocoel. The Journal of Experimental Biology 210: 403412.

Kaufmann, K.W., 1968. The biological role of Bugula-type avicularia (Bryozoa). In: Annoscia, E. (Ed.), Proceedings of the first international conference on Bryozoa. Atti della Società Italiana di Scienze Naturali e del Museo Civico di Storia Naturale di Milano 108, pp. 54-60.

Kaufmann, K.W., 1971. The form and functions of the avicularia of Bugula (Phylum Ectoprocta). Postilla 151: 1-26.

Koss, R., Diefenbach, T.J., Kuang, S.H., Doran, S.A. \& Goldberg, J.I., 2003. Coordinated development of identified serotonergic neurons and their target ciliary cells in Helisoma trivolvis embryos. Journal of Comparative Neurology 457: 313-325.

Kotikova, E.A., Raikova, O.I., Flyatchinskaya, L.P., Reuter, M. \& Gustafsson, M.K.S., 2001. Rotifer muscles as revealed by phalloidin-TRITC staining and confocal scanning laser microscopy. Acta Zoologica 82: 1-9.

Kuang, S.H. \& Goldberg, J.I., 2001. Laser ablation reveals regulation of ciliary activity by serotonergic neurons in molluscan embryos. Journal of Neurobiology 47: $1-15$.

Kuang, S.H., Doran, S.A., Wilson, R.J.A., Goss, G.G. \& Goldberg, J.I., 2002. Serotonergic sensory-motor neurons mediate a behavioural response to hypoxia in pond snail embryos. Journal of Neurobiology 52: 73-83. 
Leasi, F., Rothe, B.H., Schmidt-Rhaesa, A. \& Todar, M.A., 2006. The musculature of three species of gastrotrichs surveyed with confocal laser scanning microscopy (CLSM). Acta Zoologica 87: 171-180.

Leise, E.M., Thavaradhara, K., Durham, N.R. \& Turner, B.R., 2001. Serotonin and nitric oxide regulate metamorphosis in the marine snail Ilyanassa obsoleta. American Zoology 41: 258-267.

Lidgard, S., 2008. Predation on marine bryozoan colonies: taxa, traits and trophic groups. Marine Ecology Progress Series 359: 117-131.

Lutaud, G., 1969. La nature des corps funiculaires des cellularines Bryozoaires chilostomes. Archives de Zoologie Expérimentale et Générale 110: 2-30.

Lutaud, G., 1977a. The bryozoan nervous system. In: Woollacott, R.M. \& Zimmer, R.L. (Eds), Biology of bryozoans. Academic Press, New York, pp. 377-410.

Lutaud, G., 1977b. L'innervation de l'aviculaire pédonculé en Bicellariidae (Bryozoaires Chilostomes). Cahiers de Biologie Marine 18: 435-448.

Lutaud, G., 1979. Etude ultrastructurale du plexus colonial et recherché de connexions nerveuses interzoidiales chez le Bryozoaire Chilostome Electra pilosa (Linné). Cahiers Biologie Marine 20: 315-324.

Mair, G.R., Maule, A.G., Shaw, C., Johnston, C.F. \& Halton, D.W., 1998. Gross anatomy of the muscle systems of Fasciola hepatica as visualized by phalloidin-fluorescence and confocal microscopy. Parasitology 117: 75-82.

Mao, S., 1999. Conjugation of fluorochromes to antibodies. In: Javois, L.C. (Ed.), Methods in Molecular Biology. Immunocytochemical methods and protocols. Humana Press, Totowa, New Jersey, pp. 35-38.

Marcus, E., 1939. Bryozoarios marinhos Brasileiros. III. BoletiMs da Faculdade de Filosofia, Ciências e Letras, Universidade de São Paulo, Zoologia 3: 111353.

McKinney, F.K. \& Jackson, J.B.C., 1989. Bryozoan Evolution. Unwin Hyman, Boston, $287 \mathrm{pp}$.

Minsky, M., 1988. Memoir on inventing the confocal scanning microscope. Scanning 10: 128-138.

Morin, L.P., 1999. Serotonin and the regulation of mammalian circadian rhythmicity. Annals of Medicine 31: 12-33.

Mukai, H., Terakado, K. \& Reed, C., 1997. Bryozoa. In: Harrison, F.W. \& Woollacott, R.M. (Eds), Microscopic anatomy of invertebrates. John Wiley \& sons Inc, New York, pp. 45-206.

Muller, M.C.M. \& Schmidt-Rhaesa, A., 2003. Reconstruction of the muscle system in Antygomonas sp. (Kinorhyncha, Cyclorhagida) by means of phalloidin labeling and cLSM. Journal of Morphology 256: 103-110.

Muller, M.C.M. \& Worsaae, K., 2006. CLSM analysis of the phalloidin-stained muscle system in Nerilla antennata, Nerillidium sp. and Trochonerilla mobilis (Polychaeta; Nerillidae). Journal of Morphology 267: 885-896.

Nielsen, C., 2002. Ciliary filter-feeding structures in adult and larval gymnolaemate bryozoans. Invertebrate Biology 121: 255-261.

Owens, M.J. \& Nemeroff, C.B., 1994. Role of serotonin in the pathophysiology of depression: focus on the serotonin transporter. Clinical Chemistry 40: 288295.

Page, L.R., 2002. Comparative structure of the larval apical sensory organ in gastropods and hypotheses about function and developmental evolution. Invertebrate Reproduction and Development 41: 193-200. 
Pfistermuller, R. \& Tyler, S., 2002. Correlation of fluorescence and electron microscopy of F-actin-containing sensory cells in the epidemis of Convoluta pulchra (Platyhelminthes: Acoela). Acta Zoologica 83: 15-24.

Portas, C., Bjorvatn, B. \& Ursin, R., 2000. Serotonin and the sleep/wake cycle: special emphasis on microdialysis studies. Progress in Neurobiology 60: 13-35.

Raikova, O.I., Tekle, Y.I., Reuter, M., Gustafsson, M.K.S. \& Jondelius, U., 2006. Copulatory organ musculature in Childia (Acoela) as revealed by phalloidin fluorecence and confocal microscopy. Tissue and Cell 38: 219-232.

Ram, J.L., Fong, P.P. \& Garton, D.W., 1996. Physiological aspects of zebra mussel reproduction: Maturation, spawning, and fertilization. American Zoology 36: 326-338.

Ruchel, J. \& Muller, M.C.M., 2007. F-actin framework in Spirorbis cf. spirorbis (Annelida: Serpulidae): phalloidin staining investigated and reconstructed by cLSM. Invertebrate Biology 126: 173-182.

Ryland, J.S., 1970. Bryozoans. Hutchinson University Library, London, 175 pp.

Ryland, J.S., 1976. Physiology and ecology of marine bryozoans. Advances in Marine Biology 14: 285- 443.

Santagata, S., 2002. Structure and metamorphic remodeling of the larval nervous system and musculature of Phoronis pallida (Phoronida). Evolution and Development 4: 28-42.

Santagata, S., 2004. Larval development of Phoronis pallida (Phoronida): implications for morphological convergence and divergence among larval body plans. Journal of Morphology 259: 347-358.

Santagata, S. \& Zimmer, R.L., 2002. Comparison of the neuromuscular systems among actinotroch larvae: systematic and evolutionary implications. Evolution and Development 4: 43-54.

Scheide, J.I. \& Dietz, T.H., 1986. Serotonin regulation of gill cAMP production, Na, and water uptake in freshwater mussels. Journal of Experimental Zoology 240: 309-314.

Schopf, T.J.M., 1973. Ergonomics of polymorphism: Its relation to the colony as the unit of natural selection in species of the phylum Ectoprocta. In: Boardman, R.S., Cheetham, A.H. \& Oliver, W.A. (Eds), Animal colonies. Dowden, Hutchinson \& Ross Inc., Stroudsburg, pp. 247-294.

Schor, S.L., 1965. Serotonin and adenosine triphosphate: synergistic effect on the beat frequency of cilia of mussel gills. Science 148: 500-501.

Silén, L., 1977. Polymorphism. In: Woollacott, R.M. \& Zimmer, R.L. (Eds), Biology of bryozoans. Academic Press, New York, pp. 184-231.

Stricker, S.A. \& Smythe, T.L., 2001. 5-HT causes an increase in cAMP that stimulates, rather than inhibits, oocyte maturation in marine nemertean worms. Development 128: 1415-1427.

Sudlow, L.C., Jing, J.J., Moroz, L.L. \& Gillette, R., 1998. Serotonin immunoreactivity in the central nervous system of the marine molluscs Pleurobranchaea californica and Tritonia diomedea. Journal of Comparative Neurology 395: 466-480.

Sun, X., 1999. Combining laser scanning confocal microscopy and electron microscopy. Methods in Enzymology 307: 135-152.

Tierney, A.J., 2001. Structure and function of invertebrate 5-HT receptors: a review. Comparative Biochemistry and Physiology, Part A 128: 791-804. 
Wang, W., 2002. Cd and Se aqueous uptake and exposure of green mussels Perna viridis: influences of seston quantity. Marine Ecology Progress Series 226: 211-221.

Wanninger, A., 2005. Immunocytochemistry of the nervous system and the musculature of the chordoid larva of Symbion pandora (Cycliophora). Journal of Morphology 265: 237-243.

Wanninger, A., Koop, D. \& Degnan, B.M., 2005. Immunocytochemistry and metamorphic fate of the larval nervous system of Triphyllozoon mucronatum (Ectoprocta: Gymnolaemata: Cheilostomata). Zoomorphology 124: 161-170.

Webb, R.H., 1999. Theoretical basis of confocal microscopy. Methods in Enzymology 307: 3-20.

Weiger, W.A., 1997. Serotonergic modulation of behaviour: A phylogenetic overview. Biological Review 72: 61-95.

Winston, J.E., 1984. Why bryozoans have avicularia - A review of the evidence. American Museum Novitates 2789: 1-26.

Winston, J.E., 1986. Victims of avicularia. Marine Ecology 7: 193-199.

Winston, J.E., 1991. Avicularian behaviour - A progress report. In: Bigey, F.P. (Ed.), Bryozoa Living and Fossil. Bulletin de la Société des Sciences Naturelles de l'Ouest de France, Mémoire, H.S, Nantes, pp. 531-540.

Yamamoto, H., Shimizu, K., Tachibana, A. \& Fusetani, N., 2000. Roles of dopamine and serotonin in larval attachment of the barnacle, Balanus amphitrite. Journal of Experimental Zoology 284: 746-758.

Yamamoto, H., Tachibana, A., Kawaii, S., Matsumura, K. \& Fusetani, N., 1996. Serotonin involvement in larval settlement of the barnacle, Balanus amphitrite. Journal of Experimental Zoology 275: 339-345.

Yokoyama, F., Onozawa, K., Kakui, N. \& Imanishi, T., 2007. The selective serotonin reuptake inhibitor fluvoxamine suppresses post-feeding hyperactivity induced by food restriction in rats. Biochemistry and Behavior 87: 98-103.

Zimmer, R.L. \& Woollacott, R.M., 1977. Structure and classification of gymnolaemate larvae. In: Woollacott, R.M. \& Zimmer, R.L. (Eds), Biology of bryozoans. Academic Press, New York, pp. 57-89. 


\section{CHAPTER 5 \\ General Discussion}

\subsection{Functional morphology of avicularia}

Bryozoans are an excellent model system for studying evolutionary development. Their modular growth form allows phenotypic modifications to occur within the framework of colony astogeny and in response to environmental cues. The iteration of morphologically and functionally differentiated modules, or zooids, is an explicit expression of polymorphism reflecting a high degree of integration within the individual colony. Increasing morphological and functional disparity evolves over long time-spans and is subsequently maintained among bryozoan lineages with significant ecological and evolutionary consequences. Yet the biology and developmental patterning associated with the formation of these polymorphs is scarcely understood. This study has contributed significantly to the understanding of one of these polymorphs; the avicularium. The diversification of avicularia in a wide variety of evolutionary clades implies that their existence is of ecological importance and that they are, and have been maintained by natural selection over million of years. An extensive survey of modern avicularian morphology (Chapter 2) revealed significant diversity in form. The observed variety in palate morphology may be considered a proxy for the degree of evolutionary development and functional diversity among avicularia. The next step is to determine the ecologically relevant cues that have influenced the observed diversity in form. In her review, Winston (1984) discussed the possible functions of avicularia and these are reviewed in Chapter 1. The objective here is to revisit those potential functions in light of the additional data obtained from this study and to provide an up-to-date synthesis of evidence and current thinking. 


\subsubsection{Defence}

The most widely accepted theory for the function of avicularia is defence (Busk 1854; Canu \& Bassler 1929; Hyman 1959; Winston 1984). This theory has been questioned, however, owing to the morphological diversity of avicularia, which suggests they have more than one function (Hincks 1888). The real issue that inspires such debate may centre on the fact that, historically, perceptions of defence were in reference to the mechanical capture of organisms. In fact, it is now widely accepted that defensive mechanisms displayed by sessile marine invertebrates can either be structural or chemical (Dyrynda 1986; Peters et al. 2003). Common themes of defence in modular sessile invertebrates often involve the production of biologically active compounds. Whereas motile invertebrates are able to take evasive action in response to predation or epibiosis, immotile invertebrates have developed other strategies to inhibit such attacks (Dyrynda 1986). Various species of corals, sponges and ascidians produce secondary metabolites that are effective against biofouling, competitive overgrowth and deterring generalist predators (Bakus 1981; Peters et al. 2003; Paul et al. 2007). Bryozoans have also been identified as a potent source of secondary metabolites though whether these metabolites are produced by the bryozoan or associated bacteria is not well established (see Blackman \& Walls 1995 for a review of 33 species of bryozoans). Ecologically, these metabolites have demonstrated anti-predatory and antifouling activities (Walls et al. 1993; Blackman \& Walls 1995; Slattery et al. 1995; Lindquist 1996; Lindquist \& Hay 1996; Narkowicz et al. 2004; Sharp et al. 2007).

The site of metabolite production within the colony has not been identified in all cases and preliminary indications suggest that avicularia are not a requirement for the production of biologically active compounds (e.g. Walls et al. 1993). Production of avicularia would seem to be an excessive cost for a function that could be performed by an autozooid based on the presence of vestibular glands in many autozooids (Lutaud 1964), which is a more likely candidate for metabolite production. Avicularia can possess glands, and in the case of Nordgaardia cornucopioides (Chapter 3) the glandular region is relatively large in proportion to the area of the vestigial polypide and clearly these secretions are of significance in the function of this avicularium. The chemical nature and function of these secretions is unknown and whether the investment in the production of specialised zooids specifically to fulfil a chemical defensive role can be justified is unclear. Some of the avicularia examined in this study appeared to 
exude an organic material from the palate orifice (e.g. Stephanollona scintillans, Figure 2.20B; Escharoides excavata, Figure 2.15C; Euthyroides jellyae, Figure 2.10B, C), the precise nature and function of which is unknown but clearly warrants further attention.

Mechanical defence is the production of specific structures that physically deter potential and active threats. An example of mechanical defence in bryozoans is the production of spines (e.g. Membranipora membranacea) in response to chemical cues from a predatory mollusc. The spines are inducible and result in the reallocation of resources into defence at the expense of colony growth and reproductive output (Harvell 1986, 1990, 1991, 1992).

Chapter 4 in this study has shown that the avicularia of Bugula flabellata act as a mechanical defence against fouling and trespassing organisms. The characteristic of a mechanical receptor is the presence of a projection, whether it be hairs or cilia, from the surface of the body and innervated directly or through a secondary structure which is innervated itself by a neuron (Laverack 1968). In the bird's-head avicularium, the cilia are in contact with the external environment (Chapters $2 \& 4$ ) and are innervated by serotonergic nerves that are implicated in ciliary motor activity (Chapter 4). The avicularium has an extensive, yet condensed adductor muscle system for rapid mechanical closure of the mandible and frequently captures small organisms, or the appendages of small organisms, that trespass over the colony (Chapter 4). Based on the functional morphology and behavioural observations on the bird's-head avicularium, tactile stimuli from passing biota are the primary environmental cue to initiate a response in this avicularium. This avicularium can be considered as multi-functional based on the presence of granular secretory vesicles in the vestigial polypide (Chapter 3 ) and therefore a chemoreceptive role may be implicated also. The energetic cost of producing a multi-functional rather than a mono-functional avicularium may be justifiable to offset the variety of potential damages incurred from external factors if undefended. If the cost of producing a multi-functional avicularium is favourable, then presumably the avicularium of $N$. cornucopioides has an additional function other than that of a chemoreceptive nature. Behavioural observations may offer some insight.

Based on the theory of Harvell (1990), the defences of invertebrates are either inducible or constitutive, depending on whether or not they require environmental stimuli. The spines of $M$. membranacea are inducible and are responding to an acute stimulus, the presence of a predatory mollusc (Harvell 1986, 1990, 1991, 1992). 
Constitutive defensive structures are produced regardless of environment (Clark \& Harvell 1992). An example of a constitutive defence in a bryozoan is the production of chemical compounds such as brominated alkaloids and diterpenes that are effective in deterring predation and selectively inhibit bacterial settlement (e.g. Flustra foliacea) (Peters et al. 2003). Harvell (1990) refers to the production of inducible spines as an example of a morphological shift. In the case of avicularia, their production may be dependent on the environmental stimulus/stimuli present and whether they are inducible in some cases is unknown. The inconsistent inter-colony distribution of avicularia in some cases (e.g. Rhynchozoon zealandicum) may be explained by the possibility that some avicularia are readily inducible in response to acute stimulus/stimuli. Astogeny refers to the development of the colony, distinguishable by colony budding pattern and zooid morphology (Ryland 1970), therefore the production of inducible defences in bryozoans can be referred to as an astogenetic shift whereby resources are redirected into defensive structures rather than colony growth and development. The converse situation of a readily induced facultative defensive structure would comprise the production of avicularia within the framework of astogeny. This would therefore be a constitutive defence produced in response to a continual threshold level of stimulus/stimuli which has remained an obligatory requirement for that species. Therefore two central themes emerge that can offer an explanation as to the mosaic distribution of avicularia in cheilostome populations: A species with a low threshold to inducer concentration would readily produce avicularia in response to acute stimulus/stimuli and would seemingly involve a significant astogenetic shift with a trade-off in the allocation of resources (e.g. polymorph production versus investment in growth or reproduction elsewhere in the colony body). Conversely, the consistent, or obligatory, formation of avicularia within a colony implies the stimulus is constant and avicularian production would be predictable (and therefore genetically programmed) and no trade-offs in the allocation of resources would be required (Table 5.1). Avicularian production would be equally dependent on external factors such as temperature and food availability. Therefore variations around these two central themes will exist with intermediate components and all being influenced by how and where resources are allocated in the colony. 
Table 5.1. Two underlying central themes that can explain the occurrence of avicularia among cheilostome bryozoans in the context of a defensive function and the trade-off implications in response to an environmental stimulus/stimuli. Based on, and extrapolated from, the theory of Harvell (1990) and Clark \& Harvell (1992).

\section{Type of defence}

\begin{tabular}{lcc} 
Implications/Response & Facultative & Obligatory \\
\hline Type of defence & Inducible & Constitutive \\
Type of stimulus & Acute & Threshold \\
Cost incurred & Additional & Integral \\
Resource allocation & Flexible & Fixed \\
Extent of astogenetic shift & Significant & Nil \\
Colony growth rate & Reduced & Unaffected \\
Reproductive output & Reduced & Unaffected \\
\hline
\end{tabular}

The taxonomic distribution of avicularia among natural populations of cheilostomes has no obvious pattern. Avicularia can occur in one species of a genus and be absent in another, or be present in one colony of a species and absent in another colony of the same species (Harmer 1909; Winston 1984). Harvell (1990) proposes that in order for a defensive response to be activated an initial threshold of inducer concentration has to be reached and that there may be a disparity in the threshold level displayed by individuals giving rise to a mosaic distribution of tolerance within a population. Based on Harvell (1990), a population of bryozoans with defensive capabilities could be comprised of some genotypes that (1) have no threshold and produce the defence continuously and without stimulation (Figure 5.1A); (2) have a range from those with low to those with high thresholds (Figure 5.1B, C, D); and (3) have a threshold set so high that the defence is never activated in nature (Figure 5.1E). If we are to extrapolate from this theory and use avicularia as an example of a defensive strategy then additional considerations are required to incorporate a theoretical response of avicularia to low levels of a stimulus that is not considered in the Harvell model (Figure 5.2). In natural populations of cheilostome bryozoans there may be species that (1) have no threshold and produce avicularia without stimulation; avicularia are an 
obligatory developmental process and therefore a constitutive defensive mechanism (Figure 5.2A; e.g. Bugula flabellata); (2) have a range of thresholds and produce avicularia over low (Figure 5.2C) to intermediate (Figure 5.2B) to high (Figure 5.2D) inducer concentrations (e.g. Rhynchozoon zealandicum); (3) have a threshold set so high that avicularia are never produced in nature (Figure 5.2E). Either the species in question has the genetic underpinning to produce avicularia but are never activated or, no genetic programming exists to produce avicularia and the defensive mechanism is at the level of the autozooid (e.g. bryostatin in Bugula neritina); (4) have a threshold that co-varies with inducer concentration and therefore avicularian production increases as a function of stimuli intensity (Figure 5.2F); and (5) have a range of low thresholds and produce avicularia in low numbers as a result of low stimuli intensity (Figure 5.2G).

Factors that could potentially influence avicularium production may include one or a combination of: food availability, temperature or reproductive phase of the colony. Identifying these species-specific components is a critical step in understanding the evolution of avicularia in nature, if they perform a defensive role. The evidence from this study suggests they do and can be either (primarily) mechanical or chemical defence (Chapter 3), or both. 


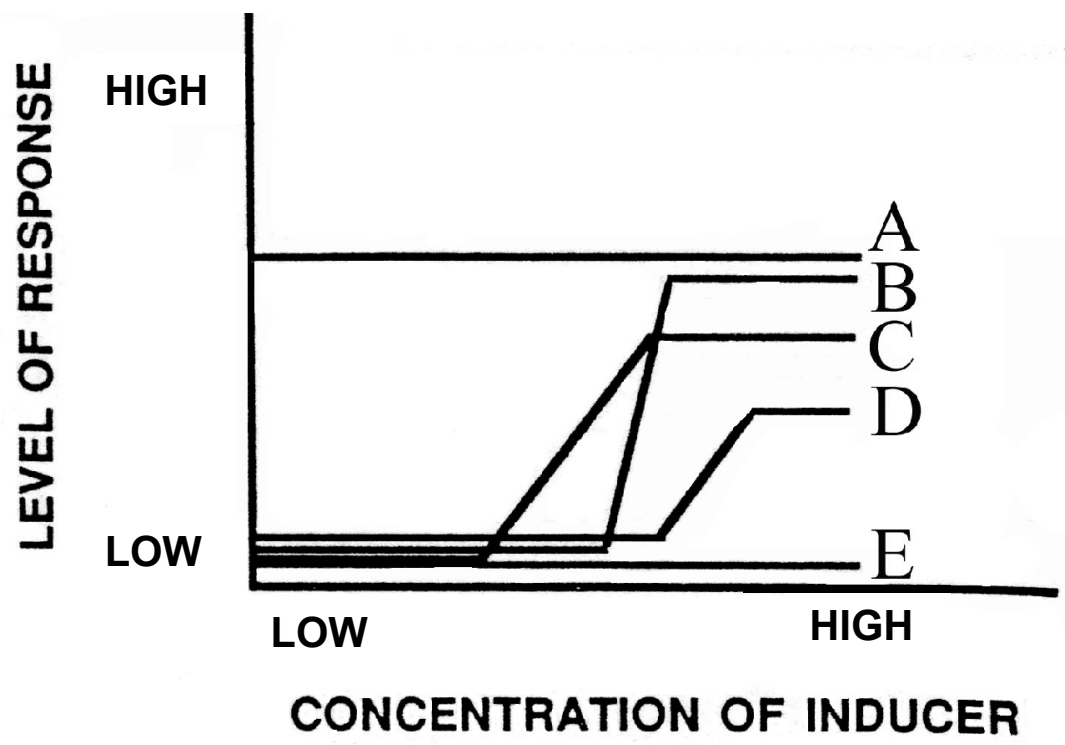

Figure 5.1. Diagram of expected range of variation in thresholds and dose response of inducible genotypes from natural populations. A-E represents a genotype and its defence response to varying levels of inducer with genotype A has no threshold and produces the defence continuously without stimulation; genotypes B-D produce the defence over a range of thresholds from low (C) to high (D); and genotype E has such a high threshold that the defence is never produced. After Harvell (1990).

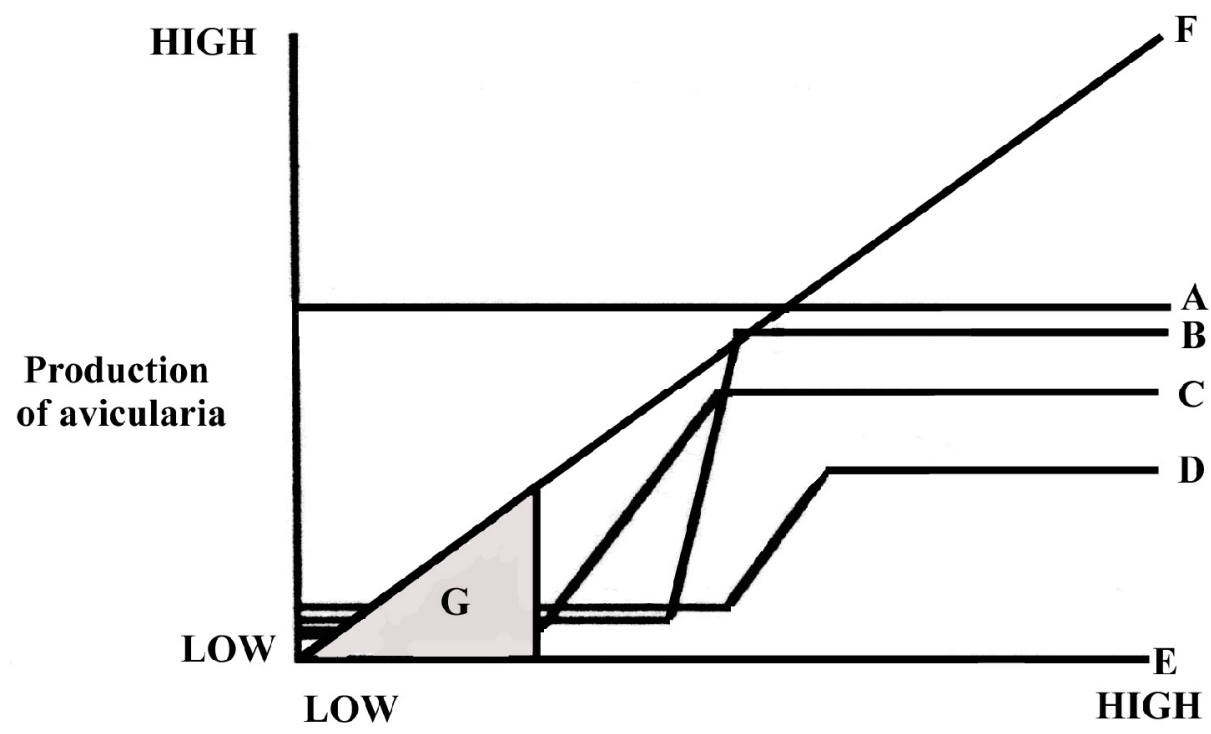

Threshold level

Figure 5.2. Diagram of potential threshold levels (to certain stimulus/stimuli) and the production of avicularia in species of cheilostome bryozoans. Species A has no threshold but produces avicularia continuously without stimulation; species B-D produce avicularia over a range of thresholds from a lower threshold (C) through intermediate (B) to a higher threshold (D); species (E) has such a high threshold that avicularia are never produced; and species (F) has a threshold level that is a function of inducer concentration; in the shaded area $(G)$ are species with variable responses to low inducer concentrations and therefore have low threshold levels. After Harvell (1990). 


\subsubsection{Cleaning}

The role of colony cleaning has been attributed to vibracula and avicularia with setiform mandibles. Lunulitiform bryozoans have disc-shaped colonies and inhabit sandy sediments. These bryozoans have developed highly specialised colonies and lifehistory strategies in order to survive such an ephemeral habitat. One strategy employed involves the production of specialised vibracula which have been observed cleaning sand grains off the colony (Cook 1963; Chimonides \& Cook 1981; Cook \& Chimonides 1984, 1987). The vibracula from the species of Caberea examined in this study (Chapter 2) do sway over the colony as if they are cleaning the colony. If one of the hair-like mandibles is touched with a fine probe or tweezers, then the majority of the vibracula on that branch begin to sway also (pers. obs). How such integrated movement and sensory perception is obtained is unclear. The sensory area of an avicularium is the palate and specifically the anatomical structures associated with the orifice (e.g. cilia of Bugula flabellata). The corresponding structure in the vibracula consisted of a tubular structure on the palate surface with a bulbous structure at the base (Chapter 2). This orifice morphology displayed remarkable consistency among all vibracula from the two species examined though until more species are examined, cannot be considered a pattern. Whether it is a ubiquitous feature of vibracula needs examining and may offer insight into the evolutionary development of vibracula. The precise sensory nature of this structure needs further examination also. The orifice covers only $\sim 1 \%$ of the total length of the vibracular base and is therefore a very small area for any direct sensory perception. The vibracular seta is capable of rotational movement and, owing to the close proximity of the orifice to the moving seta, would be subjected to a certain degree of compression. One possibility is that the orifice of the vibraculum acts as a pressure sensor detecting resistance on the sweeping seta and instigating an integrated response from surrounding vibracula in order to remove a foreign object.

\subsubsection{Bait traps}

Another theory is that avicularia may act as bait traps based on the observation that trespassing organisms become trapped for hours or even days by a closing mandible (Goldstein 1880; Harmer 1909; Winston 1986, 1991). The trapped organisms are generally too large to be consumed by autozooids, but over time they may die and decay therefore attracting ciliates and bacteria upon which bryozoans are known to feed 
(Winston 1991). The types of avicularia that are likely to perform such a function may present in a range of sizes and be adventitious, interzooidal or vicarious and possess tactile sensors (e.g. cilia) on the exposed palate. Their location in the colony in order to perform such a function may not be critical though being located near the autozooid operculum may be advantageous.

The bait-trap theory implies that the functional role of avicularia is to enhance food availability. Avicularia lack a functional gut (Winston 1984; Chapter 3) and are therefore dependent on nutrients from the parent and/or neighbouring autozooids. Their cost of production has to be met by a reciprocal activity, a function that can only be performed by avicularia. Schopf (1973) suggested that in polymorphic colonies the justification for the expression of one polymorph over another is that polymorph A must perform better than polymorph B under certain selection pressures and vice versa under a different set of selection pressures. Evidence indicates that the autozooids provide an adequate means of acquiring the necessary food resources for itself and the colony. Any modifications required in order to enhance food availability will be met by the autozooids by a morphological or developmental shift such as a redevelopment in the architecture of the colony (Gordon et al. 1987) or an increase in the number of tentacles which in turn will enhance feeding rates (Jebram 1973).

\subsubsection{Larval inoculation}

The larvae of some species of bryozoans have been found to harbour symbiotic bacteria within their pallial sinus (Woollacott 1981). Winston (1984) proposed that suboral and circumoral avicularia are suitably located to inoculate newly released larvae with their own supply of bacteria. In order to qualify as performing a bacterial inoculation function, avicularia would need to harbour a source of bacteria and have a secretory function. The internal anatomy of the avicularium would therefore consist of a dominant region of glandular cells and associated cilia in order to direct the secretions to the external environment.

Avicularia often have extensive overgrowth of bacteria (Chapter 2), however the peristomial (and therefore orally) located avicularia examined in this study were microbe-free (e.g. Mucropetraliella n. sp. Figure 2.16E, F). Rhynchozooon zealandicum has a highly irregular colony design and avicularia can be located in rather cryptic locations (Figure 2.22A). The avicularia of $R$. zealandicum species were relatively clean 
except for what appeared to be a light covering of a single strain of bacteria (Figure 2.22B). It may be possible for some avicularia to function as a bacterial-dip for newly released larvae based on their proximity to the autozooid operculum (e.g. Figure 2.16E), associated bacteria (e.g. Figure 2.22B) and the fact their mandibles are open when in a relaxed state. Observations on live reproducing and avicularian-bearing colonies will provide further insight into this theory. This could be potentially combined with fluorescent localisation techniques (e.g. FISH) that can target specific strains of bacteria.

\subsubsection{Distribution of food/nutrient storage}

The possibility that avicularia may function as nutrient reserves during unfavourable conditions was proposed by Winston (1984). The avicularia of Crassimarginatella exilimargo have a reduced polypide and 2-4 tentacles and a functional gut (Hastings 1945). In this instance an avicularium has the capacity to feed and to therefore retain and distribute nutrients. Standard avicularia do not possess a functional gut. The vestigial polypide of the bird's-head avicularium is maintained by nutrients via the funicular system of the parent autozooid. Nutrients or cell organelles are redirected to the rostrum and may be recycled based on the presence of a spherical body in the rostrum containing degraded organelles (Chapter 3 ). Whether this structure is a reserve for nutrients to be redirected to the autozooid is unclear but unlikely. The structure is closely associated with mucous cells in the rostrum and is possibly associated with biochemical reconstruction. The colony of B. flabellata dies down into dormant stolons during unfavourable conditions (pers. obs). If there is a more localised degeneration at the level of the autozooid as a result of predatory attack or alien overgrowth then, generally, surrounding autozooids redirect resources into the production of specialised zooids (e.g. kenozooids) (McKinney \& Jackson 1989). The storage of nutrients is not the function of the avicularia in B. flabellata and $N$. cornucopioides (Chapter 3).

\subsubsection{Current manipulation}

In their relaxed state, the open mandibles of certain avicularia may be able to manipulate water currents over the colony and act as current baffles (Winston 1984). 
The flow of water over erect colonies is influenced by the growth form characteristics of the colony such as relative branch size, branching pattern and branch alignment. Encrusting bryozoans tend to be found on ephemeral habitats such as Macrocystis fronds, stones and shells. Encrusters can also be found on the underside of rocks or crevices. Therefore bryozoan colonies are generally located within the boundary layer (McKinney \& Jackson 1989), which is defined as a thin layer of minimal water velocity adjacent to the substratum. The depth of the boundary layer is influenced by surface rugosity, velocity and viscosity of the water. The molecular viscosity of the water is the dominant characteristic at the level of the colony and beyond the colony turbulence becomes more important (S. Delaux, NIWA, 2008, pers. comm.). The geometric design of the colony such as the presence of spines, pores, prominent ovicells and the open mandibles of avicularia can all influence the localised fluid dynamics and mixing over the colony. The localised currents produced by feeding autozooids will further influence the hydrodynamics over the colony. The development of geometric structures within the colony can therefore enhance fluid mixing in an otherwise stagnant medium. It would therefore be possible for the open mandibles of avicularia to influence localised hydrodynamics and the remixing or entrainment of nutrients. However, the production of avicularia purely for hydrodynamic purposes seems unlikely and may be secondary to an alternative function. If additional structures are required within the colony for hydrodynamic purposes it would appear logical to invest in the production of spines or similar kenozooids that do not require the metabolic demands of avicularia (e.g. the maintenance of a vestigial polypide and associated musculature).

\subsubsection{Support and locomotion}

Colony support and locomotion have been attributed to the vibracula of lunulitiform species (Cupuladriidae, Lunulitidae, Otionellidae, Selenariidae) inhabiting soft sediments. Colonies were observed lifting themselves off the sediment with the bristle-like mandibles of the vibracula in order to avoid being covered by sediment (Cook 1963; Cook \& Chimonides 1978; Chimonides \& Cook 1981). No lunulitiform bryozoans were collected or examined in this study. Extensive observations on this group have been made and the behaviour of these vibracula is well documented and provide convincing evidence for a supportive and cleaning function for these polymorphs (Cook 1963; Cook \& Chimonides 1978; Chimonides \& Cook 1981). 


\subsection{Evolutionary and ecological implications of the study}

Based on evidence from the fossil record and from this study, the diversification and maintenance of adventitious types of avicularia over vicarious and interzooidal types implies there is an evolutionary advantage to the production of adventitious avicularia. Of the bryozoans collected in this study, $86 \%$ had adventitious avicularia (Chapter 2). Of the deep-sea bryozoans collected during the Galathea voyage, $82 \%$ had adventitious avicularia (Hayward 1981). This high frequency and diversity of adventitious types may be correlated with an increased coloniality in cheilostome bryozoans. Colony integration is defined as a measure of the degree of interdependence and cooperation among modules within a colony. Key features of integration include an increase in colonial over modular functions and/or the formation of non-feeding heterozooids (e.g. avicularia) by forming heterozooids as either an intrinsic component of the colony or in response to local environmental conditions (Schopf 1973; McKinney \& Jackson 1989). The production of one or more adventitious avicularia on the frontal surface of an autozooid increases organic continuity and specialisation by the addition of these polymorphs and thereby increases the formation of functional units within a given area of the colony. As this study highlighted (Figure 2.23; Chapter 2), the density of avicularia is greatest in those colonies with adventitious types only or by combining adventitious and vibracular types, thereby increasing coloniality and specialisation within a smaller spatial scale. It may be advantageous to gradually dilute spatially and functionally limited types such as vicarious and interzooidal over evolutionary time. The ecological implications of such a shift in specialisation point towards maximising functionality within a smaller spatial scale in response to an increase in an ecologically relevant cue (e.g. epibiont density). Differences in the frequency of the different types of avicularia may simply be due to the absence of some species from some biogeographic regions (Hughes \& Jackson 1990).

The ultimate driving force for the proposed increase and diversification of adventitious types may be of ecological origin. Vicarious avicularia, by definition, replace an autozooid in the budding pattern (Hyman 1959; Silén 1977; Winston 1984). Contemporary cheilostomes may be undergoing an evolutionary shift in colony design. Where the evolutionary trend from the Early Cretaceous Wilbertopora involved gradual modification from autozooid to vicarious to interzooidal and finally adventitious 
(Cheetham et al. 2006), the evolutionary trend in contemporary avicularia could potentially be directed to extensive modification in adventitious types only. For example, contemporary vicarious avicularia can be replaced by an autozooid and then one or more adventitious types located within the area of the autozooid. Therefore, the increased production of adventitious avicularia and removal of a space-filling vicarious type may, in part, be an adaptation in response to availability of hard substrata. An understanding of this proposal can be greatly enhanced by ascertaining precisely the function of vicarious avicularia and whether those needs can be met by an adventitious type. The dominance of adventitious types may also be a response to an increase in predator and epibiont pressure. The fossil record may provide insight to the inducible ecological factors responsible for the initial modification of zooids into avicularia during the Cretaceous. Contemporary avicularia can similarly be adapting and modifying in response to ecological cues also. The morphological evidence from this study supports this pattern owing to the dominance of adventitious types collected (86\%), their morphological divergence at the level of the avicularian orifice, density within a colony (Chapter 2) and the disparate vestigial polypide ultrastructure in two bugulids (Chapter 3). The next step is to determine what the ecological inducers are.

\subsection{Future research}

Based on the findings from the current study, I conclude that avicularia are morphologically equipped to perform many functions which can fit under the umbrella term of defence. No broad statements can be made regarding the defensive mechanism involved in the function of avicularia and each avicularium-bearing species should be treated in isolation. Where more than one form of avicularium occurs in a single colony, then each avicularium form should also be treated in isolation. Manipulation experiments would be a logical progression from this study.

Issues to consider in the experimental design include the fact that in natural populations there will be colony-specific morphological adaptations to localised environmental cues. Therefore experimental manipulation studies should utilise a single colony (single genotype) and cultured until sufficient growth has been obtained. As a starting point future research should focus on one species that only possesses one type of avicularium in order to avoid any confounding results. Manipulation experiments in parallel with electron microscopy and behavioural observations should then be 
conducted in order to establish the precise defensive mechanism for the avicularium in question. By repeating the process with other avicularium-bearing species, a bigger picture will develop as to the true extent of functional and morphological diversity among cheilostome bryozoans. A proposed study is outlined here.

\section{Characteristics of a model bryozoan:}

1) Is easily accessible for collection and monitoring

2) Has large and/or conspicuous avicularia

3) Has an encrusting growth form

4) Is hardy and can withstand culturing

5) Has a well understood life-history strategy and particularly stages of degeneration and regeneration (may require regular collection and monitoring prior to experimentation)

\section{Research to be conducted:}

1) TEM. Ultrastructural anatomy of the avicularium

2) SEM. Palatal and orificial anatomy

3) Behavioural observations

4) Experimental manipulation: quantitative analysis of the effect of avicularian density and subsequent colony response to an ecologically relevant cue (Figure 5.3) in the laboratory. An example of a relevant cue may be a known predator (e.g. nudibranch). Monitor growth rate and colony modifications

5) Experimental manipulation: quantitative analysis of the effect of avicularian density and monitor subsequent colony response (Figure 5.4) in the field. Monitor growth rate and colony modifications

\section{Outcomes of research:}

1) Cellular-level anatomy with insight into the underlying mechanisms of avicularian function: secretory, mechanoreceptive etc

2) Gross anatomical detail

3) How the avicularium responds to various stimuli

4) Quantitative analysis into the effect of de-activating avicularia and manipulating avicularian densities in the colony whilst exposed to ecologically relevant cue(s) 
5) A holistic approach towards the interpretation and understanding of the functional role of avicularia

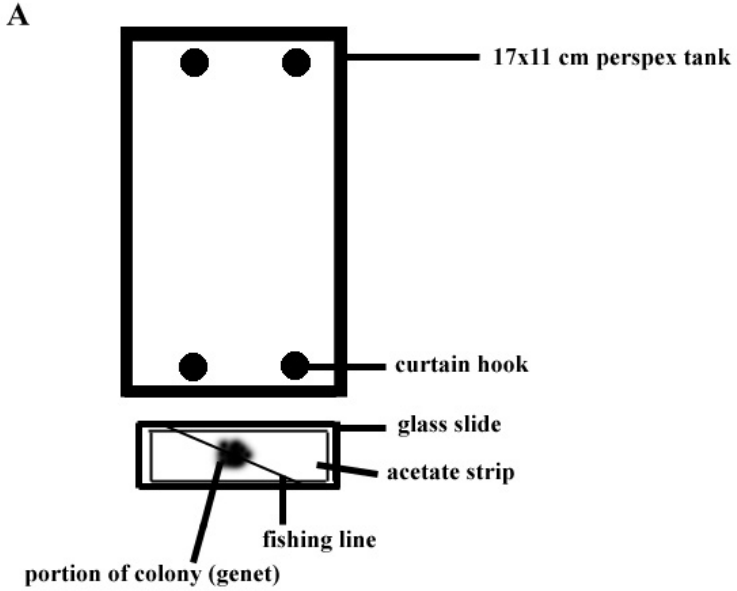

B
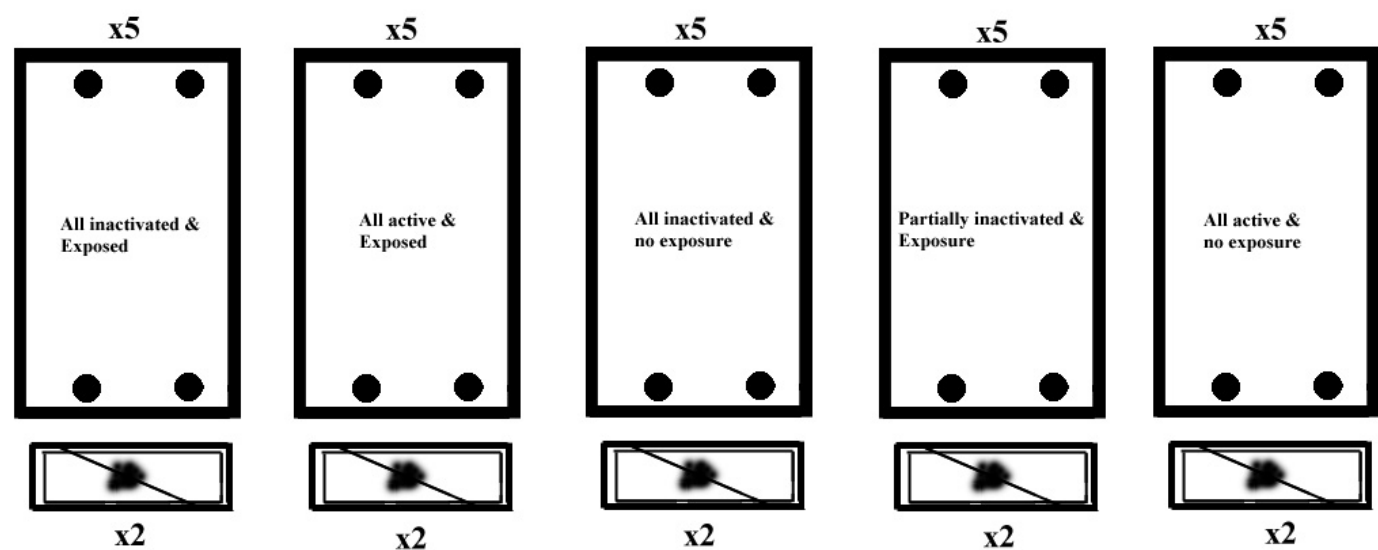

Figure 5.3. Experimental design for the manipulation of avicularian densities in the laboratory. (A) A single individual (clone) is cultured until sufficient growth has occurred to provide 50 equal-sized portions of the colony ( $=50$ genets). A single genotype is used for the experiment to negate any affects caused by localised adaptations of individuals. Each tank holds two genets in case one dies though only one result per tank is used in order to avoid pseudoreplication. Bryozoans are placed on a strip of acetate which is then placed on a glass slide and held down by fishing line. The slides are then slotted into curtain hooks glued to the bottom of $17 \mathrm{x} 11 \mathrm{~cm}$ perspex tanks containing $1 \mu \mathrm{m}$ UV-filtered seawater. The tanks are aerated by stirrer paddles. The genets are exposed to five treatments: (1) All avicularia inactivated and exposed to a known predator; (2) All avicularia active (untouched) and exposed to known predator; (3) All avicularia are inactivated with no exposure (control for effect of damage to avicularia); (4) Partial inactivation of avicularia in colony and exposed to known predator (effect of localised inactivation); (5) All avicularia active (untouched) and no exposure (control). There are five replicates per treatment (x 5). The inactivation of avicularia can be achieved by either piercing with a needle or detaching them from the colony. 

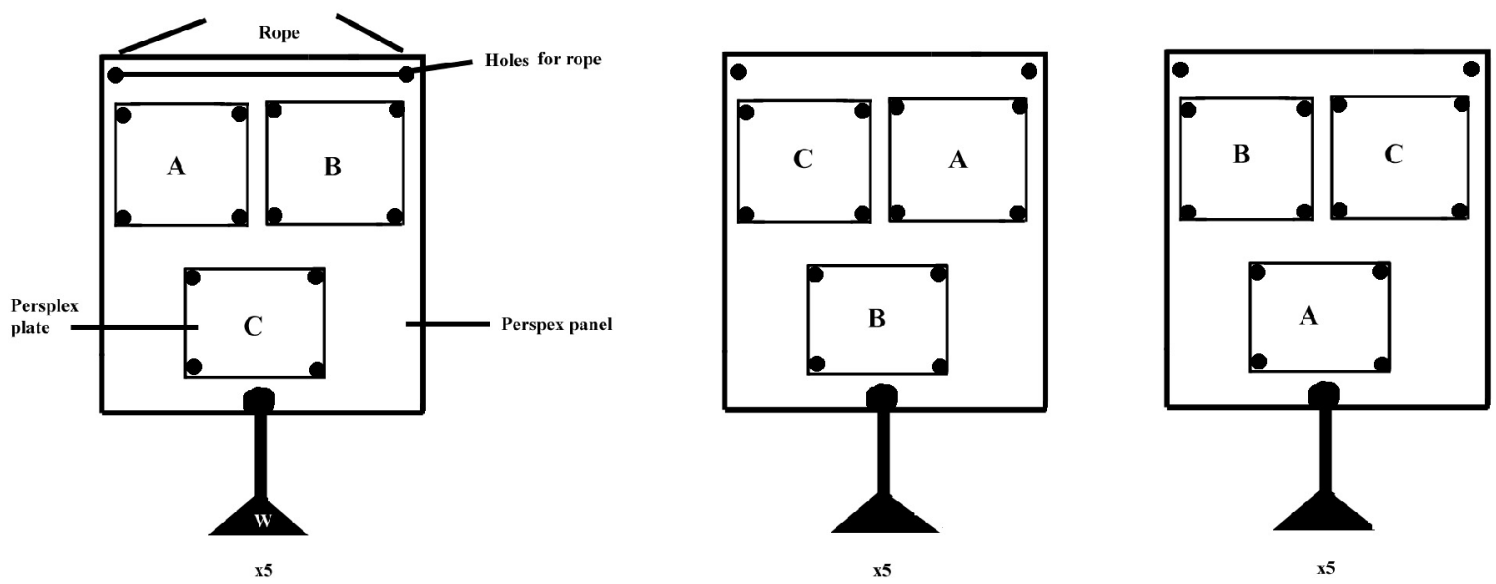

Figure 5.4. Experimental design for the manipulation of avicularian densities in the field. The design incorporates three blocks each with a different layout of experimental units. All treatments (A, B \& C) are represented in each block and therefore any differences from one block to another cancel out in the measurement of differences among treatments. The treatments are relocated between blocks to account for small-scale variation among experimental units (or treatments) in each block (Underwood 1997). A single genotype is cultured and encouraged to grow onto 45 perspex plates. The plates are attached to perspex panels by cable ties on each corner. Weights are placed at the bottom for stabilisation and holes drilled at the top for insertion of rope. The rope is then suspended off a suitable surface (e.g. pier). Treatments are as follows: (A) All avicularia are active (untouched; control); (B) All avicularia inactivated; (C) Partial inactivation of avicularia (effect of localised inactivation). There are five replicates per treatment. There will be differences in colony density between treatments therefore the data will need to be standardised. To test site differences, repeat the design.

\subsubsection{Biochemical analyses of avicularian glands}

Glandular regions were found in Bugula flabellata and Nordgaardia cornucopioides (Chapter 3) and based on their respective locations in the avicularium, have different functional roles and therefore biochemical constituents. Further research should be directed into establishing the chemical basis of the respective glandular secretions and their ecological implications. The process should involve the removal of the avicularia from the colony and preserving them (e.g. methanol, freezing) prior to biochemical analysis. Owing to the compactness of the branches in the colony and close association of the avicularium to the parent autozooid, removal is technically challenging in B. flabellata. Conversely the avicularia of $N$. cornucopioides would be technically easier to remove by virtue of their long peduncle. In addition to analysing the avicularia, the colony should be screened for biological activity as a whole also. 


\subsection{Conclusions}

This study is the first to examine the functional morphology of avicularia. No other significant research has documented the comparative biology of avicularia for decades. Though anecdotal, the most widely accepted theory for the function of avicularia is defence. Historically, perceptions of defence were in reference to the mechanical capture of organisms. It is now widely accepted that forms of defence in sessile marine invertebrates can either be structural or chemical hence, prompting a complete revision in how we interpret defence. The anatomical differences in the vestigial polypide of Bugula flabellata and Nordgaardia cornucopioides support this where a mechanoreceptive and chemoreceptive function have been implicated in their respective avicularia. The SEM survey of avicularia further supports a multi-faceted defensive function: avicularia are far more anatomically diverse than previously indicated and are therefore anatomically equipped to perform many different functions. Ecologically, the anatomical disparities imply developmental plasticity in response to localised environmental cues that can ultimately impact ecosystem dynamics of associated and transient micro- and macrobiota. This research also indicates an evolutionary shift towards a particular type of avicularia, adventitious, with an evolutionary dilution of other more spatially, and metabolically costly types (e.g. vicarious and interzooidal), presumably in favour of maximised functionality over a smaller spatial scale of the colony. In addition, this study supports previous suggestions that avicularia have evolved more than once with the occurrence of morphologically plesiomorphic types (on a gross level) with designs ranging from basic to highly derived (e.g. the bird's-head avicularium). This directional evolution will ultimately have a significant impact on colony functioning in subsequent cheilostome lineages. The adaptability of avicularia will ultimately be the evolutionary relevant trait selected for and thereby promoting functional diversification among avicularia. An understanding of the factors driving functional diversity and the processes of their formation will ultimately shed light on the relationship between their development and evolution and is critical in ascertaining the function of avicularia. 


\subsection{References}

Bakus, G.J., 1981. Chemical defense mechanisms on the Great Barrier Reef, Australia. Science 211: 497-499.

Blackman, A.J. \& Walls, J.T., 1995. Bryozoan secondary metabolites and their chemical ecology. In: Rahman, A. (Ed.), Studies in natural products chemistry. Elsevier Science, Amsterdam, pp. 73-112.

Busk, G., 1854. Remarks on the structure and function of the avicularian organs of bryozoans; and on their value as diagnostic and vibracular characters in the classification of those creatures. Transactions of the Microscopical Society 2: 26-33.

Canu, F. \& Bassler, R.S., 1929. Bryozoa of the Philippine region. Smithsonian Institute. U.S. National Museum Bulletin 100: 1-685.

Cheetham, A.H., Sanner, J., Taylor, P.D. \& Ostrovsky, A.N., 2006. Morphological differentiation of avicularia and the proliferation of species in mid-Cretaceous Wilbertopora Cheetham, 1954 (Bryozoa: Cheilostomata). Journal of Paleontology 80: 49-71.

Chimonides, P.J. \& Cook, P.L., 1981. Observations on living colonies of Selenaria (Bryozoa, Cheilostomata). II. Cahiers de Biologie Marine 22: 207-219.

Clark, C.W. \& Harvell, C.D., 1992. Inducible defenses and the allocation of resources: A minimal model. The American Naturalist 139: 521-539.

Cook, P.L., 1963. Observations on live lunulitiform zoaria of polyzoa. Cahiers de Biologie Marine 4: 407-413.

Cook, P.L. \& Chimonides, P.J., 1978. Observations on living colonies of Selenaria (Bryozoa, Cheilostomata). I. Cahiers de Biologie Marine 19: 147-158.

Cook, P.L. \& Chimonides, P.J., 1984. Recent and fossil Lunulitidae (Bryozoa: Cheilostomata) 1. The genus Otionella from New Zealand Journal of Natural History 18: 227-254.

Cook, P.L. \& Chimonides, P.J., 1987. Recent and fossil Lunulitidae (Bryozoa, Cheilostomata), 7. Selenaria maculata (Busk) and allied species from Australasia. Journal of Natural History 21: 933-966.

Dyrynda, P.E.J., 1986. Defensive strategies of modular organisms. Philosophical Transactions of the Royal Society of London. Series B 313: 227-243.

Goldstein, J.R.Y., 1880. Notes on living Polyzoa. Journal of the Microscopical Society of Victoria 1: 42-50.

Gordon, D.P., Clark, A.G. \& Harper, J.F., 1987. Bryozoa. In: Pandian, T.J. \& Vernberg, F.J. (Eds), Animal Energetics. Academic Press, Inc, San Diego, pp. 173-199.

Harmer, S.F., 1909. Presidential address, Report, 78th meeting of the British Association for the Advancement for Science, 1908, pp. 715-731.

Harvell, C.D., 1986. The ecology and evolution of inducible defenses in a marine bryozoan: Cues, costs, and consequences. The American Naturalist 128: 810823.

Harvell, C.D., 1990. The ecology and evolution of inducible defenses. The Quarterly Review of Biology 65: 323-340.

Harvell, C.D., 1991. Coloniality and inducible polymorphism. The American Naturalist 138: 1-14.

Harvell, C.D., 1992. Inducible defenses and allocation shifts in a marine bryozoan. Ecology 73: 1567-1576. 
Hastings, A.B., 1945. Notes on Polyzoa (Bryozoa).-II. Membranipora crassimarginata auctt., with remarks on some genera. Annals and Magazine of Natural History, series 11 12: 69-103.

Hayward, P.J., 1981. The cheilostomata (Bryozoa) of the deep sea. Galathea Reports 15: 21-68.

Hincks, T., 1888. The Polyzoa of the St. Lawrence: a study of Arctic forms. Annals and Magazine of Natural History, series 6, 1: 214-231.

Hughes, D.J. \& Jackson, J.B.C., 1990. Do constant environments promote complexity of form? The distribution of bryozoan polymorphism as a test of hypotheses. Evolution 44: 889-905.

Hyman, L.H., 1959. The invertebrates: Smaller coelomate groups Chaetognatha, Hemichordata, Pogonophora, Phoronida, Ectoprocta, Brachiopoda, Sipunculida. The coelomate bilateria. McGraw-Hill Book Company, Inc, New York, 783 pp.

Jebram, D., 1973. Preliminary observations on the influences of food and other factors on the growth of Bryozoa with the description of a new apparatus for cultivation of sessile plankton feeders. Kieler Meeresforschungen 29: 50-57.

Laverack, M.S., 1968. On the receptors of marine invertebrates. Oceanography and Marine Biology Annual Review 6: 249-324.

Lindquist, N., 1996. Palatability of invertebrate larvae to corals and sea anemones. Marine Biology 126: 745-755.

Lindquist, N. \& Hay, M.E., 1996. Palatability and chemical defense of marine invertebrate larvae. Ecological Monographs 66: 431-450.

Lutaud, G., 1964. Sur la structure et le rôle des glandes vestibulaires et sur la nature de certains organes de la cavité cystidienne chez les Bryozaires chilostomes. Cahiers de Biologie Marine 5: 201-231.

McKinney, F.K. \& Jackson, J.B.C., 1989. Bryozoan Evolution. Unwin Hyman, Boston, $287 \mathrm{pp}$.

Narkowicz, C., Blackman, A.J., Lacey, E., Gill, J. \& Heiland, K., 2004. Screening Tasmanian marine organisms for antiparasitic activity. Phytochemistry Reviews 3: 333-335.

Paul, V.J., Arthur, K.E., Ritson-Williams, R., Ross, C. \& Sharp, K., 2007. Chemical defenses: from compounds to communities. Biological Bulletin 213: 226-251.

Peters, L., Gabriele, K., Wright, A., Pukall, R., Stackebrandt, E., Eberl, L. \& Riedel, K., 2003. Secondary metabolites of Flustra folacea and their influence on bacteria. Applied and Environmental Microbiology 69: 3469-3475.

Ryland, J.S., 1970. Bryozoans. Hutchinson University Library, London, 175 pp.

Schopf, T.J.M., 1973. Ergonomics of polymorphism: Its relation to the colony as the unit of natural selection in species of the phylum Ectoprocta. In: Boardman, R.S., Cheetham, A.H. \& Oliver, W.A. (Eds), Animal colonies. Dowden, Hutchinson \& Ross Inc., Stroudsburg, pp. 247-294.

Sharp, J.H., Winson, M.K. \& Porter, J.S., 2007. Bryozoan metabolites: an ecological perspective. Natural Product Reports 24: 659-673.

Silén, L., 1977. Polymorphism. In: Woollacott, R.M. \& Zimmer, R.L. (Eds), Biology of bryozoans. Academic Press, New York, pp. 184-231.

Slattery, M., McClintock, J.B. \& Heine, J.N., 1995. Chemical defenses in Antarctic soft corals: evidence for antifouling compounds. Journal of Experimental Marine Biology and Ecology 190: 61-77.

Underwood, A.J., 1997. Experiments in ecology. Cambridge University Press, Cambridge, 504 pp. 
Walls, J.T., Ritz, D.A. \& Blackman, A.J., 1993. Fouling, surface bacteria and antibacterial agents of four bryozoan species found in Tasmania, Australia. Journal of Experimental Marine Biology and Ecology 169: 1-13.

Winston, J.E., 1984. Why bryozoans have avicularia - A review of the evidence. American Museum Novitates 2789: 1-26.

Winston, J.E., 1986. Victims of avicularia. Marine Ecology 7: 193-199.

Winston, J.E., 1991. Avicularian behaviour - A progress report. In: Bigey, F.P. (Ed.), Bryozoa Living and Fossil. Bulletin de la Société des Sciences Naturelles de l'Ouest de France, Mémoire, H.S, Nantes, pp. 531-540.

Woollacott, R.M., 1981. Association of bacteria with bryozoan larvae. Marine Biology 65: 155-158. 


\section{APPENDIX 1}

Glossary (Based on Ryland, 1970: Bryozoans; Hayward \& Ryland, 1999: Cheilostomatous Bryozoa, Part 2, Barnes \& Crothers (eds) Synopses of the British Fauna No.14)

Adventitious

avicularium

Anascan

Ancestrula

Ascophoran

Astogeny

Autozooid

Avicularian orifice

Avicularian palate

Basal

Brown body

Cystid

Distal

Ectoderm

Fenestrula

Frontal membrane
Heterozooid located on the frontal surface of an autozooid

A suborder composed of taxa whereby a frontal membrane covers the top of the autozooid

The founding zooid in a colony formed by metamorphosis of a sexually produced larva. A planktonic larva finds suitable substrata, settles and undergoes rapid metamorphosis (within minutes) until eventually a fully functional gut with feeding tentacles is formed. The ancestrula then begins the budding process and subsequent iterative units, or zooids, are formed that ultimately give rise to a bryozoan colony

A suborder composed of taxa whereby the frontal surface is calcified (e.g. Celleporella)

Development of a colony by budding

Zooid with functional polypide

Opening in the avicularian palate often associated with sensory structures (e.g. cilia). Homologue of autozooid orifice

Membrane covering the frontal surface of the avicularium and is sealed by the closed mandible

Under-side of an autozooid

Coloured spheroid in autozooid resulting from aggregation of non-histolysable residue of a degenerated polypide

Cellular and skeletal layers of a zooid wall

Side of the zooid directed away from point of origin

Membrane continuous with the palate and surrounds the vestigial polypide

Open space in reticulate colony (e.g. Reteporella)

Transparent membrane covering the top of the autozooid in some anascan taxa (e.g. Bugula) 
Funicular system

Gymnocyst

Heterozooid

Interzooidal

avicularium

Kenozooid

Lophophore

Mandible

Operculum

Opesia

Orifice

Palate

Polymorphism

Polypide

Retractor muscles

Rosette-plate

Rostrum
Cord of mesenchymatous tissue strands for metabolite transport within and between zooids

Calcification of the frontal surface of an autozooid

Modified zooids (e.g. kenozooids). Heterozooids are devoid of a functional gut

Heterozooid located between two autozooids. Generally smaller than the autozooids in the colony

Morphologically diverse heterozooid devoid of any internal structures usually found in parts of colony requiring reinforcement or attachment

Tentacles and mouth

Articulated part of an avicularium, moved by muscles in order to seal or expose the avicularian palate. Homologous to the operculum of the autozooid

A hinged fold of the frontal membrane characteristic of cheilostomes. Can be reinforced with sclerite. When closed, the operculum covers the orifice of the autozooid

Frontal surface of an anascan autozooid

Opening in tentacle sheath through which the polypide is everted

Outer membrane of the avicularium continuous with the ectoderm from which an orifice is derived. The ectoderm surrounds the vestigial polypide

Morphological and functional differentiation of the component units of a colony

Lophophore and gut combined. The apparatus required to capture, digest, and egest food

Muscles arising from the proximal end of the zooid, inserting on the pharynx and the base of the lophophore. Withdraws the polypide into the cystid

Multiporous subcircular area in vertical walls of Cheilostomatidae for the passage of mesenchymatous fibres (funicular system) between zooids

Distal portion of an avicularium occasionally forming a spike 
Tentacle sheath

Vicarious avicularium

Vibraculum
Cuticle-free membrane resembling an introvert surrounds the pharynx and terminal part of the rectum, and thus joining the lophophore to the lower, protective part of the zooid wall

Heterozooid budded as an autozooid and therefore takes the place of an autozooid in the budding sequence. Either of equal, larger, or smaller size than autozooids within the colony

Heterozooid with a hair-like mandible 


\title{
APPENDIX 2
}

Fixation solutions and protocols for electron microscopy (Chapters 2 \& 3)

\author{
*2x stock solution of $\mathrm{CAB}$ \\ (Store in the fridge)
}

$\begin{array}{lc}\text { Sodium cacodylate } & 4.28 \mathrm{~g} \\ \text { Sucrose } & 21.2 \mathrm{~g} \\ \text { Distilled water } & \text { Make up to } 100 \mathrm{ml}\end{array}$

Method For $0.1 \mathrm{M} \mathrm{CAB}$ washes, combine 2x stock solution with equal volume of distilled water.

$* 25 \mathrm{ml}$ working solution of $2.5 \%$ glutaraldehyde in $0.1 \mathrm{M}$ sodium cacodylate and $10.26 \%$ sucrose (Final osmolarity of $750 \mathrm{~m}$ OsMol)

$2 \mathrm{x}$ stock solution of $\mathrm{CAB}$

$12.5 \mathrm{ml}$

$25 \%$ glutaraldehyde

$2.5 \mathrm{ml}$

Distilled water

$10 \mathrm{ml}$

Method Fix specimens for $1.5-2 \mathrm{~h}$ in a fume hood.

*Use in fume hood and wear gloves and goggles 


\title{
*8 ml of $1 \%$ osmium tetroxide
}

\author{
$4 \%$ osmium tetroxide \\ $2 \mathrm{ml}$ \\ $2 \mathrm{x}$ stock buffer solution \\ $4 \mathrm{ml}$ \\ Distilled water \\ $2 \mathrm{ml}$
}

Method Rotate specimens for $2 \mathrm{~h}$ in a fume hood.

\section{*8 ml Black osmium}

$\begin{array}{lc}4 \% \text { osmium tetroxide } & 2 \mathrm{ml} \\ 0.4 \mathrm{M} \mathrm{CAB} & 2 \mathrm{ml} \\ & \\ 2 \% \text { Potassium fermo-arsenic } & 4 \mathrm{ml}\end{array}$

Method Rotate specimens for $2 \mathrm{~h}$ in a fume hood.

*Use in fume hood and wear gloves and goggles 


\section{Epon resin}

$\begin{array}{lr}\text { Procure } & 493.0 \mathrm{~g} \\ \text { NMA } & 296.1 \mathrm{~g} \\ & 110.7 \mathrm{~g} \\ \text { DDSA } & \\ & 13.0 \mathrm{ml}\end{array}$

Method

1. Mix the resin components (Procure, NMA, DDSA) thoroughly (avoid creating bubbles) for $10 \mathrm{~min}$

2. When mixed add the BDMA hardener and thoroughly mix again for $10 \mathrm{~min}$

3. Pour into (labeled and dated) $100 \mathrm{ml}$ resin bottles

WARNING: Make up the resin in a fume hood and wear gloves.

\section{Uranyl acetate stain}

Methanol (Analar grade)

$50 \%$ Ethanol (Analar grade)

Method

To a half and half solution of methanol and ethanol add uranyl di-acetate until saturated. Store in a bottle in the dark (highly photosensitive).

Procedure

Place a few drops into an embryo dish and place grids section-side down onto the stain and cover with a black box. Leave for 5-8 min. Wash grids with boiled distilled water. 
Appendix 2 Solutions and Protocols

\section{Lead citrate}

$\begin{array}{ll}\text { Distilled water } & 200 \mathrm{ml} \\ \text { Lead citrate } & 0.2 \mathrm{~g} \\ & \\ 10 \mathrm{~N} \mathrm{NaOH} & 0.1 \mathrm{ml}\end{array}$

Method

1. Boil the water for $10 \mathrm{~min}$ to remove $\mathrm{CO}_{2}$ then cover with glad-wrap and allow to cool

2. Remove $5 \mathrm{ml}$ of the boiled and cooled water and add the lead citrate and $\mathrm{NaOH}$

3. Shake well to mix

Procedure

In a Petri dish (with lid) place five to six $\mathrm{NaOH}$ pellets and dampen with boiled distilled water. Place a lid from an embedding capsule in the Petri dish and add a couple of drops of lead citrate with a glass pipette. Place the lid over the Petri dish until ready to stain grids. Place grids section side down in the lead citrate, cover the dish with the lid and leave for $10 \mathrm{~min}$. Rinse the grids with boiled distilled water (avoid breathing for the first $17 \mathrm{sec}$ of rinsing). Avoid contact with $\mathrm{CO}_{2}$ as the lead citrate will precipitate over the sections. 


\section{Toluidine Blue stain}

$\begin{array}{lc}\text { Borax } & 5 \mathrm{~g} \\ \text { Distilled water } & 100 \mathrm{ml} \\ \text { Toluidine blue } & 1 \mathrm{~g}\end{array}$

Method

1. Add the borax to the distilled water, mix and stand overnight

2. Add the toluidine blue then stir with a magnetic flea for $4 \mathrm{~h}$. Stand overnight

3. Filter into a glass container

Procedure

Cover the one micron thick sections (that are on the glass slide) with a generous amount of Toluidine Blue. Pace on a hot plate until a silver halo appears around the stain.

Wash the stain off with distilled water and place the slide back on the hot plate until completely dry. 


\title{
1 L $20 \%$ EDTA
}

\author{
EDTA (di-sodium salt) \\ $200 \mathrm{~g}$ \\ Milli Q or Barnstead filtered water \\ $500 \mathrm{ml}$ \\ $\mathrm{NaOH}$ pellets \\ $\sim 10$
}

\section{Method}

1. Place all components in a large beaker or conical flask, with a magnetic flea, on a stirrer until dissolved

2. Keep adding $\mathrm{NaOH}$ pellets until the solution is clear

3. Top up to $\sim 950 \mathrm{ml}$ with water, $\mathrm{pH}$ to 7.2 with $\mathrm{HCl}$ and adjust volume to $1 \mathrm{~L}$

\section{Procedure}

Place samples in a vial with $1.5 \mathrm{ml} 20 \%$ EDTA and $1.5 \mathrm{ml} 0.2 \mathrm{M}$ sodium cacodylate buffer. Rotate at $4^{\circ} \mathrm{C}$. Decalcify colonies for approximately $4 \mathrm{wk}$.

\section{Microadhesive}

$0.5 \%$ Formvar in chloroform

Procedure

Dip the grids in the microadhesive using tweezers and immediately place onto a piece of filter paper to dry. 


\title{
Solutions for Laser Scanning Confocal Microscopy (Chapter 4)
}

\section{8\% Paraformaldehyde}

\author{
Distilled water \\ $500 \mathrm{ml}$ \\ Paraformaldehyde "Prill" \\ $40 \mathrm{~g}$ \\ $10 \mathrm{~N} \mathrm{NaOH}$ \\ Few drops
}

Method

1. Place $300 \mathrm{ml}$ of the distilled water on a heated stir plate and heat to $60^{\circ} \mathrm{C}$

2. Add the paraformaldehyde and stir with a magnetic flea for at least an hour and a half

3. Add a drop at a time of $\mathrm{NaOH}$ until the solution clears

4. Bring volume up to $500 \mathrm{ml}$ using distilled water

5. Leave to cool

6. Store in a sealed container at $4^{\circ} \mathrm{C}$

7. Use within a week

Procedure

For 4\% paraformaldehyde fixative, combine equal quantities of $0.2 \mathrm{M}$ PBS and $8 \%$ paraformaldehyde. Fix samples for either $4 \mathrm{~h}$ at room temperature or overnight at $4^{\circ} \mathrm{C}$ in a fume hood or a sealed container. It is important samples are fixed in fresh paraformaldehyde (less than a week old) so make up smaller quantities of $8 \%$ solution as required. 


\section{0x Phosphate Buffered Saline (PBS)}

$\begin{array}{lc}\mathrm{NaCl} & 80 \mathrm{~g} \\ \mathrm{KCl} & 2.0 \mathrm{~g} \\ \mathrm{Na}_{2} \mathrm{HPO}_{4} & 14.4 \mathrm{~g} \\ \mathrm{KH}_{2} \mathrm{PO}_{4} & 2.4 \mathrm{~g} \\ \text { Distilled water } & 800 \mathrm{ml}\end{array}$

\section{Method}

1. Dissolve all ingredients in the distilled water

2. Adjust $\mathrm{pH}$ to 7.4

3. Adjust volume to $1 \mathrm{~L}$ with additional distilled water

4. Sterilise by autoclaving 


\section{Antifade Mounting Media}

1,4-diazabicyclo[2.2.2] octane (DABCO) $\quad 0.2 \mathrm{~g}$

Glycerol $9 \mathrm{ml}$

$0.2 \mathrm{M}$ Tris buffer containing $0.02 \%$ Sodium azide $\left(\mathrm{NaN}_{3}\right) \quad 1 \mathrm{ml}$

Method

1. In a glass beaker add the $\mathrm{DABCO}$ to the glycerol and heat to $50^{\circ} \mathrm{C}$ on a hot plate (do not use a microwave) until dissolved (should be a clear liquid)

2. Add the Tris and $\mathrm{NaN}_{3}$ solution (in a fume hood)

3. Keep the antifade wrapped in foil and in the fridge, avoid contact with light

WARNING: $\mathrm{NaN}_{3}$ is incredibly volatile and toxic use gloves, goggles and a fume hood. It is an oxidiser and reacts with metal. Dispose of with care.

\section{Modifications to the immunocytochemistry protocol}

A major fault with the serotonin immunocytochemistry experiments was the lack of repeatability and extensive non-specific binding making a definitive neuroanatomical description difficult. Non-specific binding is basically positive staining that is not the result of antigen-antibody binding (Fetsch \& Abati 1999).

Some common causes of non-specific binding include:

1. The attachment of protein to highly charged collagen and connective tissue elements of the tissue (Fetsch \& Abati 1999)

2. Binding of the primary or secondary antibody to the tissue through interactions that do not involve the antigen combining site (Javois 1999) 
3. Incorrect antibody dilutions; high concentrations can cause high background noise (Fetsch \& Abati 1999)

4. Inadequate fixation: Poorly fixed tissue exhibits intense non-specific binding. Poor fixation can arise if the specimen is too thick (Fetsch \& Abati 1999)

5. Inadequate rinsing between incubations (Fetsch \& Abati 1999)

6. The reagents used in the protocol (Mao et al. 1999)

7. Cross-reactivity of the immunoglobulin solution (Mao et al. 1999)

8. Detergents such as Triton $\mathrm{X}-100$ denature some proteins and have been found to contain impurities that are capable of binding to the sulphydryl groups in proteins leading to loss of antigenicity and high background autofluorescence (Melan 1999)

Possible steps to improve the outcome of immunocytochemically processed samples and minimize non-specific binding:

1. Increase the concentration of the serum (Javois 1999)

2. Dilute the antibody by increasing the salt concentration in the diluent and washing solutions (Mao et al. 1999). For example, 1:10 Tris:saline solution (Fetsch \& Abati 1999)

3. Use fresh paraformaldehyde as a fixative (Melan 1999)

4. Rinse samples well at the end of the primary and secondary incubation period and three times in the buffer wash (Fetsch \& Abati 1999)

5. Dehydrate the samples after secondary antibody incubation and washing has been completed using an ethanol series then mounted on glass slides in a 2:1 solution of benzyl benzoate and benzyl alcohol (Wanninger et al. 2005; Wanninger, pers. comm.)

Other suggestions:

1. Keep the samples cool throughout the processing

2. Once incubated in secondary conjugated antibody, keep samples in the dark

3. Use fresh tissue 


\section{References}

Fetsch, P.A. \& Abati, A., 1999. Overview of the clinical immunohistochemistry laboratory. In: Javois, L.C. (Ed.), Methods in Molecular Biology. Immunocytochemical methods and protocols. Humana Press, Totowa, New Jersey, pp. 405-414.

Javois, L.C., 1999. Fluorescent labelling of surface or intracellular antigens in wholemounts. In: Javois, L.C. (Ed.), Methods in Molecular Biology. Immunocytochemical methods and protocols. Humana Press, Totowa, New Jersey, pp. 131-140.

Mao, S., Javois, L.C. \& Kent, U.M., 1999. Overview of antibody use in immunocytochemistry. In: Javois, L.C. (Ed.), Methods in Molecular Biology. Immunocytochemical methods and protocols. Humana Press, Totowa, New Jersey, pp. 3-10.

Melan, M.A., 1999. Overview of cell fixatives and cell membrane permeants. In: Javois, L.C. (Ed.), Methods in Molecular Biology: Immunocytochemical methods and protocols. Humana Press, Totowa, New Jersey, pp. 45-55.

Wanninger, A., Koop, D. \& Degnan, B.M., 2005. Immunocytochemistry and metamorphic fate of the larval nervous system of Triphyllozoon mucronatum (Ectoprocta: Gymnolaemata: Cheilostomata). Zoomorphology 124: 161-170. 


\section{APPENDIX 3}

Table 2.8. Taxonomic spread of anascan species examined relative to the total number of New Zealand families of order Cheilostomata, arranged in roughly phylogenetic order from least to most derived according to the classification of Gordon (2008).

\begin{tabular}{|c|c|c|c|c|c|}
\hline Suborder & Morphological Grade & Superfamily & Family & Species & Comments \\
\hline Malacostegina & & Membraniporoidea & $\begin{array}{l}\text { Electridae } \\
\text { Membraniporidae }\end{array}$ & & $\begin{array}{l}\text { no avicularia } \\
\text { rare avicularian analogues }\end{array}$ \\
\hline Inovicellina & & Aeteoidea & Aeteidae & & no avicularia \\
\hline Scrupariina & & Scruparioidea & Leiosalpingidae & & no avicularia \\
\hline & & & Scrupariidae & & no avicularia \\
\hline \multirow[t]{31}{*}{ Neocheilostomina } & Pseudomalacostegomorpha & Calloporoidea & Antroporidae & & \\
\hline & & & $\begin{array}{l}\text { Bryopastoridae } \\
\text { Calloporidae }\end{array}$ & & \\
\hline & & & Chaperiidae & Chaperiopsis rubida (Hincks, 1881) & \\
\hline & & & Farciminariidae & & \\
\hline & & & Foveolariidae & Odontionella cyclops (Busk, 1854) & \\
\hline & & & Hiantoporidae & & \\
\hline & & & Quadricellariidae & & \\
\hline & & Flustroidea & Flustridae & & \\
\hline & Cellulariomorpha & Buguloidea & Beaniidae & Beania magellanica (Busk, 1852) & \\
\hline & & & Bugulidae & Bicellariella ciliata (Linnaeus, 1758) & \\
\hline & & & & Bugula flabellata (Thompson in Gray, 1848) & \\
\hline & & & & Nordgaardia cornucopioides (d'Hondt, 1983) & \\
\hline & & & Candidae & Caberea rostrata (Busk, 1884) & \\
\hline & & & & Caberea zelandica (Gray, 1843) & \\
\hline & & & & Scrupocellaria ornithorhyncus (Thomson, 1858) & \\
\hline & & & & Tricellaria catalinensis (Robertson, 1905) & \\
\hline & & & Epistomiidae & & \\
\hline & & & Euoplozoidae & & \\
\hline & & & Rhabdozoidae & & \\
\hline & Cryptocystomorpha & Microporoidea & Aspidostomatidae & & \\
\hline & & & Calescharidae & & \\
\hline & & & Lunulariidae & & \\
\hline & & & Macroporidae & & vicarious avicularian \\
\hline & & & Microporidae & Opaeophora lepida (Hincks, 1881) & analogues \\
\hline & & & Monoporellidae & & \\
\hline & & & Otionellidae & & \\
\hline & & & Poricellariidae & & \\
\hline & & & Selenariidae & & \\
\hline & & & Steginoporellidae & & vicarious avicularian \\
\hline & & & Thalamoporellidae & & gues \\
\hline & & Cellarioidea & Cellariidae & $\begin{array}{l}\text { Cellaria pilosa (Kirchenpauer, 1869) } \\
\text { Cellaria tenuirostris (Busk. 1852) }\end{array}$ & \\
\hline
\end{tabular}


Table 2.9. Taxonomic spread of ascophoran species examined relative to the total number of New Zealand families of order Cheilostomata arranged in roughly phylogenetic order from least to most derived according to the classification of Gordon (2008).

\begin{tabular}{|c|c|c|c|c|c|}
\hline Suborder & Morphological Grade & Superfamily & Family & Species & Comments \\
\hline \multirow[t]{39}{*}{ Neocheilostomina } & Cribriomorpha & Cribrilinoidea & $\begin{array}{l}\text { Cribrilinidae } \\
\text { Euthyroididae }\end{array}$ & Euthyroides jellyae (Levinsen, 1909) & \\
\hline & & Bifaxarioidea & Bifaxariidae & & \\
\hline & & Catenicelloidea & Catenicellidae & Catenicella pseudoelegans (Gordon, 2008) & \\
\hline & & & & Claviporella aurita (Busk, 1852) & \\
\hline & & & & Costaticella bicuspis (Gray, 1843) & \\
\hline & & & & Costaticella solida (Levinsen, 1909) & \\
\hline & & & & Cribricellina cribraria (Levinsen, 1909) & \\
\hline & & & Eurystomellidae & & no avicularia \\
\hline & & & Petalostegidae & & \\
\hline & Hippothoomorpha & Hippothooidea & Chorizoporidae & & \\
\hline & & & Hippothoidae & & rare avicularian analogues \\
\hline & & & Pasytheidae & & no avicularia \\
\hline & & & Trypostegidae & & avicularian analogues \\
\hline & Umbonulomorpha & Arachnopusioidea & Arachnopusiidae & Arachnopusia unicornis (Hutton, 1873) & \\
\hline & & & Exechonellidae & & rare avicularian analogues \\
\hline & & Adeonoidea & Adeonidae & & \\
\hline & & & Inversiulidae & & no avicularia \\
\hline & & Lepralielloidea & Dhondtiscidae & & \\
\hline & & & Lepraliellidae & & \\
\hline & & & Romancheinidae & Escharoides angela (Hutton, 1873) & \\
\hline & & & & Escharoides excavata (MacGillivray, 1860) & \\
\hline & & & & Exochella armata (Hincks, 1882) & \\
\hline & & & & Exochella jullieni (Gordon, 1989) & \\
\hline & & & Sclerodomidae & & \\
\hline & Lepraliomorpha & Smittinoidea & $\begin{array}{l}\text { Bitectiporidae } \\
\text { Smittinidae }\end{array}$ & Parkermavella n. sp. & \\
\hline & & & Watersiporidae & & no avicularia \\
\hline & & Schizoporelloidea & Buffonellodidae & & \\
\hline & & & Calwelliidae & & no avicularia \\
\hline & & & Cryptosulidae & & no avicularia \\
\hline & & & Cyclicoporidae & & no avicularia \\
\hline & & & Eminooeciidae & & \\
\hline & & & Escharinidae & Chiastosella exuberans (Gordon, 1989) & \\
\hline & & & & Chiastosella watersi (Stach, 1937) & \\
\hline & & & Gigantoporidae & & \\
\hline & & & Hippopodinidae & Hippomenella vellicata (Hutton, 1873) & \\
\hline & & & Lacernidae & & \\
\hline & & & Lanceoporidae & & i \\
\hline & & & $\begin{array}{l}\text { Margarettidae } \\
\text { Mawatariidae }\end{array}$ & & no avicularia \\
\hline & & & Microporellidae & Microporella agonistes (Gordon, 1989) & \\
\hline
\end{tabular}




\begin{tabular}{|c|c|c|c|c|c|}
\hline Suborder & Morphological Grade & Superfamily & Family & Species & Comments \\
\hline \multirow{17}{*}{$\begin{array}{l}\text { Neocheilostomina } \\
\text { (cont'd) }\end{array}$} & & & Petraliellidae & Mucropetraliella $\mathrm{n} . \mathrm{sp}$. & \\
\hline & & & Phorioppniidae & & no avicularia \\
\hline & & & Porinidae & & \\
\hline & & & Schizoporellidae & & \\
\hline & & & Teuchoporidae & & \\
\hline & & Urceoliporoidea & Urceoliporidae & & no avicularia \\
\hline & & Didymoselloidea & Didymosellidae & & \\
\hline & & Mamilloporoidea & Cleidochasmatidae & & \\
\hline & & Cellenoroidea & Crepidacanthidae & Celleporing orandis (Gordon 1989) & \\
\hline & & Celleporoidea & Celleporidae & Celleporina wellingtonensis (Gordon, 2008) & \\
\hline & & & & Osthimosia sirena (Gordon, 2008) & \\
\hline & & & Hippoporidridae & & \\
\hline & & & Phidoloporidae & Reteporella gracilis (Gordon, 1989) & \\
\hline & & & & Reteporella aurentiace (Gordon, 2008) & \\
\hline & & & & Rhynchozoon zelandicum (Gordon, 2008) & \\
\hline & & & & Stephanollona scintillans (Hincks, 1885) & \\
\hline & & Conescharellinoidea & $\begin{array}{l}\text { Conescharellinidae } \\
\text { Lekvthoporidae }\end{array}$ & & \\
\hline
\end{tabular}




\section{APPENDIX 4: URL addresses to view all images}

\section{SEM's 1}

http://docs.google.com/Presentation?id=dgnhzfp4_50p4gd7kc4\&invite=rhn3c8

\section{SEM's 2}

http://docs.google.com/Presentation?id=dgnhzfp4_16683d8z2d2\&invite=fv5gwgn

\section{SEM's 3}

http://docs.google.com/Presentation?id=dgnhzfp4_389n9x6tff8\&invite=sm53p2

\section{SEM's 4}

http://docs.google.com/Presentation?id=dgnhzfp4_538gcjfhcj\&invite=gz7ctkv

\section{SEM's 5}

http://docs.google.com/Presentation?id=dgnhzfp4_710f2s3g7hd\&invite=fcpswcq

Bird's-head avicularium with captured organisms

http://docs.google.com/Presentation?id=dgnhzfp4_0dtmds4ff\&invite=hbdn7qf

\section{SEM's BUGULOIDEA}

http://docs.google.com/Presentation?id=dgnhzfp4_130dxd3ztfz\&invite=ggcqfrs

\section{SEM's Bugula flabellata}

http://docs.google.com/Presentation?id=dgnhzfp4_151fxczgkg7\&invite=hrzt4t2

\section{Confocal microscopy: muscular system of Bugula flabellata}

http://docs.google.com/Presentation?id=dgnhzfp4_18g7vxn2hq\&invite=7f7mf2 